DOE/EH-0282

(Volume 2 of 2)

\title{
Task Group Report \\ to the Assistant Secretary for Environment, Safety and Health on Oversight of Chemical Safety at the Department of Energy
}

\section{Volume Two: Appendices}

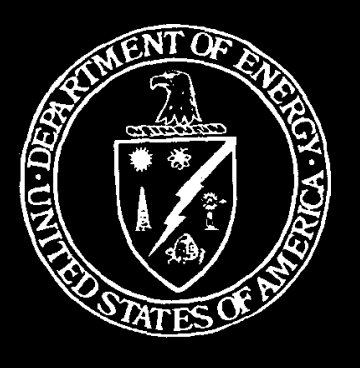

November 1992

\author{
U. S. Department of Energy
}

Assistant Secretary for Environment, Safety and Health

Office of Deputy Assistant Secretary for Safety and Quality Assurance 
This report has been reproduced directly from the best available copy.

Available to DOE and DOE contractors from the Office of Scientific and Technical Information, P.O. Box 62, Oak Ridge, TN 37831; prices available from (615) 576-8401, FTS 626.8401

Available to the public from the National Technical Information Service, U.S Department of Commerce, 5285 Port Royal Rd., Springfield, VA 22161. 


\section{Task Group Report to the Assistant Secretary for Environment, Safety and Health on Oversight of Chemical Safety at the Department of Energy}

\section{Volume Two: Appendices}

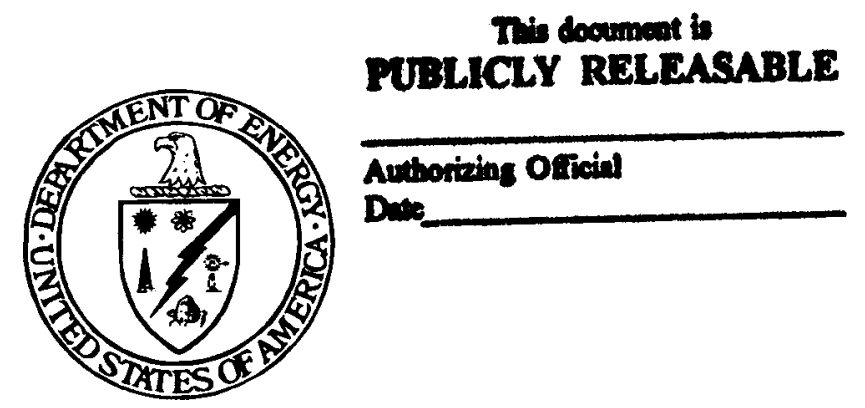

November 1992

U. S. Department of Energy

Assistant Secretary for Environment, Safety and Health

Office of Deputy Assistant Secretary for Safety and Quality Assurance

Washington, D. C. 20585 



\section{DISCLAIMER}

This report was prepared as an account of work sponsored by an agency of the United States Government. Neither the United States Government nor any agency thereof, nor any of their employees, makes any warranty, express or implied, or assumes any legal liability or responsibility for the accuracy, completeness, or usefulness of any information, apparatus, product, or process disclosed, or represents that its use would not infringe privately owned rights. Reference herein to any specific commercial product, process, or service by trade name, trademark, manufacturer, or otherwise does not necessarily constitute or imply its endorsement, recommendation, or favoring by the United States Government or any agency thereof. The views and opinions of authors expressed herein do not necessarily state or reflect those of the United States Government or any agency thereof. 


\section{DISCLAIMER}

Portions of this document may be illegible in electronic image products. Images are produced from the best available original document. 


\section{TABLE OF CONTENTS}

\section{VOLUME TWO: APPENDICES}

APPENDIX A - Secretarial Information Memorandum $\ldots \ldots \ldots \ldots \ldots$

APPENDIX B - Chemical Safety Oversight Review (CSOR) Task Group and

Workplace Chemical Accident Risk Review (WCARR) Members . . . . . . . 12

APPENDIX C - Chemical Safety Oversight Review (CSOR) Trip Report of Los

Alamos National Laboratory (LANL) $\ldots \ldots \ldots \ldots \ldots \ldots \ldots \ldots \ldots$

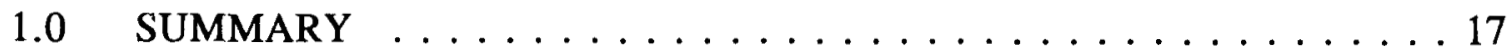

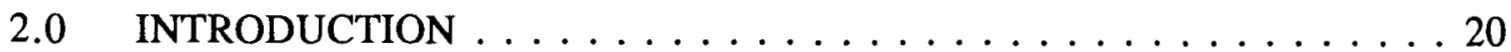

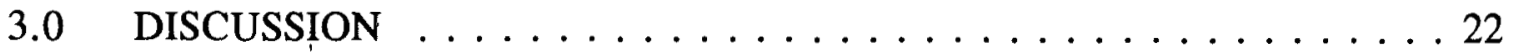

3.1 Chemical Hazard and Risk Analysis $\ldots \ldots \ldots \ldots \ldots \ldots 22$

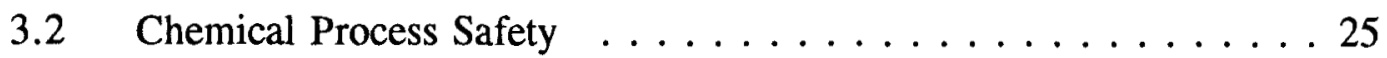

3.3 Chemical Laboratory Safety $\ldots \ldots \ldots \ldots \ldots \ldots \ldots$

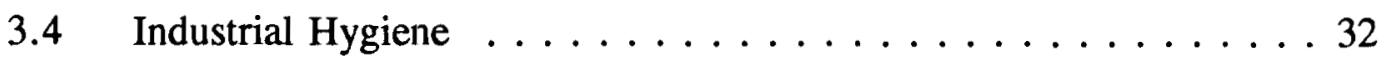

3.5 Conduct of Operations $\ldots \ldots \ldots \ldots \ldots \ldots \ldots \ldots \ldots$

APPENDIX D - Chemical Safety Oversight Review (CSOR) Trip Report of Savannah

River Site (SRS) . . . . . . . . . . . . . . . . . . . 54

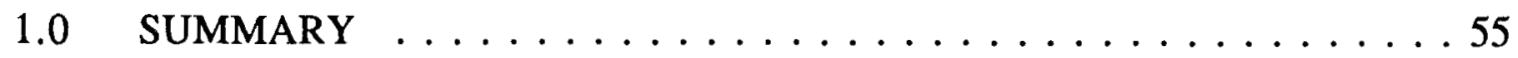

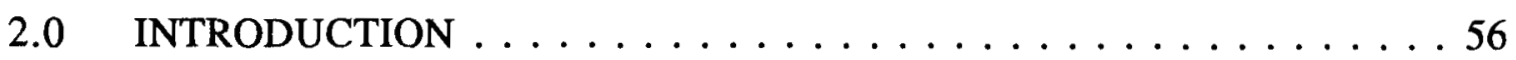

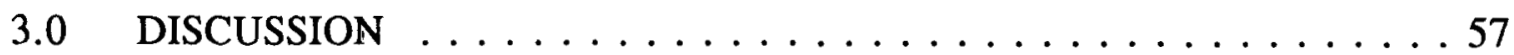

3.1 Management and Operations $\ldots \ldots \ldots \ldots \ldots \ldots \ldots$

3.2 Chemical Hazard and Risk Analyses . . . . . . . . . . 65

3.3 Chemical Laboratory Safety $\ldots \ldots \ldots \ldots \ldots \ldots \ldots$

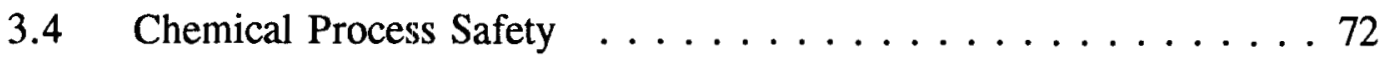

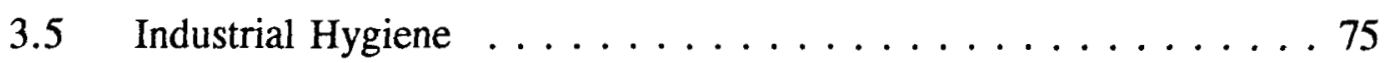


APPENDIX E - Chemical Safety Oversight Review (CSOR) Trip Report of the Y-12

Plant . . . . . . . . . . . . . . . . . . . . . . . 106

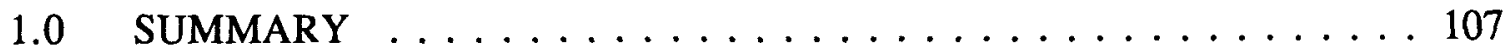

2.0 INTRODUCTION . . . . . . . . . . . . . . . . . . . . . 109

2.1 Background . . . . . . . . . . . . . . . . . 109

2.2 Chemical Characterization $\ldots \ldots \ldots \ldots \ldots \ldots \ldots \ldots$

3.0 HAZARD AND RISK ANALYSIS $\ldots \ldots \ldots \ldots \ldots \ldots \ldots \ldots 11$

3.1 Hazard Identification/Risk Assessment . . . . . . . . . . 111

3.2 Incorporation of Hazard and Risk Analysis Into Design and Operation of Chemical Facilities . . . . . . . . . . . . . . 113

3.3 Chemical Process Safety . . . . . . . . . . . . . . . 114

3.4 Chemical Laboratory Safety $\ldots \ldots \ldots \ldots \ldots \ldots \ldots$

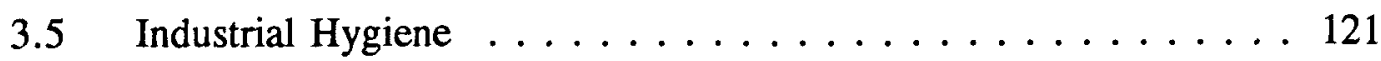

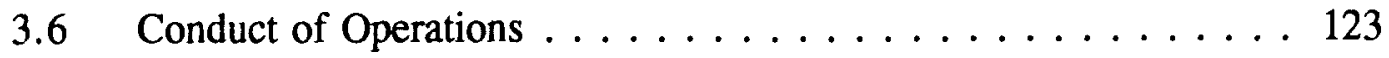

3.7 Management and Operations $\ldots \ldots \ldots \ldots \ldots \ldots \ldots \ldots$

APPENDIX F - Chemical Safety Oversight Review (CSOR) Trip Report of Oak

Ridge National Laboratory (ORNL) . . . . . . . . . . . . . . . . . 143

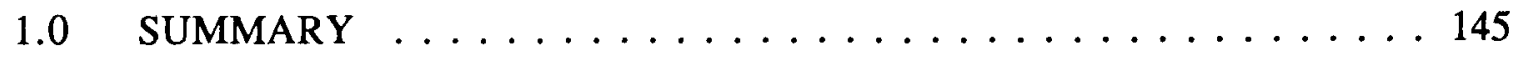

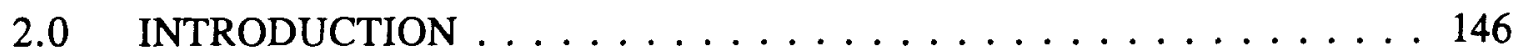

3.0 HAZARD AND RISK ANALYSIS $\ldots \ldots \ldots \ldots \ldots \ldots \ldots \ldots$

3.1 Hazard Identification/Risk Assessment . . . . . . . . . . . 148

3.2 Incorporation of Hazard and Risk Analysis Into Design and

Operation of Chemical Facilities . . . . . . . . . . . . 157

3.3 Process Safety Management $\ldots \ldots \ldots \ldots \ldots \ldots \ldots$

3.4 Chemical Laboratory Safety $\ldots \ldots \ldots \ldots \ldots$

3.5 Industrial Hygiene $\ldots \ldots \ldots \ldots \ldots \ldots \ldots \ldots \ldots \ldots$

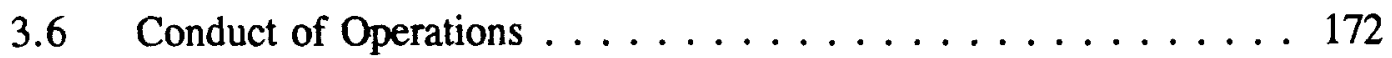

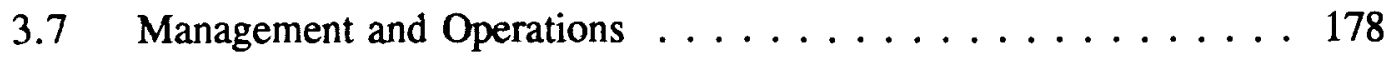


APPENDIX G - Chemical Safety Oversight Review (CSOR) TRIP Report of

Lawrence Livermore National Laboratory (LLNL) . . . . . . . . . . . . . 197

1.0 SUMMARY . . . . . . . . . . . . . . . . . . . . . . . . . 199

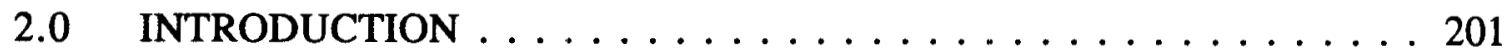

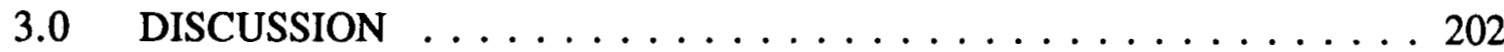

3.1 Chemical Hazard and Risk Analyses . . . . . . . . . 202

3.2 Chemical Laboratory Safety $\ldots \ldots \ldots \ldots \ldots \ldots$

3.3 Chemical Process Safety . . . . . . . . . . . . . . 208

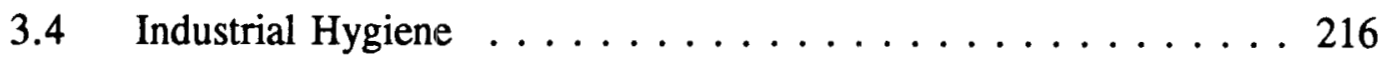

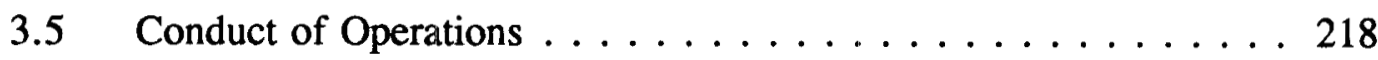

APPENDIX H - Short List of Hazardous Chemicals Used In Department of Energy

Operations (DOE) and Their Characteristics . . . . . . . . . . . . 247

APPENDIX I - Summary of Department of Energy (DOE) Chemical Incidents . . . 264

APPENDIX J - Summary of Comparative Analysis of

Department of Energy (DOE) Orders

to the

Occupational Safety and Health (OSHA) Administration

Part 29, Code of Federal Regulations (CFR), Section 1910.119 Requirements . . . . 276 
APPENDIX A - Secretarial Information Memorandum 


\section{memorandum}

DATE: April 3, 1992

REPLY TO ATTN OF:

SUBUECT: INFORMATION:

TO:

The Secretary
EH-30:J. E. Fitzgerald:3-5532

Establishment of an Office of Environment, Safety and Health (EH) Chemical Safety Oversight Task Group to Review Department of Energy (DOE) Horkplace Chemical Safety Programs

THRU: Acting Under Secretary

BACKGROUND:

Tiger Team Assessments and other DOE-wide facility safety reviews have identified widespread deficiencies in chemical process safety and in chemical storage and use that could affect worker and public safety and health and the environment at DOE facilities. The significance of this issue, including the need for interim control policies and standards, should be addressed on an expedited basis.

EH has established a Chemical Safety Oversight Task Group to be the focal point for identifying programmatic deficiencies and the need for short-term and long-term actions to characterize and address chemical safety and health issues.

\section{DISCUSSION:}

Deficiencies in chemical process safety and in the storage and use of chemicals at DOE facilities have been brought to our attention in a number of ways: (1) review of DOE's occurrence reporting system which enumerated a series of recent chemical accidents and incidents; (2) general observations of a wide range of inadequate safety precautions at DOE facilities during oversight visits; and (3) findings and concerns identified by Tiger Teams. An annotated summary of these observed deficiencies is provided in Attachment 1.

\section{Review Need}

At DOE facilities, chemical safety deficiencies have, in some cases, led to worker injuries and posed potential increased risk to workers and the general public. There have been two deaths at DOE facilities $(1984,1985)$ related to chemical process safety within the past 10 years. In other recent incidents, it is fortuitous that severe injuries or even fatalities have not occurred. Existing DOE process controls for ensuring chemical safety (or the implementation of whatever process controls exist) in many instances have not proved adequate to ensure worker safety, and additional short-term and longterm programmatic actions need to be considered.

EH has initiated a longer range workplace chemical safety review which will involve a detailed top-down evaluation of the respective Program Secretarial officer (PSO) programs. The current review is an EH information gathering 
and field review effort designed to identify overt chemical safety program weaknesses, to determine the DOE status of conformance with the pending (effective May 26, 1992) Occupational Safety and Health Administration rule on Process Safety Management of Highly Hazardous Chemicals (29 CFR Part 1910.119), and to facilitate improved chemical safety policy and guidance for application at DOE facilities over the next year.

The seriousness of the circumstances noted above, and as reflected in Attachment 1, however, indicates the need for near-term oversight and policy attention on the part of EH. The objective would be to identify needed actions to ensure that particularly hazardous materials are adequately controlled and that sufficient safety analyses and operating controls are applied for significant chemical hazards. The EH Chemical Safety Oversight Task Group is the focal point to accomplish this objective by identifying, on a sampling basis, significant safety deficiencies and establishing interim policies to cope with them while longer term programmatic upgrades proceed.

Task Group/Review Approach

The EH task group will be supported by a team of chemical safety experts, with close coordination with all affected PSOS. EH will pursue this matter as part of its independent oversight role as identified in Secretary of Energy Notice (SEN)-1OF-92 and SEN-6E-92. The EH task group will make every effort to minimize its impact on PSO resources. Through the use of EH staff, contractors, and consultants, and through coordination with participating PSOs, EH will use existing reports and studies, and expertise and technical information available at Headquarters and contractor sites, to develop an integrated overview of chemical safety. The EH task group efforts will focus on identifying significant management control deficiencies and determining the need for improvements and interim policy development, and will also note those areas which appear to require immediate corrective actions by PSOs.

The approach includes: (1) an accelerated review of selected process and laboratory facilities having substantial quantities or usage of the most hazardous chemicals to identify management and control deficiencies which may require immediate attention; (2) a review of key areas of DOE Orders, limits, and operating procedures related to chemical safety; and (3) a longer term evaluation of chemical safety policy and guidance, safety review processes, and operational practices to identify needed improvements in existing DOE Orders and program requirements. 
Attachment 2 provides a copy of our memorandum to the PSOs requesting their assistance in this study.

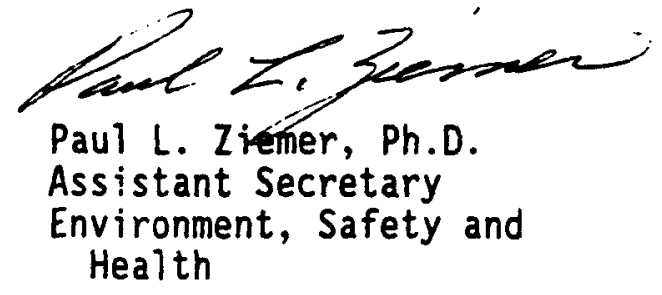

2 Attachments 
Attachment 1

SUMMARY OF SELECTED CHEMICAL SAFETY DEFICIENCIES

AT THE DEPARTHENT OF ENERGY (DOE) FACILITIES

References and details of the accidents, incidents, events, and information listed below are available from EH-33.1.

1. DOE Chemical Safety Accidents/Incidents: The following accidents and incidents are selected examples for the period January 1, 1991, to March 4, 1992, indicating significant deficiencies in a number of chemical safety areas: hazards identification; safety, risk, and accident analyses; conduct of operations; work control and work control procedures; engineering controls; emergency preparedness; and design and function of structures, components, and equipment:

- 3/3/92 - Sulfuric Acid Release - Three workers performing maintenance on a deionized water system received sulfuric acid burns. The system was being purged using clear water; however, the system contained pockets of sulfuric acid. The workers were observing water exiting a drain line when acid surged from the line, splashing on them. Two of the workers suffered minor burns while the third had mostly first degree burns over 25 percent of his body, with some second degree burns and some skin damage around the eyes. ALO-PI-GEND-PINELLAS-1992-0010

- 3/3/92 - Trichloroethane Fumes - Concentrations of trichloroethane exceed permissible Occupational Safety and Health Administration (OSHA) exposure limits during cleaning operations at an accelerator. Operations were stopped when a supervisor noticed the fumes. Workers involved were taken to medical for monitoring.

- 2/17/92 - Nitric Acid Explosion - A screw capped bottle of Nitric Acid exploded in a storage cabinet shortly after a lab employee had combined several containers of nitric acid for volume reduction and disposal purposes. The explosion splashed the lab employee's clothes, the cabinet, and the floor, and broke a hydrochloric acid bottle, releasing its contents. Adjacent areas of the facility were evacuated; however, no one was injured.

- 1/24/92 - Hydrogen Fluoride (HF) Release - A rupture disk installed in a HF vaporizer opened, releasing about 600 pounds of liquid and gaseous $\mathrm{HF}$. An open drain vaive diverted the HF from the stack to a partially enclosed dock area and surrounding areas for about 2-1/2 hours until the rupture disk was isolated. A total of 17 employees received medical attention as a result of the incident.

- 1/23/92 - Unknown Sample Disposal - A technician disposing of historical samples opened an unmarked container of white powder and experienced a burning sensation in his throat. He disposed of the sample in a dumpster, where it was detected by another person. Three individuals were taken to the medical clinic, examined, and released.

- 1/23/92 - Sodium Spill - Approximately five gallons of liquid sodium spilled onto bermed asphalt at a sodium treatment facility when the shell of a cold trap failed for unknown reasons. A sodium oxide vapor plume was formed and entered the control room where two employees were remotely controlling the operation. Medical observation of one employee indicated no apparent health effects. 
- 11/21/91 - Zirconium Addition to Dissolver - Zirconium alloy in a container with scrap Pu-238 was introduced into a scrap recovery dissolver. Operational Safety Requirements (OSRs) prohibit the introduction of zirconium alloy into the dissolver because of the potential for hydrogen generation. A material file entry that indicated the zirconium alloy was overlooked by an engineer.

- 11/12/91 - Inadvertent Waste Transfer - Approximately 2840 pounds of unneutralized waste was inadvertently transferred to waste management from a facility tank. An incorrect special procedure defined the wrong valve setup for the transfer.

1 10/18/91 - Mercury Spill - About 60 pounds of mercury (exceeding the limit for Comprehensive Environmental Response, Compensation, and Liability Act (CERCLA) reportable quantity of one pound) was spilled on a truck bed and road surfaces at a DOE site during shipment of 2,000 pounds of excess mercury to an off-site dealer. About 150 pounds of contaminated soil and gravel were transferred to recovery drums. The occurrence report indicated a lack of operational control in inspecting the shipment before transport. One of the shipping cylinders appeared to have leaked slightly during preparations for moving.

- 7/9/91 - Methyl Ethyl Ketone Peroxide (MEKP) Spill - Two one-gallon plastic containers of MEKP were dropped and one of the containers burst open as a subcontractor was removing and packaging chemicals from a DOE building. A subcontractor employee was splashed in the eye with a small amount of MEKP. The employee was sent to a hospital for evaluation and treatment. The chemical had been stored for over 4 years and was subject to decomposition into more hazardous, unstable compounds.

- 4/2/91 - Carbon Tetrachloride (CCL4) Leak - About 587 pounds of CCL4 (exceeding the reportable 10 pound CERCLA limit) leaked while being transferred from drums into a storage/transfer tank. The direct cause was operational error on the part of the operators. The contributing causes included inadequate procedure and inadequate or defective design of the CCL 4 storage/transfer tank.

- 2/12/91 - Crystallized Picric Acid and Diethyl Ether Disposal - Two potentially explosive chemicals had been allowed to desiccate and/or age to a potentially hazardous state. In the process of disposing of these surplus chemicals from the laboratory, it became evident that no policy and standards on hazard communication, laboratory operations, emergency planning, and handling of hazardous materials existed at this DOE facility.

- $2 / 9 / 91$ - Acidic Uranium Release - Rupture of Dissolver - A chemical explosion occurred in a Dissolver in a Hot Chemistry Lab while a batch of unirradiated scrap fuel material was being dissolved. The explosion ruptured the lower portion of the glass dissolver vessel, splattering acidic uranium sntution an three operations personnel. The three operators, and one member of the Emergency Response Team, received alpha contamination. Contaminated personnel used safety showers and received medical treatment; no apparent injury resulted from acid exposure. 
2. Recent Concerns of the Office of Nuclear Safety (NS): The Office of Nuclear Safety, in a series of memoranda to PSOs documenting NS site visits, identified a number of chemical safety issues. Some of the key findings noted are summarized below:

- Dissolver Explosion (Refer to the 2/9/91 event in item 1 above). The laboratory and Field office responsible for the material that exploded were not made aware of a 4-month-old report investigating the event. The report deduced that the material shipped contained epsilon phase zirconium and other materials not listed on the shipping label.

- Arsine is an extremely toxic and flammable gas that until recently was being used at a facility only 200 meters from public buildings. The process for handling the gas appeared to contain single failure points, and potential personnel errors or mechanical failures could result in an unmitigated release of the gas. Use of this gas at this facility has been terminated, and NS believes it should not be reinitiated here or elsewhere until the potential health effects of a large release have been determined, appropriate mitigating measures taken, and formal DOE acceptance of the risks has been made.

- Phosgene gas is currently in use at a plutonium metal process facility. Phosgene gas is poisonous and heavier than air. NS believes there are safety concerns regarding both the design and the operating controls of the process being used.

- Chemical agents with radioactive tracers were processed in a room of a currently occupied facility. This room is awaiting decontamination and decommissioning (D\&D). Some decontamination has been performed, but funds provided to complete the O\&D were spent for other purposes. Plans for completing D\&D and protecting the building's occupants are unclear.

- Nitrous oxide abatement: DOE appears to be many years behind the commercial industry in nitrous oxide abatement and removal technologies. As the presence of nitrous oxides in the ventilation ducts and stacks of nuclear facilities pose significant problems for worker safety, the environment, and public health, the investigation of existing commercial technology and the use of DOE research and development resources to address this problem should be expedited.

3. Tiger Team/Technical Safety Appraisal Findings: The Office of Environment, Safety and Health staff are currently characterizing the chemical safety findings and concerns identified in the Tiger Team and Technical Safety Appraisal (TT/TSA) processes as part of a newly established Workplace Chemical Accident Risk Review program. The following examples of widespread chemical safety weaknesses are based on some preliminary assessments of TT/TSA findings and concerns:

- Chemical and non-radiological hazards not adequately characterized.

- Lack of exposure data or surveillance and monitoring programs for potential personnel exposure for hazardous chemicals.

- Improper/incompatible chemical storage in laboratories and facilities.

- Non-compliance with OSHA Hazardous Materials requirements and OSHA Toxic and Hazardous Substances requirements.

- Mindset that the [chemical] plant poses no unusual or unique risks. 
DATE: April 3, 1992

REPLY TO ATTN OF:

SUBUECT:

TO:
EH-33.1

INFORMATION: Establishment of an Office of Environment, Safety and Health (EH) Chemical Safety Oversight Task Group to Review Department of Energy (DOE) Workplace Chemical Safety Programs

Assistant Secretary for Defense Programs

Assistant Secretary for Conservation and Renewable Energy

Assistant Secretary for Environmental Restoration and Waste Management

Assistant Secretary for Fossil Energy

Assistant Secretary for Nuclear Energy

Director of Emergency Planning and Operations

Director of Energy Research

Tiger Team assessments and other DOE-wide facility safety reviews have identified significant problems with chemical process safety and with chemical use and storage at the Department's facilities. During the next several months, as part of our oversight responsibilities, EH will review the overall management of chemical operations and laboratory activities. This will include design and safety review processes, mechanisms for identifying chemical hazards and assessing risks, and means of reducing and controlling actual or potential chemical releases and exposures to workers, the general public, and the environment. Attached is an EH information memorandum to the Secretary of Energy discussing these activities.

EH requests that affected Program Secretarial Officers (PSOs) provide the coordination necessary for the EH Chemical Safety Oversight Task Group to carry out this task. The task group will conduct an overview of Departmental chemical safety, identify any generic deficiencies in chemical safety in the DOE complex, identify measures and controls necessary to improve operations, and develop recommendations for both short-term actions necessary to address immediate problems, and longer term actions directed at broader program improvement. EH will al so assess the overview results to develop policy and related guidance as necessary. PSO coordination will particularly be useful in the screening of chemical source terms and candidate facilities, identification of pertinent information and data, and arrangement of a limited number of site and facility visits.

The task group efforts will include the following: (1) conduct of reviews of DOE-wide chemical safety information and overview of selected high-risk programs in an expedited manner to identify any serious deficiencies; (2) screening of deficiencies identified in these reviews to determine their safety significance and focusing on serious generic deficiencies to determine any need for prompt corrective actions, and (3) recommending what interim measures and standards are needed to establish an adequate level of chemical safety controls for PSOs to implement at DOE facilities. 
EH will complete the chemical safety review within 120 days of the date of this memorandum, and develop a report outlining the task group's findings and recommendations. EH will provide a draft of the report for review for technical accuracy prior to distributing the final version.

In addition to completing the short-term tasks, the EH will also carry out longer term workplace chemical safety program performance review activities.

We would appreciate if you identify a point-of-contact for the EH chemical safety review to Joseph Fitzgerald (EH-30) so that we can keep you informed of the progress of our chemical safety overview activities and coordinate field activities.

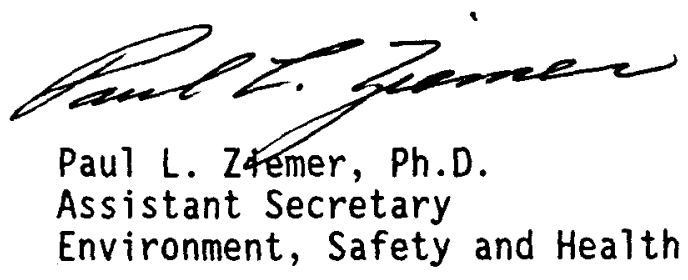

Attachment

CC:

NS-1 


\section{APPENDIX B - Chemical Safety Oversight Review (CSOR) Task Group and Workplace Chemical Accident Risk Review (WCARR) Members}





\section{MEMBERS}

\begin{tabular}{|c|c|}
\hline $\begin{array}{l}\text { CSOR TASK GROUP } \\
\text { MEMBERS }\end{array}$ & \\
\hline John W. Arendt & $\begin{array}{l}\text { Consultant to Office of Risk Analysis and } \\
\text { Technology (EH-33), Office of Environmental, } \\
\text { Safety and Health }\end{array}$ \\
\hline Robert W. Barber & Director, EH-33, Team Leader of X-10 CSOR \\
\hline John M. Brooks & EG\&G, Idaho, Consultant to EH-33 \\
\hline Delbert Bunch & MSI, Consultant to EH-33 \\
\hline Melvin E. Cassady & $\begin{array}{l}\text { Consultant to Office of Health Physics/Industrial } \\
\text { Hygiene Programs, EH- } 41\end{array}$ \\
\hline Check (Tony) C. Eng & Senior Risk Assessment Engineer, EH-33 \\
\hline Joseph E. Fitzgerald, Jr. & $\begin{array}{l}\text { Deputy Assistant Secretary, Office of Safety and } \\
\text { Quality Assurance, EH-30 }\end{array}$ \\
\hline John Gahimer & Battelle-Columbus Laboratory, Contractor to EH-33 \\
\hline Rudy I. Hansen & $\begin{array}{l}\text { Battelle Pacific Northwest Laboratory (PNL), } \\
\text { Contractor to EH-33 }\end{array}$ \\
\hline Richard E. Johanson & PNL, Contractor to EH-33 \\
\hline Sanjeva Kanth & $\begin{array}{l}\text { Chemical Engineer, Office of Occupational Safety } \\
\text { (EH-31) }\end{array}$ \\
\hline Michael Lloyd & Battelle-Columbus, Contractor to EH-33 \\
\hline Thomas I. McSweeney & Battelle-Columbus, Contractor to EH-33 \\
\hline V. Pasupathi & Battelle-Columbus, Contractor to EH-33 \\
\hline Carol A. Peabody & Technical Assistant to Director, EH-30 \\
\hline Peter J. Pelto & PNL, Contractor to EH-33 \\
\hline
\end{tabular}




\begin{tabular}{|l|l|}
\hline $\begin{array}{l}\text { CSOR TASK GROUP } \\
\text { MEMBERS }\end{array}$ & PNL, Contractor to EH-33 \\
\hline John A. Piatt & $\begin{array}{l}\text { Acting Deputy Office Director, EH-33, Team } \\
\text { Leader of LANL and Y-12 CSORs }\end{array}$ \\
\hline Robert W. Poe & Industrial Hygienist, EH-41 \\
\hline Jacqueline D. Rogers & Director, Risk and Technology Division, EH-33.1, \\
\hline Richard J. Serbu & Team Leader of SRS and LLNL CSORs \\
\hline Fred C. Shelly & EG\&G, Idaho. Consultant to EH-33 \\
\hline John S. Stone & Kaiser Engineering, Contractor to EH-33 \\
\hline Dan M. Stover & Consultant to EH-33 \\
\hline Pamela J. Sutherland & Battelle-Columbus, Contractor to EH-33 \\
\hline Dennis S. Walters & PNL, Contractor to EH-33 \\
\hline Ronald E. Wright & PNL, Contractor to EH-33 \\
\hline Jay A. Young & Consultant to EH-33 \\
\hline William J. Zielenbach & Battelle-Columbus, Contractor to EH-33 \\
\hline \begin{tabular}{|l} 
MEMBERS PROVIDED LONG- \\
TERM WORKPLACE \\
CHEMICAL ACCIDENT RISK \\
(WCARR) SUPPORT
\end{tabular} & \\
\hline Robert Carson & \\
\hline Kenneth Murphy & Compa Industries, Inc., Consultant to EH-33 \\
\hline Ali Tabatabai & Risk Group Team Leader, EH-33 \\
\hline \hline
\end{tabular}




\section{APPENDIX C - Chemical Safety Oversight Review (CSOR) Trip Report of Los Alamos National Laboratory (LANL)}





\subsection{SUMMARY}

An evaluation of the present status of chemical safety at Department of Energy (DOE) facilities is being performed by the DOE Office of Environment, Safety and Health. The purpose of this evaluation is to identify any generic deficiencies in chemical safety in the DOE complex, to identify the measures and controls necessary to improve chemical operations, and to develop recommendations for both short-term actions to address immediate problems and long-term actions oriented at broader programmatic improvements. The evaluation is supported by a series of reviews at selected facilities. The information obtained is important in terms of its general contribution to understanding the current status of chemical safety and to facilitate a broad reexamination of the chemical safety practices within the Department.

The first facilities visited as part of this evaluation were located at the Los Alamos National Laboratory (LANL) site in Los Alamos, New Mexico, which is operated by the University of California. During the review, the team examined chemical operations typical of LANL and evaluated several ongoing and planned program improvements that will increase emphasis on chemical safety at both the site and facility level.

Most chemical-related operating activities at LANL are performed in multipurpose laboratories, grouped within the buildings by basic programmatic functions. Various other chemical activities, such as waste treatment and material receiving and storage, are performed in facilities that perform support functions. Chemicals are procured through a centralized process, and a minimum stock of chemicals is maintained in the stores inventory. Thousands of different chemicals are used at the site, ranging from relatively innocuous types to highly hazardous and toxic types, such as known human carcinogens, reproductive toxins, and highly acute and chronic toxins. The majority of the chemicals are of the types and quantities found in typical analytical laboratories. The more hazardous and toxic chemicals include large quantities of chlorine (water treatment), moderate quantities of standard acids and bases; fluorine gas, hydrofluoric acids, plating cyanide compounds, and similar compounds; and very limited quantities of highly toxic gases, such as phosgene and arsine.

LANL does not have a site-wide chemical risk management strategy. There are, however, several programmatic efforts related to chemical safety and risk identification at LANL. LANL has developed a toxicological hazard classification method to classify its facilities as High $(\mathrm{H})$, Medium (M), Low (L), and No Hazard (N). The LANL facilities are required to perform different levels of safety analyses, commensurate with the hazard levels. A Low-hazard facility requires a preliminary hazard analysis (PHA), a Moderate-hazard facility requires a Safety Assessment (SA), and a Highhazard facility requires a Safety Analysis Report (SAR). SARs have been completed for some buildings and are in draft or final form. However, hazards and safety documentation is deficient for most facilities, and a timetable has not been established to complete the needed documentation. 
LANL has implemented a health hazards assessment process. The identification and prioritization of facility hazards were based on a review of an inventory from 1989. The facilities were prioritized by hazards on the basis on an in-house assessment scheme. This prioritization may not accurately represent the potential hazards because the inventory is dynamic and has changed significantly since 1989 and because existing controls, which may or may not be effective and/or utilized, were used in the evaluation process.

The traditional safety analysis and health hazards assessment methodologies being implemented by LANL have not been integrated into a single assessment tool. Neither of these methodologies specifically addresses the chemical risk to workers. Current assessment methodologies either do not include facility workers or do not address the potentially unsafe scenarios or situations that may result from chemically related activities in the workplace or its environs. Further, the chemical safety evaluation process for workers is not performed in a timely manner. An example that illustrates both points involves the safety assessments done for the Ceramics and Metals Research (CMR) Building. The chemicals found in the facility were assessed from the standpoint of initiators for nuclear events. The same data indicated significant impacts to workers which, if not mitigated against, would have serious consequences. The team was informed that an assessment of the impact to workers could be performed later if directions are received from DOE to do so. However, many of the changes under consideration for the CMR Building that would address risks to the public, as identified in the Interim Safety Analysis Report (ISAR), will be completed before the evaluation of risks to the workers can be finished. In this case, backfitting to address worker risks may not be economically feasible, which will result in the use of administrative controls as the only mitigation alternative.

The team made several specific observations relating to unassessed risk related to chemicals at LANL. One of the most significant of these is that the site has no strategy for handling and disposing of hazardous or toxic compressed gas cylinders. These cylinders, some containing significant quantities of gas, are pervasive at LANL. At two facilities where there are large numbers of cylinders, the team observed that neither the facility safety analysis nor the health hazards assessment included the added risks to workers or the public associated with the handling and storage of these gas cylinders. In addition, the team observed that in the TA-41 facility, where DOE specifically ordered discontinuance of use of arsine gas as the result of an external audit, the arsine cylinder that was previously located in a laboratory has been encased and installed in a fume hood. However, the concept of "triple containment" has not been applied consistently for other arsine cylinders or toxic gas applications at the site. At TA-46, for example, arsine was being stored with other gas cylinders in an outside storage shed.

In another situation, partially filled cylinders and lecture bottles of several hazardous and toxic gases, including phosgene, arsine, germane, and others, were found in a portable storage container.

Germane has the potential to decompose and self-ignite in air. Thus, a germane leak could result in 
catastrophic release of the other gases. Some of the gas cylinders were for "one-time-use only"; others were more than 10 years old. The latter cannot meet Department of Transportation (DOT) requirements for shipping. (DOT requires containment retesting on a 5-year basis.) With the possible exception of the original gas supplier agreeing to take back unused portions of toxic gases such as arsine, LANL has no viable method for disposing of these obsolete materials.

Another unassessed risk at LANL involves the unwillingness or inability of the County Fire Department (contractor to DOE for fire protection) to respond to a fire or other situation involving chemicals and/or nuclear agents. County firemen have not received "first responder" training. They have chosen not to enter any of the buildings in emergency situations without assistance from the Hazardous Materials (HAZMAT) Team, which usually takes a longer period of time to assemble at the site. In a recent incident involving the explosion of a waste container, the Fire Department was at the scene 20 to 30 minutes before they attempted entry into the building, even though they were fully dressed in personal protective equipment and persons inside the building, who were attempting to provide first-aid to victims, were dressed in casual clothing. This impact of the ineffectiveness of the Fire Department has not been taken into account for facility operations.

Chemical safety has not had a significant driver, either internally or externally, which would allow it to compete for priority against other high-profile environmental and nuclear safety issues. The net effect has been that, depending on the insights gained from the hazard identification and risk assessment process, each facility manager implements his or her own plan. This has resulted in chemical inventory reductions and the use of less hazardous chemicals. Mid-level managers and workers appeared to have a positive attitude toward safety risks, particularly when those risks were nuclear-related, but were less sure how to address chemical safety from a risk standpoint. Development of an Occupational Safety and Health Administration (OSHA) Laboratory Safety Program is underway at LANL. While its implementation will significantly enhance chemical safety within the facilities, the plans for full implementation are projected over the next 4 years.

In the industrial hygiene (IH) area, it was observed that the basic requirements of the recent OSHA regulation, Title 29 of the Federal Regulations (CFR), 1910.1450, with respect to development of a Chemical Hygiene Plan are being met at LANL. A revised draft plan has been written but has not been implemented.

Various facilities and processes were reviewed to determine if elements were in place to reduce the overall level of hazard to workers and site employees who are not immediately involved in the work process. Work control practices currently in place address routine hazards for employees actively involved in the various LANL processes. However, the elements of the programs may not be mature enough to reduce the level of risk to noninvolved workers and the general site population to an acceptable level. Further, increased emphasis in direct-reading instrumentation/monitoring, inventory 
control, hazard analysis, and process safety is needed to reduce the level of risk to site employees to an acceptable level.

\subsection{INTRODUCTION}

This chemical safety oversight review of the Los Alamos National Laboratory (LANL) is one of a series of reviews of the overall management of chemical operations and laboratory activities at Department of Energy (DOE) facilities. These reviews will address safety review processes, mechanisms for identifying chemical hazards and assessing risk, and means of reducing and controlling actual or potential chemical releases and exposures to workers, the public, and the environment. The review of LANL was conducted June 8 - 12, 1992. A closeout with LANL and DOE Albuquerque Field Office (DOE/AL) management was conducted to discuss the preliminary findings and conclusions from the review.

LANL is situated on approximately 27,500 acres (43 square miles) of DOE-owned land, 24,000 acres (87 percent) of which are located within Los Alamos County, New Mexico. There are currently 50 designated technical areas at LANL, with locations and spacing that reflect historic development patterns, topography, and functional relationships. LANL's onsite population of approximately 11,000 , including University and subcontractor employees, is housed in more than 2,200 buildings totaling about 7.5 million square feet. DOE controls the area within the LANL boundaries and has the option to completely restrict access.

The organization of work at Los Alamos provides a number of channels through which information about chemical safety practices and requirements can be communicated. Functionally, there are two main groups with responsibility in this area. The University of California is the management and operating (M\&O) contractor and user of more than 2,000 facilities for approximately 8,000 employees. Johnson Controls, Inc. (JCI), is the main support services contractor, with more than 1,000 employees. JCI operates main utility services, including the water treatment systems, which use large quantities of chlorine. Smaller organizations, such as VWR (which supplies chemicals) and the Fire Department provide services that can also impact chemical safety. Approximately 12,000 people support operations at LANL.

LANL is a multipurpose laboratory, functionally reporting to DOE's Office of Defense Programs. The Albuquerque Field Office implements DOE Headquarters direction and provides continuous onsite direction through an area office.

As part of a major effort to deal with changing environment, safety, and health (ES\&H) expectations and increased external oversight, the Laboratory Director has approved a number of policies that 
assign responsibilities related to ES\&H. Director's Policy 103 provides the umbrella mandate for safety, and identifies the ES\&H Council as the "Office of Primary Responsibility." This group, the Directors, and the Associate Directors, meet periodically with the Laboratory Director. Agendas focus on current ES\&H issues.

Policy 106 deals with occupational health and safety (OSH) management. It assigns the ES\&H Council to perform annual reviews of goals for OSH programs and assess performance in this area. The first year under this policy ended September 16, 1991. Goals apparently have not yet been established at LANL, nor have specific plans been developed to perform the required assessments, with or without goals. The Council function is a logical mechanism to assist in communicating and enforcing policies related to chemical safety, but it does not appear that chemical safety has been a specific topic in Council meetings.

The Office of Quality, Policy and Performance is taking the lead in developing a top-down strategic plan for the Laboratory. The plan will ultimately provide the framework for developing performance goals and more quantitative measures of performance. Planning has not proceeded beyond the broad, conceptual stage. Chemical safety would be a proper topic to include in such efforts.

Discussions with senior management showed an evident determination to improve ES\&H performance and identified a number of initiatives in that direction. However, conflicting guidance on implementation of DOE Orders and other criteria and the burdens associated with a massive improvement program were cited as reasons that progress in some areas was lagging. Chemical safety was not identified as an area of major concern, except as it relates to other ES\&H improvement programs.

Use of risk management techniques to improve decisions on allocation of resources is being pursued through the Associate Director Quality, Policy and Performance. This program is not in place, and no specific schedules have been set for its incorporation into operational or programmatic decisions. As a result, actions in the area of chemical safety presently depend on the individual adjustments in programs and operations that take place at all levels in the organization.

The interfaces between JCI and the University of California appear to be clearly spelled out. JCI maintains its own staff capabilities for workplace safety for those operations under its direct control. Chemical safety practices are not required to be the same as those of the University of California. $\mathrm{JCI}$ is not represented on the ES\&H Council. 


\subsection{DISCUSSION}

Chemical safety activities at LANL were expected to meet a hierarchy of controls that span management of risk to providing personal protective equipment. This hierarchy of controls, which includes (1) Risk Management, (2) Process Chemical Safety, (3) Chemical Laboratory Safety, and (4) Industrial Hygiene, was assessed during the review. Superimposed on these areas is the degree to which formality and discipline are practiced in the execution of functions. This was assessed as part of the conduct of operations review. The results of the review are discussed in the following sections.

\subsection{Chemical Hazard and Risk Analysis}

A generic hazard and risk analysis process includes hazards identification and risk assessment, development of a risk management strategy, and establishment of a safety envelope for facility operations. The review of LANL's chemical activities focused on these activities.

\subsubsection{Risk Management Strategy}

LANL does not have a site-wide chemical risk management strategy. Each facility, depending on safety insights gained from the hazard identification and risk assessment process, implements its own risk reduction plan. Some notable risk reduction measures have been taken as a result of the process, including a tremendous reduction of hazardous chemical inventories at some facilities and the use of less hazardous chemical substitutes.

LANL has developed a toxicological hazard classification method to classify its facilities as High $(\mathrm{H})$, Medium (M), Low (L), and No Hazard (N). The establishment of a toxicological hazard classification scheme is useful if all hazards at all facilities are identified and appropriately controlled. Accordingly, LANL has classified its facilities into these same four classes, with 3 facilities classified as $\mathrm{H}, 27$ as $\mathrm{M}, 327$ as $\mathrm{L}$, and 1,961 as $\mathrm{N}$.

The LANL facilities are required to perform different levels of safety analysis, commensurate with the hazard levels. A Low-hazard facility requires a preliminary hazard analysis (PHA), a Moderatehazard facility requires a Safety Assessment (SA), and a High-hazard facility requires a Safety Analysis Report (SAR). A PHA is a qualitative hazard assessment that uses proven techniques, such as Failure Mode and Effect Analysis (FMEA), and requires minimal safety documentation. An SA requires a qualitative risk analysis to determine a safety envelope and the identification of appropriate engineering and administrative controls. An SAR includes a quantitative risk analysis to determine a safety envelope and is structured to meet all current DOE SAR requirements. Some buildings have completed safety analysis reports (SARs) in either draft or final form. However, most are deficient in 
hazards and safety documentation, and a timetable has not been established to complete the needed documents.

Since the hazard identification/risk assessment level of analysis is commensurate with the hazard level assigned to a facility, plant vulnerabilities may not be identified in a comprehensive manner to support a risk management strategy and define a facility safety envelope. For example, the SA for the Compressed Gas Processing Facility (an M-hazard facility) was performed and appeared to be a useful safety document for taking certain risk reduction measures. However, because an SA is a less detailed analysis than an SAR, certain hazards, such as seismic events that can cause toxic gas release and explosion, were not included in the analysis. In this case, seismic events were not evaluated because it was determined that they were not credible based on their low frequency of occurrence (less than $10^{-6}$ per year). However, the consequence of a seismic event could be very large with a high calculated risk. Here, the SA provides only a partial insight to risk. A more extensive analysis could result in the facility being reclassified. The SA does, however, provide some notable riskreduction measures, including the recommendation to move the toxic gas storage shed (TA-3-SM-474) farther away from the flammable gas storage facility (TA-3-SM-1650) and to install concrete posts around the toxic gas storage shed for minimizing the consequence of an onsite transportation accident. However, these activities have not yet been initiated.

Because the current DOE guidance on safety analysis primarily focuses on protection of the general public from radiological hazards, LANL has adopted the same focus. As an example, an Interim Safety Analysis Report (ISAR) has been developed to determine the safety upgrades for the Ceramics and Metals Research (CMR) Building. The focus of the safety upgrades will be to provide an extra margin of safety to protect the public from radiological accidents. Chemicals were considered in a scoping analysis as initiators of nuclear events.

Safety insights gained from the ISAR and the scoping analysis are being used to develop a more indepth radiological safety analysis for protecting the public. The team feels that the scoping analysis is a positive step in addressing chemical safety, but a more detailed chemical safety analysis for protecting workers should have been performed as part of the ISAR process. Safety upgrades to protect workers from chemical accidents in the CMR Building will be minimal or will be deferred until a more comprehensive chemical safety analysis has been performed.

\subsubsection{Establishment of Safety Envelope for Facility Operations}

The risk analysis process establishes the safety envelope for facility operations. For the facilities reviewed, including the Plutonium Facility (TA-55-PF-4) and the CMR Building (SM-29), the team observed that chemical safety has not been evaluated to the same extent as radiological safety. Here, it was noted that the emphasis was placed on determining the risk to the public and that management 
strategy was focused on providing additional safety margin to protect the general public, rather than considering potential impacts to workers. Therefore, the safety envelope for chemical operations has not been well defined. Further, the Plutonium Facility Final Safety Analysis Report (FSAR) identified a very large number of chemicals that are used at PF-4, including fluorine, phosgene, hydrogen fluoride, chlorine and nitric acid. However, a bounding accident analysis was performed for only one chemical, phosgene, and no other phosgene accident scenarios, particularly those applicable to the workers, were evaluated that would provide a more comprehensive understanding of chemical risk.

\subsubsection{Team Observations of Safety Deficiencies}

The main thrust of the team's review was aimed at identifying significant (i.e., imminent danger) safety deficiencies. While no significant deficiencies were found, several minor deficiencies were noted during the course of the site visit as reflected in the following table. The section on chemical process safety also describes the team's observations. 


\begin{tabular}{|c|c|c|}
\hline HAZARDS & ENGINEERING CONTROLS & $\begin{array}{l}\text { ADMINISTRATIVE } \\
\text { CONTROLS }\end{array}$ \\
\hline $\begin{array}{l}\text { Toxic gases in transportainer } \\
\text { (TA-46-277) including arsine } \\
\text { (about } 1 \text { pound), germane, and } \\
\text { phosgene. }\end{array}$ & $\begin{array}{l}\text { Temporary storage with no } \\
\text { special engineering controls. }\end{array}$ & $\begin{array}{l}\text { Transportation is locked and } \\
\text { the key is controlled. It is } \\
\text { properly posted with hazard } \\
\text { warning signs. }\end{array}$ \\
\hline $\begin{array}{l}\text { Two } 30 \mathrm{lb} \text { phosgene cylinders } \\
\text { in Room } 116 \text { on South Dock } \\
\text { of Building TA-55-PF3. }\end{array}$ & $\begin{array}{l}\text { Valves and piping connecting } \\
\text { to the cylinders appeared to be } \\
\text { industrial grade. Hazard } \\
\text { analysis was performed after } \\
\text { equipment was installed and } \\
\text { was not used to assure that the } \\
\text { safety envelope was properly } \\
\text { defined. }\end{array}$ & $\begin{array}{l}\text { Written SOP developed in } \\
1991 .\end{array}$ \\
\hline $\begin{array}{l}\text { Toxic gases stored in } \\
\text { aluminum shed (TA-3-SM- } \\
476 \text { ), including cylinders of } \\
\text { ammonia, chlorine, and } \\
\text { phosgene. Also contains used } \\
\text { cylinders of unknown gases } \\
\text { waiting for disposal. }\end{array}$ & $\begin{array}{l}\text { Temporary storage with no } \\
\text { engineering controls. Cylinders } \\
\text { are not fully secured inside of } \\
\text { shed. Shed is located in } \\
\text { parking lot close to vehicle } \\
\text { path. Plan to install concrete } \\
\text { posts to minimize } \\
\text { consequences of traffic } \\
\text { accidents. }\end{array}$ & $\begin{array}{l}\text { Two person rule to access } \\
\text { chemicals. Locked shed. }\end{array}$ \\
\hline Beryllium in TA-3-141. & $\begin{array}{l}\text { No fire fighting capability. } \\
\text { sprinkler system. }\end{array}$ & None. \\
\hline $\begin{array}{l}\text { Compressed gases in loading } \\
\text { dock room in TA-41. Gases } \\
\text { include nitrogen, argon, and } \\
\text { hydrogen. }\end{array}$ & $\begin{array}{l}\text { Forklift vehicle charging } \\
\text { operation performed within } 2 \\
\text { feet of closest cylinders. No } \\
\text { engineering controls to prevent } \\
\text { vehicle from puncturing } \\
\text { cylinders or knocking them } \\
\text { down. }\end{array}$ & Forklift operator training. \\
\hline
\end{tabular}

\subsection{Chemical Process Safety}

The primary elements of process safety management comprise three areas: technology; personnel; and facilities. Elements involving technology and personnel are discussed in the following sections with respect to the findings of the Chemical Safety Oversight Review (CSOR) of LANL.

\subsubsection{Technology}

The technology elements of process safety management include process technology, process hazards analysis, and the management of change. Findings in these areas are discussed below. 


\subsubsection{Process Technology.}

All processes should be continuously reviewed and upgraded for safety and efficiency. For hazardous processes, new systems or techniques should be sought to increase inherent safety. Also, processes requiring or producing fewer numbers or smaller quantities of hazardous process materials, intermediates, byproducts, and wastes should be sought.

As previously noted, the sizes of inventories in specific facilities have been reduced. Less hazardous chemicals are being substituted in processes where highly toxic materials are currently used; however, the most common-risk reduction method being used is administrative controls. Administrative controls are the least effective method in that they rely on the knowledge and compliance of all personnel interacting with the chemical processes. Adequate and appropriate training of personnel was not verified by the CSOR Team. However, the team did receive appropriate safety briefings before entering process facilities.

Discussions with facility personnel also revealed that engineered controls are often used to reduce accident potential. However, in the past, these controls have most often been backfit to existing systems, rather than integrated into process designs. Administrative procedural reviews are in place to ameliorate existing shortcomings, but the CSOR Team did not verify their effectiveness.

At TA-55, the Plutonium Facility, and TA-3-66, the SIGMA Building, facility personnel offered several examples of chemical substitution projects. At TA-55, staff are attempting to eliminate the use of phosgene. Also at TA-55, the use of hydrogen is being minimized by storing most of the hydrogen as a metal hydride and generating it as needed. At TA-3-66, staff are trying to eliminate cyanide materials from two of three plating operations. These initiatives have been undertaken voluntarily, without management directive.

"Chem-free" days are an example of a waste management program sponsored by the Office of Environmental Restoration and Waste Management (EM) to reduce the numbers and quantities of unneeded chemicals on the LANL site. However, waste gas cylinders, which are not accepted under the "chem-free" program, are currently stored in sheds around the LANL site. Gas cylinders are of various sizes, and some are up to 40 years old. Removal of the cylinders, some of which contain class A poisons, has been extremely slow. Currently the only way to "dispose" of extremely poisonous gases at LANL is to return the cylinders to the company supplier.

\subsubsection{Process Hazards Analysis}

Hazards analyses should be conducted as early as possible, preferably in the design stage of any process, to identify, eliminate, protect against, or mitigate potential process hazards. In addition, periodic hazards reviews should be conducted for existing facilities, especially if process changes or upgrades are under consideration. 
A system of facility hazard classification has been developed and implemented at LANL. All buildings have been assigned one of four levels of hazard: High, Moderate, Low, or No Hazard. Classification is based on an evaluation of the energy sources and chemical, radiological, and environmental hazards present within a facility.

Discussions with facility personnel revealed that preliminary hazards analyses and/or safety analyses are planned or in process for all facilities that have received classifications of High, Moderate, or Low. Current documents reflect an emphasis on radiological safety concerns. A more detailed description and evaluation of the hazards classification program and the status of chemical safety documentation for LANL facilities are presented in the Hazards and Risk Analysis section. The methods of collecting information on process hazards and the likelihood of process failures are considered below.

In general, hazards classification and documentation at LANL have addressed facilities rather than processes. Chemical process hazards analyses of various types have been performed sporadically and sometimes informally. However, discussions with facility personnel revealed that review processes that could be used to trigger such analyses are being initiated at several facilities.

A great variation among facilities exists at LANL. While personnel at most facilities understand the chemical hazards posed there, a unified approach to dealing with the hazards was not evident. Estimates of accident probabilities varied greatly in quality. No organization fully considered safety documents as "living" documents. Discussions with facility personnel and review of various safety documents revealed little standardization of approach in identifying credible initiating events and in modeling the releases from these events. No analyses are full Probabilistic Risk Assessments (PRAs). Detection and mitigation equipment are not credited in release evaluations, and release models are not standardized. Inconsistencies may result from the use of several contractors with different approaches. Additional guidance documents are needed.

Discussions with facility personnel and review of documents also revealed that LANL uses Failure Modes and Effects Analysis (FMEA) almost exclusively for development of credible accident scenarios. FMEAs are usually written in narrative, not tabular, form. A common FMEA tabular format is needed. Because FMEAs must reflect actual operating practices, as opposed to ideal behavior, the individuals operating a facility should participate in developing its FMEA. They should also participate in assessing its hazards of operation. The advantage of using their knowledge is twofold. First, the staff themselves become more aware of the hazards associated with equipment and operations. And second, the resulting hazards assessment incorporates the interfaces between the equipment and operations and operations personnel. Insight may be gained for both normal operations and accidents or process upsets.

With respect to specifications for control and monitoring equipment, review of several safety documents showed that most do not address these systems. The safety document for TA-55 addresses detectors for phosgene but considers no other gas releases because a bounding accident approach was 
used. In addition, there is no analysis of the likelihood of a detector being in the failed state when an accident occurs. Thus, there is no basis for determining either the need for redundant detectors or the appropriate inspection and surveillance programs.

A review of safety reports revealed that a variety of methods is used to model releases. Each facility appears to have different modeling approaches to the same types of accidents. A reference list of modeling methods is needed, including recommended methods for modeling spills, vessel failures, fires, explosions, and releases of gases and particulates.

\subsubsection{Management of Change}

A formal, integrated process should exist for initiating and accommodating changes in facility and equipment design and process operations. All changes should be documented; facility diagrams and/or process piping and instrumentation diagrams (P\&IDs) should be updated; operations and safety manuals, maintenance schedules, and standard operating procedures (SOPs) should be updated; and personnel should be trained or retrained in a coordinated and timely manner.

A formal procedure has recently been implemented at LANL to review proposed new facilities and modifications to existing facilities. A more detailed description of this procedure and an evaluation of its status is presented in the Conduct of Operations section. Changes in processes to reduce risks are discussed below.

In general, management of change at LANL has addressed facilities rather than processes. Simple chemical hazards analyses have been performed sporadically and sometimes informally for new processes and/or experiments. Hazards analyses are rare for changes to existing processes and/or experiments. Discussions with facility personnel did not reveal a plan to develop a formal process to document process changes.

Discussions with facility personnel revealed that many individuals would like to eliminate extremely poisonous gases and other hazardous chemicals from their inventories. In one case (i.e., arsine at TA-41), discontinuance of use was ordered by DOE. However, waste management personnel stated that LANL has no way to dispose of Class A poison gases if a supplier will not take them back. Thus the risks posed by these chemicals have not been eliminated. In fact, given the collection and gradual deterioration of the vessels, the risk is increasing slowly, day by day. The magnitude of the risk increase is unknown. The tanks have exceeded their reinspection dates. DOT requires a hydrostatic test every 5 years, before the tanks are refilled.

Sọme gases are stored in "one-time-use-only" bottles. Many show evidence of being stored or left outside for long periods of time. Collecting several of these bottles, particularly those that are more than 10 years old, in one location is not safe. The potential interactions may lead to a worse release. 
In TA-46-277, a transportainer, several pounds of toxic and flammable gases have been stored for several years. One, germane $\left(\mathrm{GeH}_{4}\right)$ decomposes in air and may ignite (Bertherick's Handbook of Reactive Chemicals, p. 1139). The risk of mixing germane with arsine, phosgene, and other cylinders containing flammable compounds has not been considered from a safety standpoint. The transportainer is locked and located inside the TA-46 protected area. There are no detectors to warn area workers of a release. If the gases were removed to Waste Management's "Area L" in TA-54, they would be stored outside. However, collecting these gases in one location is not safe, given their age and unknown design specifications. Also, some might not meet the current DOE regulations for transport on public roads.

The installation of detection systems can reduce risk. One of the CSOR team members toured TA-55 a year ago. The improvements made within a year have been significant. Additional controls have been placed on phosgene, hydrogen fluoride (HF), and chlorine supply systems. However, the changes may not incorporated the best engineering practices. For example, in Room 114 in the PF-4 area of TA-55, there are six hydrogen detectors. Four are located at the room exhaust point, about 2 feet from the floor. Their alarm points are set at 200 parts per million (ppm), well below the 4 percent lower flammability limit for hydrogen. Another detector is placed in the exhaust duct from the hydrogen cabinet. It, too, is set to alarm at $200 \mathrm{ppm}$. The detector in the glove box is set to alarm at 2 percent. Whether or not the monitors, located close to the floor, will ultimately detect a release of hydrogen into the room is questionable. Because the monitors, which are set at $200 \mathrm{ppm}$, saturate at high concentrations, the need for a $200 \mathrm{ppm}$ detector in the exhaust duct is also questionable. Similar questions exist for the placement of the HF detectors in a supply room (Room 429) of TA-55. They seemed to be neither close to where individuals work nor where leaks are likely to occur. The need for redundancy in the supply room depends on the reliability of the instruments. All of these questions could be the subject of safety studies. The new Safety Review Committee at TA-55 could identify needed safety studies. Such individual safety studies could greatly facilitate the next revision of the SAR for the facility.

Risk reduction at LANL can also be realized by incident evaluation. Although the risk for some LANL facilities might be controlled by common-cause accidents, such as earthquakes, the continuing evaluation of minor incidents or procedural violations could result in significant risk reductions if findings are incorporated into safety documents and practices. DOE's Occurrence Reporting and Processing (ORPS) system might function to identify accident causes. However, LANL facility personnel stated that the ORPS format is not very useful. In general, they are unable to relate the report on an accident at another site to a potential accident at LANL. A database of incidents (e.g., spills, fires, and leaks) is needed for LANL to improve the quality of their safety evaluations.

\subsubsection{Personnel}

The personnel elements of process safety management include emergency planning and response and training and performance. Findings in these areas are discussed below. 


\subsubsection{Emergency Planning and Response}

A formal, written emergency response plan should exist, and both onsite and appropriate offsite personnel should be trained to respond to accidents including releases, fires, explosions, and natural disasters.

Emergency evacuation procedures for LANL facilities are well documented, and personnel are trained. All visitors to a facility are briefed on emergency signals and response procedures.

There is a trained HAZMAT Team that responds to any releases of hazardous materials within the LANL site boundary. Discussions with facility personnel revealed, however, that contracted emergency response providers are not fully trained to respond to all types of emergencies. A more detailed discussion of emergency response operations at LANL is presented in the discussion of management of operations. This section addresses emergency response needs from a chemical hazards perspective.

Planning and execution of emergency drills enhances personnel awareness of potential process hazards and the severity of possible consequences. At TA-55, the Plutonium Facility, the last emergency evacuation drill was staged as a chemical accident rather than a nuclear criticality. The use of a chemical initiator helped increase the awareness of chemical hazards at the facility.

Incidents have occurred in which fire fighters refused to enter an area because they did not have "first-responder" training. From a worker-safety perspective, when a staff member is overcome in a chemical release, he or she must be rescued quickly. First responders must be able to don appropriate personal protective equipment (PPE) and enter the affected area with instruments appropriate to assess the release situation in minutes. In addition, building managers must be able to tell the first responders quickly what potential hazards they might encounter. When it is fully operational, the Automated Chemical Inventory System (ACIS) might provide this function.

\subsubsection{Training and Performance}

All personnel should be appropriately and fully trained in both job and process safety and emergency procedures. This area is addressed in detail in the discussion on management and organization. Training and performance, as they relate to chemical process safety, are discussed below.

There were many evidences that training, both on-the-job and formal classroom training, is taking place. And staff training awareness, overall, was very high. However, the recognition of the need for improved performance was much less evident. There were indications of inadequate awareness of the chemical process safety concepts described above. In at least two instances, facility managers appeared unable to recognize hazards. In those cases, the managers also appeared to consider LANL's safety assessment requirements as a necessary formality for operations and not as a useful tool for assuring safe operations. 


\subsection{Chemical Laboratory Safety}

Generally, operating activities at LANL are expected to meet proven and accepted practices and requirements to assure chemical safety. These include, but are not limited to, the National Academy of Science (NAS) Laboratory Chemical Safety "Prudent Practices" incorporated in the OSHA regulations and the National Fire Protection Association (NFPA) "improved risk" fire protection criteria. As a best practice, all workers should be trained to recognize and report hazards, and facility managers should be held accountable for the tracking and correction of the noted hazards. In the laboratories, researchers should take ownership of the work space, the various chemicals used, and the wastes produced. They should also take responsibility for the safety of their activities, including the safety of others who share the building space. The laboratory managers should be accountable to assure that the ownership and responsibility are taken.

\subsubsection{Chemical Hygiene Plan}

The OSHA Laboratory Standard was promulgated in 1990. The regulation requires that laboratories write a Chemical Hygiene Plan to cover safety and health issues in the laboratory. Enforcement of the plan must be done by the Chemical Hygiene Officer (CHO) and/or a Chemical Hygiene Committee. The plan should cover safe laboratory work practices and information about the hazards in the workplace, including emergency procedures.

Implementation of this plan, including job-specific training, could reduce the risk and consequences of an incident at LANL. A draft Chemical Hygiene Plan has been written, but not implemented. There has not been a CHO appointed nor a committee formed to enforce the provisions of the Chemical Hygiene Plan. LANL is currently training its laboratory workers under a general Hazard Communication training program.

The draft Chemical Hygiene Plan identifies good laboratory work practices, such as use of engineering controls, etc., for "Category I" chemicals. Category I chemicals are defined as known human carcinogens, reproductive toxins, and high acute and chronic toxins. Although Category I chemicals appear to have good evaluation and control procedures in place, other "less toxic" chemicals such as suspected carcinogens, are controlled by few processes or procedures.

\subsubsection{Hazardous Materials Inventory}

The current inventory system at LANL appears to exist in a variety of formats, ranging from handwritten hardcopy to computer database files. It is updated annually in accordance with a formal program. An automated system is planned that will identify chemical hazards and Material Safety Data Sheets (MSDSs) associated with the inventory. Prudent lab practices and safety regulations require a list of hazardous chemicals at the workplace. An annually updated inventory system does not adequately represent the hazardous chemicals that can be in the work area at any given time and does not demonstrate best work practices. As an example, a TA-141 flammable storage cabinet had a 
list of chemicals on the front dated August 1991. Located inside the cabinet were different chemicals than those identified on the list.

Hazards information, including an up-to-date inventory, that is accessible to emergency response personnel can limit the consequences of an incident within a facility. It is evident that the current chemical inventory system does not provide up-to-date hazard information in a retrievable format for emergency response personnel. Types of hazards (e.g., toxic and fire) should be identified and made available on a real-time basis for emergency response purposes.

Knowing the quantities of hazardous material in the building can help risk analysis personnel better evaluate the hazards associated with a facility. This information is essential for fire hazard analysis efforts and building loading reviews. Accumulation of excessive quantities of hazardous materials within a facility will increase the consequences of a fire or explosion. Quantities of hazardous materials are not known in most LANL facilities. Some of the facilities toured had already minimized their inventories. However, there is no adequate procedure in place to prevent the buildup of flammables, highly toxic, corrosive, or reactive materials.

MSDSs provide information on the basic hazards presented by each chemical. All individuals who were interviewed stated that the MSDS were available in the process area for all chemicals in use at that particular facility.

\subsection{Industrial Hygiene}

\subsubsection{Hazard Recognition and Control}

A critical element to the reduction of risk in IH programs is the early recognition of hazards present in the workplace. Attempts should be made to minimize the number and quantities of hazardous materials onsite, and an aggressive substitution program should be in place. Responsibilities for documentation of control programs should be as clear, consistent, and concise as possible in order for large, diverse-mission facilities to reduce the overall level of risk for the site population. Controls on critical systems should be documented utilizing existing, mature risk management systems that have demonstrated reliability of risk management at the site.

Various facilities and processes were reviewed to determine if elements were in place to reduce the overall level of hazard to workers and to site employees who were not immediately involved in the work process. The CSOR Team found that the work control practices currently in place are reducing the level of risk for employees actively involved in the various LANL processes that were reviewed. However, the elements of the programs reviewed may not be mature enough to reduce the level of risk to workers and the general site population to an acceptable level. Further, increased emphasis on direct-reading instrumentation/monitoring, inventory control, hazard analysis, and process safety is needed to reduce the level of risk to site employees to an acceptable level. 
Highly hazardous or toxic materials used in processes were found to have direct-reading monitors that were sufficient for the operation in place in some locations, e.g., the TA-55-4 Bottle Storage Room. The TA-55 operating organization also plans to connect remote monitoring systems. This practice will enhance the safety of site personnel, and it should be extended to all areas containing high-hazard materials.

Locations were observed (e.g., TA-35-125, A-16) in which highly toxic materials were found in large quantities without dedicated direct-reading monitors. Increased emphasis should be placed on using direct-reading instrumentation in locations where high hazard materials are used. Interim measures should continue, using portable direct-reading instruments during short duration operations, until fixed systems are installed. Portable direct-reading instruments should not be relied upon to control hazards that are ongoing, even if infrequent, particularly in areas where the materials are stored in pressurized systems or are placed in hoods in operating areas, such as in TA-41-04. Although process controls are in place, some areas of LANL (e.g., TA-35-135 and TA-3-170, the Gas Facility) were observed that contained large volumes of pressurized inert gas without direct-reading instrumentation that would notify occupants of oxygen-deficient atmospheres.

\subsubsection{Hazards Communications Program}

A rormal hazards communications (HAZCOM) program is a mandatory requirement for all facility workers and visitors. The program includes well-prepared, primer-level information for the safe handling and storage of chemicals, minimum requirements for labeling of chemical containers, and instructions on the recognition of chemical hazards and use of MSDSs. The overall effectiveness of this initial presentation in the workplace depends on job-specific HAZCOM training and continued reinforcement by supervision.

At LANL, a complete file of MSDSs exists on the site-wide electronic database that can be accessed at all facilities. In addition, most facilities keep several "hard" copies of pertinent MSDSs on hand. Facility staff reported that the electronic database was difficult to access and could be too slow to provide the needed information in an emergency situation. In many cases, the number of MSDSs was so large as to be unusable. Providing electronic access to pertinent MSDSs on an individual workeror facility-specific basis was not a part of the LANL HAZCOM program.

As noted in the HAZCOM training, the two most preferred methods of reducing chemical hazards are eliminating the toxic or hazardous chemicals and substituting non-toxic or less hazardous chemicals for them. Both methods are being somewhat successfully practiced at the facilities visited. Substantial reductions of chemical inventories have been accomplished in all facilities, and an automated chemical inventory system is being adopted by the site. However, a workable method of controlling inventories (i.e., eliminating unwanted or obsolete chemicals and keeping quantities to an absolute minimum), other than general reliance on administrative control, has not been identified. It was noted that the degree of attention to chemical inventory control varied significantly among 
facilities and appeared to be a function of the facility manager's awareness of requirements, rather than of a site-wide direction.

Plans developed for inventory control, when implemented and allowed to mature, will reduce the current level of risk. Some organizations, such as MST-5 in TA-3-29, have a good inventory control system currently in place. An effort has also been made within this organization to reduce the amount of materials on hand, and quantities of materials in this area were considered in the ISAR. Several problems still exist in implementation that preclude the further reduction of risk. There is no evidence of a systematic review of chemical purchases by IH prior to materials arriving onsite. This could be problematic because (1) such a strategy is not consistent with good waste minimization policy; (2) highly hazardous materials may be procured for existing processes (that have been reviewed and approved) without consultation from $\mathrm{IH}$; and (3) a delivery transportation incident might result in previously unidentified hazards to response personnel. During discussions with site personnel, no plans to develop a pre-order approval process were identified.

Substitution of less hazardous materials is often left to the line organization. For example, although TA-55 personnel were not aware of the existence of the DOE/AL Toxic Material Advisory Committee, they were performing substitution evaluations of materials already in inventory. Quantities of materials are reviewed by $\mathrm{IH}$ personnel only on an annual basis or as identified in formal and less timely programs, such as the health hazard inventory, and during large-scale process upgrades such as the ES\&H checklist.

The current system allows for the possibility of ever increasing quantities, thereby increasing the resources needed to evaluate and control the use, storage, and disposal of hazardous material. No specific controls, computer-generated reports, or flags are available to readily identify increased quantities of previously "approved" hazardous materials. There was no evidence that the IH staff (HS-5) have a mechanism or requirement to review all chemical purchases at a frequency greater than annually. Existing review systems do not specify material quantity limits for specific zones, nor does the proposed inventory system specify order quantity limits. While the current system of hazard recognition and control appears effective for currently identified processes, substantial time could elapse between the arrival of small quantities of materials onsite that should be evaluated (hazard evaluation and sampling) concurrent with the use of the material. Laboratory-wide ES\&H checklists for identification of chemical hazards are limited to programmatic changes, design modifications, and requests for services.

Several operations were reviewed involving highly toxic materials or large volumes of inert gases under pressure which were not readily identified as critical safety systems through the existing quality control process. Failure of system components, such as valves and piping, at other facilities has resulted in personnel injury and/or property damage.

While direct-reading monitors are in place in some of these areas, this does not preclude an accident event from occurring. The quality process using the graded approach would substantially reduce the 
risk of an accident for pressurized, highly toxic systems. Inclusion of high pressure/highly toxic system components into the quality program would enhance site employees' safety. Components should be subjected to procurement control and receipt inspection, pressure and compatibility, and quality engineering review and approval for all new installations and maintenance/preventative maintenance activities.

LANL has implemented a Health Hazards Assessment program. The identification and prioritization of facility hazards were based on a review of an inventory from 1989 . The review took into consideration the frequency and duration of chemical use by work, quantity of material used, the hazards associated with the chemical (ref. N. Irving Sax), and presence of existing controls. The facilities were prioritized by hazards based on this evaluation scheme. This prioritization may not accurately represent the potential hazards because the inventory is dynamic and has changed significantly since 1989. Also, existing controls, which may or may not be effective and/or utilized, were used in the evaluation process. Chemical hazard identification should be conducted to include all potential hazards present in a facility without regard to existing control measures.

An example of an effective hazard analysis was observed in the TA-35-125, A-16 LASER laboratory. An SOP/hazard assessment that was written by the line organization's Health Safety and Environment staff member covered in detail the activity described, identity of personnel performing the operation, necessary training, requirement for annual review, and documented training of personnel to the SOP. The SOP also referenced Operating Procedures which were found in the workplace. Such specific operations procedures based on current inventory are critical to risk reduction.

\subsection{Conduct of Operations}

Assessment of chemical safety in the workplace and the potential risk to workers from chemical hazards involves an examination of practices and procedures, at every level, which govern operations. Information was gathered at LANL in Design and Analysis, Control and Primary Containment, Mitigation of Chemical Accidents, and Chemical Accident Recovery. These assessment areas were selected to represent the successive "levels of defense" commonly used to prevent injury to the general public and to site and facility workers and to prevent the damage to or the loss of government property.

The operating facilities evaluated in this assessment are either multi-purpose laboratory spaces, grouped into buildings by basic chemical function, such as powder metallurgy, laser technology, and plutonium work or by support facilities, such as waste treatment, and material receiving and storage. The safety requirements and responsibilities for the support facilities, with a relatively constant work mission, are well defined. However, the safety requirements and responsibilities for the laboratories are less concrete. In the laboratories, researchers are typically assigned a specific space which they occupy for the duration of their experiments. When experiments are completed, researchers may continue to perform additional related work in the same laboratory or may move to another area. Thus, several unrelated chemical operations may be performed simultaneously within the same 
facility, and, at the same time, modifications maybe underway to set up laboratories for new or continuing work.

To make necessary modifications, researchers should share the responsibility with the facility or building owner for the proper selection and installation of equipment and services. When experiments require the use of more than one chemical, the engineering requirements of the most hazardous should govern the quality of equipment selected or the classification of services required, e.g., corrosionresistant piping for acids/bases or explosion-proof electrical service for highly flammable chemicals. Similarly, the use of engineered controls or safeguards, such as containments, shielding, redundant safety devices, and increased ventilation rates, should be based on the most hazardous chemical in use or planned for use within a facility. Thus, the number and quantities of chemicals that will be permitted within a facility could be limited.

The adoption of specific, step-by-step operational procedures should be based on a "graded approach" which considers the potential consequences of the worst chemical hazard. The more severe the consequence, the more exhaustive the search for ways or methods to mitigate the hazards. Procedures and equipment to minimize the effects of small chemical accidents or spills should be based on the worst chemicals, and "worst case" chemical accident scenarios should govern the accident recovery or emergency preparedness procedures. Finally, all workers should be trained and proficient in practicing hazards awareness and identifying potential hazards in the workplace, and a system should exist to track and correct the hazards identified.

The following sections focus on identifying the differences between the LANL programs and practices, compared to the program outlined above.

\subsubsection{Design and Analysis}

A formal program, the ES\&H Questionnaire, has been implemented at the LANL site to review and approve proposed facility modifications prior to initiating work. The purpose of the program is to verify that all ES\&H criteria have been considered. Although this program is a positive improvement, it is very immature, and the amount of information presented in the questionnaire is limited. There is no evidence that the document is controlled or updated to accommodate revisions to the subject facility or process. Further, there is no evident linkage between the information on the questionnaire and either the subsequent engineering decisions that are made or the degree of quality assurance required to verify that the design, selection of equipment and components, and workmanship are of sufficient quality to assure safety. For example, a gaseous hydrogen cylinder and vented enclosure were installed in a laboratory area of less than adequate electrical classification (i.e., not explosion-proof). Also, unsupported tubing with compression tubing fittings at every connection was used on a phosgene transfer line. Based on the consequences of leakage of these gases (i.e., explosion and poisoning, respectively) the adequacy of the installations should have been questioned through a series of formal design and operational readiness reviews. 
The changing functions of laboratory spaces, as new experiments are conceived or existing experiments are expanded, also pose a substantial chemical-related risk to workers when formal PHAs, SAs, and SARs are not required prior to making structural or process modifications. Although requirements for additional services, such as ventilation, containments, barriers, and piped fluids are appropriately addressed in the ES\&H Questionnaire, other important requirements, such as upgrades to electrical enclosures and receptacles, increased fire protection, availability of different fire suppression agents, or additional safety showers and eyewash stations, can be overlooked in the design. The scope of the design review program does not appear to address these requirements nor is the engineering design thorough enough to do so.

During several brief facility tours, the CSOR Team noted that many hazards, most of which were of minor consequence, were present but unidentified. It is apparent that more emphasis needs to be placed on training and practicing hazards awareness at the site.

\subsubsection{Control and Primary Containment}

The CSOR Team found that most of the chemical-related laboratory and process work was performed in accordance with written operating procedures. A few of these procedures were quickly reviewed, but the overall effectiveness of the procedures, including the effectiveness of training to the procedures, was not evaluated.

For chemical procurement and receiving, LANL provided a comprehensive review of the procedures, training, and personnel qualification requirements for handling, storing, and shipping chemicals within the site boundaries. The procedures, training, certification requirements, and associated record documentation for these activities are among the best in the chemical industry and exceed those imposed by DOE.

There was some evidence of a work control program, including the use of "burn" permits for heat producing operations, such as welding, in the chemical process and laboratory areas. However, the overall effectiveness of the program was not evaluated by the CSOR Team.

Significant disparity exists among facilities in the storage of flammables. Indoor flammable storage cabinets without vent plugs were found directly adjacent to plugged-vent cabinets. Several cabinets did not have internal spill protection (not required, but a preferred practice). No deficiencies were noted in proper handling and storage of flammables outside the storage cabinets.

Compressed gases were identified as being the most significant problem in the storage of chemicals. A large number of highly toxic and hazardous compressed gases are handled, stored, and used at LANL. Of all the chemicals used onsite, compressed gases represent the highest accident potential. Thousands of compressed gas cylinders were observed which were properly identified and restrained. However, at one laser facility, two unrestrained cylinders were found; one, a full bottle of helium. 
These cylinders were in the same racks as several identical cylinders which were properly restrained.

A final concern relating to compressed gases is the repeated use in several facilities of unsupported small-bore tubing with light-duty compression fittings in lieu of rigid prefabricated manifolds, with braided metal-covered flexible "pigtails" and heavy-duty threaded fittings at the bottle connection points.

\subsubsection{Mitigation of Chemical Accidents}

With the exception of attention to fire protection, it appears that the site has effective programs to deal with the mitigation of chemical accidents. There are adequate supplies of PPE, and the proper training in its use has been provided. Secondary containment has been provided for most toxic and hazardous liquids. Each operating/laboratory area has been equipped with cleanup kits for small spills, and specific individuals in each facility have received the necessary training in their use.

Facilities are equipped with appropriate numbers of well-placed safety showers and eyewash stations. However, additional emphasis should be placed on ensuring that necessary quantities of temperaturecontrolled (tempered) water are available for outdoor showers and eyewashes during the winter. Further, the installation of flow alarms on remote safety showers and eyewashes should be considered to warn operators of others who may require assistance in using eyewashes or showers or require first-aid or other medical treatment.

All unneeded chemicals and chemical wastes are collected and processed or disposed of in the Waste Treatment area. There are specific chemical waste acceptance criteria that must be met prior to acceptance at the facility, including appropriate controls for radioactive mixed wastes.

Attention to facility fire protection systems is a concern. In one area, it was noted that outdoor storage containers had been equipped with dry (freeze-protected) sprinkler systems, but water to these systems had been "valved-off" because of a Tiger Team concern that, in the event of a fire, unlimited amounts of fire water would flood the containers and cause the uncontrolled release of hazardous chemicals (a real concern). However, the containers are now without fire protection. Building safety personnel did not know the status of these sprinkler systems, which is of even greater concern.

Site employees receive periodic training in the use of portable fire extinguishers. However, it does not appear that workers are always aware of the proper type of fire extinguishers required for their specific work or of the location of the nearest extinguisher. In a beryllium work area, with limited amounts of beryllium metal in storage containers/cabinets, an oxy-acetylene welding torch had apparently been used for soldering tubing joints (no work was being performed at the time), but neither a fire extinguisher for beryllium nor a general purpose dry chemical extinguisher could be located. In another facility, it was noted that no wet sprinkler coverage was provided because of chemical incompatibility. Yet, the only fire extinguisher that was provided in the room was a waterfilled "pressure bottle." 
Use of the accident/occurrence reporting system (ORPS) and the follow-up investigation process at LANL was briefly evaluated and found to be acceptable. However, it was reported by LANL that they thought the ORPS format was too cumbersome to use effectively for site purposes and that an alternate method was utilized at the site to communicate "lessons learned." However, based on the differences noted between facilities in the conduct of operations, the "lessons learned" program needs additional emphasis.

\subsubsection{Chemical Accident Recovery}

The methodology being utilized for developing Emergency Preparedness Plans (EPPs) was evaluated. The results of PHAs, SAs, and SARs, combined with the inputs from facility supervisors and safety and hygiene representatives and the "current" chemical and radiological inventories, are utilized as the bases for facility specific EPPs. Although this seems appropriate, it should be recognized that the PHA process is still under development and has not been validated for accuracy; the SA and SAR processes are also under development, but are based on preventing exposures and injuries to the general public without fully accounting for the protection of workers; and concerns were expressed by LANL personnel indicating that inputs obtained from building managers are not current with regard to chemical inventories.

The inputs from building managers, including supposedly up-to-date locations and quantities of hazardous and toxic chemicals, are used as the basis for preparing pre-fire plans. The pre-fire plans are utilized by the Los Alamos County Fire Department as the basis of all site-related training and should be as accurate as possible to maximize the effectiveness of fire-fighting efforts. As a result of not incorporating these inputs, the pre-fire plans do not reflect current fire-fighting needs and have been found to be inconsistent across the site.

The overall effectiveness of the County Fire Department in dealing with a fire within a chemical or nuclear/chemical area is questionable. County firemen have not received the "first responder" training as defined in the OSHA regulations and cannot enter many of the buildings without assistance from the HAZMAT Team. Thus, their initial efforts at the scene are limited to normal fire-fighting and the possible placement of external chemical containment barriers. It should also be noted that the HAZMAT Team may require a significant amount of time to respond to a call (several minutes on day shift and up to almost an hour on the off-shift). Thus, the need for accident and fire mitigation should be emphasized (see previous section).

The approval of a Memorandum of Understanding (MOU) between the site and the County for the "mutual aid" of emergency services is pending. The site HAZMAT Team will provide high-level services to the County, and the County Fire Department will continue its coverage under the current contract terms for basic fire-fighting services. 

Appendix A--Biographies 

Name: $\quad$ John M. Brooks

Area of Resp.: Industrial Hygiene

Affiliation: EG\&G-Idaho, Idaho National Engineering Laboratory

Experience: 9 Years

- $\quad$ EG\&G Idaho, INEL

- Unit Manager, Safety Systems Inspection and Engineering Unit. Responsible for management of professionals performing industrial hygiene, environmental, industrial safety, fire safety and quality engineering.

- $\quad$ Senior Scientist, Environmental Technology. Prepared and reviewed Sampling and Analysis Plans and Health and Safety Plans for remedial investigations and corrective actions for RCRA/CERCLA sites.

- $\quad$ Rockwell International, Rocky Flats Plant

- $\quad$ Principal Industrial Hygienist: responsible for Respiratory Protection Program (RPP), comprehensive industrial hygiene (IH) coverage of production divisions, and RCRA/CERCLA coverage.

- $\quad$ Martin Marietta Energy Systems, Oak Ridge Y-12 Plant

- Industrial Hygienist: responsible for the RPP and comprehensive IH coverage of production divisions. Supervised subcontracted IH services for RCRA/CERCLA investigations and closures.

- $\quad$ Martin Marietta Energy Systems, Oak Ridge National Laboratory

Industrial Hygiene Technical Leader, Field Studies Section: responsible for RPP and Hazard Communication program administration and comprehensive IH coverage for ORNL research divisions.

Education: $\quad$ M.P.H., Environmental and Occupational Health and Safety, University of Tennessee, 1983

B.S., Public Health, University of Tennessee, 1981

NQA-1 Auditor 
Name: $\quad$ Del Bunch

Area of Resp.: Management and Organization

Affiliation: Management Strategies, Inc.

Experience: 30 years, with Westinghouse, North American Aviation, USDA, USDOE, USNRC, and private consulting

- Chemical pesticides research, investigating impact of pesticides, and their control.

- Environmental R\&D investigating consequences of accidental releases of hazardous materials.

- $\quad$ Safety and risk analysis of nuclear and non-nuclear facilities.

- Safety engineer for plutonium facility.

- $\quad$ Program manager, responsible for safety and siting of major DOE projects.

- Senior manager at USNRC, including development of safety and siting criteria, development of resource management strategy for licensing reviews.

- $\quad$ Senior manager at DOE, including positions as DAS for Safety, Health and Quality Assurance, and as Principal Deputy Assistant Secretary for Nuclear Energy.

- Management consultant, providing expertise in risk-based resource management, performance improvements management, and program strategy development.

Education: $\quad$ BA, Chemistry, Whitman College

JD, University of Florida

LLM, University of Florida 
Name: $\quad$ Check (Tony) C. Eng

Area of Resp.: Hazard and Risk Analysis

Affiliation: $\quad$ USDOE/Office of Risk Analysis And Technology

Experience: 19 Years with USDOE, NRC, FERC and Corps of Engineers

- Senior risk assessment engineer: chemical safety review, non-radiological policies and standards development.

- Senior technical staff member of the Advisory Committee on Nuclear Facility Safety (ACNFS): supported the ACNFS in identifying DOE-wide environmental, safety and health issues and prepared ACNFS recommendations to Secretary of Energy.

- $\quad$ Project manager/risk assessment engineer: managed USDOE's high level waste performance assessment programs.

- $\quad$ Project manager/risk assessment engineer: managed NRC's probabilistic risk assessment programs for reactors, fuel cycle facilities and high level waste geologic repositories.

- $\quad$ Project manager/civil engineer: conducted hydroelectric power studies for FERC.

Project manager/hydraulic engineer: conducted hydraulic, hydrologic and structural analyses for Corps of Engineers' civil projects.

Education: $\quad$ M.S., Civil Engineering, U. of Maryland, College Park, MD

Other: $\quad$ Registered Professional Engineer, Maryland

Member, American Society for Civil Engineers

Member, American Institute of Chemical Engineers 
Name: $\quad$ Janice E. Hill

Area of Resp.: Coordinator

Affiliation: EG\&G Idaho, Idaho National Engineering Laboratory

Experience: 14 Years

- $\quad$ EG\&G Idaho, INEL

- $\quad$ Senior Administrator: Support and assist DOE-HQ in staffing Technical Safety Appraisal and Management Teams. Maintain rosters of consultants and laboratory personnel in all technical disciplines.

- Participated as Report Coordinator for the Safety and Health Subteam on the Tiger Team Assessment at the Paducah Gaseous Diffusion Plant, the Solar Energy Research Institute, the Los Alamos National Laboratory, Strategic Petroleum Reserves, and the Naval Petroleum Reserves.

- Administrator: Assisted in the planning and handled logistics for the teams onsite for the Technical Safety Appraisals conducted at the Advanced Test Reactor. Acted as liaison between EG\&G Idaho management and team members during onsite appraisal.

- Coordinated responses for the Facility Action Plan. Designed and maintained a computerized system for tracking corrective action. Maintained hard copy files and produced regular status reports.

- $\quad$ Senior Administrative Specialist: Performed full secretarial duties in support of the Advanced Test Reactor.

Education: Numerous work-related workshops, computer courses, 'and general management skill courses.

Other: $\quad$ Certified Trainer, Crosby Quality Education System.

Member, American Nuclear Society

Member, Beta Sigma Phi 
Name: $\quad$ Richard E. Johanson

Area of Resp.: Industrial Hygiene

Affiliation: Battelle Northwest Laboratories

Experience: 12 Years

- $\quad$ Battelle Northwest Laboratories

- Industrial Safety and Health Engineer: responsibilities include Industrial Hygiene Program Development and Overview. Review and maintain a chemical hygiene protocol system for Battelle laboratory operations. Overview chemical monitoring program, hearing conservation program, site drinking-water program, hazard communication program and general consultation.

- $\quad$ State of Washington - Department of Labor \& Industries - Safety \& Health

- Conduct compliance investigations of industrial plants and employment sites for measurement and control of environmental health hazards where an employee/employer relationship exists. Investigations include measurement of air contaminations, chemical and physical exposures to employees within their work environment.

- $\quad$ Analyze laboratory data to determine type and extent of exposure to environmental hazards. Determine type of remedial action necessary to eliminate hazards including ventilation, alternative procedures and other engineering controls.

- $\quad$ Preparation of written reports on findings of investigation performed including violations notes, abatement time periods, appropriate monetary penalties, and recommendations for other enforcement action.

Education: M.S., Industrial Hygiene and Safety (MSPH), University of Washington B.S., Bacteriology and Public Health, Washington State University

Other: $\quad$ Member, American Industrial Hygiene Association 
Name: $\quad$ Thomas I. McSweeney

Area of Resp.: Chemical Process Safety, Chemical Engineering Principles, Hazard and Risk Analyses

Affiliation: Battelle Memorial Institute

Experience: 24 Years Experience Nuclear Projects, Risk and Safety Assessments

- $\quad$ Project leader of DOE/DP Chemical Hazard Survey

- $\quad$ Safety Assessments and Operational Safety Requirements evaluations at Y-12 Oak Ridge, Tennessee.

- $\quad$ Risk assessment of bottling and trucking alternatives for liquid low-level radioactive waste.

- $\quad$ Numerous risk and safety analyses of radioactive material transportation systems.

- $\quad$ Assessment of SUM losses of NRC-licensed plutonium and high enriched uranium processing facilities.

- Development of expert systems for high-level waste repository siting.

- $\quad$ Project leader for assessment of severe models of reactor accidents at Savanna River Site.

Education: Ph.D., Chemical Engineering, The University of Michigan

M.A., Mathematics, The University of Michigan

M.S., Chemical Engineering, The University of Michigan

B.S., Chemical Engineering (cum laude), The University of Notre Dame

Other: $\quad$ Member of American Institute of Chemical Engineers

Member of State of Ohio Seismic Hazards Evaluation Board 
Name: $\quad$ Robert W. Poe

Area of Resp.: Team Leader

Affiliation: USDOE/Office of Risk Analysis and Technology

Experience: 20 Years USDOE/ERDA/AEC

- Manager, operational analysis and compliance activities monitoring the safety performance of contractors and field offices.

- Manager, EH Site Representatives Program, conducting occupational safety and health inspections of contractor facilities.

- Team Leader for Safety Subteam of Tiger Team Assessment.

- Conducted quality assurance or standard assessments of field office and contractor programs.

- $\quad$ Performed health physics and industrial hygiene assessment and appraisals of contractor programs.

- $\quad$ Manager, DOE Standards Program.

Education: $\quad$ M.S., Physics, Vanderbilt University, Nashville, TN

Other: Member Health Physics Society 
Name:

John S. Stone

Area of Resp.: Conduct of Operations

Affiliation: Kaiser Engineers Hanford (KEH) detailed to USDOE EH-30

Experience: 23 Years, professional engineering in design, construction and operations management, consulting, and program management.

- $\quad$ Program Manager, KEH, temporarily assigned to DOE-Germantown to help develop safety assessment programs, evaluate contractor safety performance and proposed corrective action plans; resolve compliance issues, and conduct site safety assessments.

- $\quad$ Principle Design Engineer, KEH, managed multi-discipline nuclear related design projects and performed detailed mechanical design analyses.

- $\quad$ Engineering Design Consultant, nuclear, petroleum, petroleum chemical, pulp and paper, and inorganic chemical operations.

- $\quad$ Plant Production Supervisor, inorganic chemicals operations.

- $\quad$ Plant Engineer, project and maintenance management and engineering responsibilities for inorganic chemical operations.

Education: $\quad$ B.S., Mechanical Engineering, Washington State University, Pullman, WA

Other: $\quad$ Member American Society of Mechanical Engineers.

Registered Professional Engineer, Montana and Washington. 
Name:

Pamela J. Sutherland

Area of Resp.: Chemical Process Safety; Chemical Hazard and Risk Analysis

Affiliation: Battelle-Columbus, Energy Systems Group

Experience: 7 Years

Senior Scientist, Environment, Safety and Health. Member of a chemical and radiological safety team to evaluate the safety of operating nuclear facilities within the weapons complex. Estimated potential interactions and evaluated potential for severe chemical accidents - fire, explosions, spills and incompatible mixings.

- $\quad$ Conducted Hazard and Operability Studies (HAZOPs) to assess the potential for onsite fatalities and/or serious injuries, offsite environmental or safety impacts, significant plant downtime and/or capital losses of equipment, and significant process upset and/or loss of product containment.

- $\quad$ Responsible for technical administration of contracts for development of guidance documents in preparation of a safety analysis report (SAR) for a geologic repository for high-level radioactive waste.

Managed a risk assessment contract to estimate worst-case environmental and human health consequences of demolishing a laboratory building contaminated with chemical warfare material.

- Directed development of occupational radiation protection and emergency planning guidance documents.

Managed design, coordination, and development of technical workshop materials for two national and four international training seminars and workshops in chemical and nuclear safety.

Education: $\quad$ M.S., Biological Sciences, University of Illinois

M.A., Linguistics, Columbia University

B.S., (cum laude) Mathematics, University of Illinois

Other: American Association for the Advancement of Science, American Institute of Biological Sciences, New York Academy of Sciences, Alpha Lambda Delta, Phi Beta Kappa, Sigma Xi, Phi Kappa Phi 



\section{APPENDIX D - Chemical Safety Oversight Review (CSOR) Trip Report of Savannah River Site (SRS)}





\subsection{SUMMARY}

A Chemical Safety Oversight Review (CSOR) of the Savannah River Site (SRS) was conducted by a Department of Energy (DOE) Team from the Office of Environment, Safety and Health (EH) from July 6, 1992, through July 10, 1992. The purpose of the SRS CSOR was to review chemical processes and chemical use and storage at SRS on the basis of a limited sampling. The review focused on high-hazard/high-risk processes and activities and their potential risk to workers within a facility and co-located workers. The objectives of the review were to identify any significant management, programmatic, and technical deficiencies that would require prompt action by $\mathrm{EH}$ and the line organizations.

The seven-member CSOR Team identified a key concern related to a lack of safety analysis and operational safety requirements for a nonnuclear, nonradiological water treatment process. This concern may have DOE-wide implications. The review also identified formal and structured elements addressing chemical safety in both dedicated and integrated requirements, programs, plans, processes, procedures, training, and management. Consistent with the orientations stressed by DOE over the past several years, radiological risks are clearly perceived as greater and more significant than chemical risks by SRS. As a result, chemical safety is not programmatically developed, managed, analyzed, or supported to the same degree as radiological safety. The Team also compiled observations and descriptions of SRS chemical safety programs and activities as part of a long-term EH chemical safety oversight program.

In general, chemical safety for nuclear facilities at SRS is better defined and managed than for nonnuclear facilities. Chemical safety is managed at the area manager level; there is no structured chemical safety program. Hazard identification, safety and risk analysis, configuration management, maintenance, and conduct of operations are formal and structured at nuclear facilities, including reactors and nonreactor nuclear facilities. At chemical process facilities and chemical use facilities, chemical safety is considerably less formal and structured, although the chemical risks may be equal or greater. In both cases, analysis of chemical hazards, particularly in relation to worker safety, receives far less attention and resources than radiological safety. Sitewide programs encompass safety analysis reviews and process hazard reviews; however, safety analysis reviews are only conducted for nuclear facilities. In this mode, significant risks from chemical accidents may not be effectively analyzed and worker safety not given the attention indicated by the actual risk. The Process Hazard Review (PHR) system provides an excellent means to identify and mitigate operational hazards at SRS nonnuclear facilities, but the process does not always incorporate important external events, nor does it require sufficient accident analyses for highly hazardous chemical processes. Industrial hygiene (IH) activities are becoming better organized and supported, but there is some confusion in the transition, and not all IH functions are being appropriately served. Chemical inventory and control has been formalized, and there are consistent efforts to improve these systems. Emergency preparedness is adequately structured, although local chemical emergency drills have not yet been 
developed. A vast fault tree database provides information and lessons learned from many years of chemical operations which are factored into site operations and safety reviews.

\section{$2.0 \quad$ INTRODUCTION}

The Savannah River Site (SRS) is a nuclear materials production and research installation for the Department of Energy (DOE). SRS is managed by DOE's Savannah River Field Office (DOE/SR) and operated by the Westinghouse Savannah River Company (WSRC). The facility covers some 300 square miles and is located near Aiken, South Carolina.

The SRS Chemical Safety Oversight Review (CSOR) is one of five accelerated reviews being conducted as part of the Office of Environment, Safety and Health (EH) Workplace Chemical Accident Risk (WCARR) program, as outlined in the Paul L. Ziemer to the Secretary Action Memorandum of April 3, 1992, "Establishment of an Office of Environment, Safety and Health Chemical Safety Oversight Task Group to Review Department of Energy Workplace Chemical Safety Programs." These reviews are being conducted to identify any significant deficiencies in chemical safety that have DOE-wide implications and that may require prompt actions by $\mathrm{EH}$ and the line organizations.

The CSOR Team's principal efforts were focused on investigating chemical systems and chemical use and storage to (1) identify significant chemical safety deficiencies; (2) assess their risk significance, particularly to workers within a facility and co-located workers; and (3) determine their relevance and importance to DOE-wide chemical safety. General public and environmental impacts were also considered. In pursuing the primary investigations critical to short-term chemical safety concerns, the Team investigated the overall aspects of chemical safety at SRS and compiled much additional information germane to EH's long-term WCARR program. The thrust of the CSOR was on information gathering and analysis, not on compliance.

The details of the Team's review efforts, including observations and descriptions, derived concerns and findings, recommendations, and notes on compliance items, are documented in Section 3.0. The Team identified some compliance items related to Occupational Safety and Health Administration (OSHA) requirements, DOE Orders, and SRS procedures. These were conveyed to the appropriate contractor personnel. The items are documented in Appendix A, OSHA-Related Notes, as well as in the body of this report.

The SRS CSOR was conducted in accordance with the EH Office of Safety and Quality Assurance (EH-30) Protocol for Chemical Safety Reviews (Draft, April 15, 1992), using the companion Lines of Inquiry (Draft, April 1992) and the recently drafted Lines of Inquiry Suitable for Application to Chemical Laboratories (Draft, July 6, 1992). 
The SRS CSOR Team, under the direction of a DOE Team Leader, was composed of DOE staff and consultants with expertise in various aspects of chemical safety, including process safety management; industrial hygiene; hazards, safety, and risk analysis; management and operations; and chemical laboratory safety. Biographical sketches of the team members are provided in Appendix B.

The Team evaluated defense-in-depth for chemical processes, as well as for chemical use and storage. This evaluation included design and analysis, control and primary containment, mitigation of chemical accidents, and chemical accident recovery. Team reviews included walkdowns and examinations of process systems and laboratories, observation of ongoing activities, document and procedure reviews, interviews, and general program reviews. Appendix $\mathrm{C}$ provides a list of facilities visited by the team and identifies the SRS personnel from each major area who participated in the review process or provided general input.

The Team's effort was devoted primarily to process and facility walkdowns; verifying system and equipment functions; and ascertaining the application of industrial hygiene, process safety review, safety procedures, and safety analysis to the system and processes in place to assure the protection of workers within facilities and co-located workers, as well as the protection of the general public and the environment.

The Team met with management and technical representatives from each of the major areas reviewed both before and following each area walkdown. Individual and small group meetings were also held, and interviews were conducted by Team members. In an exit meeting on Friday, July 10, 1992, the Team reviewed the results of the CSOR and provided a copy of the draft report to DOE/SR and WSRC.

\subsection{DISCUSSION}

The Department of Energy (DOE) Chemical Safety Operations Review (CSOR) Team review of the Savannah River Site (SRS) chemical safety programs and practices was intended primarily to investigate any chemical safety deficiencies and identify any significant deficiencies with DOE-wide implications. In the course of the review, routine findings and understandings of chemical safety at SRS evolved and were documented. Discussions and descriptions of the Team's review efforts are summarized below. The Team's observations reflect experience related to DOE and other Federal requirements, industrial standards and good practices, and lessons learned from other DOE programs and activities.

\subsection{Management and Operations}

The team reviewed the management and operations of SRS as related to chemical safety programs and practices. The results of the Team's review are discussed below. 


\subsubsection{Organization}

There are several major elements that form the framework for the basic chemical safety program at SRS. The principal line programs (defense and waste management) fall under Westinghouse Savannah River Company (WSRC) sitewide organizational controls. WSRC has a common procedures system, a sitewide safety and health program (including industrial hygiene), a somewhat limited central process hazard review program, and a formal facility safety analysis review program. The site is organized into functional and operational areas under centralized WSRC control and DOE/SR oversight.

WSRC has guidance documents for performing safety analyses and Process Hazards Reviews (PHRs), and several of the area organizations have developed standard operating procedures to implement these sitewide documents. 'All the mechanisms are present to identify hazards and develop implementation plans to reduce the risks associated with handling hazardous chemicals.

As might be expected at a large site, a few coordination and implementation problems were observed, some of which might be attributed to funding priorities. There were some instances, as discussed in Section 3.1.3, in which improvements recommended as part of a proposed facility modification were not recommended for similar facilities. Because there is no centralized review of PHRs, a list of suggested improvements across the site has not been compiled.

\subsubsection{Roles and Responsibilities}

Responsibilities for chemical safety are vested primarily in the area managers and area organizations. Cross-cut on chemical safety occurs through the safety and health organization, procedures organization, safety and process review organizations, and emergency response organizations. A coordinating role is played by the process safety management process through the Process Management Subcommittee.

\subsubsection{Conduct of Operations}

Assessment of chemical safety in the workplace, along with the potential risk to workers and, in many cases, to the general public, involves an examination of the practices that govern operations. This is particularly true for chemical safety, which involves many manual operations in comparison to nuclear safety. Many of the chemical operations at SRS are batch-type operations, such as unloading and mixing chemicals, and the controls that protect workers rely heavily on correct procedural implementation rather than design features. The Team gathered information in the areas of procedural controls, design and analysis, mitigation of chemical accidents, and chemical accident recovery to support its review of this area. 


\subsubsection{Procedural Controls}

The operating facilities evaluated ranged from nonreactor nuclear facilities involved in production to nonnuclear facilities that support general site functions. In all cases, emphasis was placed on those chemicals and related chemical operations with the highest potential for serious worker injury or those that could result in offsite health effects.

WSRC has established a sitewide procedure that recognizes the need to develop and implement procedural controls for a wide range of activities, including those involving the use of chemicals. The governing procedure requires each WSRC Division to develop procedures and guidance that implement this overall guidance. The guidance provided on the WSRC site-wide level establishes the four categories of procedures listed below.

CATEGORY 1 (UET) Step-by-step procedures that must be in the possession of the worker or operator and that generally require initials as each step is completed. (Hence the designation Use Every Time - UET.)

CATEGORY 2 (UET) Procedures required to be in the possession of the worker or operator that require signature after a series of steps or when the activity is completed.

CATEGORY 3/

Procedures generally kept on file for reference and or CATEGORY 4 training that are not required to be in the possession of the worker.

At the nonreactor nuclear facilities, critical or particularly dangerous activities are covered by Category 1 procedures, which generally appear to be well implemented. For example, all procedures for unloading large volumes of nitric acid or sodium hydroxide from tanker trucks were considered to be Category 1 procedures for which there were specific step-by-step instructions, including the necessary safety precautions. The Team noted that the procedures were detailed and included steps for wearing appropriate full-acid suits during hookup and tank sampling - activities within the procedure that involve a higher potential risk to the worker:

In contrast, the limited number of nonnuclear facilities under the cognizance of Power Operations Division (D-Area and 5G Pumphouse) that were observed by the Team were not nearly as mature in their conduct of operations program with respect to procedure development and use. For instance, an activity virtually identical to a nuclear area Category 1 procedure activity (unloading of large- volume nitric or sulfuric acid tankers) was performed at the D-Area as a Category 3 procedure, which does not require the procedure to be available at the work location. Additionally, it was not clear that Power Operations Division management personnel were aware that this was a Category 1 procedure at other SRS facilities. 
Other observed deficiencies at the 5G Pumphouse provide some insight into the status of the conduct of operations program within nonnuclear facilities that may be indicative of DOE-wide weaknesses. Taken singularly, the deficiencies constitute noncompliances that, in and of themselves, require correction but are not particularly critical. However, considering that the Power Operations Division operates gaseous chlorine systems with source terms well above the OSHA Threshold Quantity (TQ) of 1500 pounds for chlorine (in one case within 100 yards of the site boundary), the weaknesses demonstrated by the deficiencies take on added significance. In addition to lockout/tagout deficiencies and incomplete application of PHR findings, the Team identified deficiencies such as a lack of chlorine monitors; a lack of specific emergency response plans for a chlorine leak; a lack of procedural and operating limitations to control external activities, such as maintenance; a lack of formality in following procedures; and the lack of a safety analysis report (SAR) or external events analysis. The Team also observed that heavy lifts over the chlorine cylinders were being performed using a trolley crane that had not been load tested and a lifting hook that had not been nondestructively examined. These deficiencies, in combination, indicate a risk path that requires a more indepth analysis to ensure the safety of workers and the general public. The details of the CSOR Team review of the gaseous chlorine systems are provided in Appendix D, "Details of the 6815G Pumphouse Review."

\subsubsection{Design and Analysis}

The basic processes for design and analysis are controlled under an integrated schedule and encompass Justifications for Continued Operations (JCOs), Operational Safety Requirements (OSRs), SARs, and Configuration Management (CM) for high- and moderate-hazard nuclear facilities. DOE Orders $5481.1 \mathrm{~B}, 5480.5,6430.1 \mathrm{~A}$, and 5480.23 provide the requirements that govern design and analysis for most of the processing facilities reviewed. The processes are formal and structured for all nuclear facilities. The WSRC Facility Safety Analysis Manual (WSRC-9Q) describes the requirements and guidelines that apply to WSRC safety analysis activities, including chemical hazards, for nonreactor facilities and projects, and establishes the SAR system.

\section{Design and Analysis}

Procedures are available for facility design and modifications in the Engineering and Engineers Service Procedure manual. Procedures cover functional design criteria, design control, configuration management, and quality assurance.

Configuration Management procedures require that all proposed designs and design changes be reviewed and approved before design is initiated. The process includes initial approval of the concepts, a process safety review, and a hazards review prior to beginning the design work. Worker safety is included in the process safety review.

SRS has no SAR requirements for nonnuclear facilities with purely chemical safety hazards; however, PHRs are conducted for these facilities to varying degrees. The PHRs are described in the SRS 
Process Safety Management Manual (a reference manual). Policy and procedure for the PHR program are provided in Procedures for Control of Nuclear Safety Documents (WSRC-11Q).

The PHRs provide qualitative analyses of particular chemical and chemical/nuclear processes that are intended to limit risks associated with operations of a process. PHRs can provide a very effective means for reducing risk associated with processes; thereby, reducing the risk to workers within a facility and co-located workers. The PHR process is centrally administered. Formal implementation training is conducted, area activities are coordinated, and trained and experienced teams are used to conduct the PHRs.

The PHRs differ significantly from SARs in that SARs describe risks and provide both a qualitative and quantitative analysis of processes at a facility, including accident analysis. In some instances, credible accidents at nonnuclear chemical facilities may be overlooked, because SARs are not required and the PHRs generally do not cover accident analysis or incorporate events external to operations.

\section{Industrial Ventilation}

The team observed venting systems for several tanks. Venting was generally to atmosphere. In some cases, tanks were located outside so that ventilation to control employee exposure was not necessary. There were some operations that required local exhaust ventilation. It was not clear if system design was optimum for worker safety. In a limited review, the Team did not verify that system modifications had been performed to achieve as low as reasonably achievable (ALARA) exposures with engineering controls. SRS representatives reported that exposure calculations have been conducted in some circumstances, and respiratory protection has been required as an additional precaution for the protection of operators. This condition was noted in the M-Area casting furnace.

\section{Pressure Relief Valves}

SRS systems use pressure relief valves for all pressure vessels. In most cases, these valves would discharge to the atmosphere. No data have been developed that indicate whether employees would or would not be exposed from relief activation. The pressure relief valves are on an annual preventative maintenance schedule. To test the pressure relief valves, the system is locked out, and the valves are removed and benchtested to make certain that relief occurs at the proper pressure.

\subsubsection{Control and Primary Containment}

Some SRS facilities have not conducted integrity reviews (ultrasonic pressure tests, visual inspections, etc.) of chemical holding tanks and lines, even though some facility systems are aging, show evidence of corrosion, and still carry corrosive chemicals.

Balance checks on fluid transfers are performed at waste management and defense facilities, but not at power management facilities. 


\subsubsection{Mitigation of Chemical Accidents}

\section{Procedures for Off-Normal Events and Conditions}

With the exception of certain deficiencies in emergency preparedness, it appears that the site has effective programs to deal with the mitigation of chemical spills or releases. However, it seems that there are inconsistencies in implementation of the written procedures. For example, the procedure for hydrofluoric acid spills requires evacuation of the area and notification of the Hazardous Material (HAZMAT) Response Team and the Environmental Coordinator. A decision is made by the line regarding who should mitigate the spill. This decision is made after consultation with the HAZMAT team and a review of written procedures. The procedures define who will do the cleanup, based on the quantity of material and the toxicity of the chemical. Procedures for handing chemicals and chemical processes were available; however, parameters defining normal limits and off-normal limits were not included in the procedures.

\section{Training in Off-Normal Procedures}

With the exception of the hazardous waste handling operators and the HAZMAT Team, the operators who have to deal with spills and releases have had only 45-60 minutes of training. This training may not be adequate in the event of a spill that does not trigger an emergency. SRS procedures do not require the operators to handle a spill that involves a significant health hazard and requires an "Emergency Response" under Title 29 of the Code of Federal Regulations (CFR) Part 19910.120. This standard for hazardous waste and emergency response requires workers (in this case, the HAZMAT Team) to receive 40 hours of emergency response training.

\section{Installed Safety Equipment}

Facilities are equipped with the appropriate number and types of safety showers and eyewash stations that are readily accessible. SRS has installed safety showers and eyewash stations on the upper and lower levels of chemical unloading stations. The stations are equipped with heating tapes for freezing periods. The stations are on two different test schedules; both are tested monthly. In addition, the operating procedure requires that a station be tested prior to any activity that could result in the splashing of a corrosive chemical.

\section{Personal Protective Equipment}

SRS provides the personal protective equipment (PPE) necessary to handle the chemicals found onsite, and employees are trained in how to properly don and doff PPE, what type of PPE to use during specific procedures (defined by their procedures manual), and how to check equipment integrity. There are also facilities for storage of the equipment. 
Each employee required to use respiratory protective equipment is trained in its wear, inspection, storage, and availability. The Work Completion Package defines the respiratory protection required for a particular job. This protection is determined by health/physics (HP) personnel. While not fully implemented onsite, the process requires that the employee take his/her respirator card and a copy of the description of the PPE requirements to an issue point, where the proper respirator is issued. SRS is currently evaluating a "single-use" concept in which the respirator will be returned for cleaning and exchanged for a clean respirator after a job has been completed or at the end of the shift, if the job has not yet been completed.

There may be a problem in the level of expertise of training for the personnel assigned the task of selecting PPE. Up to the present time, the Industrial Hygiene (IH) Department has not routinely been involved in oversight and day-to-day review of the respirator selection process. IH has been involved mainly in the development of related policies and procedures. HP inspectors and supervisors and IH technicians have received detailed training on respirator selection. Although it has not yet been proceduralized, IH will be involved in selecting respirators for each job. In addition to specifying IH involvement in respirator selection through a procedure, the Work Clearance Permit will require IH to review jobs and, when necessary, specify respiratory protection.

\section{$\underline{\text { Secondary Containment }}$}

Chemical storage tanks are generally diked with a sufficient volume to hold the contents of the largest tank, and sumps are normally used to purnp and process rainwater, spillage, or leakage. Incompatible chemical tanks are generally separately diked, although there are instances in which only a single dike is in place for acid and base storage tanks. Chemical spills are controlled with containment areas that drain to a sump tank or diked area. Hazardous nonradiological spills are usually handled by the Fire Department's Spill Team. A form detailing events of the spill is completed for each spill.

\section{Control of Radioactive Contaminants in Wastes}

Chemical wastes are characterized before disposal, and radioactive contaminants are evaluated as part of this characterization.

\subsubsection{Chemical Accident Recovery}

\section{Emergency Preparedness Plan}

The Emergency Management Department (EMD) is responsible for conformance with the Hazards Assessment Programs, Emergency Action Level and Impact Assessment Programs, and Site Item Reportability and Issue Management Programs. EMD has four sections: Emergency Operations, Training Exercises, Area Programs, and Program Integration. 
Emergency drills using PHR information and simulated chemical spills are not routinely conducted at SRS. Although PHRs have been conducted to identify hazards, the information has not been incorporated into Emergency Preparedness Plans (EPPs). Until recently, the emphasis has been on radiological emergencies.

EMD has increased from 8 people to its current staff of 41 over the last 3 years. An SRS Emergency Action Level (EAL) project plan draft has been prepared. This plan is unfunded and is in the category of new initiatives. Appendix E describes the EAL project plan effort.

\section{Emergency Preparedness Plan Training}

There is no EPP training for chemical accidents. More information regarding EPP is provided below.

\section{$\underline{\text { Notification and Evacuation Plan }}$}

Employee protection drills are conducted as follows:

(1) nuclear incident drill 2 per year per shift

(2) shelter protection drills 1 per year per shift

(3) area evacuation drill 1 per year per shift

(4) toxic gas drill 1 per year per shift

(5) rescue team scenario 1 every 2 months per shift

\section{Life Safety - Disaster Warning System}

SRS has a life safety - disaster warning system to notify employees, subcontractors, and other personnel of potential or actual life-threatening conditions. The system is tested, including actuation, every morning, Monday through Friday. The signals are: voice for emergency alert; slow warble take shelter; fast warble - evacuate; very fast warble - toxic gas release.

\section{Plant Medical Staff Alert}

Not observed.

\section{Chemicals and Reagents for Emergency Treatment}

Not observed.

\section{Engineered Emergency Barriers and Containments}

The team observed engineered emergency barriers. The Team noted that related procedures were available and that employees were trained in their use. 


\section{Emergency Response Team}

There are 38 members on the Hazardous Materials Response Team (HAZMAT Team). Organizationally, the Team is within the Fire Department. The HAZMAT Team responds to all chemical emergencies. Procedures for the HAZMAT Team were available, but were not reviewed by the CSOR Team.

\section{EPP Drills}

Realistic drills in emergency preparedness and accident response are conducted for radiological accidents; however, drills are not usually conducted for chemical accidents. Until recently the emphasis has been on radiation incidents. In line with the increased emphasis on chemical safety and the plans being developed by EMD, chemical accident drills are planned for the future.

\section{Emergency PPE Requirements}

Specialized PPE is available for use in an emergency, and personnel are trained in its use.

\section{Offsite Interface Agreements for Emergencies}

This was not addressed.

\section{Offsite "Expert" and DOE Reporting Call List For Emergencies}

This was not addressed.

\subsection{Chemical Hazard and Risk Analyses}

The Team reviewed the chemical hazards and practices and controls over the hazardous chemicals at selected SRS facilities. Facility walkdowns were conducted to identify: (1) chemical hazards and their risk significance; (2) adequacy of the management and controls of the chemical operations; and (3) potential impact to workers and the public if sufficient management and controls are not in place. Safety documents, including guidance and analyses, were reviewed to determine their adequacy in addressing chemical safety. During the course of the CSOR, the Team also discussed chemical safety with various WSRC staff. Based on these review activities, the Team made several observations. Section 3.2.1 addresses issues that have high-risk significance to the worker and the general public. Section 3.2.2 addresses programmatic issues and notable observations, which will be assessed by EH as part of the longer-term EH Workplace Chemical Accident Risk Review (WCARR) program. 


\subsubsection{Risk Significance of Chemicals Used at SRS Facilities}

The SRS facilities reviewed by the Team use many types of hazardous chemicals including chlorine, nitric acid, hydrofluoric acid, and sulfuric acid. These chemicals are used in large amounts for various chemical operations. The following two sections summarize the Team's observations of SRS nuclear and nonnuclear facilities.

\subsubsection{Nuclear Facilities}

The Team did not find any significant chemical risk issues for SRS nuclear facilities. The Team reviewed the chemical source terms, practices and controls over the source terms, and potential effects to the workers and public if the source terms were released. The nuclear facilities visited included the separations facilities (F- and H-Canyon), waste management facilities (e.g., tank farms, Effluent Treatment Facility, Defense Waste Processing Facility), and facilities in the 700 and 300 Areas. The Team concluded that most of the chemical safety analyses in the SARs are not fully adequate, especially the analyses for determining the effects to the workers. Quantitative accident analyses were not performed in sufficient detail, and operating safety requirements were not adequately established. Consequently, the safety envelope for chemical operations at the nuclear facilities is not well defined.

\subsubsection{Nonnuclear Facilities}

The situation for SRS nonnuclear facilities is even less defined than for its nuclear facilities. It is probable that chemicals used in the nonnuclear facilities pose a higher risk to workers and the public than chemicals used in the nuclear facilities. Citing a lack of DOE implementing guidance for safety analyses of nonnuclear facilities and DOE's emphasis on radiological safety to the public, SRS has not performed safety analyses for nonnuclear facilities. Although SRS has completed PHRs stemming from DuPont initiatives in the early 1980s, the requirements in DOE 5481.1B (1986) to identify and analyze nonradiological hazards have not been met to the same degree as for radiological hazards. Consequently, the safety envelopes for many chemical operations have not been determined, since the principal design criteria, accident analysis, and operating safety requirements have not been established or performed.

The Team visited the chlorine unloading and storage facility and the 5G Pumphouse in the D Area and determined that these facilities are high-risk facilities. Both facilities have large source terms, relatively poor work practices and controls over these source terms (see discussion in the Management and Operations section and in Appendix D), and the risk to workers and the public is high.

Both facilities have a large quantity of chlorine. The chlorine storage facility in the 400D Area has a capacity to store about 70 one-ton cylinders of chlorine (140,000 pounds). Currently there are 48,000 pounds of chlorine ( 24 one-ton cylinders) stored in the facility, and 4,000 pounds ( 2 one-ton cylinders) are hooked up for day-to-day operation. The 5G Pumphouse has a storage capacity of 
8,000 pounds (four cylinders). All four cylinders have their "pigtails" connected to the main manifold. One cylinder is tagged empty. It was stated, and indicated in procedures, that only two cylinders $(4,000$ pounds) are valved into the chlorinator.

Both facilities are located at the site boundary near the Savannah River. The facilities are about 3 miles from Route 125, a public road that goes through SRS. If a catastrophic accident occurred at either of these two facilities, a large amount of chlorine could be released to the detriment of some workers within facilities, co-located workers, and the general public boating on the Savannah River or riding on Route 125.

In the near future, these facilities will need to comply with the OSHA Process Safety Management (PSM) regulation (OSHA 1910.119), since the amount of chlorine stored exceeds the OSHA TQ limit of 1500 pounds. The OSHA rule requires these facilities to satisfy the 14 PSM elements outlined in the rule, which includes elements similar to the elements in the DOE SAR requirements.

\subsubsection{Chemical Safety Programs and Activities}

This section describes the Team's review of the SRS safety programs and activities from a programmatic point of view. Observations made from this review will feed into the longer term EH chemical safety program (i.e., policy and guidance development) as well as the short-term initiatives of EH-30, such as interim policy and guidance development.

In general, SRS has a matured safety program as reflected by its early initiatives in chemical safety prior to development of DOE safety requirements. DuPont, a leading U. S. chemical company that operated SRS prior to April 1989, left behind a legacy of chemical experience and expertise. Since the early 1980s, PHRs that effectively address chemical hazards have been completed for many facilities. These PHRs were initiated outside of early DOE requirements and guidance and may be a standard for other DOE facilities. However, the effort is still short of the DOE 5481.1B requirements to analyze nonnuclear hazards, and there are still many problems in chemical safety at SRS that would be resolved by full implementation of the PHR process, in conjunction with safety analyses.

Another notable initiative of the DuPont safety staff was development of the computerized fault tree database, which began in the 1970s. This database provides one of the essential elements for performing a risk assessment. Currently it contains about 300,000 events describing actuarial incidents and component failure data. The database is also being used by other DOE sites. Another notable initiative is the development of the first nonreactor nuclear facility SAR in 1980 . This was done in advance of DOE Order 5481.1A (1981). 


\subsubsection{Safety Analysis}

Given these notable activities, much of the SRS safety review is documented in "old format" SARs. The focus of the old format SAR (typically, a one-volume report with abbreviated accident analysis and no identified operating safety requirements) was still on radiological risk to the public. Chemical safety analysis, especially one focused on the worker, was minimal or was not performed at all. The focus was "bottom-line" oriented; that is, the objective of the SAR was to demonstrate that the risk (probability times consequences of accidents) from facility operations was acceptable. Operating safety requirements (OSRs) were not a part of the SAR. Some OSRs were issued as stand-alone documents to establish the safety envelope for adverse chemical reactions related to facility operations. They were based on abbreviated accident analyses and PHRs and did not establish a welldefined operating safety envelope. For example, the OSRs for the separations facilities were contained in DPW-85-101, and waste management OSRs were contained in DPW-86-103.

Currently, there are old format SARs for most nuclear facilities. The Team reviewed several of these SARs and concluded that (1) chemical hazard identification/risk assessment is not fully adequate, (2) chemical safety related to workers is not well addressed, and (3) the chemical safety operating envelope is not well defined. The SARs reviewed included the FB-Line SAR (April 1988) and the Building 211-H, Outside Facilities SAR (March 1992).

WSRC is in the process of changing its safety programs and activities. The impetus of this change is requirements for SAR development established by Savannah River Operations Manual (SROM) 5480.5-1 (1989), an implementation guidance document for DOE Orders 5481.1B (1986) and 5480.5 (1986). Currently, the SAR process is being reviewed to determine its adequacy for addressing DOE Order 5480.23 (April 1992)).

SROM-5480.5-1, "Savannah River Operations Manual on Nonreactor Nuclear Facilities Safety Analysis Report Format and Content Guide," directs the SRS contractor to address both radiological and nonradiological hazards in the facility safety analysis. Risks to the operating personnel, the public, and the environment are also required to be evaluated. In addition, the SAR is required to describe principal design criteria, accident analysis, conduct of operation, operational safety requirements, and emergency preparedness for hazardous chemical operations.

In response to the DOE requirements, WSRC published Manual $9 Q$ in 1991 to help interpret general DOE safety analysis guidance and to present a logical approach to satisfy DOE requirements. The objectives of Manual $9 \mathrm{Q}$ are to provide assurance that (1) unusual hazards are systemically identified and their potential impact is understood; (2) reasonable measures to eliminate, control, or mitigate hazards are taken; and (3) documented safety analyses are available for supporting safe facility operations. Manual $9 \mathrm{Q}$ covers facility hazard classification, risk-based analyses, and operational safety requirements. 
The new SAR requirements and guidance initiated an integrated approach to the SAR upgrade. The components of the Integrated SAR Program include the "new format" SAR, JCOs, OSRs, and Configuration Control. The new format SAR consists of multiple volumes and is comparable to those developed for commercial reactors. Currently, only several SARs have been prepared in accordance with the "new format." They include the HB-Line, F-Canyon, H-Canyon, and FB-Line. The Team reviewed selected portions of the F-Canyon SAR. The new format addresses chemical safety in much more detail than the old format. Workers within the facility and at co-located facilities are also evaluated in more detail than in the old format SAR. An extensive review of the technical adequacy of the chemical safety analyses is beyond the scope of this review.

\subsubsection{Hazard Classification}

Manual 9Q also establishes the hazard classification scheme for SRS. Hazard analysis is performed and documented in a Hazard Analysis Document (HAD) to identify the level of SAR documentation and the level of approval required. SRS is in the process of classifying all of its facilities.

Chemical criteria along with radiological criteria for both onsite (worker) and offsite (public) risk have been established. Chemical hazard classification (High, Moderate, Low, and General Use) is based on Emergency Response Planning Guidelines (ERPG) values (airborne concentration values) at three severity levels: ERPG-3, ERPG-2, and ERPG-1. If ERPG values are not available, Immediately Dangerous to Life and Health (IDLH) values are used. In addition, Incremental Cancer Risk (ICR) values are calculated for all known or expected carcinogens. The use of ERPG values for hazard classification is consistent with the Los Alamos National Laboratory (LANL) hazard classification concept reviewed by the LANL CSOR Team. SRS facilities are classified according to the following chemical criteria.

\begin{tabular}{|l|l|l|l|l||}
\hline & General Use & Low & Moderate & High \\
\hline Onsite (100 meters) & $<$ ERPG-1 & $\geq$ ERPG-1 & $\geq$ ERPG-2 & $\geq$ ERPG-3 \\
\hline Offsite (site boundary) & $<0.01$ IDLH & $\geq 0.01$ IDLH & $\geq$ ERPG-1 & $\geq$ ERPG-2 \\
\hline
\end{tabular}

The development and review of these WSRC chemical criteria are being coordinated with other Westinghouse-operated DOE sites through a Westinghouse M\&O [management and operating] Subcommittee on Radiological Risk Acceptance Criteria Development. Other Westinghouse companies, including Hanford, Idaho Falls, Waste Isolation Pilot Project (WIPP), and West Valley, will probably use the same chemical and radiological criteria.

A detailed review of the appropriateness of the chemical criteria is beyond the scope of this review. The Westinghouse approach, along with the approaches of other DOE sites and DOE Headquarters organizations, should be reviewed as part of the longer term DOE/EH-30 chemical safety activities in developing DOE-wide policy and guidance in this area. 


\subsubsection{Process Safety Management}

As indicated earlier, PHRs have been performed for many SRS facilities since the early 1980s. However, they were performed without any formal guidance. In August 1987, the Process Safety Management Committee published the SRS Process Safety Management Manual (DPSPM-GEN-13) to formalize the guidance for systematic review for each SRS process that could result in a catastrophic accident. In 1990, the SRS PSM Subcommittee of the Site Safety Review Committee updated the information in DPSPM-GEN-13 and issued it as WSRC-IM-90-135. Courses are conducted to train the facility staff in the use of hazard analysis techniques. Documented training of the PHR process dates back to 1985 .

A PHR is criteria-based and compares potential consequences of identified hazards with a quantitative set of accident criteria. The hazard assessment techniques outlined in the manual are similar to those used in risk assessment and those recommended in the OSHA PSM Rule. They include techniques such as HAZOP, Failure Mode and Effect Analysis (FMEA), What-If, Fault Tree, and Event Tree Analyses.

PHRs are performed at least once every 7 years throughout the lifetime of a facility. The types of PHRs are classified as screening, preliminary, design, preoperational, and periodic. A periodic PHR is repeated every 3 to 7 years, depending on the complexity of the process and the severity of the consequences associated with the process, to ensure that no existing hazard has been overlooked and no new hazard has been introduced into the process since the last PHR.

The CSOR Team believes there should be a link between the HAD and PHR processes. At present, the PHR interval is arbitrarily selected without any consideration of the level of hazards. The HAD should guide the frequency and level of analysis and the techniques used in a PHR. A high-hazard facility or process should be assessed using more comprehensive techniques, such as HAZOP or event tree/fault tree analyses. Currently, the SRS PHR process does not address external events, such as natural phenomena events, that can cause potential releases of the hazardous materials.

The Team reviewed several periodic PHRs, as well as several screening and preoperational PHRs, for various types of SRS facilities or processes. They include the Gaseous Chlorine Facilities, Second Uranium Cycle at the H-Canyon, Effluent Treatment Facility (ETF), Dilute Effluent Treatment Facility (DETF), Defense Waste Processing Facility (DWPF), and Precipitate Hydrolysis Experimental Facility (PHEF). The Team identified inconsistencies in the PHRs. These inconsistencies may be the result of two factors: (1) the absence of a PHR form and content guide (although the PSM does provide general guidance on the format and content of the PHR); and (2) the lack of a technical review by a central group. The recent centralization of PHR training may improve the consistency among organizations. 
Some PHRs were conducted in a comprehensive manner. The DETF PHR addressed chemical incompatibilities using the "What If" technique. The PHEF PHR used fault tree analysis to provide a more comprehensive evaluation of the chemical hazards.

In several cases, the PHRs did not appear to have identified all the hazards. For example, in the evaluation of the acid vent system in the cold chemical preparation area, the DWPF PHR considered only the loss of ventilation air and its effect on the workers during the addition of dry chemicals to the mixing tanks. The PHR did not consider the hazards associated with adding nitric acid fumes and fine particles of sodium nitrite, potassium permanganate, boric acid, cupric formate, and dust to a common-drum high efficiency particulate air (HEPA) filter. Potassium permanganate, sodium nitrite, and nitric acid are powerful oxidizers, and the formate radical is a reductant. The likelihood of a fire in the filter may be extremely high.

There were some instances in which the PHR process did not identify some potential hazards that are indirectly related to chemical hazards. For example, the PHEF and the Cold Chemical Preparation area of the DWPF have liquid nitrogen tanks with loading valves that are not protected by vehicle barriers.

The PHR provides two levels of results: action items and recommendations; both are based on accident criteria. Action items must be implemented. It appears that action items are being addressed by the nuclear facilities; however, the Team observed that many PHR action items have not been addressed by the management of the chlorine operations. The Team believes that the PHR is a valuable process; however, if its safety insights are not properly integrated into the facility operation, the PHR becomes merely a paper study of much less value. The Management and Operations section also discusses this issue.

As stated in the $9 \mathrm{Q}$ Manual, the PHR concept was introduced to support the facility safety analysis process. The results of a PHR are actions that are implemented to ensure that process hazards are limited and the facility is operating within the safety envelope established by the SAR. However, the Team believes that many SARs have not adequately established the safety envelope for chemical operations, especially for workers. Moreover, a PHR can not be used to support the SAR for nonnuclear facilities because safety analyses are not required. The Team believes there is a real need to integrate the PHR and SAR processes.

\subsection{Chemical Laboratory Safety}

Generally, operating activities at SRS laboratories are expected to meet proven and accepted practices and requirements to assure chemical safety. These include, but are not limited to, the National Academy of Sciences (NAS) Laboratory Chemical Safety "Prudent Practices" incorporated in the OSHA regulations. As a best practice, all workers should be trained to recognize and report hazards, and facility managers should be accountable for the tracking and correction of the noted hazards. In the laboratories, researchers should take the ownership of the work space, the various chemicals used, 
and the waste produced. They should also take responsibility for the safety of their activities, including the safety of others who share the building space. The laboratory managers should be accountable to assure that ownership and responsibility are taken.

\subsubsection{Chemical Hygiene Plan}

The OSHA Laboratory Standard, OSHA 1910.1450, was promulgated in 1990. The regulation requires that laboratories have a written Chemical Hygiene Plan and that a Chemical Hygiene Officer be assigned or a committee with that function be established. If the procedures involved are not part of a production process, nor in any way simulate a production process, they are covered under the laboratory standard and must comply only with the Hazard Communication standard. Both laboratory areas that were reviewed had a written Hazard Communication Program and Chemical Hygiene Plan.

\subsubsection{Hazardous Materials Inventory}

The current inventory system at the laboratories is a computerized system, and the inventory is updated annually. The SRTC system can access information in several ways. The system provides toxicity information and information for the National Fire Protection Association (NFPA) label and can print labels and identify a location. The thrusts for this program are minimizing waste and providing employee toxicity information. The SRTC is also developing a program to use floor plans that will identify the location of chemicals, quantities, exposure levels, and material safety data sheet (MSDS) information by room and even by cabinet within the room.

\subsection{Chemical Process Safety}

The primary elements of chemical process safety management can be divided and summarized into three areas: technology, personnel, and facilities. The Team's findings in these areas are discussed below.

\subsubsection{Technology}

The technology elements of chemical process safety management include process technology, operating procedures and safety practices, and the management of change. Findings in these areas are discussed below.

\subsubsection{Process Technology}

The standards for process technology require that all processes should be continuously reviewed and upgraded for safety and efficiency. New systems or techniques should be sought for hazardous processes to increase inherent safety. Also, processes requiring or producing fewer numbers of smaller quantities of hazardous process materials, intermediates, byproducts, and wastes should be sought. 
At SRS, the PHR provides a mechanism for continuously improving process safety. In addition to the PHR, efforts are underway to reduce the risk associated with processing steps. Two were mentioned by Waste Management staff. One change that is being considered would eliminate the need for hydroxyl amine nitrate as a chemical to destroy nitrites. Another was the proposed substitution of less toxic and flammable compounds for methylene chloride and acetone, respectively. It was also pointed out that freon had been substituted for trichloroethane. This was recognized as an interim fix. In addition, there is an excess chemical list that provides a mechanism for transferring chemicals that are no longer used.

Some efforts are underway to minimize the risk from hazardous chemicals by process changes and by placing chemicals on the excess list. Based on a limited review, no deficiencies or recommendations were noted in the PHRs for this area; however, additional efforts in this area could be valuable.

\subsubsection{Operating Procedures and Safety Practices}

Safety, maintenance, and operations manuals and/or standard operating procedures (SOPs) in written form should exist for all processes. In addition, management should promote safety consciousness and good practices, and safety awareness and good housekeeping should be evident at all levels.

The Team reviewed SOPs for many chemical process operations. Almost all batch chemical handling operations used Category 1 procedures. Category 1 means that they are "use every time" procedures. (See Section 3.1.3.1 on Procedural Controls.) The one exception found was the procedure for unloading bulk shipments of sulfuric acid in the 400-D area. Given the risk of skipping a step or reversing a step, and the potential consequences of such an error, the use of Category 1 procedures should minimize the effects of human error by requiring operators to initial each step in the procedures.

Facility personnel had a very positive attitude toward safety, and management expressed an eagerness to enhance chemical process safety as a result of the visit by the CSOR team.

In the Waste Management Division, the Team observed an excellent practice. If a procedural step was identified in the PHR as being important to reducing the likelihood or consequence of an accident, it was flagged with a "Q." If the procedural step was an OSR administrative control, it was flagged with an "S." A procedural step that was tied directly to a technical standard was flagged with a "T." If any procedure step was flagged with a "Q," "S," or "T," the procedure number was similarly flagged. This coupling of the procedural step to the PHR, OSR, and Technical Standards should mean that changes to the related steps should not occur without the corresponding modification to process or limit. 


\subsubsection{Management of Change}

There should be a formal, integrated process for initiating and accommodating changes in facility and equipment design and process operations. The PHR and configuration management processes appear to be effective methods for management of change.

\subsubsection{Personnel}

The personnel elements of process safety management include emergency planning and response and training and performance. These are discussed below.

\subsubsection{Emergency Planning and Response}

There should be a formal, written emergency response plan, and both onsite and appropriate offsite personnel should be trained to respond to accidents including releases, fires, explosions, and natural disasters. (See Sections 3.1.4.3 and 3.1.4.4.)

\subsubsection{Training and Performance}

Personnel should be appropriately trained in both job and process safety and in emergency procedures. Training and performance, as they relate to chemical process safety, are discussed below.

There is ample evidence that chemical safety training, both on the job and formal class room training, is taking place at SRS. At meetings with the CSOR team, Chemical Coordinators explained many of the chemical hazards associated with the processes. The presence of such individuals at the site facilitates the communication of chemical process safety. The PHR process also supports this training attitude. In two instances, the operating managers did not appear to have a good understanding of the chemical process hazards; however, the current level of awareness of chemical process safety appears appropriate at SRS.

Important elements of process safety include the availability of chemical inventory data and the availability of MSDSs at the work site. SRS has a centrally maintained, sitewide hazardous chemical inventory. One individual in each area is responsible for performing an annual inventory of chemicals and reporting it to the centralized site. One volume of the four-volume inventory lists chemicals for which there are no MSDSs; however, MSDSs for most chemicals are available to workers. Many of the chemicals lacking MSDSs are in long-term storage, are available in small amounts, or are common-usage chemicals (e.g., cleaning chemicals) and may predate the MSDS requirement. Where MSDSs were posted, workers knew their location and had ready access to them. Ongoing activities should continue to obtain all missing MSDSs and distribute them to the places where workers review them as required. 


\subsubsection{Facilities}

The facility elements of process safety management include mechanical integrity and pre-startup facility and process safety reviews. These are discussed below.

\subsubsection{Mechanical Integrity}

The mechanical integrity of all process equipment, piping, vessels, and tankage should be maintained through a formal, written plan, including schedules for inspections, testing, and maintenance. Written procedures should be available, and maintenance personnel should be trained. Logs should be maintained for all surveillance, inspections, calibrations, tests, and maintenance work. In addition, new equipment should be verified as meeting design criteria and standards.

Although there does not appear to be a significant safety problem, some of the chemical tanks and piping systems in the older facilities show some evidence of corrosion, and there is no formal program in place for measuring wall thickness or determining system integrity. The chemical tanks in the Effluent Treatment Facility in $\mathbf{H}$ Area are ultrasonically tested for thickness on a biannual schedule. There is no uniform program in place at SRS.

\subsubsection{Pre-Startup Reviews}

There should be a formal process for reviewing the safety of new processes and facilities or existing processes and facilities that have undergone significant modifications. Modifications to structure and equipment should be checked against design specifications; process hazards analyses should be reviewed; updates to operations, safety, maintenance, and emergency procedures should be verified; and personnel training should be verified.

A PHR is required at several steps in the design and construction process. One requirement is a preoperational PHR, which is also required when a process has undergone significant modification. The extent to which these reviews are used in the Operational Readiness Review was not evaluated.

A formal process for reviewing the safety of new processes or major improvements to existing processes does exist. Efforts should be made to make even greater use of this information source by support organizations. The review process would be helpful in areas such as the development of SARs and training materials, for example.

\subsection{Industrial Hygiene}

\subsubsection{Industrial Hygiene Program}

Line personnel seem to be confused regarding who should be contacted about IH activities. Most line personnel contact Health Protection staff for IH activities. This is due, in part, to the fact that IH was 
in the Health Protection Division until recently. IH has inadequate staffing to perform all necessary activities, such as hazard recognition, baseline and periodic sampling, and review of PHRs and engineering controls.

\subsubsection{Hazard Recognition and Control}

A element critical to the reduction of risk in IH programs is the early recognition of hazards present in the workplace. SRS has developed computer programs for their chemical inventory and is attempting to minimize chemicals. They have made considerable strides in substituting less hazardous chemicals. One area had 25 toxic chemicals, and less toxic chemicals had been substituted for all 25.

\subsubsection{Hazard Communication Program}

A formal hazards communications (HAZCOM) program should be a mandatory requirement for all facility workers and visitors. The program should be well written, and training should be both generic and job-specific. There should be constant reinforcement by supervisors.

SRS has MSDSs on over 15,000 chemicals that are onsite. It is estimated that this is roughly 85 percent of the total.

As noted in the HAZCOM training, the two most preferred methods of reducing chemical hazards are to eliminate the toxic or hazardous chemicals and to substitute non-toxic or less hazardous chemicals for them. Both methods have been very successful at the facilities visited. Reduction of chemical inventories has been accomplished in all facilities by the computerized chemical inventory system. 
Appendix A--Occupational Safety and Health (OSHA) -Related Notes 



\section{Appendix A}

OSHA-RELATED NOTES

The following are the Team's observations of noncompliance issues of Title 29 of the Code of Federal Regulations (CFR), Parts 1910 and 1926, during the Savannah River Site chemical safety review:

o Fall protection for subcontractors doing construction.

o Training of operators dealing with hydrofluoric acid. The operators have normal training and specialized training for 45-60 minutes. If these operators are required to perform spill cleanup activities on quantities or types of chemicals that require an "Emergency Response," they must have the 40 hours of training required by 29 CFR 1910.120 for emergency response.

o Deficiencies in the Lockout/Tagout Program

- $\quad$ A variety of tags are being used for different conditions, such as "caution," "danger," "do not operate," "information," and "leak." The "caution," "danger," and "do not operate" tags seem to be used interchangeably.

- $\quad$ Removal of a tagged pump without closing or modifying the existing lockout/tagout.

- Employees interviewed by team members did not seem to be aware of the procedures.

- $\quad$ The entire lockout/tagout program needs to be evaluated for effectiveness and employee knowledge of the program.

o Carcinogen Control Program

- Carcinogens or suspected carcinogens are not always clearly identified (benzene, Defense Waste Processing Facility).

- Areas containing or using carcinogens are not always restricted access nor is a $\log$ kept of those entering the area. 
o Electrical

- $\quad$ Flexible wiring (temporary) was being used in place of permanent or fixed wiring-29 CFR 1910.305(g)(2)(iii)(a-e).

- Junction box cover plates missing.

- Possible deterioration or broken insulation or cords.

- Extension cord being run through a door or wall opening.

- Corroded outlet boxes.

o Emergency Preparedness. In most areas there was no indication that simulated chemical accident exercises were being conducted. 
Appendix B--Biographies 

AREA OF RESP: Conduct of Operations

ASSOCIATION: John W. Arendt Associates, Inc.

EXPERIENCE: $\quad 48$ Years

John W. Arendt Associates, Inc.

- Senior Engineer: Provide technical assistance in the fields of: (1) UF 6 handling, (2) packaging and transportation of hazardous waste and radioactive materials, (3) quality assurance, (4) standards and regulations, (5) engineering and management consultation, and (6) safety appraisals and assessments.

JBF Associates, Inc.

Provide technical and management advice to the President in fields of uranium enrichment, standards and regulations, waste management, packaging and shipping, reactor activities, quality assurance, and safety activities including chemical safety.

Nuclear Division, Union Carbide Corporation

- $\quad$ Staff Engineer: coordinated preparation of planning document on waste management and environmental problems at Y-12. Served on Y-12 Mercury Task Force and chaired Environmental Impact Committee.

- $\quad$ Superintendent of Planning and Budgeting in Gas Centrifuge Program.

- $\quad$ Project Manager for UCC-ND Uranium Resource Evaluation, part of the National Uranium Resource Evaluation (NURE) Project.

- $\quad$ Superintendent of Physical Measurements, Inspection and Nuclear Technology.

- $\quad$ Superintendent of Inspection, Metallurgical and Nuclear Engineering.

- $\quad$ Production Supervisor for in-plant handling, measuring, storing, packaging and shipping of nuclear materials.

Manhattan Project, University of Chicago

- $\quad$ Research Assistant

EDUCATION:

OTHER:
B.S., Chemical Engineering, Marquette University

Registered Professional Engineer, State of Tennessee, 1974

Certified Nuclear Materials Manager

Member, Nuclear Standards Board, American National Standards Institute (ANSI), vice Chairman of Nuclear Standards Planning Committee Chairman, ANSI N14 Standards Committee, Packaging and Transportation of Radioactive Materials

Member, ANS, ASME, ASQC, ASNT, INMM, NSPE, TSPE, and ADPA 
NAME: $\quad$ Melvin E. Cassady

AREA OF RESP: Industrial Hygiene, OSHA

ASSOCIATION: $\quad$ Cassady Safety and Health Services, Inc.

EXPERIENCE: 27 Years

Cassady Safety and Health Services, Inc.

- Testimony in toxic tort litigation and an expert on engineering controls

- $\quad$ OSHA-type Health and Safety Audits

- Occupational Safety and Health Program Development

- $\quad$ Program Reviews and Development

National Biosystems, Inc.

- . Testimony in toxic tort litigation and an expert on engineering controls

- $\quad$ OSHA-type Health and Safety Audits

Occupational Safety and Health Administration (OSHA) Health Response Team -

Director

Performed assessments of complex industrial hygiene problems and engineering controls

Emergency response to health catastrophes

National Institute for Occupational Safety and Health (NIOSH)

- $\quad$ Performed industrial hygiene field investigations and engineering control assessments

- Criteria Document development

Kennecott Copper Corporation

- Develop hygiene program; performed industrial hygiene field surveys;

' and reviewed engineering controls

National Lead Company of Ohio (Fernald)

Monitored decontamination activities; develop water monitoring program; and conducted plant surveys

EDUCATION: $\quad$ M.S., Industrial Hygiene, University of Cincinnati

B.S., Biology/Minor Chemistry, Ft. Lewis College, Colorado

OTHER: $\quad$ Certified Industrial Hygienist

Clinical Faculty, University of Utah

Advisory Board, University of Utah 
NAME: $\quad$ Check (Tony) C. Eng

AREA OF RESP: Hazard and Risk Analysis

AFFILIATION: $\quad$ Office of Risk Analysis and Technology

EXPERIENCE: $\quad 19$ Years with DOE, NRC, FERC and Corps of Engineers

Senior risk assessment engineer: chemical safety review, non-radiological policies and standards development.

- Senior technical staff member of the Advisory Committee on Nuclear Facility Safety (ACNFS): supported the ACNFS in identifying DOE-wide environmental, safety and health issues and prepared ACNFS recommendations to Secretary of Energy.

Risk assessment engineer: conducted independent review of DOE Class A reactor probabilistic risk assessments. Developed risk assessment and safety analysis guidance for nuclear facilities.

- Project manager/risk assessment engineer: managed NRC's probabilistic risk assessment programs for reactors, fuel cycle facilities and high level waste geologic repositories.

- Project manager/civil engineer: conducted hydroelectric power studies for FERC.

Project manager/hydraulic engineer: conducted hydraulic, hydrologic and structural analyses for Corps of Engineers' civil projects.

EDUCATION: $\quad$ M.S., Civil Engineering, University of Maryland, College Park, MD

OTHER: $\quad$ Registered Professional Engineer, Maryland Member, American Society for Civil Engineers

Member, American Institute of Chemical Engineers 
NAME:

AREA OF RESP:

ASSOCIATION:

EXPERIENCE:

EDUCATION:

OTHER:
Rudy I. Hansen

OSHA, Hazard and Risk Analysis

Battelle-Pacific Northwest Laboratory

20 Years

Experience in occupational safety, industrial hygiene, human factors, fire safety, and safety management.

- $\quad$ Consulted with numerous organizations on safety issues and processes. Has assisted in program review/development and accident analysis. Has performed safety process review and audits to determine general and chemical process hazards.

Managed groups of consultants and put together a service program that significantly reduced accident frequency for those firms serviced. He managed training, industrial hygiene and general safety programs for these consulting programs. Other responsibilities included training, safety literature development, budgeting, policy and procedures development, and performance management.

- Worked on state governmental committees developing administrative rules related to safety issues. Developed with the Oregon Insurer Group the legislative response to rules related to safety and insurance. Worked on the American Society of Safety Engineer's Accreditation Committee and Career Promotion Committee in Oregon.

- Developed a Preliminary Hazard Analysis for a new research existing DOE facility. The chemical hazards, consequences and control measures were evaluated.

B.S. Physics, Oregon State University

M.S. Industrial Engineering, Oregon State University

Certified Safety Professional 
AREA OF RESP: Chemical Process Safety, Chemical Engineering, and Hazard and Risk Analysis

AFFILIATION: Battelle Memorial Institute

EXPERIENCE: $\quad 24$ Years Experience Nuclear Projects, Risk and Safety Assessments

- $\quad$ Project Leader of DOE/DP Chemical Hazard Survey

- $\quad$ Safety Assessments and Operational Safety Requirements evaluations at Y-12 Oak Ridge, Tennessee

- $\quad$ Risk assessment of bottling and trucking alternatives for liquid low-level radioactive waste

- $\quad$ Numerous risk and safety analyses of radioactive material transportation systems

- $\quad$ Assessment of Special Nuclear Material (SNM) losses of NRC licensed plutonium and high enriched uranium processing facilities

- $\quad$ Development of expert systems for high-level waste repository siting.

- $\quad$ Project leader for identification of severe accident modeling methods for production reactors at Savannah River Site.

EDUCATION: $\quad$ Ph.D., Chemical Engineering, The University of Michigan

M.A., Mathematics, The University of Michigan

M.S., Chemical Engineering, The University of Michigan

B.S., Chemical Engineering (cum laude), The University of Notre Dame

OTHER: $\quad$ Member of American Institute of Chemical Engineer

Member of State of Ohio Seismic Hazards Evaluation Board 
NAME: $\quad$ Julie A. Sellars

AREA OF RESP: Coordinator

ASSOCIATION: $\quad$ EG\&G Idaho, Inc.

EXPERIENCE: 13 Years

EG\&G Idaho

- $\quad$ Program Administrator: Support and assist DOE-HQ staffing Technical Safety Inspection teams. Maintain roster and database of consultants and laboratory personnel in all technical disciplines.

- Participated as Coordinator for the Technical Safety Appraisal Subteam on the Tiger Team Assessments at Pittsburgh Energy Technology Center, Stanford Linear Accelerator Center, National Institute of Petroleum Energy Research, Fermi National Accelerator Laboratory and the INEL/ATR Quality Assurance Inspection and Nuclear Safety Inspection.

- $\quad$ Senior Operations Technician: Assisted the engineers in data reduction and data graphics for report purposes. Maintained and input into a tracking data base of all unit milestones. Maintained and input into a data base developed by the Nuclear Regulatory Commission for tracking all work projects from our unit engineers. Responsible for all graphics and logistics for presentations made by the unit and group managers for inside and outside EG\&G Idaho, Inc.

EDUCATION: One year in Business Administration at University of Idaho Numerous night courses with Idaho State University. Numerous computer and work-related courses with EG\&G Idaho, Inc. 
NAME:

Richard J. Serbu

\begin{abstract}
AREA OF RESP: Team Leader
ASSOCIATION: DOE/Office of Risk Analysis and Technology

EXPERIENCE: 25 Years
\end{abstract}

U.S. Department of Energy, Germantown, MD

- $\quad$ Director, Risk Analysis and Technology Division, EH-33.1

- $\quad$ Acting Director, Safety Inspections Division, EH-331

- $\quad$ Acting Director, Safety Technology Division, EH-332

- $\quad$ Team Leader for Technical Safety Appraisals

Tennessee Valley Authority, Chattanooga, TN

- $\quad$ Corporate Health Physicist, TVA's Office of Nuclear Power

- $\quad$ TVA Central Emergency Response Team

U.S. Nuclear Regulatory Commission, Rockville, MD

- $\quad$ Health Physicist, technical reviewer for radiation protection and emergency preparedness for licensing and design changes for reactors, prepared safety evaluation reports, performed inspections and team evaluations, evaluated reactor emergency preparedness exercises.

- $\quad$ Task Manager for NRC/INPO Coordination Plan for Radiological Protection Activities.

- $\quad$ Contracts Project Manager for work with DOE Labs

- $\quad$ NRC Incident Response Team

General Electric, Schenectady, NY

- $\quad$ Knolls Atomic Power Lab, Kesselring Site

- $\quad$ Manager, Radiological Monitoring

- Lead Engineer, Dosimetry and Health Physics

- $\quad$ Lead Engineer, Radiological Training

- Radiological Controls Shift Supervisor

- Instructor, Chemistry and Radiological Controls, qualified as nuclear navy Engineering Laboratory Technician

- $\quad$ Kesselring Site Emergency Response Team

U.S. Air Force

- Officer, Pilot/Aircraft Commander

- KC-135, EC-135, C/EC-47. T-38, T-37, T-41

- $\quad$ Standardization/Evaluation aircrew member

EDUCATION: $\quad$ B.A. Chemistry, State University College at Potsdam, NY

OTHER: $\quad$ Member, Health Physics Society 
NAME: $\quad$ Dan M. Stover

AREA OF RESP: Management and Operations

ASSOCIATION: Technical and Professional Services

EXPERIENCE: $\quad 23$ Years

Technical and Professional Services

- $\quad$ Independent consultant specializing in the area of Conduct of Operations and Management assessments. Provides specialized technical consulting services at operating nuclear facilities. His assignments have been varied and include both program development, training and performance of various assessments at both nuclear and non-nuclear facilities. In particular, his experience has been concentrated in "Performance-Based Assessment" at both commercial nuclear power plants and at U.S. Department of Energy facilities throughout the country.

- $\quad$ Consultant to US DOE, Office of Environmental Safety and Health - Core member to the Secretary of Energy's select task group to investigate and report to the Secretary on the management practices at DOE tritium facilities which may be contributing to unplanned releases of tritium to the environment and exposure to workers. Selected as the only member to be on both assessment teams to provide overall continuity between the teams. Current consultant to EH-30 to develop and implement performance assessment programs for the EH Site Representative Program. Developed Performance Assessment guides, performed site performance assessment of DOE line management and contractor safety and health programs, prepared associated reports and assisted in review of reports from all EH Site Representatives.

- Current instructor for "Performance Based Audit and Surveillance" Course taught at nuclear utilities throughout the country. Responsible for all classroom instruction of this course which is patterned after an identical course for the Nuclear Regulatory Commission titled "Inspecting For Performance". Course content includes both concepts, background, and techniques for implementing a performance-based audit and surveillance program at an operating nuclear power plant.

Gilbert/Commonwealth

- Held both technical and supervisory/managerial positions.

U.S. Navy

Commissioned Officer in Nuclear Navy

EDUCATION: $\quad$ M.S.E. Nuclear Engineering, University of Michigan

B.S. Marine Engineering, United States Naval Academy

U.S. Naval Nuclear Power Prototype (S1W), Idaho

U.S. Naval Nuclear Power School

OTHER:

Professional Engineer (Nuclear) - Pennsylvania PE-032276-E 
Appendix C--List of Facilities Visited and Personnel Contacted 

Appendix C

LIST OF FACILITIES VISITED AND PERSONNEL CONTACTED

Date

Place

Site Services

$7 / 6 / 92$

483-D Chlorine Unloading \& Storage

Monday

483-D Receiving, Handling \&

Neutralizing Facility

D-Area, 5G Pumphouse, \&

Chlorination Facility

\section{Separations}

$7 / 7 / 92$

Tuesday

Outside Facility - F Area

FB-Line

F-Canyon

Outside Facility - H Area

HB-Line

H-Canyon

Waste Management

$7 / 8 / 92$

Effluent Treatment Facility

Wednesday

H-Area Tank Farm

241-90H Storage Building

299-H Maintenance Facility

S-422 - Frit

S-422 - Nitric Acid/Cold Feed

M-Area

$7 / 9 / 92$

341-M/32--M

Thursday

SRTC

773-A - High Level Caves

773-45A

773-A Lab

773-A - Computer Program

TNX - PHEF

678-T 
Personnel Contacted

F Area/July 7, 1992

*Dennis Gracy

Ricky Hatcher

Steve Brown

Kevin Bratt

Joe Britt

Carol Allgood

H Area/July 7,1992

*Dennis Gracy

Chuck Goergen

Roy Jackson

Danny Wray

Donna Kruzner

Tony Wood

WMF/July 8, 1992

*Bob Scaggs

Kent Sullivan

Skipp Wiggins

Robert Wilson

Mike Stressemarn

Pam DeCostello

J.C. Davis

G. Todd Wright

DWPF/July 8,1992

*Steve Sheetz

L. Jones

Steve Wilson

K. Weis

Latricia Jones

SRTC/July 8-9, 1992

*Bill Wilmarth-TNX

Meg Anderson

Bill Durant

Mike Cowan

Doug Craig
M Area/July 9, 1992

*Ming Wong

Hitt Arnold

Glenn Diener

Rich Carleton

EP/July 9, 1992

* Clark Hyder 
Appendix D--Details of the 681-5G Pumphouse Review 



\section{Appendix D \\ DETAILS OF THE 681-5G PUMPHOUSE REVIEW}

The $6815 \mathrm{G}$ Pumphouse provides cooling water to the D-Area Power plant, which in turn produces steam for site processes. Periodically, gaseous chlorine is injected into the river water for biofouling control. There are up to 4 cylinders, each containing 2000 pounds of chlorine ( 8000 pounds total); 2 cylinders are on line during chlorination operations.

There are no operational chlorine leak monitors anywhere in the 5G Pumphouse area. The nearest chlorine monitor is in the D-Area approximately 1 mile away. There are no automatic shut off valves in the process piping line. There are no local alarms, horns, or visual warnings of a chlorine release in the 5G Pumphouse area, and no alarm that can be readily heard and responded to by the public.

There are no specific emergency pre-plans to deal with a chlorine release this close to the site boundary, nor are there methods and means to safely evacuate and control potential boaters on the immediately adjacent Savannah River. The Fire Department has a boat, but it is not kept in the water and does not have pre-positioned personnel protective equipment. Similarly, Wakenhut security is not equipped to deal with the complications of an offsite chlorine release to the Savannah River.

Normally, the 5G Pumphouse is not manned except during chlorination operations and during routine daily inspections by the area operators. There are few process design features that provide for prevention or mitigation of a chlorine release accident. Instead, system operation, system lineup, and operator action are pivotal in preventing or mitigating chlorine releases and the potentially serious consequences. While the chlorination system is in operation, an operator is required to be in the area. Additionally, when a chlorine cylinder is being connected or disconnected and when the chlorination system is first placed in service, the operator is required to wear a self- contained breathing apparatus (Scott Air Pack) and to have another operator standing by with a Scott Air Pack.

When the chlorination system is not in operation, the cylinders are isolated from the process piping by manually closing the shutoff valve on the cylinder head; thereby reducing the possibility of a process piping failure causing an undetected leak when the area is unoccupied. There is a great deal of commercial history concerning the cylinders and, based on that history, little likelihood that a catastrophic leak would develop, barring some outside initiating event.

While there are no procedures or operating limits that prohibit maintenance activities during chlorination operations, it was stated that it was Power Division unwritten policy that chlorination could not be conducted when maintenance personnel were present. Such a policy minimizes the possibility that maintenance personnel could inadvertently damage process piping and cause a leak or that untrained personnel would be present during a process piping failure. The circumstances for an outside initiated event, however, are routinely encountered at the 5G pumphouse. There is an overhead trolley crane that runs directly over the chlorine cylinders. In addition to using this crane 
for cylinder replacement, the crane is routinely used for removal and maintenance of pump motors and traveling screens. It was stated that the pump motor weighs approximately 14,000 pounds. This lift is not designated as a "Critical Lift," and routine rigging practices are used. Considering the weight of the motor there is a high potential for catastrophic failure of one or more cylinders and the very rapid release of the chlorine if a drop occurred. Since neither operators nor maintenance personnel are in Scott Air Packs for this operation, there is also a high potential for fatalities in such a scenario that has not been evaluated (see section on relationship of PHRs and SARs).

Load test and inspection records for the trolley crane were requested, but the information was not available prior to the Chemical Safety Oversight Review (CSOR) Team departing the site. Subsequently, an inspection data sheet was telecopied to our EH HQ office by the contractor on July 15, 1992. A contractor-performed inspection of the subject 10 ton crane, which was conducted on July 9,1992 , indicated that the crane had not been load tested within the last 5 years nor had the lifting hook been nondestructively examined (NDE) within the last 5 years. The inspection record also indicated that the limit switches for this hoist were corroded and that corrosion was also noted on the monorail above the chlorine cylinders. A note with the telecopied information indicated that, as far as could be determined, there were no records of a load test of this crane ever being performed. From the lack of an inspection record prior to the CSOR Team's visit, it appears that periodic inspections of the trolley hoist may not have been conducted.

Additionally, a letter with the telecopied information indicated that the overhead hoist was removed from service, presumably as a result of the information provided by the CSOR Team. The letter indicated that the monorail was visually inspected and recommended that the hoist be returned to service "....after it has passed CSWE's inspection" on July 10, 1992. It is not clear from the information provided if this crane is considered in service and available for use at this time.

In addition to the workers safety issues that may be raised by the lack of adequate testing and actions, the potential catastrophic results of a dropped load on the chlorine gas cylinders at this location would indicate that a more indepth review of the risks needs to be performed prior placing the overhead crane back in service and certainly prior to conducting or allowing any additional lifts over the subject chlorine cylinders.

During the initial tour of the 5G Pumphouse, chlorination operations were in progress. The operator was aware of the need to limit non-operations personnel and informed the team of the fact that chlorination was in progress. There is a Category 1 step-by-step procedure that covers chlorination operations. The team observed that the operator had not signed off several of the steps completed as required by the procedure, including steps that involved valve manipulations. The operator also informed the team that he used procedures he kept in local files at the pumphouse. He stated that he verified that the procedure was the latest revision by comparing it to a procedure index provided by his supervisor, which is also kept locally. This is also not consistent with the document control policies observed by other divisions and required by the Westinghouse Savannah River Company (WSRC) governing document control requirements. 
Later, a component with an active Lockout/Tagout tag was found to have been removed from the system and placed in a temporary storage area. The operator at the pumphouse did not see this as a problem nor did he take any action to correct it. The following day, the same component was still in the laydown area with no action taken to clear the tag. When discussions were held with a Power Operations Lockout/Tagout coordinator, he indicated that practice was not allowed by the WSRC procedures, but he took no action, such as initiating a lockout modification, to correct the situation, which indicates a lack of appreciation for the importance of rigor in the Lockout/Tagout system.

Perspective on the safety impact of the chlorination system and its potential for severe consequences in the event of a leak can be obtained by review of the project to install a new chlorination system and its associated PHR.

A PHR for the existing system was performed in 1980 using less defined and rigorous methods than currently used by WSRC. The PHR concluded that the system could be operated with fewer hazards and less risk with the completion of a few, rather simple action items. Subsequently a new chlorination system for the 5G Pumphouse was designed to replace the old system; ostensibly because of safety deficiencies in the existing system. A thorough and comprehensive PHR was performed on the new system, including a periodic PHR a year later. The PHR concluded that safety could be assured for the new system only if certain action items were completed. The action items included, among others, requirements for periodic testing of automatic process shutoff valves; periodic testing of chlorine monitoring and alarm devices; and destruction of used pigtails/lead washers to assure they are not reused. Eight of 13 action items for the new system at 681-5G, and 7 of 13 action items at the D-Area storage facility have been completed.

It does not appear that consideration was given to applying the action items that were identified in the PHR for the new system to the existing system. In addition, a new PHR was not performed for the existing system to establish the safety envelope for continued chlorine gas system operation, especially one that considered the total lack of some of the detection and mitigation systems inherent in the existing chlorination system at the $5 G$ pumphouse. SRS had expected to place the new system into service in a timely manner; however, delays were encountered in project funding, design, procurement of test kits for the chlorination monitors, and development of procedures and training. 
$-\ldots$ 
Appendix E--SRS Emergency Action Level (EAL) Project Plan 



\section{Appendix E \\ SRS EMERGENCY ACTION LEVEL (EAL) PROJECT PLAN}

\subsection{PURPOSE}

The Savannah River Site (SRS) EAL project objective is to implement one standard approach for emergency classification at SRS. This revision of the Project Plan has recast the project into three phases. This change is a result of the need to incorporate recent Department of Energy (DOE) requirements and experience gained during the conduct of the project. The expansion of the project into three phases allows the Areas/Facilities to continue the work in progress without having to restart the development process.

\section{$1.1 \quad$ PHASE I}

The first phase, currently underway with a completion date of October 1,1992 , will establish a sitewide EAL format to provide a common methodology and reference for the various facilities and the SRS Site Emergency Response Organization (ERO). Onsite classification criteria for the release of nonradiological hazardous materials as an Alert Classification will be established. Currently in accordance with the SRS Emergency Plan (6Q), Immediately Dangerous to Life and Health (IDLH) values will be used in Phase I to classify nonradiological hazardous material. In Phase II Emergency Response Planning Guides (ERPGs) will be utilized per the guidance in the DOE 5500 series orders. In addition, the EALs for the Reactor Areas will be reviewed and revised to conform with the sitewide format and to incorporate new data from recently completed Probabilistic Risk Assessments.

\section{$1.2 \quad$ PHASE II}

The second phase will encompass the revision of the EALs concerning the release of hazardous materials (radiological and nonradiological) to more closely conform with the guidance in the DOE 5500 series orders and other applicable DOE guidance. The development of the Preliminary Technical Basis Justification Document (PTBJ) has been placed in the second phase to allow the Areas/Facilities sufficient time to develop the necessary documentation. The revision of the EALs will establish Onsite Classification Criteria for Alert and Site Area Emergencies (SAE) in accordance with the guidance of DOE order 5500.2B. The establishment of onsite evaluation criteria will facilitate the development and implementation of onsite Protective Action Guides (PAGs).

\subsection{PHASE III}

A third phase has been added to the project which will include the integration of the Emergency Classification methodology with the Site Item Reportability and Issue Management (SIRIM) program for all site process areas. An SRS Emergency classification Manual (13Q) will be developed from all 
Area/Facility EALs at SRS to ensure sitewide continuity in the assessment and classification of emergencies at SRS.

During Phase III an SRS Site Wide Hazards Assessment, as required in DOE Order 5500.3A and described in the DOE Emergency Management Guide, will be conducted. The process of developing an SRS Site Wide Hazards Assessment will be covered under its own project plan yet to be developed at a later date. Upon completion of the Hazards Assessment for an Area/Facility an EAL Technical Basis Document (TBD) will be developed. The development of a TBD is contingent upon the completion of the Hazards Assessment, as the TBD is developed from the information gathered in the Hazards Assessment and the PHASE II PTBJ for all Area/Facilities. 
APPENDIX E - Chemical Safety Oversight Review (CSOR) Trip Report of the Y-12 Plant 



\subsection{SUMMARY}

An evaluation of the present status of chemical safety at the Department of Energy (DOE) facilities is being performed by the DOE Office of Environment, Safety and Health (EH). The purpose of this evaluation is to identify any generic deficiencies in chemical safety in the DOE complex, to identify measures and controls necessary to improve chemical operations, and to develop recommendations for both the short-term actions necessary to address immediate problems and the long-term actions oriented at broader programmatic improvements. The evaluation is supported by a series of reviews at selected facilities to gather information. The information obtained is important in terms of its general contribution to understanding the current status of chemical safety and to a broad reexamination of the chemical safety practices within the Department.

The third facility visited as part of this evaluation was the Y-12 Plant (Y-12), which is located in Oak Ridge, Tennessee, and managed by Martin Marietta Energy Systems, Inc. (Energy Systems). During the review, the Team examined chemical operations typical of Y-12 and evaluated several ongoing and planned program improvements that will increase emphasis on chemical safety at both the site and the facility level.

Y-12 has traditionally considered chemical hazards along with nuclear hazards in its safety analysis process when determining risk to workers and the public. The existing, approved safety analysis reports (SARs), which were prepared in the early 1980s, concentrate on the operations associated with enriched uranium. These chemical and nuclear safety analyses were neither systematic nor comprehensive, and they did not directly lend themselves to specific operational safety requirements or limiting conditions of operation. A major program to update facility SARs is currently underway, and application guides have been established that form the basis for chemical hazard and risk analysis. A hazard classification has been performed for all Y-12 facilities. The Team's review of selected reports indicates that chemical hazards are being incorporated into the $\mathrm{Y}-12$ hazard and risk analysis program, and the general approach seems to be adequate.

Timely, high-quality hazard and risk analyses are the bases for proper design and safe operations of chemical facilities. The results of these analyses need to be translated into equipment safety classification and operations safety requirements (OSRs) to help ensure a proper design. Y-12 is currently in a transition mode in its safety analysis program. Management systems are needed to ensure that the hazard and risk analysis results are properly incorporated into the design and operation of chemical facilities. Some positive examples were noted in the coordination of SAR update program results into the emergency response program and the ongoing update of OSRs for moderate hazard facilities. Some negative examples include the recent hydrogen fluoride (HF) release and the root causes, safety issues, and deficiencies noted by the Chemical Safety Oversight Review (CSOR) Team in its review of Y-12 operations.

Chemical safety at the Y-12 plant is administered at multiple levels, with each facility developing facility-specific programs. As a result, the level and approach to chemical safety vary significantly 
among the various facilities. However, the importance of chemical safety is recognized by both operations personnel and management at the plant. Efforts are underway to integrate significant aspects of the chemical safety program, such as chemicals procurement, operator training, emergency response, etc. The CSOR Team recognizes this effort; however, a number of deficiencies in existing programs were observed. These include, but are not limited to, the following: (1) inconsistent documentation of training; (2) Material Safety Data Sheets (MSDSs) not being readily available at some facilities; (3) lack of current inventory of chemicals in most of the facilities; and (4) heavy reliance on operator experience in avoiding accidents.

The Plant Laboratory has combined several previous safety procedures into a chemical hygiene plan that meets the requirements of Title 29 of the Code of Federal Regulations (CFR) Part 1910.1450, "Occupational Exposure to Hazardous Chemicals in Laboratories," which is the Occupational Safety and Health Administration (OSHA) laboratory standard. The chemical hygiene plan does not represent an integrated safety program; it is only one of a number of standard operating procedures that address safety issues. The OSHA laboratory standard requires the use of a chemical custodian. The use of a chemical custodian in operating divisions at Y-12 would provide improved chemical inventory control. In addition, continuous attention to good chemical safety practices is mandatory to minimize chemical hazards in the Plant Laboratory. The Team noted that current chemical inventory information is not maintained at either the facility or plant level.

Site industrial hygiene programs have been established for the most part; however, education of the workers and implementation of the programs do not appear to be as mature as they should be. Additional funding and emphasis is required by management to ensure completion of training commitments.

The formal design control process used for chemical facilities in response to DOE Order 6430.1A, "General Design Criteria," is in place, but there is no single guiding document to tie safety analysis results to the required level of engineering rigor and thoroughness in design. However, the process is working by virtue of experienced personnel relying on numerous documents for guidance. A high reliance is placed on using administrative controls as the primary means for preventing or mitigating accidents rather than using engineered systems, as recommended in DOE 6430.1A. Procedural controls of process activities are adequate, but need improvement. Documentation of job-specific training to procedures is inconsistent.

The Team observed chemical vessels, piping, and storage tanks that were corroded to the extent that periodic inspections may not be enough ensure that they can be used safely. In addition, the Team identified significant external corrosion of pipe and equipment supports and pipe labeling that has been allowed to deteriorate or is nonexistent. Many outside secondary containments (diked areas, chemical pallets) are filled with rainwater, which reduces their design capacities. Y-12 Central Stores maintains a large inventory of flammables, but there is no evidence that these chemicals are controlled by appropriate separation or on the basis of chemical compatibility criteria. 
Following the January $1992 \mathrm{HF}$ release, several lessons were learned that prompted changes in the manner emergency activities are implemented. The plant's emergency planning and preparedness activities are in transition. High standards for planning and performance have been established in the improved emergency preparedness plan (EPP). Emergency preparedness training is performancebased and appears to be proceeding on a timely basis. During the reviews, the Team did not always receive emergency indoctrination training when entering a facility; however, escorts were provided fulltime.

Management has recently placed increased emphasis on self-assessment, and a self-assessment policy has been established by the Quality Division. Line and support organizations are required to develop more specific self-assessment procedures based on this policy. Currently, however, the line and support organizations have not achieved the level of performance required by plant procedures.

\subsection{INTRODUCTION}

This CSOR of Y-12 is one of a series of reviews of the overall management of chemical operations and laboratory activities of DOE facilities. These reviews will address safety review processes; mechanisms for identifying chemical hazards and assessing risk; and methods for reducing and controlling actual or potential chemical releases and exposures to workers, the public, and the environment. The Y-12 review was conducted on July $6-10,1992$. A closeout with Y-12 and DOE Oak Ridge Field Office (DOE/OR) management was conducted to discuss the preliminary findings and conclusions for the review.

\subsection{Background}

Y-12 is located to the south of Oak Ridge, Tennessee, and is managed for DOE by Martin Marietta Energy Systems, Inc. (MMES or Energy Systems). Bear Creek Road, the principal access to the site, runs east and west along the northern side of the plant. The main site area is situated in eastern Bear Creek Valley and is bounded on the south by Chestnut Ridge and on the north by Pine Ridge. The plant occupies an area approximately 0.6 mile wide by 3.2 miles long; the longer axis being essentially parallel to the ridges. The plant site area contains 811 acres, with about 600 acres enclosed by perimeter security fencing. There are approximately 233 principal buildings at the Y-12 site (excluding cooling towers, pump houses, and buildings under 1000 square feet). In addition to an extensive street system and support services (such as a dispensary, a cafeteria, fire and security departments, vehicle fleet, mail delivery, and others), Y-12 has its own utilities infrastructure, including electrical substations and a steam plant.

Y-12 was originally constructed in 1943 to 1945 with a mission to separate uranium by the electromagnetic process; today its primary mission assumptions are as follows:

- Disassembling returned units. 
- Minimum processing for safe, compliant, economical storage.

- Designing, testing, design, certifying, and procuring.

- $\quad$ Acting as "Fort Knox" for HEU.

- Maintaining production capability via Process Development Program.

- $\quad$ Providing Quality Evaluation for existing stockpile.

- $\quad$ Providing support for reconfiguration effort.

- $\quad$ Pursuing Work for Others and Technology Transfer initiatives.

- Providing Y-12 site management/landlord services.

\subsection{Chemical Characterization}

Many chemicals are used in the processes required to support production of components and the processing of source and special nuclear materials. Quantities range from under a pound (for reagents used in the Plant Laboratory) to over a million pounds (for certain chemicals used in chemical processes). The Plant Laboratory uses a wide variety of chemicals for analysis of vendor and production quality and for environmental and industrial hygiene samples. As a result, the Plant Laboratory has a high usage rate for acids and solvents, as well as a broad spectrum of other chemicals, including reproductive and carcinogenic chemicals.

Process chemicals include large quantities of acids, bases, and solvents in aggregate quantities from 10,000 pounds to over a million pounds. Freon solvents have been widely used; and, in spite of efforts to find substitutes, these chlorofluorocarbons are still present in quantities exceeding 10,000 pounds. Compressed gases include an aggregate quantity of inert gases, such as argon, nitrogen, and helium, totaling over a million pounds; and liquid and compressed oxygen totaling over a million pounds. Several processing areas typically have 850-pound cylinders of HF gas.

Various metals and metal oxides are used. There is significant use of beryllium compounds, a suspected human carcinogen. Other process chemicals that are suspected or confirmed human carcinogens include perchloroethylene, nickel compounds, and toluene diisocyanate. There are also over a million pounds of mercury stored onsite from past processing operations. (Chemical quantities were taken from inventory data reported in February 1992 under the Superfund Amendments and Reauthorization Act, Title III.) 


\subsection{HAZARD AND RISK ANALYSIS}

This section describes the hazard and risk analysis process used at $\mathrm{Y}-12$ and examines its impact on the design and operation of facilities with chemical operations.

\subsection{Hazard Identification/Risk Assessment}

Y-12 has traditionally considered chemical hazards along with nuclear hazards in its safety analysis process. The existing approved SARs, which were prepared in the early $1980 \mathrm{~s}$, concentrated on operations associated with enriched uranium. During fiscal year 1989, DOE/OR and Energy Systems formed the Safety Analysis Report Working Group and took on the task of developing and implementing a strategy to address the issue of updating SARs to revised standards and preparing new SARs for facilities for which none had been prepared. The SAR Update Program (SARUP) consists of five phases:

- Phase 0 - Continued Operation Evaluations

- Phase I - Hazard Classification and Qualitative Analysis

- Phase IA - Update Operational Safety Requirements

- Phase II - Quantitative Accident Analysis

- Phase III- Complete DOE-Approved SARs

Phase 0 included hazard identification, preliminary qualitative risk assessment, and a continued operation and action plan. Hazard screening and qualitative logic models, as well as an action plan, were completed in Phase I. Specific methods used in Phase I included preliminary hazards analysis (PHA) and hazard and operability analysis (HAZOP). Phase IA includes development of a preliminary safety class list, revisions to OSRs, and an action plan. A facility description, quantitative accident analysis, and OSR changes and action plan are included in Phase II. Specific methods used in Phase II will include fault tree and event tree analysis. In Phase III, complete SARs will be prepared.

Application guides have been prepared for Phases 0, I, IA, and II. These guides, which form the basic methodology for hazard and risk analysis at $\mathrm{Y}-12$, consider chemical hazards and nuclear hazards in an integrated manner. Phase IA is currently being completed and Phase II is underway.

As indicated in the Safety Analysis Report Summary, all Y-12-operated facilities were included in some portion of the Phase I evaluation. Facilities were assigned one of four levels of hazard: generally accepted, low, medium, and high. A substantial number of facilities represented few or no significant potential hazard consequences due to the magnitude of the hazards involved or the standard nature of the hazards. Fourteen operations received a preliminary hazard classification of moderate; no high-hazard facilities were identified. Several of the moderate rankings were based on the consequences of potential chemical releases. 
One older SAR and three Phase I reports were briefly reviewed to obtain a perspective on the Y-12 hazard and risk analysis process. The review of the older SAR supports the need to update SARs to meet current standards. The review of the Phase I reports indicates that chemical hazards are being incorporated into the $\mathrm{Y}-12$ hazard and risk analysis program and that the general approach seems to be adequate.

The Final Safety Analysis Report for chemical processes, April 1982, was briefly reviewed. An Accident Analysis Committee of operations and safety staff postulated accidents for the major facility systems. Accident categories of criticality, toxic substances, fire and explosion, and natural phenomena were defined. Bounding events were established for each accident category by expert judgment and were quantified' in terms of dose or concentration. Workers, as well as individuals both onsite and offsite, were considered in the analysis. No frequency estimates were performed for the analysis. An assessment of accidents resulting from natural phenomena was performed. This assessment was primarily qualitative. Several chemical release scenarios were postulated and quantified. Safety systems that were identified by the Accident Analysis Committee were not necessarily supported by the accident analysis; OSRs for these were developed in a separate document. The accident analysis was not comprehensive or consistent. Taking advantage of hindsight, it can be noted that no credible accidents were identified for the HF supply system from which the January 1992 release occurred. (The Building 9212 Phase I report does analyze accident scenarios for the HF supply system.)

Phase I reports on Building 9720-31, the Resource Conservation and Recovery Act (RCRA) Motel; Deuterium Facility Buildings 9805-1 and 9805; and Lithium Processing/Tank Farm Building 9204-2 were briefly reviewed. Chemical releases were the primary hazards for each of these facilities. Consequences of chemical releases were quantified in terms of exposure levels based on percentages of immediately dangerous to life and health (IDLH) or equivalent values. A consistent methodology was used in each of these assessments. A preliminary hazard identification matrix, a preliminary hazards analysis worksheet, and a hazard and operability (HAZOP) analysis worksheet were used to develop worst-case scenarios, which formed the basis for the hazard classification input form. Consequence determinations were made for each worst-case accident and were used to determine the hazard classification. Toxic releases, fires, and explosions were analyzed. The RCRA Motel was classified as generally accepted. The Deuterium Facility was classified as low hazard, and the Lithium Facility was classified as moderate hazard.

The Phase I assessment of the Y-12 water treatment plant (of interest to the CSOR Team) was still being prepared, and it was estimated that it would be completed in 6 months. The water treatment plant, which is operated by Johnson Controls, Inc., services the Oak Ridge National Laboratory (ORNL) and the city of Oak Ridge, Tennessee, in addition to Y-12. Large quantities of chlorine gas are used at both the treatment plant and the river pumping station. There is neither an SAR nor a safety assessment available for the water treatment plant. Safety-related documentation provided to the Team included consensus and good practices standards of the Chlorine Institute, cylinder connection procedures, chlorine handling and use procedures, emergency drills, training program, and 
various checklists. In spite of a lack of formal safety documentation, the water treatment plant has been very proactive in identifying and implementing safety improvements in the past few years. Examples include reducing the chlorine cylinder inventory by one-half, reorienting the chlorine feed cylinders to simplify changeout, and adding a sodium hydroxide scrubber system.

\subsection{Incorporation of Hazard and Risk Analysis Into Design and Operation of Chemical Facilities}

As discussed in Section 3.1, application guides developed for SARUP provide the methodology for current hazard and risk analysis at Y-12. This methodology considers both chemical and radiological hazards and treats them in an integrated manner. Consequences both to the workers and onsite and offsite individuals are considered. For hazards classification purposes (Phase I), onsite and offsite exposure limits are defined in terms of irreversible effects and number of people exposed. No formal chemical risk acceptance criteria or mitigation levels were identified in the application guides reviewed.

Four types of safety documentation are defined at Y-12: safety assessment (SA), safety study (SS), SAR, and system safety analysis (SSA). The type required is based on the facility's hazard classification (generally accepted, low, medium, and high). An SA (generally accepted), an SS (low), or an SAR (moderate or high) is required for new facilities, based on the hazard classification. If the hazard classification is generally accepted or the change is not safety related, only an SA is required for existing facilities. If the change is safety related, and an SS or SAR does not exist or does not meet current safety documentation requirements, an SA or SSA is required. If the SS or SAR meets current requirements, revision to the existing SS or SAR is required.

Timely, high-quality hazard and risk analyses are the basis for proper design and safe operations. The results of the hazard and risk analyses need to be translated into equipment safety classifications and OSRs to help ensure a proper design with appropriate safety systems. The Y-12 approach is new and has not been fully implemented, and additional guidance and experience is needed to judge its adequacy. Based upon the results of Phase I of the SARUP, some positive results are noted. These include the incorporation of Phase I results into the emergency response program, the ongoing updating of OSRs for moderate hazard facilities, and chemical inventory reduction for at least one chemical facility.

Management attention and management systems are needed to continue the incorporation of hazard and risk analysis into the design and operation of chemical facilities at Y-12 as the SARUP continues. There may be some weaknesses in incorporating hazard and risk analysis into design and operations of chemical facilities in the current transition environment. One example, based on the recent HF release, indicates some of these weaknesses. The Type B Investigation Report of the HF release, which occurred at Building 9212 on January 24, 1992, was reviewed. One of the recommendations was to implement additional or improved management controls and systems to detect and correct deficiencies in risk-assessment processes. The report also indicates that similar HF releases had 
occurred in 1986 and 1988. As discussed in the previous section, the SAR for this operation, which was prepared in 1982, did not identify any credible accidents for the operation and was not updated to reflect the HF incidents. (The Building 9212 Phase I report does analyze accident scenarios for the HF supply system.) This information, coupled with safety issues and deficiencies noted in the Chemical Process Safety and Conduct of Operations sections, reinforces the need for continued management attention in the incorperation of hazard and risk analysis into the design and operation of chemical facilities.

\subsection{Chemical Process Safety}

The primary elements of process safety management comprise three areas: technology, personnel, and facilities. These areas are outlined and discussed below with respect to the findings of the CSOR of the Oak Ridge Y-12 Plant.

\subsubsection{Technology}

An ongoing chemical process safety program should ensure current, complete documentation of process design and operating parameters and procedures; current, complete documentation of information relating to the hazards of materials and process technology; periodic assessment and documentation of process hazards and implementation of actions to minimize risks associated with chemical operations; and management of changes to chemical operations to maintain or enhance the safety of the facility.

\subsubsection{Process Technology}

All processes should be continuously reviewed and upgraded for safety and efficiency. For hazardous processes, new systems or techniques should be sought to increase inherent safety. Also, processes requiring or producing fewer numbers or smaller quantities of hazardous process materials, intermediates, by-products, and wastes should be sought.

Discussions with facility personnel revealed that efforts are being made to reduce the number and quantities of hazardous and toxic chemicals within many $\mathrm{Y}-12$ facilities. For example, the water treatment facility, Building 1405, has reduced its inventory of 1-ton chlorine tanks by about half over the past few years. In addition, potassium permanganate is being used as a partial substitute for chlorine at the River Pumping Station.

\subsubsection{Operating Procedures and Safety Practices}

In the area of implementation of chemical safety programs, the CSOR Team observed wide variations among the facilities at Y-12 and determined that practices at some facilities need improvement. For example, only a limited number of MSDSs are available within the RCRA storage facility, Building 9720-31. A complete listing is accessible only by computer from a separate building 
(Building 9828-6), which is located about 50 yards away. In addition, chemical inventories are not readily available for individual storage rooms within the RCRA facility; and chemical containers are often labelled with only tracking numbers, making them difficult to identify by sight. Also, all of the materials stored in this facility are considered to be mixed waste because de minimis limits for uranium have not been defined by DOE; however, the materials are not labeled as such. Only known radioactive waste containers are labeled as radioactive. Although, the RCRA storage facility, in general, uses good operating practices, as inventories increase and the moratorium on waste disposal continues, the operating procedures may need to be strengthened.

Management should promote safety consciousness and good practices, and safety awareness and good housekeeping should be evident at all levels. Housekeeping in many facilities and process areas may be considered unsatisfactory based on the "Typical Criteria for Y-12 Housekeeping and Plant Appearance" (ES\&H PA 21.c 1/92). For example, in the Bulk Storage Area (Building 9720-2), floors are littered and dirty. Spilled white powder is evident in several places. Stored chemical containers are turned so that their labels/hazard warnings are not readily visible. Little protection exists against forklift accidents; trichloroethane drums are stacked three high; and liquid chemicals are not bermed for spills.

Discussions with personnel revealed that operating procedures are available for most, if not all, processes. The extent and adequacy of the operating procedures, safety manuals, and other working safety documents were not verified by the CSOR Team. The limited number of operating procedures that the Team reviewed were general in nature. However, significant improvements are being instituted with newer procedures, which include health and safety information and signoff by both a safety engineer and a Health, Safety, Environment, and Accountability (HSEA) officer.

Several hundred gas cylinders of various sizes, some up to 40 years old, are currently on pallets and are stored prone outside the Bulk Storage Area, Building 9720-2. Many show evidence of being stored or left outside for long periods of time. Most cylinders are tagged; however, many are poorly labeled as to contents or quantity. In some cases the tags are so weathered that information on them is illegible. Y-12 management is aware of this problem, and a special task force has been set up to address it. In addition, efforts are underway to reduce the number of cylinders. It has been estimated that the number can be reduced by about a factor of three over the next 5 to 6 years.

The installation of detection systems can reduce risk. For example, using monitors in the RCRA storage facility (Building 9720-31) to detect leakage from waste containers would reduce the risk of accidental personnel exposure upon entering one of the storage rooms. Inside buildings, increased ventilation can also increase safety. For example, exhaust fans in the RCRA storage facility currently are triggered automatically by temperature sensors inside the storage rooms. During cooler weather, rooms may be vented infrequently, and vapors could accumulate. Although manual control of the fans is possible, the exhaust system could be reconfigured to activate prior to opening storage room doors, which would greatly enhance safety. 
Overall there is an intent to reduce the use of hazardous substances by substitution and to reduce the overall risk by reducing inventory. Implementation of this intent was evident in several cases. Widespread implementation, however, is not yet in place. For example, removal of excess acetone from the Bulk Storage facility should be considered. Another example is the presence of 3 years supply of nickel sulfamate in the Alpha-5 facility.

\subsubsection{Management of Change}

A formal, integrated process should exist for initiating and accommodating changes in facility and equipment design and process operations. All changes should be documented; facility diagrams and/or process piping and instrumentation diagrams (P\&IDs), operations and safety manuals, maintenance schedules, and operating procedures should be updated; and personnel should be trained or retrained in a coordinated and timely manner.

Configuration management is being implemented at Y-12 as part of SARUP. Proposed new facilities and modifications to existing facilities are reviewed according to formal procedures. Reviews are documented by safety assessments, which identify and assess the potential hazards of operation of a new or modified facility or process, and by HSEA operational readiness reviews or prestartup safety reviews.

\subsubsection{Personnel Training and Performance}

An ongoing chemical process safety program should ensure identification of the skills and knowledge necessary for each employee to perform his or her job; establishment of procedures and work practices for safe operating and maintenance activities; training for all employees to reach and maintain proficiency in safe work practices and the skills and knowledge necessary to perform their jobs; demonstration and documentation of skill proficiency prior to employee assignment to independent work and periodically thereafter; establishment of programs to ensure that employees are fit for duty; and provisions that contractors either have programs for their own employees or are included in the company's programs.

All personnel should be appropriately and fully trained in both job and process safety and emergency procedures. Training and performance, as they relate to chemical process safety, are discussed below.

Training requirements for $\mathrm{Y}-12$ personnel have their bases in Federal and state regulations; DOE Orders; and facility, process, and specific job needs. Performance-based training is in the beginning stages of implementation at the plant. Job task analyses are in progress.

Documentation of formal, classroom training for all personnel is available through a sitewide, computerized training database. Although on-the-job training occurs at Y-12, documentation of personnel qualification to perform specific operations is lacking. Supervisors and managers of the 
facilities are aware of this deficiency and are in the process of implementing appropriate corrective measures.

Discussion with operations staff at various facilities showed that operations personnel are cognizant of the hazards associated with the chemicals used in their respective facilities. In several of the facilities, there do not seem to be any facility-specific procedures or requirements for handling and storing chemicals within the facility. For example, in the Alpha-5 facility, the experience of the operators is relied upon for safe receipt and handling of the chemicals into the facility.

\subsubsection{Facilities}

An ongoing chemical process safety program includes appropriate inspection and maintenance of the facilities and equipment. At Y-12 there is recognition of the importance of such maintenance programs; however, prioritization of some of the maintenance programs has been difficult due to funding constraints.

\subsubsection{Mechanical Integrity}

The mechanical integrity of all process equipment, piping, vessels, and tankage should be maintained through a formal, written plan containing schedules for inspection, testing, and maintenance. Written procedures should exist, and maintenance personnel should be trained. Logs should be maintained for all surveillances, inspections, calibrations, tests, and maintenance work. New equipment should be verified as meeting design criteria and standards.

Corrosion is an apparent problem at the Y-12 Plant site. Many tanks and other external vessels are severely rusted. The CSOR Team did not verify that the integrity of mechanical or process systems was adequately addressed and attended to. However, adequate maintenance programs, especially for external tankage and associated equipment, were obviously lacking. Diked areas around tanks were often filled with several inches or more of water, which, in some instances, covered piping. At the lithium operations (Building 9204-2), transfer pumps have lost their supports due to corrosion. Upgrades of parts of the Lithium Operation facility are being planned.

\subsubsection{Prestartup Reviews}

A formal process should exist for reviewing the safety of new processes and facilities or existing processes and facilities that have undergone significant modification. Modifications to structure and equipment should be checked against design specifications; process hazards analyses should be reviewed; updates to operations, safety, maintenance, and emergency procedures should be verified; and personnel training should be verified.

Formal procedures to review proposed new facilities or modifications to existing facilities at Y-12 include safety assessments to identify and assess hazards early in the design process and operational 
readiness, or HSEA reviews, prior to startup. A more detailed description of these procedures and an evaluation of their status is presented in Section 3.5, Conduct of Operations.

Discussions with facility personnel revealed that prestartup reviews at $Y-12$ address both facilities and processes. However, the CSOR Team did not verify the quality or effectiveness of these reviews.

\subsection{Chemical Laboratory Safety}

Although various process operations are carried out using laboratory fumehoods, only the Plant Laboratory, Building 9995, and satellite laboratory operations meet the criteria for use of the OSHA laboratory safety standard (29 CFR 1910.1450) for control of occupational exposure to hazardous chemicals in laboratories. This standard is based primarily on the guidelines contained in the book "Prudent Practices," which was compiled and written by the National Academy of Science. To the extent that these guidelines have been formulated to prevent laboratory accidents, this is an occupational- risk-based standard.

The current chemical safety program in the Plant Laboratory is not a risk-based program that stems from detailed risk analysis of all laboratory operations. It is a compliance program against the laboratory safety standard and other OSHA and consensus standards. However, a Phase I Hazard Classification Analysis has been completed. This analysis categorized the Plant Laboratory as a moderate hazard facility, which will mandate further hazard analysis. From a worker safety standpoint, laboratory management recognizes the importance of certain safety systems, such as the ventilation system. However, this identification is based on personal knowledge as opposed to a systematic analysis.

\subsubsection{Chemical Hygiene Plan}

The Plant Laboratory prepared a chemical hygiene plan in January 1991 as required by OSHA. The revised version of this plan was reviewed and found to cover all areas required by OSHA. Since this plan deals with general "good practices," it is used as one of the criterion for self-assessments in quarterly Chemical Hygiene Plan/Safety Surveillances under the Quality Services' self-assessment program. Records indicate that such self-assessments have been completed routinely. Self-assessment findings and observations are required to be closed out.

One of the Plant Laboratory chemists serves as the Chemical Hygiene Officer as a collateral duty. This position will soon be assumed by an individual who is familiar with assessments and is just completing a Masters in Public Health, specializing in industrial hygiene.

\subsubsection{Laboratory Operations}

The Plant Laboratory provides chemical analysis for $\mathrm{Y}-12$ programs, including process, industrial hygiene, and environmental protection. 
The Team visited the Plant Laboratory to observe how chemicals are received, stored, used, and disposed of. Chemicals are received at a loading dock, then transferred either directly to laboratories or to storage. Most of the chemicals are stored in laboratories, except for bulk or large quantities of acids and solvents; each of these has its own storage room.

Almost all chemical handling takes place in laboratory hoods, which minimizes the potential for exposure. Many of the hoods are over 20 years old, and it was reported that they are being replaced as laboratory upgrades are made and funds are available. Many hoods are not designed with a bypass to allow partial closure of the sash without affecting the face velocity. Chemical splash hazards, such as those occurring during chemical transfers, would be reduced if the sash could be lowered to protect the individual's face during open chemical operations.

Housekeeping in some laboratories and in general areas, such as the storage rooms, needs improvement. This becomes increasingly important with laboratory space at a premium and laboratory staffing increasing. Attention to all safety practices is more critical in an older facility, such as the Plant Laboratory, where the facility and equipment may not provide the same level of protection that more modern facilities and equipment might provide. One example of a less than desirable situation is the location of the solvent storage room and glassware washing unit. The laboratory area used to support analysis of samples containing uranium was recently made into a radioactive zone for contamination control. As a result, it is necessary to go through the radiation zone in these labs to get to the solvent storage room or the glassware washing unit, both of which support the whole laboratory.

Laboratory operations generate chemical wastes both in terms of discarded samples and of the chemicals used in the preparation and analysis of the samples. To minimize the potential for chemical incompatibilities when disposing of samples that have a poorly characterized chemical matrix, the laboratory is attempting to return the samples to the customer whenever possible. Samples that contain uranium are collected for subsequent recovery. Chemical wastes are collected in satellite storage locations. These locations, are inside laboratories, in the solvent storage room, inside near the shipping and receiving dock, and outside the building. The acid wastes are collected in a skidmounted plastic drum that is moved by forklift when full. Consequences of a tank puncture or transportation accident outside the containment area do not appear to have been analyzed.

\subsubsection{Chemical Inventory and Inventory Control}

A separate chemical inventory is maintained for each laboratory. The format varies with the individual and may not represent the actual inventory depending on the amount of chemical turnover and purchasing since the inventory was conducted. It is recommended that inventory information be standardized for possible eventual entry into a computerized database. The principal purposes of the inventory have been to ensure the availability of MSDSs and to track what chemicals are available in the laboratories. Without a reasonably accurate inventory, it may be difficult to respond to an 
emergency, such as a chemical fire or explosion. Such information should be available for prefire planning by the Fire Department.

It was reported that significant improvements had been made in minimizing the amount of chemical storage in hoods and on countertops. The Team observed that there were still a number of hoods in which chemicals were located but where no one was working.

In a general analysis laboratory that has a large quantity of bottled chemicals on shelves, it was noted that chemicals were stored alphabetically rather than by compatibility groups. Although most of the chemicals were not liquids, a better practice would be to try to separate incompatible groups of chemicals so that breakage of any two adjacent containers would not result in a violent reaction or highly toxic reaction products.

The laboratory has recently required that all chemicals be dated when received and when opened to ensure that shelf-life recommendations are observed. This is necessary from both a quality assurance and a safety standpoint when the chemical may degrade into a reactive substance, such as peroxide forming agents. A decision was made to date all existing bottles, regardless of age, with the current date to initiate the program; thus, many bottles that obviously have been on the shelves for years have been dated with a 1992 date. These bottles should probably have been uniquely identified to indicate that the date of receipt and opening was unknown so that they would not be confused with bottles that were actually received in the 1992 timeframe. In addition, older bottles should have been reviewed to ensure that these chemicals can be used safely and will not produce questionable analyses.

There were higher quantities of some specific chemicals in laboratories than appear to be necessary. One laboratory had approximately 20 liters of acetone in 1-liter bottles. Flammable liquids are stored in flammable liquid cabinets and in under-hood cabinets. Construction of the laboratory may not provide fire separations between laboratory areas. Total quantities of flammable and combustible liquids within fire areas (areas having rated 1-hour fire separations without penetrations) should be evaluated to ensure that the flammable liquid loading limits of National Fire Protection Association (NFPA) standard 45 are not exceeded. Review of the construction of under-hood cabinets should also be performed to ensure that they meet NFPA requirements for flammable liquid storage.

The laboratory should consider establishing a chemical custodian position to help track chemical receipts, promote inventory control, provide oversight of receipt and distribution of chemicals, and provide ownership for the two chemical storage rooms and the various waste satellite storage areas outside of individual laboratories. 


\subsection{Industrial Hygiene}

\subsubsection{Hazard Recognition and Control}

An important element of an industrial hygiene program is the ability to recognize and detect hazardous chemicals in the workplace. An aggressive attempt should be made to minimize the number of chemicals in the workplace and substitute less hazardous ones, whenever possible. A comprehensive program should be developed to document responsibilities and controls to reduce risks to the site population.

Several facilities and processes were evaluated to determine if programs are developed sufficiently to properly protect site personnel from chemical hazards. The CSOR Team inspected facilities that present a potential risk to the working population. Controls have been developed by the Industrial Hygiene Department (IH) to reduce the exposure risk to site workers from process chemicals. However, the program is immature in some areas where the hazard presents unnecessary risk.

An area that has an adequate direct-reading, real-time monitor is the water treatment plant, where a chlorine detector is installed. Also, Building 9818 has an ozone meter to alert the workforce to ozone leaks. These types of monitors are needed in other high-risk areas of the plant. Overall, the plant is deficient in direct-reading monitors for those areas that pose a high risk for chemical release. An area of the plant that was found to present a high risk of chemical exposure, but which was inadequately monitored, was the HF Dock (Building 9206). Also, continued routine sampling for mercury vapor concentrations will properly characterize the hazards encountered by workers in buildings that contain large quantities of mercury. This will provide IH with the necessary information to prescribe adequate personal protective equipment.

Plant emergency procedures have been developed to provide an ordered response to postulated emergency situations. In January, an improperly aligned valve contributed to the release of large amounts of HF to the atmosphere. The investigative report from the incident stated that investigations determined that outdated indicator tubes were used to measure HF concentrations after the HF incident. Monitoring equipment, dedicated only to emergency response, is necessary to ensure adequate coverage for future emergencies.

Plant personnel are making a concerted effort to maintain proper housekeeping throughout the plant. Poor housekeeping conditions arise in old facilities where additional numbers of personnel and equipment reduce available work space. This condition was apparent in the warehouse (Building 9720-2), where conditions are not in conformance with the plant's housekeeping guidelines. Supervisors are required to ensure that their employees are aware of the plant's housekeeping guidelines and adhere to them.

Organic odors escaping from RCRA wastes stored at the RCRA Storage Facility expose workers entering the rooms to potentially high concentrations of toxic vapors that may be detrimental to those 
exposed, particularly after an accumulation of exposures over time. Exposure to individuals entering the rooms is significant, but there is little sampling data to characterize either the vapors present or their concentrations. A baseline analysis is needed for this area to characterize the risk.

Process safety reviews are in progress to evaluate chemicals that can be substituted for less hazardous ones. Additional plantwide efforts are needed to evaluate potential inventory reductions of hazardous materials.

A well-developed confined space entry program is in place and is administered by IH. All potentially hazardous enclosed spaces are being investigated to determine if they meet the requirements for "confined space"; signs are posted on those that meet the criteria. IH estimates that approximately 80 percent of the plant's confined spaces have been identified and posted with signs.

Facilities are equipped with an appropriate number of safety showers and eyewash stations. However, the placement of several stations needs to be reevaluated. The stations at the RCRA storage area were blocked when doors were in the open position. One station outside the Lithium Operation was located inside a containment dike, where spills would be excessively high. Further, installation of flow alarms on remote safety showers and eyewashes should be considered to warn operators of fellow employees who may need assistance in the use of the eyewash/shower and require first-aid or other medical treatment.

Respiratory protection training is required in those areas requiring the use of respiratory protection. Individuals must first pass a medical physical and be properly fitted for a respirator. The Team observed that one area where respirator use is required is a metal coating operation. Engineering controls are needed to minimize respiratory use.

\subsubsection{Hazards Communications Program}

A hazards communications program provides information to the worker regarding the safe handling and storage of chemicals. It also includes requirements for labeling chemical containers and provides information on chemical hazards and the upkeep of MSDS forms in the workplace. An encompassing hazards communication program has been developed and implemented by IH as part of a DOE requirement. One requirement of the program is an updated inventory of chemicals in the workplace. Flammable storage cabinets were inspected in various locations visited during the tour for inventory postings; no posted inventories or quantities of hazardous chemicals were available. It is good work practice to post inventories of hazardous chemicals in all storage cabinets. Additional efforts are needed to add and update chemical inventories and bring the program into full compliance. The Hazardous Materials Inventory System (HMIS) program may provide this capability.

The personnel assigned to the operation of the RCRA Storage Facility require additional detailed chemical training to meet the requirements of chemical compatibility for storing hazardous chemicals. Personnel at this facility receive training based on RCRA requirements, which provide detailed 
training similar to OSHA's HAZCOM training. A cursory overview of the chemicals in storage identified two areas in which there were incompatibilities. Peracetic acid in a container labeled "danger, do not touch" and picric acid, which is known to become a shock-sensitive explosive after crystal formation, were both stored in a flammable liquid storage bay, providing a potential source of release and ignition for the bottled flammable liquids in the room. In another bay, thionyl chloride was stored with bases, some of which were aqueous solutions, even though thionyl chloride is not compatible with water and should have been stored in the bay with water reactive substances. The wastes at the RCRA site were included in the computerized MSDS program. The RCRA storage site, which is excluded from the 1910.1200 hazard communication program but which requires an equivalent program under RCRA, has a less than acceptable MSDS program. The MSDS binder in the office contains few of the MSDSs for the wastes stored at the facility. The terminal that provides access to the central MSDS files is located outside the area in a small building approximately $\mathbf{5 0}$ yards away. Access to MSDS information is required to be readily available in the immediate workplace.

\subsection{Conduct of Operations}

Assessment of chemical safety in the conduct of operations in workplaces with potential risk to workers from chemical hazards involves an examination at all levels of the practices and procedures that govern these operations. Information was gathered at Y-12 in assessment areas of Design and Analysis, Control and Primary Containment, Mitigation of Chemical Accidents, and Chemical Accident Recovery. These assessment areas were selected to represent the successive "levels of defense," which are commonly used to prevent injury to site and facility workers and to the general public and to prevent damage or loss of government property.

The operating facilities evaluated in this assessment are, for the most part, chemical processing facilities that use chemicals in bulk quantities. Facility activities are supported by limited, multipurpose chemical laboratory spaces. Chemical processes are located in buildings by basic operational functions (such as uranium processing, lithium operations, plating operations, and others) and by support facilities (such as water treatment and material receiving and storage). The safety requirements and responsibilities for the processing facilities, which have a relatively constant work mission, are reasonably well defined.

To make process refinements and modifications, the Health and Safety (H\&S) staff should assist the facility or building owner in the proper selection and installation of equipment and services. When a single process requires the use of more than one chemical, the engineering requirements of the most hazardous chemical should govern the quality of equipment selected or the classification of services required (e.g., corrosion-resistant piping for acids/bases or explosion-proof electrical service for highly flammable chemicals). Similarly, the use of engineered controls or safeguards, such as containments, shielding, redundant safety systems, and ventilation rates, should be based on the most hazardous chemical in use or planned for use within a facility. 
The generation of specific, step-by-step operational procedures should be based on a "graded approach," which considers the potential consequences of the greatest, credible chemical hazard. The more severe the estimated consequence is, the more exhaustive the search for methods to mitigate the hazards should be. Procedures and equipment to minimize the effects of small chemical accidents or spills should be based on the most hazardous chemical present, and "worst-case" chemical accident scenarios should govern the accident recovery or emergency preparedness procedures. Finally, all workers should be trained and be proficient in practicing hazards awareness or the identification of potential hazards in the workplace, and a system should be in place to track and correct the hazards identified.

The following sections focus on identifying deficiencies in Energy Systems Y-12 programs and practices, compared to the program outlined above.

\subsubsection{Design and Analysis}

The continued safety of chemical system operations depends heavily on the degree of rigor and thoroughness of the initial engineering design and the selection process used for materials, equipment and other components. Ideally, the application of engineering controls should be based on the "graded approach," as defined above. Also, reliance on engineered safeguards, rather than on administrative controls, is a preferred method of preventing catastrophic system failure and reducing risk to workers and to the general public.

Energy Systems has developed a formal program by which to control the design process at $\mathrm{Y}-12$. The documented program addresses the need for preliminary and final safety analyses, quality assurance, engineering design analyses, acceptance testing, material certifications, change control in design and construction, formal design reviews, etc. This program appears to be developing and improving with use and seems to capture the basic requirements of DOE Order 6430.1A.

No single document was identified that formally ties the results of the safety analyses (i.e., the inherent risk and consequence of system failure) either to the methodology or degree of engineering effort to be performed or to the level of quality assurance required to verify that the design, selection of equipment and components, and workmanship are of sufficient quality to ensure safety. However, it appears that there is a less formal system in place that relies on several documents to achieve this end. A thorough evaluation by the Team could not be performed in the time available.

In its evaluation of the hazards analysis for older facilities, such as Lithium Operations, the CSOR Team noted a high degree of reliance on administrative control, rather than on engineered hardware, to prevent or mitigate potential accidents. Because the OSRs, which should incorporate the results of hazards analyses for all chemical facilities, are not well-developed or formalized, excessive reliance on administrative control is a potential programmatic weakness at Y-12. Also, during several brief facility tours, the Team noted many hazards, most of which were of minor consequence, that had not 
been identified by building supervision. It is apparent that more emphasis needs to be placed on training and practicing hazards awareness in the workplace.

\subsubsection{Control and Primary Containment}

The CSOR Team found that much of the chemical-related process work was governed by written and approved operating procedures. A brief review of these procedures showed that many were very general in nature, but both new and recently revised procedures had received documented H\&S and Engineering reviews. H\&S cautions were positioned in front of the operational steps in the procedure and highlighted. Quality Assurance (QA) reviews of the procedure development process were not evident. However, some hazardous process areas, such as lithium chemical operations, were found to be conducted without a full set of written OSRs. Although the continuation of such operations in this mode in lithium operations is not as safe as it could be, the facility is attempting to update and implement its standard operating procedures and develop OSRs. A brief procedures review conducted by the Team could not gage the overall effectiveness of the procedures or determine if the procedural links to existing OSRs and the identified safety systems were made. Quality of the final products is adequately controlled in respect to meeting DOE specifications.

A review indicated that operators have received training in the required general plant safety procedures, applicable H\&S procedures (including HAZMAT), and hazardous material procedures related to their chemical area. Although operators have received on-the-job training (OJT) in specific procedures for their area, for the most part, their qualifications are inconsistently documented. Y-12 is currently adding job-specific training records to the plant database. The training record database is immediately available to all supervisors to check current information on the status of operator training and qualifications.

Y-12 facilities acquire chemicals through "just-in-time" procurement from the Y-12 onsite stores or by direct delivery (e.g., bulk delivery) to storage tanks at the facilities. The facility inventory of many chemicals is minimized through just-in-time suppliers. Basic process chemicals are secured from established sources to consistently meet specifications. Onsite chemical delivery drivers must have valid state commercial driver's licenses, and forklift drivers must have licenses showing training and qualification by Energy Systems. In addition to the required specific safety training (e.g., HAZMAT, emergencies, fire response), chemical transporters also receive documented hands-on training in the selection and use of proper tiedowns specific to the type of load to be delivered. The tiedown qualifications are maintained locally and are not entered in the $\mathrm{Y}-12$ computer training records database. For transport of hazardous materials, drivers receive a printout of the associated material hazards and emergency responses to carry in the Department of Transportation (DOT) pouch in the vehicle cab. They are instructed to contact emergency forces in the event of a spill and are to remain near the site to supply information to the emergency responders.

Because chemical waste is under a Zero Rad moratorium from DOE, CSOR Team observations of offsite shipping and related packaging could not be made. Sodium hypochlorite solution from lithium 
operations is stored in onsite tanks and is periodically transferred offsite in tank trucks; the preparation and documentation for this was not evaluated. Raffinate from uranium operations is collected in tank trucks for transportation and disposal at the West End waste facility.

The Team observed that equipment, including a number of outdoor pressure vessels, pressure piping and storage tanks, was heavily corroded. Although operating personnel expressed some concern about the need to recoat these primary containments, they noted that the necessary maintenance funding was not available for such repair. The Team did not verify that periodic nondestructive examination was being performed on these containments to ensure their integrity.

Most storage tanks and larger pressure vessels were properly labeled, but a significant number of both process and service piping runs were found to be unlabeled or not appropriately color-coded. Although there are formal piping specifications in place for process and service applications, they have not been implemented uniformly throughout the $Y-12$ site. For example, in the lithium operations facility, new acid piping was observed to be equipped with spray shields at flanged connections; the older acid piping, located directly adjacent to the new piping and in areas where leakage would contact workers, had no shields in place.

The Team noted no deficiencies in proper handling and storage of flammables outside of approved storage cabinets in operating areas. However, in Y-12 Central Stores (Building 9720-2), there appeared to be little emphasis on the control of quantities and separation of various flammables.

\subsubsection{Mitigation of Chemical Accidents}

It appears that the site has developed and implemented programs to deal with the mitigation of chemical spills and other types of accidents. Although most toxic and hazardous liquid chemicals in the operating areas have been identified adequately and labeled uniformly, only the larger quantities, such as bulk storage tanks, have been provided with secondary containment. Unfortunately, several inches of rainwater had been allowed to collect in most of the containment berms and dikes observed. A formal engineering design directive defining a 7-inch "freeboard" for rainwater collection within these containments has been issued. However, the Team noted several instances of diked containment areas having excessive rainwater; in some cases, there was extreme corrosion from previous wetting of piping and equipment supports in these partially filled contained areas. A number of the new, plastic, spill-containment pallets for the containment of drummed quantities of chemicals have been placed in outdoors service. These were also filled with rainwater; some to the extent that water was in contact with the bottom of the drums on the pallet. There did not appear to be a program for pumping or periodically draining the containment pallets.

In most cases secondary containment for smaller quantities of chemicals, regardless of hazard or toxicity, has not been provided. Some operating areas have been equipped with cleanup kits for spills (e.g., absorbers, etc.), but it was not determined that specific individuals in such facilities had 
received the necessary training in their use. There appears to be an adequate supply of personal protective equipment (PPE), but the adequacy of training in its use was not evaluated.

Site employees receive periodic training in the use of portable fire extinguishers. Generally, the types selected and the mounting locations of extinguishers are appropriate. However, in the flammables area in Building 9720-2, where significant quantities of chemicals are stored, the size and capacity of extinguishers provided are inadequate to handle almost any fire situation. There is a wet sprinkler system installed that will activate, but which may not be capable of saving the facility or of preventing further explosions and related injuries. It was noted that no wet sprinkler coverage was provided in Building 9701-5 because of chemical incompatibility.

Use of the Occurrence Reporting and Processing System (ORPS) and the followup investigation process at Y-12 was briefly evaluated and found to be acceptable. The site has recently started to use the reporting information as the basis of safety and health trending analyses, and a "lessons learned" program is in place. Few chemical incidents have occurred, however.

\subsubsection{Chemical Accident Recovery}

Because of the nature of Y-12 operations, workers are specifically trained in emergency preparedness. Drills, including realistic mock chemical releases in which both operations and emergency responders are actively involved, are routinely performed. Emergency "first responders" are receiving performance-based qualification training, but the program has not been completed. Escorts and/or permanently assigned building operations personnel were provided for the CSOR Team tours to ensure that the appropriate actions would be taken and the members would be accounted for in the event of an emergency. These are positive program attributes.

Conversely, with the exception of the operation at the Kerr Hollow Quarry, no additional building indoctrination information regarding building function, expected building or process hazards, locations of emergency egress routes, or other pertinent data was provided by Energy Systems before the Team entered the work areas. Only a few of the facilities visited required a sign-in/sign-out sheet for personnel accountability in the event of an emergency. These are program enhancements that may be needed.

Appropriate Memoranda of Understanding (MOUs) have been developed with the local and State agencies that provide mutual emergency aid. Likewise, an agreement with a local hospital for the emergency treatment of chemically exposed or injured workers has been in effect for some time. These are positive portions of the site EPPs.

The methodology being used to develop EPPs was evaluated. The results of SAs and SARs, combined with the inputs from facility supervisors and H\&S organizations and information regarding the "current" chemical and radiological inventories, are used as the bases for EPPs. Although this seems appropriate, its relative effectiveness depends on the validity and availability of these inputs. 
At Y-12, the existing SAs and SARs for process facilities are still being upgraded and have not been fully validated for accuracy. The ability of facility managers to produce near "real-time" information regarding chemical inventories during emergencies, particularly during the "back shifts," is questionable. Therefore, the EPP development process at Y-12 appears to be acceptable, but the EPPs developed to date may not be fully effective because of the apparent immaturity of their supporting programs.

\subsection{Management and Operations}

\subsubsection{Management}

The Team reviewed Y-12 management's implementation and oversight of chemical safety. Discussions were held with the Manufacturing Division, a line organization that has responsibility for chemical safety within their facilities; the IH Division of the HSEA Department, which provides support to line management in implementing chemical safety; and the Quality Division, which performs independent oversight of safety programs being implemented by staff and line organizations.

The Manufacturing Division has chemical safety responsibility for five operating divisions. Their operational procedures contain health and safety considerations that reference safety policy developed by IH. Although the safety information contained in the current operational procedures does not provide detailed safety directions to the plant staff, more comprehensive safety instructions are being implemented in the new operational procedures that are being developed as part of the operational procedures upgrade program. A review of recently developed operational procedures confirms that additional guidance regarding safety information is being included.

Review of divisional operational procedures by HSEA is based on a graded-risk approach. Those organizations that are potentially high hazard are required to have their procedures reviewed for inclusion of adequate safety guidance by HSEA. Review of operational procedures by IH personnel for facilities with lower hazard operations is not a requirement. The reason for the graded-risk approach is that a large volume of procedures is being developed and a limited number of HSEA staff is available to complete the required reviews.

The Manufacturing Division conducts surveillances, audits, and self-assessments to determine environment, safety, and health management performance. A review of these oversight activities indicates that they are broad in scope and contain substantive issues, but are limited in the topical area for IH given that they are performed annually. Few of the oversight activities specifically address chemical safety. Tracking of findings is accomplished informally, as there are no procedures that provide for a uniform method of deficiency tracking.

Training of operations personnel in chemical safety is provided in a hazardous communication class, nuclear chemistry basics class, and on-the-job training. Training documentation is maintained for each individual. When a certified operator or supervisor has been absent from certified duties for 
more than 3 months, selected retraining, including written and oral examinations and operational evaluations, is provided as deemed necessary prior to reassignment.

The IH Department provides technical personnel to assist the line organization in implementing its safety responsibilities. Among other tasks, these personnel perform hazardous chemical sampling and area hazardous characterization and validate job safety.

IH personnel conduct surveillances for compliance with their plant-level procedures. They have developed checklists to use during surveillance activities for each of the IH topical areas applicable to Y-12. A review of surveillances applicable to chemical safety indicates that the oversight program is narrowly focused and fails to inform management of significant recurring deficiencies. Numerous individual data sheets for surveillances conducted at various facilities were reviewed. All of these covered carcinogen control, and almost all identified exactly the same two findings. Although these surveillances spanned almost a full year, the same two deficiencies were found at each location. There was no indication that a programmatic solution to these deficiencies was considered or that other facilities were made aware of the high frequency of occurrences of these two deficiencies. In addition, there is no reporting mechanism that would make upper level management aware that numerous identical deficiencies were being identified by the IH Department. There also is no formal tracking or trending of these deficiencies that could be used as a tool to alert management to similar multiple deficiencies. IH is in the process of implementing a self-assessment program.

The Quality Division conducts independent oversight audits of $\mathrm{Y}-12$ programs. The Division also establishes the policies and subordinate documents for self-assessments. The Team reviewed a carcinogen control audit performed by Quality Department personnel. The report, which was extensive and thorough, identified over 120 initial findings. It also clearly identified the criteria used to identify the deficiencies and provided comments on many of the findings for further clarification. The report was transmitted to the organization audited, and a response with corrective actions was requested within 30 days.

A review of the responses to these findings showed that less than half of the findings have been addressed. For those findings that have received action plans, there is no indication that any have been completed. In addition, there has been little or no management action to follow up on these open items or to pursue the findings for which there has been no response. Part of the reason given for this lack of management response is the ongoing transitioning from the old Plant Tracking System to the new Energy System Action Management System. Most of the personnel resources are devoted to transferring findings from external audits to the new tracking system. Internal technical audits have received a lower priority.

The plant has increased its emphasis on self-assessment. A three-tiered self-assessment system has been defined. The bottom tier consists of the self-assessments, inspections, and surveillances to be performed by the line organizations. The middle tier consists of audits, inspections, and surveillances to be performed by support organizations, such as industrial hygiene, quality assurance, etc. The top 
tier consists of an independent oversight performed by the Assessments Department in the Quality Division. The line and support organizations have not all achieved the level of performance required by plant procedures in the self-assessment area. Only a few programs have been formalized to include all the expected attributes of a good program. The Assessments Department is conducting reviews of divisional programs in order to achieve better compliance, improve overall compliance, and improve self-assessment capabilities.

Although each of the organizations evaluated (line, IH and Quality) appears to be taking chemical safety seriously, there is no structured chemical safety management program. This fact is demonstrated by the multiple informal oversight programs and tracking and trending databases and by the lack of management followup of identified deficiencies. In addition, the degree of implementation of safety programs in general varies significantly across the plant. While some organizations have a well-developed formal safety program, others have a much less structured and effective program.

\subsubsection{Risk Management}

As a part of a major effort to deal with changing expectations, $\mathrm{Y}-12$ is implementing an Integrated Resource Management System. This system is a tool for establishing priorities in a variety of areas, including safety and health, and is based on managing risks. It has been used by HSEA, for example, to establish criteria and parameters for line organizations to identify and support all safety-related projects that are to be included in the Y-12 budget. The system has been formalized in procedure and is currently applied to all plant programs. 
Appendix A--Biographies 

Name: $\quad$ Robert W. Poe

Area of Resp.: Team Leader

Affiliation: USDOE/Office of Risk Analysis and Technology

Experience: 20 Years USDOE/ERDA/AEC

- Manager, operational analysis and compliance activities monitoring the safety performance of contractors and field offices.

- Manager, EH Site Representatives Program, conducting occupational safety and health inspections of contractor facilities.

- $\quad$ Team Leader for Safety Subteam of Tiger Team Assessment.

- $\quad$ Conducted quality assurance or standard assessments of field office and contractor programs.

- Performed health physics and industrial hygiene assessment and appraisals of contractor programs.

- $\quad$ Manager, DOE Standards Program.

Education: $\quad$ M.S., Physics, Vanderbilt University, Nashville, TN

Other: Member Health Physics Society 
Name: $\quad$ V. Pasupathi

Area of Resp: Chemical Process Safety; Hazard and Risk Analysis

Affiliation: Battelle

Experience: 25 Years

- $\quad$ Program Manager, waste tracking database management and review and surveillance of contractor waste management activities at Pantex Plant.

- $\quad$ Manger of D\&D Technology Department at Battelle. Managed activities associated with overall planning of $D \& D$ of radioactively contaminated facilities. Managed preparation of waste management plans, waste certification plans, decontamination work plans, site specific plans for DOE-ER five year plans and prepared DOE-ER prioritization system scores.

- Manager, Nuclear Technology Section. Managed the hot cell facility at Battelle. Was responsible for large industrial and government projects involving design, construction and operation of testing systems.

- $\quad$ Responsible for environmental and radiological safety, site emergency procedures and facility quality assurance procedures.

- On-site inspection experience at commercial nuclear facilities including Arkansas Nuclear One - Unit 2, Palisades, Big Rock Point, Calvert Cliffs and St. Lucie-1.

- $\quad$ Principal Development Engineer, Combustion Engineering, Inc. Responsible for design of experiments to validate design of nuclear fuel elements.

- $\quad$ Engineer, Westinghouse Nuclear Fuels Division. Responsible for nuclear fuel development studies.

Education: $\quad$ B.S., Chemistry, University of Madras, India

B.E., Metallurgy, Indian Institute of Science

M.S., Materials Science, University of Florida

Other: $\quad$ Member of Sigma xi 
Name: $\quad$ Peter J. Pelto

Area of Resp: Chemical Engineering Principles; Hazard and Risk Analysis

Affiliation: Battelle, Pacific Northwest Laboratory

Experience: 19 Years

- $\quad$ Group Leader, Risk and Safety Analysis.

- $\quad$ Project manager for Liquified Gaseous Fuels Release Prevention and Control Project.

- $\quad$ Project manager, task manager and technical contributor to numerous risk and safety analyses of energy related systems including nuclear reactors and fuel cycle facilities; nuclear waste facilities; chemical waste facilities; and chemical facilities.

- $\quad$ Preparation of safety analysis reports (SAR) for DOE nuclear and chemical facilities at Hanford.

Education: $\quad$ M.S., Chemical Engineering, University of Washington

B.S., Chemical Engineering, Carnegie Mellon University

Other: $\quad$ Registered Professional Engineer, Washington 
Name: $\quad$ John A. Piatt

Area of Resp. Industrial Hygiene

Affiliation: Battelle Northwest Laboratories

Experience: 20 Years

- $\quad$ Perform risk and safety analyses for chemical operations in various DOE facilities at Hanford and responsible for safety documentation of PNL's new Environmental and Molecular Sciences Laboratory.

- Developed an occupational health and safety program for the International Atomic Energy Agency's Department of Safeguards.

Served as Senior Industrial Hygienist for the 3000 member Pacific Northwest Laboratory.

Served as Regional Safety Manager for US Fish and Wildlife supporting managers of fish hatcheries and wildlife refuges in a six state region.

- $\quad$ Served as system safety engineer at headquarters, U.S. Army Test and Evaluation Command, and at two proving grounds. Provided support of safety test design and evaluation as well as supporting technical occupational safety \& health issues of the proving grounds.

Education: $\quad$ M.E., Industrial Engineering (System Safety), Texas AM University, 1974

B.S., Industrial Engineering, University of Washington, 1971

B.S., Mechanical Engineering, University of Washington, 1971

Other: $\quad$ Certified Safety Professional (CSP)

Certified Industrial Hygienist (CIH)

Professional Engineer (PE) in Safety Engineering in the State of California Member of System Safety Society 
Name: $\quad$ JaNae Shanahan

Area of Resp: Coordinator

Association: EG\&G Idaho, Inc., Idaho National Engineering Laboratory

Experience: 6 Years

EG\&G Idaho, Inc.

- Currently assigned to the INEL as the Technical Leader for the word processing.

- $\quad$ Participated in LANL Tiger Team Assessment as Coordinator of the Safety and Health Subteam.

- $\quad$ Participated in the NIPER Tiger Team Assessment as Coordinator.

- $\quad$ Coordinated with DOE, Idaho Field Office, and DOE Headquarters in the production of the INEL Tiger Team Assessment Factual Accuracy Report.

- Interacted with other Coordinators in the preparation of administrative support during the INEL Tiger Team Assessment. Technical Support Leader/Coordinator for word processing support during the INEL assessment.

- Workleader for two years of the Electronic Publications Center, Technical Publications Department, which includes coordinating the production of technical reports (informal and formal). Interaction with Writing/Editing, Graphic Arts, Word Processing, and Printing for finalization of reports.

- $\quad$ Served as assistant to Unit Administrator.

- $\quad$ Served as a member of a Quality Circle that specialized in better interdivision communications to improve the quality of production and customer relations.

Education: Eastern Idaho Technical College

Other: $\quad$ Certificate of Applied Science in the Office Occupations Program Legal Secretarial Certificate in the Legal Secretarial Program 
Name: $\quad$ Fred C. Shelly

Area of Resp: Occupational Safety \& Health; Industrial Hygiene

Affiliation: EG\&G Idaho, Inc., Idaho National Engineering Laboratory

Experience: 18 Years

EG\&G Idaho, INEL

Safety Engineer, Safety Systems Inspection and Engineering Unit. Oversee compliance of industrial safety activities for Facilities and Maintenance Department.

Rockwell International/EG\&G, Rocky Flats Plant

- Senior Principal Industrial Hygienist/Safety Engineer, comprehensive industrial hygiene coverage including beryllium and uranium machining, hazard communication program, confined space permits, hearing conservation, and recordkeeping. Comprehensive industrial safety oversight of lockout/tagout, machine guarding, railing $\&$ toeboards and chemical laboratory safety.

Reynolds Electrical \& Engineering Company, Nevada Test Site

Laboratory Section Chief. Developed laboratory methodology, purchased state-of-theart instrumentation, and acquired AIHA/CDC laboratory accreditation. Supervised a staff of four chemists.

Bethlehem Steel Corporation

Analytical chemist in AIHA accredited laboratory. Researched new analytical methods for the American Iron \& Steel Institute.

Education: $\quad$ B.S. Chemistry, Allentown College, Center Valley, PA, 1971

Other: $\quad$ Certified Industrial Hygienist (CHI)

Certified Safety Professional (CSP) 
Name: $\quad$ John S. Stone

Area of Resp.: Conduct of Operations

Affiliation: Kaiser Engineers Hanford (KEH) detailed to USDOE EH-30

Experience: 23 Years, professional engineering in design, construction and operations management, consulting, and program management.

- $\quad$ Program Manager, KEH, temporarily assigned to DOE-Germantown to help develop safety assessment programs, evaluate contractor safety performance and proposed corrective action plans; resolve compliance issues, and conduct site safety assessments.

- $\quad$ Principle Design Engineer, KEH, managed multi-discipline nuclear related design projects and performed detailed mechanical design analyses.

- $\quad$ Engineering Design Consultant, petroleum, petroleum chemical, pulp and paper, and inorganic chemical operations.

- $\quad$ Plant Production Supervisor, inorganic chemicals operations.

- $\quad$ Plant Engineer, project and maintenance management and engineering responsibilities for inorganic chemical operations.

Education: $\quad$ B.S., Mechanical Engineering, Washington State University, Pullman, WA

Other: $\quad$ Member American Society of Mechanical Engineers

Registered Professional Engineer, Montana and Washington 
Name: $\quad$ Pamela J. Sutherland

Area of Resp.: Chemical Process Safety; Hazard and Risk

Affiliation: Battelle-Columbus, Energy Systems Group

Experience: 7 Years

Senior Scientist, Environment, Safety and Health. Member of a chemical and radiological safety team to evaluate the safety of operating nuclear facilities within the weapons complex. Estimated potential interactions and evaluated potential for severe chemical accidents - fire, explosions, spills and incompatible mixings.

Conducted Hazard and Operability Studies (HAZOPs) to assess the potential for onsite facilities and/or serious injuries, offsite environmental or safety impacts, significant plant downtime and/or capital losses of equipment, and significant process upset and/or loss of product containment.

Responsible for technical administration of contracts for development of guidance documents in preparation of a safety analysis report (SAR) for geologic repository for high-level radioactive waste.

Managed a risk assessment contract to estimate worst-case environmental and human health consequences of demolishing a laboratory building contaminated with chemical warfare material.

- Directed development of occupational radiation protection and emergency planning guidance documents.

Managed design, coordination, and development of technical workshop materials for two national and four international training seminars and workshops in chemical and nuclear safety.

Education: $\quad$ M.S., Biological Sciences, University of Illinois

M.A., Linguistics, Columbia University

B.S., (cum laude) Mathematics, University of Illinois

Other: $\quad$ American Association for the Advancement of Science, American Institute of Biological Sciences, New York Academy of Sciences, Alpha Lambda Delta, Phi Beta Kappa, Sigma Xi, Phi Kappa Phi 
Name: $\quad$ Ronald E. Wright

Area of Resp: Operational Safety and Regulatory Analysis/Assessment of Industrial Health and Safety Program Management

Affiliation: Pacific Northwest Laboratory

Experience: 27 Years

Pacific Northwest Laboratory

- $\quad$ Project Manager. Managed safety performance assessment program.

- $\quad$ Program Manager. Managed nuclear safety assessment program.

Portland General Electric

- Engineer. Instrumentation and control engineering at the Trojan Nuclear Power Plant.

Idaho Nuclear Engineering Laboratory

- Systems Analyst. Clinch River Breeder Reactor probabilistic risk assessment.

- Lead risk analyst for the special isotope separation vulnerability analysis program.

- $\quad$ Lead risk analyst for Air Force base energy vulnerability analysis program.

Mountain States Energy

- Operations Branch Manager. Managed Component Development Integration Facility of Magnetohydrodynamic Power Plant.

Westinghouse Nuclear Training Center

- Classroom Instructor. Provided training in nuclear power plant systems.

Education: B.S., Electrical Engineering Technology, Purdue University 
Name: $\quad$ William J. Zielenbach

Area of Resp: Conduct of Operations

Affiliation: Battelle Columbus, D\&D Operations Group

Experience: 36 Years

Battelle Columbus

- Technical Assurance Manager for D\&D of Battelle Columbus Nuclear Material Facilities.

- $\quad$ Staff Scientist, Security Evaluations (3) and Technical Safety Appraisals (12) of DOE facilities; nuclear package QA.

- $\quad$ Project Manager, nuclear fuel cycle case studies and facility safety analysis.

- Project Leader and Member, various programs for design and operation of irradiation experiments for Materials Testing Reactor, Engineering Test Reactor, Battelle Research Reactor, Experimental Breeder Reactor-II, University of Michigan Reactor (fueled and nonfueled).

- $\quad$ Researcher, development of high-temperature air frame bearings and seals, and naval bearings; materials development for Aircraft Nuclear Propulsion program.

Education: $\quad$ B.S., Chemical Engineering, University of Pennsylvania

M.S., Nuclear Engineering, Ohio State University

Other: $\quad$ Member, American Nuclear Society 


\section{APPENDIX F - Chemical Safety Oversight Review (CSOR) Trip Report of Oak Ridge National Laboratory (ORNL)}





\subsection{SUMMARY}

A Chemical Safety Oversight Review (CSOR) of the Oak Ridge National Laboratory (ORNL) was conducted by a Department of Energy (DOE) Team from the Office of Environment, Safety and Health (EH) from July 13, 1992, through July 17, 1992.

From the standpoint of gross statistics, ORNL's record shows no history of major chemical accidents. However, unintended releases have occurred, and there has been ample evidence of opportunities to make substantial improvements without significant (or any) increase in cost of operations. Many improvement programs are, in fact, underway. This is due, in part, to direction from DOE.

ORNL is currently in a transition mode in the systems used to manage hazardous materials. Experience has shown that timely, high-quality analyses of hazards are a fundamental and necessary first step. Realization of the goals of safety management requires that the results of hazards analyses be translated into practical, effective operating practices that are understood and respected by all employees.

Chemical safety at the ORNL plant is not a separately administered program. The mechanisms for ensuring safe management of hazardous chemicals are embedded in existing management systems; in industrial hygiene, risk assessment, and other topical area programs; and in facility operating procedures. Martin Marietta Energy Systems (MMES) has developed generic hazard communication (HAZCOM) and chemical hygiene plans that incorporate the requirements of the HAZCOM standard and the Occupational Safety and Health Administration (OSHA) laboratory standard. Implementation of these generic plans has been effective in several operations reviewed by the Team, and the requirements of the OSHA laboratory standard and the recent OSHA regulation dealing with process safety management were understood by some laboratory elements.

However, a cross-check of actual programs and procedures against applicable OSHA criteria is not specifically required. In addition, management controls over day-to-day operations to ensure good chemical safety practices are variable. Line management at the Division Director level or below is relied upon to implement general environment, safety, and health (ES\&H) programs and procedures. In this context, considerable variation was found in line management capabilities and effectiveness. The Team noted examples of outstanding and progressive management, with resultant controls over chemical hazards. In some cases, there has been diligent application of DOE requirements and good practices. However, in other cases, safety and health organizations and senior management did not appear to provide the support needed to ensure that performance meets expectations.

MMES has undertaken several ambitious programs that will lead to improved handling of hazardous materials, including chemicals. These programs include measures related to greater formality in operations; development of a new hazardous material inventory system; assessment of the chemical hazards posed in existing operations; and performance of varying levels of safety analyses, depending upon the hazards at each facility. 
Improvements in the area of conduct of operations should provide immediate and substantial improvements in management of all risks, including hazardous chemical risks. For example, chemical inventory data could be used to devise new programs to reduce the quantities of chemicals onsite to the amount that is actually needed, and information from safety analyses could be used to determine the appropriate controls to be imposed upon each facility. More specifically, information from safety analyses could be used to determine the combination of DOE Order requirements and OSHA regulations appropriate to each facility class that should be incorporated into policies, procedures, and programs (although ORNL's planning has not developed in this area).

ORNL appears to have a sufficient quantity of chemicals of sufficient hazard to warrant special care in all aspects of their use and handling. Even when the quantities and types of material are such as to pose no real danger to life and health, except to a single worker directly handling chemicals, the Team observed practices that seemed to be inappropriate. The Team's report records these observations. This information will be valuable in assembling and synthesizing a set of broad recommendations for further assessment after all five site visits have been completed.

From the standpoint of observations specific to ORNL, the following may be noted. There was evidence of top-level direction to search for and control possible chemical accidents (as evidenced from the records of the ES\&H Coordinating Committee). Administration of chemical safety requirements appears to be largely dependent upon the discretion of Division Directors. As a result, the level and approach to chemical safety vary significantly among ORNL's facilities. The feedback mechanisms to ensure that each Division Director complies with requirements were dependent upon the individual characteristics of the respective Associate Laboratory Director; other mechanisms to ensure effective performance, including oversight programs, did not appear to be effective.

Qualifications and capabilities of Division Safety Officers and Chemical Hygiene Officers have been specified, but the Team noted instances in which needed capabilities were lacking. To some extent, this exacerbates the dependence on the individual characteristics of Division Directors and contributes to the deficiencies noted in the report.

The Team observed a spectrum from notable practices to undesirable situations. For example, storage of old government-owned gas cylinders in the 7000 Area poses significant hazards, and efforts to control these hazards did not appear to be adequate. However, some organizations, such as the Environmental Sciences Division (ESD), reflected determined, well-focused efforts to achieve chemical safety.

\section{$2.0 \quad$ INTRODUCTION}

An evaluation of the present status of chemical safety at DOE facilities is being performed as outlined in a Secretarial Action Memorandum, "Establishment of an Office of Environment, Safety and Health Chemical Safety Oversight Task Group to Review Department of Energy Workplace Chemical 
Safety Programs," dated April 3, 1992. These evaluations will address safety review processes, mechanisms for identifying chemical hazards and assessing risk, and means of reducing and controlling actual or potential chemical releases and exposures to workers, the public, and the environment.

The information obtained from visits to five representative sites is important in terms of its general contribution to understanding the current status of chemical safety and to a broad reexamination of the chemical safety practices within the Department.

The ORNL CSOR Team, under the direction of a DOE Team Leader, was composed of DOE staff and consultants with expertise in various aspects of chemical safety, including: process safety management; industrial hygiene; chemical hazards; safety and risk analysis; management and operations; and chemical laboratory safety. Biographical sketches of the Team members are provided in Appendix A.

ORNL, which is the fourth facility visited as part of the CSOR, is located in Oak Ridge, Tennessee, and managed by MMES. The review of ORNL was conducted from July 13-17, 1992. The Team evaluated the various management, engineering, and procedural controls used to achieve safety. These controls included design and analysis; equipment and structures that provided the primary measures to prevent and contain accidents; capabilities to mitigate accidents; and accident recovery capabilities. The Team reviews included walkdowns and examinations of process systems, laboratory operations, storage, use, and handling. Reviews of documents were performed, including procedures, correspondence, and minutes of key meetings. Interviews were conducted with management and staff, in addition to those made during the course of walkdowns.

OSHA has developed criteria specific to three broad areas: the minimum standards established in Title 29 of the Code of Federal Regulationis (CFR), Part 1910.1200 (Hazard Communication Standard); the more rigorous standards of 29 CFR 1910.1450 for laboratory use of hazardous chemicals; and the newly promulgated standards for chemical process safety management, issued by OSHA as 29 CFR 1910.119. Existing and draft DOE nuclear-safety Orders and regulations cover many of the same areas as the OSHA standards for chemical facilities; however, the OSHA standards provide an appropriate framework against which to judge chemical safety in the DOE complex. The Team conducted a broad-based examination of the practices at ORNL that influence safe management of hazardous chemicals.

The Team came to understand that the missions of ORNL require use of a wide range of facilities, varying from those that manufacture chemicals to the more commonplace chlorination systems used for water treatment. In addition, ORNL-conducted research requires the use of powerful oxidants and reductants in experimental applications.

Although researchers have the choice of purchasing supplies and services from commercial sources, the nature of work at a government-owned establishment implies continued reliance on available 
facilities and staff. Researchers must also devise ways to perform their work in compliance with a complex array of rules and regulations and to seek opportunities for improvement -- all in an environment of constrained resources. From the standpoint of managing hazardous chemicals, the fundamental questions have to do with the efforts made to identify hazards and take effective measures to protect workers and the public.

The Team attempted to address these questions during the course of interviews and facility inspections. Chemical operations typical at ORNL were visited, and the Team evaluated several ongoing and planned program improvements that will increase emphasis on chemical safety at both the site and the facility level.

The Team conducted a closeout with ORNL and DOE Oak Ridge Field Office (DOE/OR) management to discuss the preliminary findings and conclusions for the review. These findings and conclusions are summarized in the following sections of the report.

\subsection{HAZARD AND RISK ANALYSIS}

This section describes the hazard and risk analysis process used at ORNL and examines its impact on the design and operation of facilities with chemical operations.

\subsection{Hazard Identification/Risk Assessment}

Until approximately 1989, ORNL did not include chemical hazards in its formal safety analysis program unless they were present in a nuclear facility for which a safety analysis report (SAR) was being prepared. SARs were not prepared for many ORNL facilities, and the existing, approved SARs concentrate on reactor and radiochemistry operations. Chemical process safety analysis is rarely accorded the same level of importance as nuclear/radiological hazards in safety analyses throughout the DOE complex.

DOE Order 5481.1B requires that the nuclear and chemical hazards presented by DOE operations be analyzed in approved safety analysis documents. The extent and rigor of these analyses are to be proportional to the hazards presented by the subject facilities. The applicability of DOE 5481.1B is stated to be limited to those hazards unique to DOE operations that have the potential to impact the public, the environment, or the workers. This limitation has been widely interpreted at DOE sites to exclude most chemical hazards as "standard industrial hazards" in nature, on the basis that existing codes and standards ensure that such hazards are controlled by the special safety requirements contained therein. However, it is clear that the intent of DOE, as evidenced by recent trends in its guidance, is to strengthen the analytical basis for the safety envelope within which all DOE facilities must operate. This includes the contribution to facility risk of chemical processes within the facility. This approach is consistent with trends in the chemical industry. 
Despite this, it appears that there is a tendency at ORNL to group the hazards associated with chemicals into a field designated as "standard industrial hazards." This is most apparent in the Facility Safety Evaluation/Hazard Screening approach developed to upgrade safety analyses for the facilities managed by MMES. By grouping chemical hazards into a "standard industrial" category, a more methodical analysis of these hazards may be avoided or overlooked. This reduces the likelihood that these hazards will be factored into the basis for safe facility operation, and the controls necessary to maintain operations within the safety envelope may not be accorded the importance they deserve (e.g., as in Safety Limits).

Many different types of safety-related documents are written and approved at ORNL in preparation for the startup of a new facility or the continued operation of an existing facility, for example, the Part B permit for the Resource Conservation and Recovery Act (RCRA) TSD facility (Building 7653). However, the SAR and the accompanying operational safety requirement (OSR) document are the only places where these different safety strategies and criteria could conceivably be brought together and presented.

Recently, MMES began a much more forward-looking effort to address chemical hazards. During fiscal year 1989, DOE/OR and MMES formed the Safety Analysis Report Working Group and took on the task of developing and implementing a strategy to address the issue of updating SARs to revised standards and preparing new SARs for facilities for which none had been prepared. The SAR Update Program (SARUP) consists of five phases:

- Phase 0 - Continued Operation Evaluations

- Phase I - Hazard Classification and Qualitative Analysis

- Phase IA - Update Operational Safety Requirements

- Phase $1 \mathrm{l}$ - Quantitative Accident Analysis

- Phase III- Complete DOE-approved SARs

Phase 0, which has been completed, included hazard identification, preliminary qualitative risk assessment, and a continued operation and action plan. In Phase I, hazard screening was performed, and qualitative logic models and an action plan were prepared. Specific methods used in Phase I include preliminary hazards analysis (PHA) and hazard and operability analysis (HAZOP). Phase IA includes a preliminary safety class list and OSR revisions and action plan. A facility description, quantitative accident analysis, and OSR changes and action plan are included in Phase II. Specific methods used in Phase II include fault tree and event tree analysis. In Phase III, complete SARs will be prepared.

Application guides have been prepared for Phases 0, I, IA, and II. These guides, which form the basic methodology for hazard and risk analysis at ORNL, were prepared under the direction of the Central Safety Evaluation Team (CSET). The guides consider chemical hazards and nuclear hazards in an integrated manner and address both the worker and the public. Phase $I$ is currently being completed; Phase IA is being initiated. 
All ORNL-operated facilities are being included in some portion of the ongoing Phase I evaluation. A preliminary hazards screening (PHS) was performed on ORNL facilities to determine if further hazard screening was required. The PHS process, which was designed to be performed by operations staff or subcontractors using a guidesheet/checklist, was the responsibility of the Facility Safety Evaluation Team (FSET). The process required quantitative information relative to facility hazards, and threshold limits from commonly accepted standards were used as the basis for deciding whether a facility required further analysis.

ORNL facilities that do not exceed the threshold limits are classified as "Generally Accepted," which means that standard ORNL procedures and programs are to be applied in providing a safe and healthful workplace. The product of the PHS process is a quantified checklist which becomes, in effect, the facility manager's operating license for those facilities in the Generally Accepted category. The checklist will be revised if conditions within its scope change. The PHS determined that 593 ORNL facilities were in the Generally Accepted category.

Facilities subjected to the formal hazard screening are assigned one of four levels of hazard: Generally Accepted, Low, Moderate, and High. Preliminary results of the Phase I program for ORNL indicate that 74 facilities were classified as Generally Accepted; 19, were classified as Low; 9, as Moderate; and 3, as High. The three High-hazard facilities are nuclear facilities. Several of the Moderate rankings were based on the consequences of potential chemical releases. Table 3-1 provides a list of confirmed and proposed Moderate- and High-hazard facilities at ORNL.

The approach, assumptions, and criteria by which MMES determines the hazard classification of facilities at ORNL (as discussed above) are provided in the document "Safety Analysis Report Update Program, Hazard Screening Application Guide," CSET-2, dated December 1990. In conversations with MMES personnel who were involved in the creation and implementation of the hazard screening process, the Team gained a better understanding of the advantages and limitations of this process. Table 3-2 provides the radiological-specific hazard-screening criteria, and Table 3-3 provides the nonradiological-specific hazard-screening criteria; both as extracted from the CSET-2 document.

A Phase I determination of a hazard level represents only a preliminary hazard level; further evaluations may be conducted to confirm whether or not the hazard level can withstand more rigorous scrutiny. While this can act as a check system to ensure that the hazard level is a reasonable determination, based upon the hazard presented by the facility, there is a concern that this additional iteration could result in a reduced hazard level by conducting additional analyses until a set of assumptions is discovered that supports a lowered level. This is not meant to imply that such is the goal of this process, but the iterative emphasis does appear to be concentrated in a downwardadjusted, rather than an upward-adjusted, direction. This also points out a concern common to any qualitative rating system of this type: the sensitivity of the evaluation process to subtle shifts in base assumptions. The major advantage of this hazard level process is in providing a basis for a graded approach to the safety analysis program. 
The Team briefly reviewed one older SAR and three Phase I reports to obtain a perspective of the ORNL hazard and risk analysis process. The review of the older SAR supports the need to update SARs to meet current standards. The review of the Phase I reports indicates that chemical hazards are being incorporated into the ORNL hazard and risk analysis program, and the general approach seems to be adequate. Some potential issues and concerns with the implementation of hazard screening and the Generally Accepted category are discussed below.

The Team briefly reviewed the Final Safety Analysis Report (FSAR) for the Radiochemical Processing Plant (RPP), August 1984, and found that consequences were calculated only in terms of radiological dose. Chemical consequences were not considered directly, but only as an initiating event for a radioactive release. This SAR is a good example of the past practice of identifying worstcase accidents using limited analysis and engineering judgment and emphasizing nuclear hazards over chemical hazards. This review supports the need for the SARUP, which is currently underway at ORNL. 


\section{TABLE 3-1 ORNL MODERATE- AND HIGH-HAZARD LEVEL FACILITIES}

\begin{tabular}{llllc}
\hline Prop. ID & Prop. Name & Division & Designation & $\begin{array}{c}\text { Haz. } \\
\text { Lvl. }\end{array}$ \\
\hline 3019A & Radiochemical Dev. Center & Chemical Technology & NR Nuclear & M \\
7503 & Molten Salt Reactor Experiment Bldg. & WM\&RA & NR Nuclear & $* *$ \\
7507 W & Mixed Hazardous Waste Storage Pad & WM\&RA & Nonnuclear & M- \\
7652 & Hazardous Waste Storage Area & WM\&RA & Nonnuclear & M-H \\
7653 & Chemical Waste Storage Facility & WM\&RA & Nonnuclear & M-H \\
7654 & Long Term Hazardous Waste Storage Facility & WM\&RA & Nonnuclear & M-H \\
7823 & LLW Staging/Storage Facility & WM\&RA & Nonnuclear & M-H \\
$7827 \& 2829$ & Shielded Dry Well Facility & WM\&RA & NR Nuclear & M \\
$7830 A$ & Oil Storage Tank & WM\&RA & Nonnuclear & M-H \\
7900 & High Flux Isotope Reactor & Research Reactors & Reactor & H \\
7920 & Radiochem Engineering Development Center & Chemical Technology & NR Nuclear & H \\
LLLWS & Liquid Low Level Waste System & WM\&RA & NR Nuclear & H \\
\hline
\end{tabular}

** Hazard screening is scheduled for completion by December 31, 1992. 
TABLE 3-2 RADIOLOGICAL-SPECIFIC HAZARD SCREENING FOR HEALTH EFFECTS

\begin{tabular}{|l|l|l||}
\hline \multicolumn{1}{|c|}{ HAZARD CLASS } & \multicolumn{1}{|c|}{ ONSITE } & \multicolumn{1}{c|}{ OFFSITE } \\
\hline \hline HIGH & $\begin{array}{l}\text { Irreversible effect to a large number of } \\
\text { people. }\end{array}$ & $\begin{array}{l}\text { Reversible effect to a large number of } \\
\text { people. }\end{array}$ \\
\hline MODERATE & Irreversible effect to a few people. & Reversible effect to a few people. \\
\hline LOW & Reversible effect to a few people. & Negligible health effect. \\
\hline GENERALLY ACCEPTED & Negligible health effect. & Negligible health effect. \\
\hline
\end{tabular}

Radiological health effect exposure levels

$\begin{array}{ll}\text { Irreversible: } & >100 \mathrm{rem} \\ \text { Reversible: } & 10-100 \mathrm{rem} \\ \text { Negligible Health Effect: } & <10 \mathrm{rem}\end{array}$

(These limits are used for hazard screening purposes only.) 
TABLE 3-3 NONRADIOLOGICAL-SPECIFIC HAZARD SCREENING FOR HEALTH EFFECTS

\begin{tabular}{|c|l|l||}
\hline \multicolumn{1}{|c|}{ HAZARD CLASS } & \multicolumn{1}{|c|}{ ONSITE } & \multicolumn{1}{c|}{ OFFSITE } \\
\hline \hline HIGH & $\begin{array}{l}\text { Irreversible effect to a very large number } \\
\text { of people. }\end{array}$ & $\begin{array}{l}\text { Irreversible effect to a large number of } \\
\text { people. }\end{array}$ \\
\hline MODERATE & $\begin{array}{l}\text { OR } \\
\text { people. } \\
\text { of people. }\end{array}$ \\
\hline LOW & $\begin{array}{l}\text { Irreversible effect to a large number of } \\
\text { Irreversible effect to a few people. } \\
\text { OR }\end{array}$ \\
\hline GENERALLY ACCEPTED & $\begin{array}{l}\text { Reversible (or less) effect to a few } \\
\text { people. }\end{array}$ & $\begin{array}{l}\text { Reversible effect to a large number of } \\
\text { people. }\end{array}$ \\
\hline
\end{tabular}

Chemical health effect exposure levels

Irreversible:

Concentration $>1.0 *$ IDLH [immediately dangerous to life and health]

Reversible:

$0.1 * \mathrm{IDLH} \leq$ Concentration $\leq 1.0 * \mathrm{IDLH}$

Negligible Health Effect: Concentration $<0.1 *$ IDLH

(These limits are used for hazard screening purposes only.) 
Another issue involves the timeliness of analyses relative to the operation of newer facilities. The Team visited the RCRA Waste Storage Facility (Building 7653) and reviewed the hazard screening for the facility. The hazard screening (dated March 12, 1992) indicates that Building 7653 is a Moderateto High-hazard facility. The facility has been operated since 1986 without an FSAR or an OSR. In discussions with MMES safety analysis personnel, this facility was identified as an example of the former way of doing business at the site. Prior to the implementation of the hazard assessment process in support of the SARUP, a facility of this nature would likely have had no analysis beyond a safety assessment. This is evident in the fact that the facility has operated for approximately 6 years without an SAR or OSR. Therefore, the recent decision to revisit this facility, which resulted in the determination that an SAR and OSR are required for Building 7653, represents a positive improvement in the safety analysis program with regard to the analysis of chemical hazards.

It is the CSOR Team's understanding that discussions are underway to use information in the RCRA Part B permit to establish OSRs for Building 7653. While this cross-fertilization effort is laudable, care should be taken in the use of limits for which adequate bases have not been established via detailed analysis. It is unclear whether the safety envelope for this facility, as envisioned by the Environmental Protection Agency (EPA), is compatible with, or superior to, DOE safety analysis program expectations. The FSAR for Building 7653 is scheduled to be prepared in fiscal year 1996.

Phase I reports on Process Waste Treatment Building 3544, General Stores Building 7001, and Chemical Waste Storage Facility Building 7653 were briefly reviewed. Chemical releases were analyzed for each of these facilities and were the primary hazards for Building 7001 and Building 7653. For Building 3544, the hazards from chemicals were considered as a standard industrial hazard and not analyzed further. Consequences of chemical releases were quantified in terms of exposure levels based on percentages of immediately dangerous to life and health (IDLH) or equivalent values. A preliminary hazard identification matrix and a PHA worksheet were used to identify worst-case scenarios. Process Waste Treatment Building 3544 was classified as Generally Accepted; General Stores Building 7001 was classified as Low hazard; and Chemical Waste Storage Facility Building 7653 was classified as a Moderate- to High-hazard facility.

An example of a Low-hazard facility is the Holifield Heavy Ion Research Facility (Building 6000). This facility possesses an approved FSAR (ORNL/CF-81/330/R1) and an OSR (ORNL/CF-81/331). While every facility manager knew the hazard level of the facility for which they had responsibility, the manager of Building 6000 impressed the CSOR Team by knowing the status of his facility's safety analysis documentation and was quickly able to provide document numbers to the Team for its use in conducting further reviews. While this might appear to be a trivial issue, it indirectly points to a line management that displays a level of ownership for the safety documentation of its facility. This is an important contributor to a successful facility safety program, and it is hoped that other facility managers display similar interest in the safety documentation of their facilities.

These Phase I reviews illustrate that chemical hazards are being considered in the SARUP process at ORNL and for some operations are the dominant hazards. The methods and application of these 
methods to assess chemical hazards at ORNL appear to be reasonable. However, the CSOR Team has identified some concerns with the hazards screening process and the appropriate use of the Generally Accepted category. As no additional safety analyses are required for existing facilities placed in this category, the criteria used need to be carefully understood and reviewed to ensure that chemical hazards are not incorrectly categorized as "standard industrial hazards." Procedures need to be established to ensure that once a facility is properly designated as Generally Accepted, changes in operations or inventories do not result in an increased hazard level above Generally Accepted. In addition, hazards that appear to have the potential to impact facility workers or adjacent site workers could be considered as Low hazard but are reported as Generally Accepted.

It is unclear whether the intent of DOE 5481.1B is being met with regard to the assignment of hazard levels. Part of this is due to the vagaries inherent in the guidance provided by DOE 5481.1B. There remains a concern that the Generally Accepted category may be used in lieu of establishing some ceiling limits or threshold quantities of chemicals that may be used at such facilities. MMES safety analysis personnel recognize that there is a "gray area" with regard to the lower end of the hazard spectrum.

A detailed assessment of the appropriateness of the ORNL hazard and risk analysis approach, the corresponding screening criteria, and the validity of individual facility hazard level designations is beyond the scope of this chemical safety oversight review. The overall approach, however, represents a noteworthy and positive addition to ORNL's safety analysis program. The ORNL approach, along with the approaches of other DOE sites and DOE Headquarters' organizations, will be reviewed as part of the longer-term DOE/EH-30 chemical safety activities in developing DOEwide policy and guidance in this area.

Safety analysis is not the only mechanism by which chemical safety is, or could be, studied. Another example is the comprehensive Health Hazard Survey. This survey was conducted to (1) identify primary operations, (2) determine the hazards in the operation, (3) determine the engineering controls in place or what should be implemented, (4) determine personal protective equipment (PPE) requirements, (5) determine qualitative exposure levels, (6) assign operation identification numbers for computerized tracking, and (7) determine associated sampling requirements.

The Industrial Hygiene (IH) Section retains a record of all comprehensive and periodic survey information via the Occupational Health Information System (OHIS) computerized database. The OHIS database is also used to select when operations will be resurveyed. Operations are prioritized according to the Priority Action Code (PAC) assigned to each hazard in each operation. Operations that have the most severe hazards (PAC1) are scheduled first, then PAC2, PAC3, and PAC4 operations. After operations are selected and prioritized, health hazard surveys are conducted and data collected for entry into the OHIS database. The survey results are distributed to the Division Safety Officer for implementation of recommendations of the findings where feasible. 
Yet another hazard analysis tool that could be used at ORNL is the new OSHA regulation for chemical process safety (29 CFR 1910.119). This regulation is discussed in depth in section 3.3. It is not clear that the intent of this OSHA regulation is well understood at ORNL, nor has its applicability to ORNL operations been recognized. The OSHA regulation is geared toward detailed hazard reviews of processes involving certain highly hazardous chemicals in quantities at or exceeding specified thresholds. There appears to be some confusion as to whether or not this OSHA regulation applies to ORNL. This may be based upon a misconception that, if ORNL has no facilities currently covered by the regulation, then the regulation does not apply. In fact, the regulation applies to ORNL, regardless of whether or not the site currently has processes that qualify under the regulation.

As in many regulations, 29 CFR 1910.119 contains the minimum requirements necessary to satisfy the intent of the regulation. Good industrial practice would dictate that some similar, though perhaps proportional, level of hazard analysis also be conducted for those processes that are not subject to the OSHA rule due to the lack of a named chemical or insufficient quantities to meet the threshold criteria for subject chemicals. Such practice, as demonstrated by a procedural hierarchy designed to implement methodical analytical examinations of chemical processes at ORNL, is not apparent.

In theory, many of the requirements for a methodical, detailed chemical process safety program, as delineated in 29 CFR 1910.119 , should already exist under the auspices of the current DOE safety analysis documentation program. In practice, chemical process safety analysis is rarely accorded the same level of importance as nuclear/radiological hazards in safety analyses throughout the DOE complex.

In summary, while chemical hazards are reviewed in depth at ORNL from many perspectives (e.g., laboratory safety and industrial hygiene), there does not appear to be a defined, systematic chemical process safety program. It should be noted that, while safety analysis has been cited as a possible venue for implementation of a chemical process safety program, an indepth review of the DOE safety analysis review and documentation system, its implementation at ORNL, and the suitability of this system for satisfying the compliance issues arising from 29 CFR 1910.119 are beyond the scope of this review.

\subsection{Incorporation of Hazard and Risk Analysis Into Design and Operation of Chemical Facilities}

As discussed in section 3.1, application guides developed for SARUP provide the methodology for current hazard and risk analysis at ORNL. This methodology considers both chemical and radiological hazards and treats them in an integrated manner. Consequences to the worker, onsite individuals, and offsite individuals are considered. For hazards classification purposes (Phase I), onsite and offsite exposure limits are defined in terms of reversible and irreversible effects and number of people exposed. No formal chemical risk acceptance criteria or mitigation levels were identified in the application guides reviewed. 
Four different types of safety documentation are defined at ORNL and may be required based on the hazard classification of a given facility. These are safety assessments (SAs), safety studies (SSs), system safety analyses (SSAs), and SARs. For new facilities, an SA (Generally Accepted), an SS (Low), or an SAR (Moderate or High) is required based on the hazard classification. For changes to existing facilities, only the SA is required if the hazard classification is Generally Accepted or the change is not safety related. If the change is safety related, and an SS or SAR does not exist or does not meet current safety documentation requirements, an SA or SSA is required. If the SS or SAR meets current requirements, revision to the existing SS or SAR is required. The safety analysis program does not appear to meet the requirements of DOE 5480.23 at this time with regard to nuclear facilities, but it is understood that activities are underway to implement this order. This is understandable, as the DOE Order was issued less than 8 months ago, and movement toward compliance is expected over a set period of time. However, given the current status of the SARUP, it is important that the requisite changes be made quickly in the program implementation documents so that SARs for nuclear facilities at ORNL do not require further backfitting.

Timely, high-quality hazard and risk analyses are the basis for proper design and safe operations. The results of the hazard and risk analyses need to be translated into equipment safety classification and OSRs to help ensure a proper design with appropriate safety systems. The above approach is new and has not been fully implemented at ORNL. Phase IA studies to update OSRs are being initiated. There is a need for continued management attention to incorporate the results of hazard and risk analysis into the design and operation of chemical facilities.

\subsection{Process Safety Management}

On February 24, 1992, OSHA issued a rule comprised of 14 elements, addressing a systematic way of managing hazards associated with processes using highly hazardous chemicals. The standard is entitled "Process Safety Management (PSM) of Highly Hazardous Chemicals." For the purpose of this report, the standard will be referred to as the PSM rule. The 14 elements of the PSM rule include: process safety information, employee involvement, process hazard analysis, operating procedures, training, contractors, prestartup safety review, mechanical integrity, hot work, management of change, incident investigation, emergency planning and response, compliance audits, and trade secrets.

The primary intent of the PSM rule is to minimize incidents involving hazardous chemicals that may result in a catastrophic-type accident. The standard covers processes in which storage, use, manufacturing, handling, or onsite movement of such highly hazardous chemicals exceed the threshold quantities prescribed by the standard at any time. The term "process," as defined by the standard, should not be confused with a chemical process defined in the chemical engineering field. The term applies to (1) containers holding chemicals listed in Appendix A of the standard that exceed the quantities specified in the standard; and (2) flammable liquids or gases in quantities of 10,000 pounds or more, except products used solely for heating or fuel, that may inadvertently be released 
from the containers in the event of an accident and lead to a catastrophe. The standard also applies to facilities that manufacture pyrotechnics and explosives.

In order to verify that the management systems in place at ORNL address the 14 elements of the PSM rule, the CSOR Team selected several facilities within ORNL that contained either relatively large amounts of hazardous chemicals or contained very toxic materials, irrespective of quantity. Several hazardous chemicals with qualifying quantities, as defined above, were evaluated by the Team. These chemicals are identified in the following table.

TABLE 3-4

FACILITIES WITH LARGE AMOUNTS OF HAZARDOUS CHEMICALS

\begin{tabular}{|c|c|c|}
\hline & Material & Quantity/Capacity \\
\hline Building 3544 & $\begin{array}{l}69 \text { to } 71 \% \text { nitric acid } \\
93 \% \text { sulfuric acid } \\
50 \% \text { sodium hydroxide }\end{array}$ & $\begin{array}{l}7,000 \text { gallons } \\
450 \text { gallons } \\
2,000 \text { gallons }\end{array}$ \\
\hline Building 4515 & $\begin{array}{l}\text { Chlorine } \\
\text { Ammonia } \\
\text { Hydrogen }\end{array}$ & $\begin{array}{l}150 \text { pounds (indoor) } \\
150 \text { pounds (indoor) } \\
12 \text { cylinders } \\
220 \text { cubic feet each }\end{array}$ \\
\hline Building 4508 & Potassium cyanide & 30 pounds \\
\hline Building 7001 & $\begin{array}{l}\text { Chlorine } \\
\text { Flammable gas cylinders } \\
\text { (several types) } \\
\text { Other types of toxic gases }\end{array}$ & $\begin{array}{l}4 \times 150 \text { pounds } \\
\text { Several hundred cylinders } \\
\text { Several cylinders }\end{array}$ \\
\hline Building 7653 & $\begin{array}{l}\text { Varied [small quantities of } \\
\text { several types of hazardous } \\
\text { chemicals consisting of toxic, } \\
\text { flammable and reactive } \\
\text { materials including } \\
\text { approximately } 30 \text { pounds of } \\
\text { picric acid (explosive)] }\end{array}$ & \\
\hline Building 7917 & $\begin{array}{l}\text { Sulfuric Acid }(95 \%) \\
\text { Nitric Acid }(66 \%)\end{array}$ & $\begin{array}{l}5,000 \text { gallons } \\
1,500 \text { gallons }\end{array}$ \\
\hline Building 3608 & $\begin{array}{l}\text { Sulfuric acid (93 to } 95 \% \text { ) } \\
\text { Sodium Hydroxide (18\%) }\end{array}$ & $\begin{array}{l}5,000 \text { gallons } \\
17,000 \text { gallons }\end{array}$ \\
\hline
\end{tabular}

Initially, after a preliminary survey of the facilities within ORNL, the Team identified three tanks containing 95 percent sulfuric acid that may be subject to the requirements of the PSM rule.

However, after visiting one of the facilities, it was determined that the 95 percent sulfuric acid being 
used is not oleum, a chemical listed in Appendix A of the PSM rule. The Team identified flammable cylinder storage areas that may be subject to the requirements of the PSM rule because inventories may exceed 10,000 pounds per location. The management systems that address the requirements of the PSM rule for one of the above facilities were evaluated through a series of management interviews.

The Team selected the Water Treatment facility, Building 3608 , for evaluation because of the large quantities of sulfuric acid being handled.

The Water Treatment facility had an up-to-date process and instrumentation diagram (P\&ID). Its accuracy was not physically verified by the Team. The Material Safety Data Sheet (MSDS) for sulfuric acid refers to the 95 percent sulfuric acid as oleum. Since sulfuric acid is available in two forms, oleum and aqueous sulfuric acid, the information provided on the MSDS is misleading. As a result, there is a potential for oleum to be received in place of sulfuric acid.

A written plan of action regarding employee participation in the PSM program and other safety programs should be in place and implemented. Employees should be included in the formal process hazard analyses and routine hazards audits of the workplace, as their input is important in assessing potential hazards. Employees participate in weekly safety meetings. In addition, a Division meeting at the Water Treatment facility is held quarterly and involves all division employees. Because a process hazard analysis was not conducted at the Water Treatment facility, questioning employee involvement in the process hazard analyses does not apply.

Process hazard analysis is the cornerstone of the PSM rule, which also includes systematic review of a chemical process to determine the potential associated hazards. Appropriate methods must be chosen to conduct hazard analyses of the processes. These methods include "what-if" checklists, HAZOP, failure mode and effects analyses (FMEA), fault tree analyses, or equivalent methods. Process hazard analyses, as defined by OSHA, were not conducted at ORNL for the processes defined by the PSM rule. Although the standard was published recently, various chemical industry groups have recognized the necessity of conducting such analyses for several years. The Chemical Manufacturers Association (CMA) published a report entitled "Process Safety Management (Control of Acute Hazards)" in 1985 that recommended the usage of process hazard analyses for all processes involving chemicals. Also, the American Petroleum Institute (API) published recommended practices in "Management of Process Hazards" (API 750), January 1990. The Center for Chemical Process Safety Committee of the American Institute of Chemical Engineers (AICHE) has issued guidelines on technical management of chemical process safety. The conduct of process hazard analysis has not been prioritized at ORNL. There may be several flammable compressed gas cylinder storage areas or areas of other flammable storage at ORNL that may exceed the 10,000 pounds threshold quantity prescribed in the PSM rule.

Equipment used to process, store, or handle highly hazardous chemicals must be designed, constructed, and maintained to minimize the risk of release of hazardous materials. This requires that 
a mechanical integrity program be included for all containers, including compressed gas cylinders at ORNL. Properly tested cylinders received at ORNL may be at various onsite locations for several years without going through any type of mechanical integrity tests. Written procedures for training process maintenance employees and for testing equipment, including pressure vessels and storage tanks, should be in place and implemented. In addition, ORNL should have an ongoing mechanical integrity assurance program. This program should include provisions for the identification and categorization of equipment and instrumentation, as well as for inspections and tests, and should define testing and inspection frequencies.

The storage tanks at the Water Treatment facility are examined annually by ultrasound (UT). Instruments are on the preventive maintenance program. Instruments and pumps are included in plant equipment maintenance, and their inspection remains on schedule. This information was gathered during management interviews. No verification was performed during this evaluation to determine whether or not there was a breakdown in the management systems associated with the preventive maintenance program.

There are approximately 2,000 compressed gas cylinders of various types (toxic, flammable, reactive) that have been in storage near Building 7000 for the last 2 years awaiting removal from the site. ORNL is struggling with this removal issue and has been unable to resolve the issue satisfactorily. The mechanical integrity of these cylinders is questionable, because they are badly corroded externally.

During the ORNL evaluation, several areas were identified by the Team as having the potential for chemical releases or deficiencies in the chemical safety program. These include the following:

- A chlorine cylinder (150 pounds) was found stored inside a laboratory facility (Building 4516) that was never used. This cylinder had no valve cap, and the Compressed Gas Association recommends that chlorine be stored outside. The Chlorine Institute recommends that emergency kits to contain or overpack leaking cylinders be available at sites handling chlorine. There were no such emergency kits available at this laboratory facility. Chlorine monitors were not provided to warn employees of a chlorine leak, as recommended by the Chlorine Institute.

- All potential hazards associated with an experimental process involving the introduction of hydrogen and chlorine into a laboratory furnace in the abovementioned laboratory were not identified by a step-by-step PHA methodology.

- In the same laboratory, an unused ammonia cylinder was being stored along with other flammable gases. It is a poor practice to store toxic materials in fairly large quantities within a closed room, as there is an increased risk due to confinement. 
- Several of the government-owned cylinders of flammables and oxidizers, which are incompatible materials, were stored together near the 7000 area. These cylinders contain many different gases, including flammable materials (e.g., acetylene, propane, methane, hydrogen) and toxic compounds (e.g., chlorine, hydrogen sulfide). From an inventory standpoint, these cylinders are considered empty, even though they may contain quantities of gas and may be essentially full. Empty cylinders are generally accorded the same treatment for safety purposes as full cylinders.

Most of these empty cylinders have been identified as having no further programmatic use. The cylinders have been accumulated over the past several years, and efforts have been made to surplus them to various commercial vendors over that period. These ongoing efforts have not been successful. The delay in disposal is due, in part, to the DOE moratorium on offsite shipments. The accumulation of this volume of essentially useless material is problematic at best. At worst, it presents an unknown and potentially serious safety concern. Because the inventory of these cylinders is unknown, it is conceivable that a large inventory of flammable and toxic gases has been accumulated in this area. The condition of these cylinders ranges from nearly pristine to significantly deteriorated. Segregation of these cylinders on the basis of the incompatibility of their contents is not well demonstrated. Because of the large volume of cylinders involved, the handling and storage capacity of the department appears to be overtaxed, with stored cylinders overflowing designated storage areas and racks.

Some items associated with handling practices should be noted, including storing short cylinders among large cylinders; storing cylinders without valve caps (several "empty" acetylene cylinders were observed in this condition); cylinders lacking restraints; and the very loose packing of cylinders within restraint areas, which essentially results in no restraint. Good practice items observed include the implementation of a "just-in-time" inventory system to reduce the stockpile of hazardous materials onsite and the provision of well-designed storage racks.

Operations at the High Temperature Materials Laboratory (HTML) constitute another aspect of gas cylinder use at the ORNL. The CSOR Team observed that gas cylinders appear to be stockpiled at the point of use in several of the laboratories at the HTML. Many of these gases are common to several processes, while others are not used on a regular basis. Another common practice was to have large-volume cylinders on hand to supply research stations requiring only small quantities of gas. It may be prudent to investigate the need for provision of a gas shed located on the exterior of the facility, with a manifold system to provide gases to the laboratories within. This would reduce the overall risk to the occupants of the facility.

- One of the bays of Building 7666 was designated as "Explosives A" storage area, and the bay was not designed for storage of explosives. Picric acid (an explosive) was being stored in one of the bays of this building. Explosives should be stored in magazines, as required by OSHA regulations. 
- There may be a potential for inadvertent mixing of sulfuric acid (95 percent) with sodium hydroxide during a filling operation, as the tanks are located adjacent to each other at Building 3608 and the fill piping is similar in size and routing. Methods to minimize such an inadvertent mixing, in addition to those used by ORNL, include the use of different-sized nozzles with different color codes and placement of warning or caution signs near the two tanks.

Formal, written operating procedures should be developed and should provide clear instructions for safe chemical process operations. Procedures should include steps for each operating phase, safe operating limits, and safety and health considerations and should also identify and explain the operation of associated safety systems. Procedures should be readily accessible to employees and should be reviewed as often as necessary to assure that they are current. The Water Treatment facility at ORNL had standard operating procedures in place. The Team did not conduct an indepth review to verify the contents and accuracy of these procedures.

The operator training provided by ORNL at the Waste Water Treatment facility (Building 3608) may be deficient. An operator interviewed at the facility did not know the concentration of the sulfuric acid being handled at the facility, and he was unable to find and define the concentration after consulting the associated process operating procedures.

The safety records of contractors should be considered when selecting contractors for plant maintenance. The outside contractors at the ORNL facility are informed of potential process hazards at preconstruction meetings, at which time all applicable emergency procedures are explained.

A permit system should be in place for hot work conditions on or near a covered process. There is a permit system at ORNL for maintenance activities, but efficiency of the system has not been verified through internal audits.

\subsection{Chemical Laboratory Safety}

To be productive, a research laboratory must include a high proportion of workers who are proud of their knowledge and competence and who perceive that they are in charge of their work. These employees usually perceive themselves as competent in safety matters and know how to recognize a safety hazard and what to do to protect themselves and others. They take ownership of their assigned workspaces. These personal traits are fostered by supervisors who insist on an attitude of safety in the execution of laboratory procedures and who place the highest priority on safety. Likewise, safety in chemical laboratories, depends on similar attitudes within management levels, including Division Safety Officers, Division Chemical Hygiene Officers, and, especially, Division Directors. 


\subsubsection{Productive Workers for Safety}

In the short time available it was not possible to interview and evaluate the safety attitudes of all laboratory workers and supervisors. However, limited attitude sampling was performed in each of the facilities visited by the Team. One Division Director, who clearly qualifies as laboratory management (the ORNL Chemistry Division), was interviewed. Although there are indications of less than full compliance with safety regulations in the Chemistry Division, there is no particular reason for concern about safety. In time, the few deficiencies noted by the Team will be corrected, although perfection may never be attained.

\subsubsection{Safety Practices in the Laboratory Environment}

Beginning in 1972 with the publication of "Safety in the Chemical Laboratory" by the Manufacturing Chemists' Association, the chemical literature has described current standard safety practices. Notable publications in this area include "Prudent Practices" in 1981 and "Improving Safety in the Chemical Laboratory" in 1991. These and other references are more specifically described in Appendix B of the OSHA laboratory standard and are available in the ORNL library. The safety practices described in these publications were applied to the activities observed in visits to ORNL laboratories.

The Team noted very few violations of the requirement to wear appropriate eye protection in the variety of spaces where such protection is necessary. For the record, in the experience of the Team members, perhaps as many as 90 percent of the chemical laboratories in the United States do not comply fully with this safety standard; ORNL laboratories clearly are in the top 10 percent bracket with respect to this essential safety practice.

Similar comparisons cannot be made with respect to other, equally important though perhaps not equally imperative, safety practices. The Team observed the deviations from standard safety practices described below (not necessarily in order of importance or frequency). These deviations are indicative of underlying deficiencies in the implementation of chemical safety into the practice of chemistry in the ORNL laboratory operations.

\subsubsection{Reactively Incompatible Chemicals}

Reactively incompatible chemicals were found in several chemical storage cabinets at ORNL. In two instances, the reaction between these incompatibles could have been so violent, had it occurred, as to destroy the entire laboratory space in which the cabinets were located.

\subsubsection{Crowded Storage}

The Team found shelves in storage cabinets so loaded with bottles of chemicals that some of the bottles were not totally on the shelves and instead stuck out, over the shelf edges. 


\subsubsection{Access to Emergency Safety Equipment}

Access to one safety shower and eyewash fountain (Room 54, Building 2001) was found to be impeded by the location of a trash can, refrigerator, and centrifuge so that, in the event of an emergency, it is likely that neither shower nor fountain could be used properly.

\subsubsection{Misuse of Protective Gloves}

Laboratory personnel were observed using gloves for protection without knowing whether the material of the glove chosen to be worn would be impermeable to the chemical(s) being handled. In addition, laboratory personnel did not know that even a "proper" glove material is always permeable after it has been worn and exposed to the chemical for a certain length of time (usually a few hours, but in some cases, only a few minutes).

\subsubsection{Hoods Used with Improper Face Velocities}

Hoods with face velocities well above 100 feet/minute were used as though the face velocity were properly regulated. Authorities on hood use agree that for almost all purposes a hood face velocity of $80 \mathrm{feet} / \mathrm{minute}$ plus or minus $20 \mathrm{feet} / \mathrm{minute}$ (with the hood opening set at its typical setting for the uses to which that hood is put) is the desirable range. (See ANSI Z9.5, entitled "Laboratory Ventilation.") When this standard becomes final, ORNL must adopt its recommendations, including establishment of a Laboratory Ventilation Management Program.

\subsubsection{Misuse of Chemical Storage}

Chemicals that had not been used for more than 1 year are being stored on laboratory shelves, instead of being returned to general storage. This is being done on the basis that the chemicals might be needed in the future; however, there is no plan whatsoever to use them in the foreseeable future. In addition, hoods are being used to store chemicals for several weeks. Clearly, standard chemical storage safety practices are not being used in all ORNL laboratories.

\subsubsection{Material Safety Data Sheets}

MSDSs are not, in general, a fully reliable source of information. With a few exceptions, most chemical manufacturers rely on supporting literature, as well as the MSDSs literature, for provision of information, including associated hazards, protective clothing requirements, anecdotal requirements for exposure and ingestion, etc. Consequently, any information in an MSDS must be verified. ORNL attempts to verify manufacturers' information before using it in their MSDSs. However, unverified information remains in the ORNL MSDSs. When this occurs, the information is accompanied by an editorial code that indicates that the information has not been verified. The users of the ORNL MSDSs, the laboratory workers, are generally not aware of the code and are accepting the unverified information as correct. 
Although there may be valid reasons related to potential liability for repeating unverified information in an MSDS, there is at least an equally compelling necessity to clearly state in plain words, not in a coded manner, that such information is not verified. Because unverified hazard information is being treated as though it were correct, ORNL employees handling chemicals apply unnecessary and sometimes cumbersome procedures to protect themselves against hazards that may not exist (or are not recognized as existing in the associated MSDSs). These practices, through the unnecessarily cumbersome procedures used, may cause an accident wherein the real, verified hazards of a chemical could cause harm.

There is another concern that arises from inclusion of information that is perceived as frivolous or wrong by users. Since that information is "obviously" wrong, users might conclude that other information in the MSDS is also wrong, and the respect accorded to an MSDS is, therefore, reduced. As an example, the MSDS for sodium chloride appears to state that sodium chloride

might be a mutagen. This is coded in that MSDS as unverified. Users who do not know the code think the MSDS for sodium chloride presents other information that is also wrong. Such an attitude toward one MSDS soon translates into a lack of respect for other MSDSs, and the utility of an MSDS as a reliable source is lost.

The laboratory procedures used in work with many of the chemicals at ORNL properly require the use of gloves. However, in none of several instances observed by the Team (approximately 15) was it known to workers that the gloves being worn would, in fact, protect against exposure to the chemical(s) being used. In the two instances where the MSDS was checked, it was not helpful. The MSDS said to use gloves, but it did not specify glove material. In such cases workers stated that they saw no need to check with anyone concerning what glove material would protect them because, if a specific glove material were required, the MSDS would so state. Consequently, laboratory workers are frequently unknowingly exposed to chemicals by wearing inappropriate gloves because of the inadequacy of the pertinent MSDS.

The MSDSs promulgated by ORNL use the Hazardous Materials Inventory System (HMIS) hazard number system. For fire and reactivity hazards, the numerical rating used is the same as that used by the National Fire Protection Association (NFPA) to protect firemen when they are fighting a fire. In that situation, the NFPA has determined, for example, that concentrated nitric acid has a low reactivity, rating it as a 1, the next to lowest rating. However, in typical laboratory use, this acid at even moderate concentrations is relatively reactive. For laboratory use, concentrated nitric acid should be rated at least as a 3 (the next to highest rating) in reactivity. The use of NFPA reactivity ratings for chemicals used in the laboratory is a serious error, one which leads to failure to use adequate precautionary measures. The application of the concept of reactivity should be consistent with the requirements of the OSHA laboratory standard, 29 CFR 1910.1450.

The health hazard ratings in the HMIS system are also incorrectly based, in large part, upon misuse of both threshold limit values (TLVs) data from American Conference of Government Industrial 
Hygienists (ACGIH) and LD50 and similar data from Registry of Toxic Effects of Chemical Substances (RTECS). Thus, the ACGIH clearly describes how to properly use TLVs and states that they are not to be used in evaluating health hazards. For example, a substance with a TLV of 10 parts per million (ppm) is not necessarily more toxic than another substance with a TLV of $100 \mathrm{ppm}$. Further, direct use of LD50 and similar data from RTECS is wrong because the data reported by RTECS are not reliable, as RTECS itself warns. The instructions in the RTECS User's Guide clearly state that RTECS is only a "pointer to the literature" and, therefore, "the original reference should always be consulted" before relying on the information. But in some instances ORNL relies on LD50 and similar data presented in RTECS as though it were valid and does not consult the original literature to verify scientific and toxicological validity. This manner of use of ACGIH and RTECS data to determine health hazard ratings is not acceptable.

Currently at ORNL, the HMIS numbers given in the MSDS are copied onto special labels (similar in appearance to NFPA 704 diamond labels), which are placed on chemical containers. The Team noted that, in many cases, the HMIS label was put on containers in such a manner as to obscure the information on the suppliers' labels, which already meet OSHA regulations. This defacement of suppliers' labels is a violation of OSHA regulations 29 CFR 1910.1200 and 29 CFR 1910.1450. If used correctly, the ORNL HMIS label should be applied only to containers that have no label or have an incomplete supplier's label. In addition, such a label should be applied in manner that it in no way covers or obscures a supplier's label that is complete and complies with OSHA regulations. ORNL has a policy in accordance with this label application method. However, based on Team observations, this policy is not enforced.

\subsubsection{Inventory Control}

Team members' experience suggests that chemists in research laboratories often are reluctant to relinquish control over the containers of chemicals in their possession because chemical purity is of the utmost importance. Often, the integrity of contents of the containers cannot be assured because of multiple users, and it is sometimes difficult to obtain new containers of high-purity replacements in a timely manner. This attitude leads to the physical retention of containers of chemicals for very long periods, during which time the chemical may deteriorate and become either unsafe or unusable or both. Because this practice is unsafe, chemists must be persuaded to allow proper inventory control. The inventory control to be established is simple in principle but detailed in its execution. One potentially workable method is as follows:

Each container of a chemical taken from the general stock inventory or received from outside is assigned to a cognizant chemist or technician. The inventory identifies the quantity of chemical and the cognizant individual, and the inventory is flagged to require that the cognizant person be accountable for that chemical at a later time (i.e., return the residual contents, if any, to general stock or present an appropriate reason for keeping it under cognizance until the end of the next succeeding time period). 
At present, one can enter almost any ORNL laboratory and find many different chemical containers that have partially decomposed and still decomposing labels and that are not being tracked by anyone.

Recently ORNL established a system for reviewing all purchase orders to assure that an MSDS is available for hazardous materials. At the present time, approximately 200 purchase orders are reviewed each day. If there is an MSDS available, the chemical may be ordered. If there is no MSDS, the supplier is contacted, and an MSDS is requested. When the hazardous material is received, the MSDS is sent to another ORNL section where it is reviewed for accuracy and completeness, edited, converted to a standard format, and entered into an online electronic database. The information is also entered into the HMIS. Reports can be generated for inventory, SARA Tier2 , MSDSs, and management planning. The system will also identify the area where the hazardous material is located. There are elements of the program that have not yet been completed; however, it is anticipated that the basic system will be implemented by January, 1993. With HMIS and the Accelerated Vendor Inventory Delivery (AVID) system, inventories for hazardous chemicals will be reduced.

This proposed system of inventory control is a positive step, but to be fully effective, it should be expanded to incorporate the inventory control of the chemical containers that are now on hand at ORNL.

\subsubsection{Storage of Chemicals}

The general practice at ORNL is to store chemicals at the location where they are used (i.e., on laboratory shelves). Of all the chemical storage areas examined by Team members, only Building 7666, the RCRA Storage Building where nonradioactive hazardous chemicals await disposal, had a variety of chemicals stored in separate rooms or enclosed bays. Typically, in spaces where a variety of chemicals are stored, ventilation rates of at least six air changes per hour (calculated) should be provided continuously, In the Building 7666 bays, intermittent ventilation is provided only as a way to control temperature, without regard to vapor accumulation or to the exposure of workers entering these enclosed spaces.

\subsection{Industrial Hygiene}

\subsubsection{Industrial Hygiene Program}

IH functions in an advisory and oversight role, but has no apparent enforcement responsibilities. The results of $\mathrm{IH}$ surveillances and program development are given to the line organization (either the Division Safety Officer, Chemical Hygiene Officer, Chemical or HAZCOM coordinator). A division can use the report or program as is or as a basis for developing its own report or program.

Compliance with health and safety standards will still occur and include all requirements of the standard. This is a good practice, but the downside of giving the line organization the responsibility for health and safety program implementation, with no effective check and balance, is that the line 
may not, and usually does not, have the necessary technical expertise. The line is not using the industrial hygienist to review problem safety reports or other health and safety reports such as preliminary hazard reports or SARs.

\subsubsection{Hazard Recognition and Control}

An important element of an industrial hygiene program is the ability to recognize and detect hazardous chemicals in the workplace. An aggressive attempt is being made to minimize the number of chemicals in the workplace, but only minimal efforts are being made to substitute hazardous materials with less hazardous ones.

Several facilities and processes were evaluated to determine if programs are developed sufficiently to properly protect site personnel from chemical hazards. The CSOR Team has inspected facilities that present a potential risk to the working population. Controls have been developed by IH to reduce the exposure risk to site workers from process chemicals.

A comprehensive Health Hazard Survey was conducted by MMES to (1) identify primary operations; (2) determine the hazards in the operation; (3) identify the existing engineering controls and evaluate the need for additional controls; (4) determine personal protective equipment requirements; (5) determine qualitative exposure levels; (6) assign operation identification numbers for computerized tracking; and (7) determine associated sampling requirements. IH retains a record of all comprehensive and periodic survey information via the Occupational Health Information System (OHIS) computerized database. The OHIS database is also used to schedule operations for resurvey. Operations are prioritized according to the priority action code (PAC) assigned to each hazard in each operation. Operations that have the most severe hazards (PAC1) are scheduled first, followed by PAC2, PAC3, and PAC4 operations. After operations are selected and prioritized, health hazard surveys are conducted and data are collected for entry into the OHIS database. The survey results are distributed to the Division Safety Officer for development and implementation of remedial actions, as required.

An area that includes an adequate direct-reading, real-time monitor is the accelerator, Building 6000. The accelerator has a blanket of sulfur hexafluoride contained in a pressurized vessel, which is used as insulation. The $\mathrm{SF}_{6}$ is about seven times heavier than air. If a leak occurs, the change in pressure is not easily measured. ORNL has performed safety analyses and developed emergency plans to protect against leaks. For example, in order to alert the workforce to an $\mathrm{SF}_{6}$ leak, oxygen analyzers have been placed in several areas to measure the decrease in oxygen as a result of the leak. The division has established two setpoints for the alarm system. The setpoint in the area of the accelerator is 19.5 percent; for the general building the setpoint is 16.5 percent. In the opinion of the CSOR Team, the selection of a 16.5 percent alarm level is too close to the oxygen levels at which health effects have been demonstrated. IH has, on several occasions, recommended the setpoint be established at 19.5 percent. 
A well-developed confined space entry program is in place and is administered by IH. All potentially hazardous enclosed spaces are being investigated to determine if they meet the requirements for "confined space," and a sign will be posted on those which meet that criteria. IH reports that the majority of plant confined spaces have been identified and posted.

Facilities are equipped with an appropriate number of safety showers and eye wash stations. Flow alarms have been installed on remote safety showers and eyewashes at the High Flux Isotope Reactor (HFIR) to warn operators of fellow employees who may require assistance in the use of the eyewash/shower or who may require first-aid or other medical treatment.

Respiratory protection training is required for workers in those areas that require the use of respiratory protection. Individuals must first pass a medical physical and be properly fitted for respirator use. Several areas were noted in which engineering controls are needed to minimize respiratory use.

Line management relies upon the $\mathrm{IH}$ section for implementation of the respiratory protection program with the exception of the self-contained breathing apparatus (SCBA). The responsibility for conducting the inspections and performing maintenance of the SCBA is in the Fire Department. The facilities are responsible for the funding for the necessary repairs and periodic hydrostatic testing. During the walkaround Team members noted that several essential SCBAs were tagged-out with a "Danger-Do Not Operate" tag. There was a note on the tag indicating that the units required modification. The Team has determined that the reason they are being taken out of service is that they were due for the upgrade from pressure-demand to continuous-flow refurbishing.

Managers of several facilities were not aware that the SCBAs were going to be tagged-out or why they were being tagged. Some facility managers indicated that, in the event of a release, their SCBAs would not be used. The removal from service of safety equipment, with no replacement, should be regarded as a condition requiring termination of operations. This is a hazard if a critical system is upset and hazardous chemicals are released; there would be no SCBA to use to terminate the release or effect a rescue. These units were tagged-out on June 25, 1992, and many are still out of service. The circumstances surrounding this situation were made known to ORNL management by the Team and not through communication systems relied upon by ORNL.

IH provides technical personnel to assist the line organization in carrying out its safety responsibilities. Among other tasks, IH personnel perform hazardous chemical sampling, area hazardous characterization, and validation of job safety.

IH personnel conduct surveillances for compliance with their plant-level procedures. They have developed industrial hygiene topical areas applicable to ORNL checklists for use during surveillance activities. A review of surveillances applicable to chemical safety indicates that the oversight program is narrowly focused and that it fails to inform management of significant recurring deficiencies.

There is no reporting mechanism that would make upper-level management aware that numerous 
identical deficiencies were being identified by the IH Department. There also is no formal tracking or trending of these deficiencies that could be used as a tool to alert management to similar multiple deficiencies.

\subsubsection{Hazards Communications Program}

A hazards communications program provides information to the worker regarding the safe handling and storage of chemicals. It also includes requirements for labeling chemical containers and provides information on chemical hazards and on the upkeep of MSDS forms in the workplace. An encompassing hazards communication program has been developed and implemented by IH as part of a DOE requirement. HAZCOM requirements of the program include a requirement for maintaining an updated inventory of chemicals in the workplace. It is good work practice to include the posting of inventories of hazardous chemicals in all storage cabinets. Several flammable storage cabinets were inspected in various locations in an attempt to identify inventory postings. However, no posted inventories or quantities of hazardous chemicals were found. Additional efforts are needed to add and update chemical inventories to bring the program into full compliance. The HMIS program may provide this capability. ORNL has done a considerable amount of work in labeling their secondary containers, and, in most cases, labels and hazard warnings were included on the secondary containers found in the process area. All MSDSs that were requested were available, and all hazard classifications were correct, according to the MSDS. In an acid storage room there was incompatible storage of chromic and acetic acid. This was considered a dangerous condition, and the facility was requested to separate the incompatible chemicals.

Personnel at the TSD (hazardous waste storage) facility receive training based on RCRA requirements, which provide detailed training for 29 CFR 1910.120, "Hazardous Waste and Emergency Response," and 29 CFR 1910.1200, "Hazard Communication Standards." A cursory review of the chemicals in storage identified one area that contained explosives and another that contained flammables. The area containing explosives had no explosion-proof equipment or construction.

\subsubsection{Industrial Ventilation}

ORNL developed a methodology to survey the chemistry exhaust systems for the buildup of perchlorates. They developed a five-phase program that:

- Identified hoods that historically and currently use hot perchloric acid.

- Developed safe analytical evaluation procedures and testing methodologies to confirm perchloric acid salts contamination of ventilation systems.

- Conducted testing of 74 confirmed or highly suspect hoods, and conducted random testing of 30 out of 681 low-probability hoods. 
- Analyzed data to determine risks.

- Decontaminated high-risk vent systems for repair and removal, where necessary.

The Team noted that several tanks were equipped with vents. In most cases the vents were atmospheric, and most larger tanks were located outside, so that employee exposure to vented fumes was minimized. In the laboratories, most of the work was being performed within a hood. Ventilation measurements of fume hoods are made on an annual basis.

\subsubsection{Personal Protective Equipment}

The processes requiring PPE were evaluated during the walkarounds. The operating procedures, in general, specify the PPE required for different operations. However, PPE is not always available in the area required, and it is not always in the best of condition. There were no active operations that required PPE during the Team's review.

\subsection{Conduct of Operations}

Assessment of chemical safety in the conduct of operations in workplaces with potential risk to workers from chemical hazards involves an examination at all levels of practices and procedures that govern these operations. Information was gathered at ORNL in the assessment areas of Design and Analysis, Control and Primary Containment, Mitigation of Chemical Accidents, and Chemical Accident Recovery. These assessment areas were selected to represent the successive "levels of defense" commonly used to prevent injury to site and facility workers and the general public and to prevent damage to or loss of government property.

The operating facilities evaluated in this assessment are, for the most part, multipurpose laboratory facilities using chemicals in limited quantities. There are, however, a few larger processing facilities in which bulk quantities of hazardous chemicals are used. Smaller-scale chemical processes are located in laboratory buildings by basic research function, such as high temperature materials, metals and ceramics, etc. Larger-scale process facilities with bulk chemical inventories, including the HFIR, the Integrated Equipment Test Facility, the Holifield Heavy Ion Research Facility, the Process Waste Treatment Plants (radiological and nonradiological), and others, are located in separate, dedicated buildings. Although basic chemical safety and hygiene requirements are common for all areas at ORNL, the specific safety and health requirements and responsibilities for laboratories may vary, depending on the nature of the ongoing experiments, while like requirements and responsibilities for the processing facilities with a relatively constant work mission are reasonably well defined.

To make process refinements and modifications, the Health and Safety staff should assist the facility or building owner in the proper selection and installation of equipment and services. When a single laboratory process or chemical experiment requires the use of more than one chemical, the engineering requirements of the most hazardous should govern the quality of equipment selected or 
the classification of services required (e.g., corrosion-resistant piping for acids/bases or explosionproof electrical service for highly flammable chemicals). Similarly, the use of engineered controls or safeguards (such as containments, shielding, redundant safety systems, and ventilation rates) should be based on the most hazardous chemical in use or planned for use within an individual room of the facility.

The generation of specific, step-by-step operational procedures should be based on an approach that explicitly determines what is required to control chemical hazards. The more severe the estimated consequence of the hazard, the more exhaustive the search for methods to mitigate the hazard should be. Procedures and equipment to minimize the effects of small chemical accidents or spills should consider the most hazardous chemicals that may be present, and the full range of chemical accident scenarios should be considered when developing accident recovery or emergency preparedness procedures. Finally, all workers should be trained and be proficient in practicing hazards awareness or identifying potential hazards in the workplace, and a system should exist to track and correct the hazards identified.

\subsubsection{Design and Analysis}

The continued safety of chemical system operations depends heavily on the degree of rigor and thoroughness used in the initial engineering design and in the selection process used for materials, equipment, and other components. Also, reliance on engineered safeguards, rather than on administrative controls, is a preferred method of preventing catastrophic system failure and reducing risk to both the general public and the workers.

MMES has developed a formal program by which to control the design process at ORNL. The documented program addresses the need for hazards screening, preliminary and final safety analyses, quality assurance, engineering design analyses, design verification, acceptance testing, material certifications, change control in design and construction, formal design reviews, etc. This program, which appears to be developing and improving with use, captures the basic requirements of DOE Order 6430.1A, "General Design Criteria." It is being applied to all ongoing engineering work, but resources are not available to "backfit" design control to the older, nonmodified ORNL facilities. No single document was identified that formally ties the results of the safety analyses (i.e., the inherent risk and consequence of system failure) to either the methodology or degree of engineering effort to be performed or to the level of quality assurance required to verify that the design, selection of equipment and components, and workmanship are of sufficient quality to ensure safety. However, it appears that there is a less formal system in place that relies on several documents to achieve this end.

A significant problem was identified by MMES regarding the application of engineering controls to nonnuclear, chemical-only projects. There is a general consensus within MMES Central Engineering Group that the results obtained using the formal methods for chemical hazard screening at ORNL (i.e., hazards classifications of High, Moderate, Low, or Generally Acceptable) are sound. However, it has also been established by the same organization that the corresponding levels of engineering 
rigor specified by the formal engineering design controls (i.e., factors of safety, analyses of natural phenomena, etc.) are far in excess of those that would be applied by the commercial chemical industry to the same work. Thus, as the hazards screening and engineering control processes are becoming better defined, the application of existing design and construction criteria for chemical-only projects at ORNL is resulting in excessive costs. A thorough evaluation by the Team could not be performed in the time available, but it is evident that a better method of integrating the new hazard classification system with the design criteria needs to be developed by MMES.

In its evaluation of the hazards screening process for many chemical facilities at ORNL, the CSOR Team noted that most of the chemicals were identified as representing a "standard industrial hazard," and a high degree of emphasis was placed on administrative control, rather than on engineered hardware, to prevent or mitigate potential accidents.

During the several brief facility tours, the Team noted that there were many hazards, most of which were of minor consequence, that were not identified by building supervision.

\subsubsection{Control and Primary Containment}

The CSOR Team found that most of the chemical-related process work was governed by written and approved standard operating procedures (SOPs). A brief review of several SOPs showed that they are approved and appropriately controlled with issue dates, expiration dates, and control numbers. Each of the SOPs (1) makes reference to all other associated SOPs' that are needed for clarification or preparation; (2) identifies the permits that must be obtained; (3) defines the equipment needed and the PPE required, as applicable; and (4) integrates the appropriate "Cautions" and "Warnings" into the step-by-step instructions to facilitate proper and safe performance of the work. The SOPs contained limited information and quantitative operating parameters, which indirectly define the limits of "abnormal" and "emergency" operations. This information was included in the operating steps, but was not specifically highlighted or expanded upon to the degree that recovery from the "abnormal" condition would be facilitated or that the operation could be curtailed in time to avoid the "emergency."

It is the general consensus of the CSOR Team that SOPs are not based on completed OSRs or on the limiting conditions of operation (LCOs) that would normally be contained in them. A brief procedures review conducted by the Team could not gage the overall effectiveness of the procedures or determine if the procedural links to existing OSRs and the identified safety systems had been made.

A review of electronic database training records indicated that supervisors and operators have received training in the required general plant safety procedures; applicable health and safety procedures, including general HAZCOM; and hazardous material procedures related to their specific chemical areas. The training record database is immediately available to all managers and supervisors to check current information on the status of operator training and qualifications. 
ORNL facilities acquire many of the high-use chemicals through near just-in-time procurement from the ORNL onsite stores or by direct delivery (e.g., bulk delivery) to storage tanks at the facilities. The facility inventory of these chemicals is minimized through just-in-time suppliers. Smaller quantities of chemicals that are not routinely used at the site $(e, g$, chemicals used for laboratory experiments) are direct-purchased. Basic process chemicals are secured from established sources to consistently meet specifications. Onsite chemical delivery drivers all have valid State commercial driver's licenses, even though this is not yet a firm requirement. Delivery drivers must be trained in HAZCOM procedures and in basic fire-fighting techniques using hand-held fire extinguishers.

Onsite chemical delivery drivers receive the formal copy of the Department of Transportation (DOT) shipping documents, including a listing of the associated material hazards and appropriate emergency responses to be taken in the event of an accident (i.e., essentially, the MSDS information), to carry in the vehicle cab. They are instructed to contact emergency forces in the event of a spill and are to remain near the site to supply this information to the emergency responders. In the CSOR Team indoctrination, it was noted that drivers are expected to perform limited or passive spill control (i.e., placing absorbants around spills to prevent the chemicals from entering storm sewers and other drains); however, they have not received specific training in this activity. Because individual drivers are untrained in passive spill control and may, therefore, misinterpret these informal requirements and receive potentially excessive exposures to hazardous or toxic chemicals, this is a potential programmatic weakness.

In the ORNL Receiving area (Building 7001), the Team was told that all chemical handlers had received adequate training in the control, separation, and handling of hazardous and toxic chemicals (i.e., the basic requirements of 49 CFR). In addition, a dedicated area in Receiving has been established for these chemicals, and appropriate DOT separations information has been posted. Other than inspecting the containers for damage and placing the hazardous chemicals on the dedicated shelves, there appeared to be little emphasis on following the methods prescribed by the training. Acids were found placed on the top shelves or left "hanging over" the edges of shelves in unstable positions. Acids, bases, and other highly reactive chemicals were found to be randomly mixed. It was also apparent that the Receiving area is too small for the volume of materials handled on a daily basis.

Because site-generated chemical waste is under a "Zero Rad moratorium" from DOE, the packaging and handling of site-generated wastes could not be observed by the CSOR Team.

Pressure vessels, pressure piping, storage tanks, and other equipment were observed and found to be in generally good condition, relatively free of corrosion, and well-marked with appropriate labels and chemical hazard "diamonds." The only exception found was on a tank in Building 3544 that had three hazard diamonds: two noting the contents as "Oxy" (oxidizer), with a health hazard rating of 3; and one noting the contents as "Nitric Acid," with a health hazard rating of 4. 
The Team confirmed that pressure relief devices are removed, repaired, and bench-calibrated on an annual basis. However, the Team did not verify that periodic nondestructive examination was being performed on these containments to ensure their integrity.

In operating areas, no major deficiencies were noted in proper handling and storage of hazardous and toxic chemicals in bulk quantities. However, a disparity was evident among individual facilities regarding their acceptance and use of basic chemical safety precautions, such as donning chemical goggles when entering areas of strong acid and base storage tanks. Further, workers in several of the operating areas and laboratories that routinely use chemicals directly from 55-gallon drums and smaller containers were found to be more casual in the control and containment of chemicals. In one laboratory area, the Team observed a 55-gallon drum of solvent (perchlorethylene, a suspected carcinogen) that was fitted with a spigot and drip pan to facilitate routine, uncontrolled use and cleanup. In a small, nonventilated, unposted storage shed (Building 2092) adjacent to the Team's office area, an open 55-gallon drum of DI (2-ethylhexyl) phthalate, a plasticizing agent and suspected carcinogen, was found. Several unstaffed laboratories, which the Team observed before the start of the day shift, were found with randomly placed flammables, such as acetone, nonapproved containers (i.e., outside of approved flammable storage cabinets) on the benches. The Team also noted that an "Acid Only" metal cabinet (a converted flammable storage cabinet with "flammable" markings) with strong acids present had a strong base stored inside.

\subsubsection{Mitigation of Chemical Accidents}

It is clear that ORNL has developed and implemented programs to deal with the mitigation of hazardous and toxic chemical spills and other types of accidents. Relatively well-maintained and drained (of rainwater) secondary containment dikes have been provided for all larger bulk vessels and storage tanks. In a few instances, the Team observed steel 55-gallon drums of hazardous chemicals that had been stored outdoors in corrosion-resistant overpacks rather than on rain collecting "spill pallets." These are positive steps taken to mitigate the consequences of spills. Conversely, in most of the bulk acid-handling facilities visited, none of the acid transfer piping appeared to be equipped with spray shields at flanged connections to prevent personnel exposure at greater distances. In addition, in some cases, positive displacement pumps were used in piping configurations in which the relief devices could inadvertently be isolated, which could cause an acid release with a significantly more severe consequence than a nonpressured leak.

With the exception of the overpacked drums noted above, secondary containment for smaller quantities of chemicals, regardless of hazard or toxicity, has not been provided consistently at ORNL. Some operating areas have been equipped with cleanup kits for spills (i.e., absorbers, etc.), but it was not determined that any specific individuals in such facilities had received the necessary training in their use. There appears to be an adequate supply of PPEs. The Team did not evaluate the adequacy of training in the use of PPEs. 
Site employees receive periodic training in the use of portable fire extinguishers. Generally, both the type selected and the mounting locations of extinguishers are appropriate. There is a requirement for monthly inspection of all extinguishers by the facility or user organizations. These inspections are documented on monthly inspection reports. Annual maintenance is also required and is documented using a new bar-code system and by initialing and dating the tags that are attached to each extinguisher. Although the bar-coding system is currently under development, many extinguishers are approximately 1 month overdue for their required annual inspection and maintenance.

Use of the Occurrence Reporting and Processing System (ORPS) and the followup investigation process at ORNL was briefly evaluated and found to be acceptable. The site has recently started to use the reporting information as the basis for safety and health trending analyses, and a working "lessons learned" program is in place.

\subsubsection{Chemical Accident Recovery}

Because of the nature of ORNL operations, all workers are specifically trained in emergency preparedness. Drills, including realistic mock chemical releases in which both operations and emergency responders are actively involved, are routinely performed.

The Emergency Preparedness Program (EPP) and its development methodology were briefly reviewed and found to be generally appropriate. In a chemical release or other chemical emergency, at least three ORNL response organizations are to be notified, including the Laboratory Shift Superintendent, the Shift Emergency Squad, and the hazardous materials (HAZMAT) Response Team. Both the Laboratory Shift Superintendent and the Shift Emergency Squad are onsite and could arrive at the scene within minutes of the 911 call. The HAZMAT Team may or may not be onsite, and their response may take up to an 1 hour. The Laboratory Shift Superintendent is the designated on-scene Incident Commander. If the chemical event is combined with a fire, or in the event of any fire, the ORNL Fire Department would also respond to the dispatcher's call and arrive at the scene within minutes. The senior Fire Department officer at the scene is the backup Incident Commander.

Members of Shift Emergency Squads have all qualified in an approved "first responder" program and are also trained in rescue and passive spill containment and mitigation (placement of dams and absorbers); however, they are not qualified to fight fires. HAZMAT Team members are trained to the technician level and are qualified for, and equipped with, level "A" protective gear, but are not qualified to fight fires. The Laboratory Shift Superintendent is trained and qualified in hazardous chemical and radiation work and has received training in incident command, but is not trained in fire fighting. ORNL Fire Department personnel have been trained in fire and rescue, and most have chemical and radiation worker training, some to the technician level; however, they have not been provided with level "A" chemical suits. Because each organization is trained and equipped differently, coordinating their efforts at the scene is of paramount importance to successful recovery from a chemical event. Apparently, that level of coordination has been realized during the drills, and members of the response teams are generally comfortable with the plan. However, a potentia! 
weakness in the scheme is that the Laboratory Shift Superintendent has little training or qualification in fire fighting.

Escorts and/or permanently assigned building operations personnel were provided for the CSOR Team tours to ensure that the appropriate actions would be taken and the Team members would be accounted for in the event of an emergency. In most facilities, brief building indoctrinations were provided to the Team before entering the processing or laboratory spaces. These are positive program attributes.

The methodology being used to develop EPPs was evaluated. The results of SAs and SARs, combined with input from facility supervisors and health and safety organizations and from the current chemical and radiological inventories, are used as the bases of the EPPs. Although this seems appropriate, its relative effectiveness depends on the validity and availability of these inputs. At ORNL, the existing hazards screening process, SAs, and SARs for process facilities are still being upgraded and have not been fully validated for accuracy relative to current activities and inventories. The ability of facility managers to produce near real-time chemical inventories and/or lists of other hazards during emergencies, particularly in laboratories and during the backshifts when many buildings are vacated, is questionable. The HMIS is not yet fully effective for chemical inventories, and other hazards may not be noted. Therefore, the EPP methodology and development process at ORNL appears to be acceptable, but the EPPs developed to date may not be fully effective because of the apparent immaturity of the supporting hazards identification programs.

Memoranda of Understanding (MOUs) have been developed with local and state agencies that provide mutual emergency aid. Likewise, an agreement with a local hospital for the emergency treatment of chemically exposed or injured workers has been in effect for some time. These are positive EPP attributes.

\subsection{Management and Operations}

\subsubsection{Management Organizations}

The Team reviewed ORNL management's implementation and oversight of chemical safety and held discussions with all levels of management, from the Laboratory Director of ORNL to first-line supervisors.

Each of the ORNL line and staff organizations performs activities requiring knowledge of chemical safety in day-to-day operations. Hazardous chemicals are used in the performance of research activities in the Associate Directors' organizations that are responsible for Advanced Energy Systems; Environmental, Life, and Social Sciences; Nuclear Technologies; and Physical Sciences and Advanced Materials. In addition, the Associate Director for Operations provides support to ORNL for physical plant operations and support, including material receipt and shipping, waste management operations, maintenance, engineering, fire protection, and emergency response. This support requires individuals 
to work with hazardous materials both routinely and in emergency situations. The Director for Environmental, Safety and Health Compliance provides both technical expertise relative to chemical safety and surveillance functions.

\subsubsection{Management Processes}

The ORNL safety program directs that working-level individuals should be protected from hazards and should follow safe practices when working with chemicals. A process to ensure chemical safety in the workplace has been implemented. This process includes the following elements:

- Establishing employee hazardous material training

- Providing job-site training for the workers involved with chemical handling

- Developing supervisory training courses related to hazardous material training

- Ensuring capable technical support to line organization for chemical handling operations

- Assigning responsibility for field implementation of chemical safety to facility managers

- $\quad$ Providing self-assessment by Division Safety Officers.

The following review and analysis of ORNL starts at the base of the organization and develops each layer of management protection that has been established to ensure that workers are protected against the hazards posed by the handling, storage, and use of chemicals in the workplace.

Those who attend initial general employee training receive hazards communications training to ensure that they understand the types of chemicals to which they may be exposed, how to use MSDSs to identify safety concerns, and appropriate protective actions. In addition, employees working directly with hazardous chemicals receive both a 4-hour training course and on-the-job training specifically addressing chemical safety. Included in this training are the precautions related to operations involving the use of acids, caustics, poisons, and carcinogens.

The content of the hazardous materials safety training course was designed to meet OSHA-mandated requirements. The specific content and quality of this training were not evaluated in detail during this review. However, MMES interviews and introductory presentations indicate that the required content of the training would meet the OSHA requirements.

The training process has three programmatic weaknesses. The most significant of these is that the training programs that have been developed to meet the requirements of OSHA do not provide an adequate level of information on the physical tasks of handling, storage, and disposal of chemicals being used at ORNL. This was evident during facility tours and interviews with individuals at each level of the organization. Although the training describes the hazards and protective equipment related to chemical safety, the content of the training does not provide the indepth practical knowledge needed by the worker to safely perform the handling, storage, and disposal tasks required. 
Secondly, because the job-specific training provided by supervisors is informally administrated, some organizations document the training and others do not. Of the organizations reviewed, only the training program developed by the supervisor for the Hazardous Waste Storage Facility approached what is considered to be an adequate job-specific training program. The documentation of training at the Hazardous Waste Storage Facility provides evidence that the training performed covers topics that have improved the staff's awareness of how to safely deal with the hazardous materials they are required to handle. The ORNL process does not ensure that job-specific training is documented in all organizations. This is considered a weakness because when training is being performed, but not documented, there is no evidence to demonstrate that the training is occurring. Conversely, when training is not being performed, management has no indication of the deficiency.

The last training issue identified is that there is no assurance that all individuals who should receive the training have been identified, since not all positions at the facility have been evaluated to determine training needs.

Supervisors are responsible for ensuring that: (1) workplace hazards are identified; (2) workers are trained; (3) PPE is available to the workers; and (4) workers perform the required tasks safely. To accomplish their assignments, supervisors must be able to identify chemical safety hazards in the workplace, know when and how to obtain matrix support from industrial hygiene and safety professionals in other organizations, and be able to apply the basic supervision skills that are necessary to direct and ensure the safety of their staff. As discussed above, the training program at ORNL does not provide the supervisors with the information needed to perform this task. Because this deficiency constitutes a common-mode failure in the system, there is no assurance that chemical safety hazards will be consistently identified by the supervisors, Facility Managers, or Division Safety Officers at ORNL.

Training is critical to the performance of the implementation of chemical safety in the operations organizations, since the supervisor must make the determination to request industrial hygiene or safety reviews. It was clear that individuals in the Waste Management and Remedial Action Division are effectively using industrial hygiene and safety professionals; however, this was not generally the case in other organizations the Team visited.

There is heavy reliance in the management systems at ORNL upon the decisions made by supervisors. If supervisors are ignorant of specific chemical safety issues, they are likely to fail to identify hazards or the need to use industrial hygiene support. This deficient condition was demonstrated at ORNL when two supervisors did not recognize that a hazard existed when they were confronted with equipment clearly labeled as containing excessive amounts of PCB. Other indicators of training deficiencies may be demonstrated by surveillance findings of noncompliance issues, by directly reviewing the training for individuals involved in the operation, or by observing safety practices during routine operations.

Chemical safety support is provided by safety specialists and industrial hygienists. These staff members are available, upon request, to assist supervisors in reviewing and developing workplace 
processes that ensure chemical safety for both long-term projects and single tasks. These individuals have the training and qualifications to provide professional consulting support to the line supervisors and managers. By procedure and memoranda of agreement, these services are provided when the line organization requests them; however, it was not evident that these internal organizations are being used effectively by many of the line organizations.

Facility managers are middle-level managers who usually report to the Division Directors and have line responsibilities that include facility safety. These managers are responsible for ensuring that safety policies are being implemented in the workplace. The chemical safety training requirements for these individuals are similar to those of the supervisors; consequently, the same deficiencies that applied to the supervisors apply here. However, discounting the content issues, the amount of training received varies from division to division. A training needs analysis has been performed for the Chemical Technology Division, and, although training development plans have not been completed, the process being developed by this division is proactive.

Facility managers generally have not achieved the desired level of chemical safety in their areas. Some potential reasons for this are the diversity of the facility managers' other line responsibilities, deficiencies in individual training, or facility managers not identifying chemical safety as a significant issue. At ORNL, chemical safety varies widely from location to location as described in other sections of this report. However, it was noted during the walk-through tours of ORNL facilities that implementation of chemical safety principles tends to be more effective when RCRA requirements apply in the workplace.

The Division Directors have been assigned the responsibility for ensuring chemical safety in the workplace for the employees in their division. This responsibility normally has been carried out by delegating to facility managers and providing broad guidance related to safety. The Division Directors review and approve the SARs for facilities in their division.

Although, a proactive management approach to identifying trends in chemical safety was not observed, the Associate Director for Nuclear Technologies demonstrated strong management of issues while he was Director of the Metals and Ceramics Division. He performed a review of Occurrence Reports to identify an undesirable trend in radiological contamination controls and used the capabilities of Central MMES auditing organizations to help him identify the root cause of the contamination control problems in his division. One consequence of this review was that his line management became more aware of issues related to radiological controls and improved their performance. There is no reason why use of this type of management process could not be applied to chemical safety issues at ORNL.

The Associate Laboratory Directors at ORNL are organized by functional areas as discussed in section 3.7.1. They provide policy direction to the Division Directors in their respective organizations. The need to improve chemical safety programs was recognized by the Associate Laboratory Directors interviewed. Commitment to chemical safety was demonstrated in the Environmental, Life, and Social Sciences Associate Director's management systems. There was clear 
understanding of the issues related to chemical safety, and the Associate Director's safety objectives were provided in writing to the Division Directors. The Associate Director has also implemented internal management performance tracking systems to monitor the progress of division safety goals, and there was awareness of chemical safety issues in the organization. This management focus was reflected by the quality of chemical safety implementation within the Environmental, Life, and Social Sciences Division.

\subsubsection{Management Involvement In Chemical Safety Processes}

Managers at all levels should have effective methods in place to determine whether the requirements for chemical safety are being met. This includes: (1) management by walkdown (as part of the conduct of operations activities); (2) periodic inquiries as to the status of established performance objectives and criteria; (3) use of tracking and trending data; and (5) continuing input from audit programs. Important results should be communicated both vertically and laterally in the organization.

Chemical safety at the ORNL plant is not a separately administered program. The mechanisms for assuring safe management of hazardous chemicals are embedded in existing management systems, industrial hygiene and other topical area programs, and facility operating procedures. MMES has developed a generic HAZCOM and chemical hygiene plan that was intended to comply with both the HAZCOM standard and the OSHA laboratory standard. The generic plan, which was reviewed and judged to comply fully with the OSHA requirements, was applied through two division-specific plans (Chemistry and Chemical Technology). However, effective implementation is another matter. There is no requirement or mechanism at ORNL to have the chemical hygiene plans reviewed and approved by a qualified, independent industrial hygienist. In addition, there is no requirement that a division's plans must comply with 29 CFR 1910.1450. In all events, effective implementation depends on vigilant oversight by line management, with the active support of a qualified chemical hygiene officer. The requirements of the OSHA laboratory standard and the additional requirements under the process safety regulation were, with a few exceptions, unrecognized by the managers interviewed.

The ability to show compliance with OSHA requirements (whether for laboratories, for the process systems in large waste treatment systems, or for other facilities) is largely lacking; a cross-check between actual programs and procedures and applicable OSHA criteria is not specifically required by ORNL managers. In addition, there is no evidence of effective management controls over day-to-day operations to assure good chemical safety practices. Lower levels of line management are relied upon to implement general ES\&H programs and procedures. In this context, considerable variation was found in line management capabilities and effectiveness. There were examples of outstanding and progressive management, with resultant controls over chemical hazards. In other cases, safety and health organizations and senior management did not appear to provide needed support to assure that performance met expectations.

MMES management has undertaken several ambitious programs that will lead to improved handling of hazardous materials, including chemicals. These programs include taking measures related to 
greater formality in operations, developing a new hazardous material inventory system and a program to assess the hazards posed in existing operations, and performing varying levels of safety analyses, depending upon the hazards at each facility. Presumably, improvements related to conduct of operations will provide immediate and substantial improvement in management of all risks, including hazardous chemical risks. Chemical inventory data can be used to devise new programs to reduce the quantities of chemicals onsite to those actually needed. In addition, information from safety analyses might be used to determine the appropriate controls to be imposed upon each facility; specifically, the combination of DOE Order requirements and OSHA regulations appropriate to each facility class that need to be incorporated into policies, procedures, and programs.

The ES\&H Coordinating Committee provides a forum for senior management to consider important issues in areas relating to chemical safety. This is an important contribution to the laboratory management of hazardous chemicals. Based upon a review of meeting minutes, the Team determined that the Deputy Laboratory Director has taken positive and decisive steps to assure that selected issues are reviewed, Laboratory-wide, including a recent inquiry as to vulnerabilities for chemical accidents at all ORNL facilities.

A monthly report, "Management Indicators," is also provided to senior managers. This report contains information on a variety of topics, including occurrences and injuries. However, the report does not contain specific information on chemical safety, such as progress on reducing quantities of chemicals or the number of compressed gas cylinders onsite. The use of this report is uncertain.

To determine the nature of the issues being observed during self-assessments, the 1990, 1991, and 1992 programs for the Metals and Ceramics Division were reviewed. Chemical safety deficiencies were identified in self-assessments that were performed in each of these years. The process used in Metals and Ceramics included developing performance elements, criteria, and lines of inquiry prior to performing the surveillance. Both compliance issues and programmatic root causes were identified during these assessments. Distribution of the results included all members of management in the line from the principal researcher to the Laboratory Director and his Assistant Laboratory Director. Deficiencies that were identified during these self-assessments include MSDS database system availability; asbestos-identification program weaknesses; training deficiencies related to carcinogens in the workplace; chemical safety training deficiencies, including failure to provide consistent training; and lack of training documentation. The self-assessment performed at the Metals and Ceramics Division appears to be self-critical and performed as intended in Secretary of Energy Notice (SEN) 6E. No verification of the corrective actions system was performed. Management followup on identified deficiencies indicated that none of the identified items has been closed out; however, significant progress has been made on three of the four issues identified.

In general, responsibility for compliance with chemical safety requirements was said to be managed at the Director level. The feedback mechanisms to ensure that each Division Director did, in fact, comply with requirements were dependent upon the individual characteristics of the respective 
Associate Laboratory Director; other mechanisms to assure effective performance did not appear to be effective.

With some notable exceptions, the Associate Directors do not routinely monitor performance in this area. IH provides ORNL Division Directors with generic procedures and plans (e.g., a "model" Chemical Hygiene Plan, that was intended to comply with the OSHA laboratory standard). Such generic products are developed in conjunction with the MMES central support organizations and generally include input from all MMES organizations. The Division Directors are responsible for ensuring that these generic plans are translated into plans and procedures appropriate to specific facilities.

There appears to be wide variation in performance. Some facilities, such as at the Waste Management Handling Area, the Steam Plant, and the Nonnuclear Process Area reflected substantial management interest and attention. The housekeeping and operational setup at other facilities evidenced a lack of involvement by management.

Where there is not a strong manager assuring chemical safety, it appears that the management system will not obtain timely or useful information about chemical safety. IH performs surveillances of chemical safety operations and provides reports to management about observations, but apparently makes no attempt to enforce correction of any findings of deficiencies. Failure to correct deficiencies will not be observed until the next surveillance, generally the following year. Based on the small sampling of operations and on interviews, the Division Safety Officers and Chemical Hygiene Officers may not have the needed skill base to be effective in a decentralized, matrixed organization. Communication upward to senior management does not appear to effective, in any case.

In summary, the surveillance process does not assure that programmatic issues (root cause) are identified when compliance issues are found, as indicated by the following:

- Information may not be used by management.

- Corrective actions are not being pursued.

- Poor housekeeping is left uncorrected.

- $\quad$ Easily observed deficiencies are not seen by most management and are not always communicated to a high-enough level.

Again, some managers have taken steps to avoid these situations, and their operations show care and attention to actions that promote workplace safety. Although MMES is to be commended for undertaking many new initiatives that will benefit ES\&H performance, the management of change at the division level is not effective. Requirements are identified in support organizations and followthrough is not always performed in line organizations. 


\section{Appendix A--Biographies}



NAME:

Robert W. Barber:

AREA OF RESP: Team Leader

ASSOCIATION: Department of Energy

EXPERIENCE: $\quad 35$ Years, Department of Energy (DOE), Office of Environment, Safety and Health (EH)

Director, Office of Risk Analysis and Technology

- $\quad$ Manager DOE's oversight of nonnuclear safety programs, transportation and packaging, and the resolution of safety deficiencies at DOE facilities.

- Led the development and implementation of DOE nuclear safety program following the Three Mile Island, Unit 2 accident, including multidiscipline safety appraisal program.

- Managed the design, construction, and operation of several Atomic Energy Commission (AEC) nuclear facilities, including the Loss of Fluid Test Facility.

- Managed the interrelationships between two new Federal agencies: the Energy Research and Development Administration (ERDA/DOE) and the Nuclear Regulatory Commission (NRC).

- Managed complex nuclear projects involving numerous participants and organizational relationships.

- Managed multifacility, multidiscipline safety and health program, and led multidiscipline technical staff in the resolution of engineering, safety, and health issues.

Analyzed complex safety and health problems to determine root causes and corrective actions.

EDUCATION: $\quad$ B.S., Chemical Engineering and Chemistry, Tufts University

OTHER: Oak Ridge School of Reactor Technology

Federal management courses, including the Federal Executive Institute

Charter Member, Federal Senior Executive Service 
NAME:

Delbert Bunch

AREA OF RESP: Management and Organization

ASSOCIATION: $\quad$ Management Strategies, Inc.

EXPERIENCE: $\quad 30$ Years, Westinghouse, North American Aviation, USDA, USDOE, USNRC, and private consulting

- Chemical pesticides research, investigating impact of pesticides, and their control.

- $\quad$ Environmental R\&D investigating and consequences of accidental releases of hazardous materials.

- $\quad$ Safety and risk analysis of nuclear and nonnuclear facilities.

- $\quad$ Safety engineer for plutonium facility.

- $\quad$ Program manager, responsible for safety and siting of major DOE projects.

- $\quad$ Senior manager at USNRC, including development of safety and siting criteria, development of resource management strategy for licensing reviews.

- Senior manager at DOE, including positions as Deputy Assistant Secretary for Safety, Health, and Quality Assurance, and as Principal Deputy Assistant Secretary for Nuclear Energy.

- Management consultant, providing expertise in risk-based resource management, performance improvements management, and program strategy development.

EDUCATION: $\quad$ B.A., Chemistry, Whitman College

J.D., University of Florida

L.L.M., University of Florida 
AREA OF RESP: Industrial Hygiene

ASSOCIATION: Cassady Safety and Health Services, Inc.

EXPERIENCE: 27 years

Cassady Safety and Health Services, Inc.

- Testimony in toxic tort litigation and as expert on engineering controls.

- $\quad$ OSHA-type Safety and Health Audits.

- Occupational Safety and Health Program Development.

- $\quad$ Program Reviews and Development.

National BioSystems, Inc.

- Testimony in toxic tort litigation and as expert on engineering controls.

- $\quad$ OSHA-type Safety and Health Audits.

OSHA Health Response Team - Director

- $\quad$ Performed industrial hygiene field investigations and engineering controls.

- $\quad$ Criteria Document development.

Kennecott Copper Corporation

- Develop hygiene prograrn, performed industrial hygiene field surveys, and reviewed engineering controls.

National Lead Company of Ohio (Fernald)

Monitored decontamination activities, developed water monitoring program; and conducted plant surveys.

EDUCATION: $\quad$ M.S., Industrial Hygiene, University of Cincinnati

B.S., Biology/Minor Chemistry, Ft. Lewis College, Colorado

OTHER: $\quad$ Certified Industrial Hygienist

Clinical Faculty, University of Utah

Advisory Board, University of Utah 


\begin{abstract}
AREA OF RESP: Process Safety Management
ASSOCIATION: US DOE Headquarters

EXPERIENCE: 10 years

USDOE, Office of Occupational Safety, Division of Technical Support
\end{abstract}

- Occupational Safety and Health Manager. Responsible for development of technical guidance documents in the area of occupational safety. Program Manager in the development of tools for DOE-wide implementation of the Process Safety Management standard published by the Occupational Safety and Health Administration (OSHA).

- $\quad$ Participate in safety appraisals and progress assessments.

- $\quad$ Provide interpretation of OSHA standards.

USDOL, OSHA, General Industry Compliance Assistance

- $\quad$ Safety Engineer. Responsible for the development of a Directive for National Emphasis Program "Petrochemical Special Emphasis Program (PETROSEP), giving directions to compliance personnel in conducting compliance inspections at petrochemical facilities.

- $\quad$ Provide interpretation of OSHA standards and develop directives interpreting the performance based OSHA standards.

- Conducted various chemical plant inspections assessing chemical process safety.

- $\quad$ Conducted several workplace accident investigations involving chemical releases and explosions.

West Virginia Department of Natural Resources, Division of Hazardous Waste Management

- $\quad$ Chemical Engineer. Reviewed Part B applications for RCRA facilities.

- $\quad$ Participated in the development of State Hazardous Waste Management Regulations.

Ohio State University, Department of Mathematics, Graduate Teaching Assistant.

Assumed full duties of a mathematics instructor.

EDUCATION: M.S., Chemical Engineering, Ohio State University, Columbus, Ohio (1982);

B.S. Chemical Engineering, Osmania University, Hyderabad, India. 
NAME:

Michael Lloyd

AREA OF RESP: Chemical Process Safety

ASSOCIATION: Battelle

EXPERIENCE: $\quad 11$ Years

- Process Safety Management. Development corporate policies and procedures for compliance with DOE Orders governing safety analysis, configuration management, and independent safety review.

- $\quad$ Prepared safety analyses for several DOE facilities. Author of numerous project and facility safety assessments.

- $\quad$ Toxic Release Risk Analyses. Developed procedure for assigning DOE Hazard Level Classification to facilities by utilizing dispersion modelling of inventories of toxic materials (focusing on uranium compounds).

- $\quad$ Conducted PHAs and FMEAs as a subfunction to preparing DOE SARs and Safety Assessments.

- $\quad$ Received DOE certification as an Accident Investigator (AI). Participant in several accident investigations.

- $\quad$ Participated in the development and operation of a DOE contractor Emergency Operations Center. Developed emergency procedures for DOE multi-use manufacturing facility. Audited compliance to emergency procedures.

- $\quad$ Member of DOE-wide team which developed and taught a DOE Headquarters course "Chemical Process Hazards: Analysis and Incidents for DOE facility representatives.

EDUCATION: $\quad$ B.S., Chemical Engineering, Tri-State University, 1981 M.S., Candidate, Environmental \& Industrial Hygiene, University of Cincinnati, College of Medicine (Dept. of Environmental Health)

OTHER: $\quad$ Member, AIChE Safety and Health Division Member, Systems Safety Society 
NAME: $\quad$ Debby K. Myler

AREA OF RESP: Coordinator/Report Preparation

ASSOCIATION: $\quad$ EG\&G Idaho, Inc.

EXPERIENCE: $\quad 4$ Years

- $\quad$ Coordinator for Quality Assurance Audit at the Idaho National Engineering Laboratory (INEL). Finalized all preparations for audit team members - security, briefing meetings, information packets, reference library, etc.

- Coordinator for the INEL/RESL Quality Assurance Inspection and Nuclear Safety Inspection Team. Coordinated preparation for, collection of, and finalization of report.

- $\quad$ Administrative Specialist for NRC Operator Licensing Support. Perform personnel actions, assemble personnel/program hours and input into tracking system, originate/update personnel training plans, coordinate records inventory.

- Maintain DOE Compliance database for Information Resources Department.

- $\quad$ Administrative support for Nuclear Reactor Research and Technology (NRRT) Department Surveillance Program.

EDUCATION: $\quad$ Various night courses with Idaho State University Numerous computer and work-related courses with EG\&G Idaho, Inc. 
NAME:

AREA OF RESP: Chemical Engineering Principles; Hazard and Risk Analysis

ASSOCIATION: Battelle, Pacific Northwest Laboratory

EXPERIENCE: 19 Years

- $\quad$ Group Leader, Risk and Safety Analysis.

- $\quad$ Project manager, task manager, and technical contributor to numerous risk and safety analyses of energy related systems including nuclear reactors and fuel cycle facilities; nuclear waste facilities; chemical waste facilities; and chemical facilities.

- $\quad$ Preparation of safety analysis reports (SAR) for DOE nuclear and chemical facilities at Hanford.

EDUCATION: $\quad$ M.S., Chemical Engineering, University of Washington

B.S., Chemical Engineering, Carnegie Mellon University

OTHER: 
NAME: $\quad$ John Stone

AREA OF RESP: Conduct of Operations

ASSOCIATION: Kaiser Engineers Hanford (KEH) detailed to USDOE EH-30

EXPERIENCE: $\quad 23$ Years, professional engineering in design, construction and operations management, consulting, and program management.

- Program Manager, KEH, temporarily assigned to DOE-Germantown to help develop safety assessment programs, evaluate contractor safety performance and proposed corrective action plans; resolve compliance issues, and conduct site safety assessments.

- $\quad$ Principle Design Engineer, KEH, manager multi-discipline nuclear related design projects, and performed detailed mechanical design analyses.

- $\quad$ Engineering Design Consultant, petroleum, petroleum chemical, pulp and paper, and inorganic chemical operations.

- Plant Production Supervisor, inorganic chemical operations.

- $\quad$ Plant Engineer, project and maintenance management and engineering responsibilities for inorganic chemical operations.

EDUCATION: $\quad$ B.S. Mechanical Engineering, Washington State University, Pullman, Washington

OTHER: $\quad$ Member, American Society of Mechanical Engineers

Registered Professional Engineer, Montana and Washington 
NAME: $\quad$ Dennis S. Walters

AREA OF RESP: Operational Safety and Regulatory Analysis/Assessment of Industrial Health and Safety Program Management ,

ASSOCIATION: Battelle, Pacific Northwest Laboratories

EXPERIENCE: $\quad 25$ Years

Battelle, Pacific Northwest Laboratories

- $\quad$ Industrial Health and Safety Consultant. Safety Performance Assessment Program.

Westinghouse Electric Corporation

- $\quad$ Operations Manager/Safety Director, Waste-to-energy plan (1,300 tons per day).

Portland General Corporation

- $\quad$ Manager, Corporate Safety, Industrial Hygiene, and Occupational Health.

- Corporate Member, Industrial Safety and Health Committee for North American Electric Light and Power Association.

Trojan Nuclear Power Plant

- Supervised control and electrical engineering.

- Coordinated design changes.

- $\quad$ Supervised material control and warehouse.

- $\quad$ Engineer in plant control and electrical engineering.

Naval Undersea Warfare Engineering Station

- $\quad$ Technical manager for Miniature/microminiature Electric Repair Program.

- $\quad$ Training, Supervisor, Torpedo Repair Depot.

EDUCATION: Senior Reactor Operator Certification

B.S., Electrical Engineering, University of Washington

B.A., Mathematics, University of Washington 
NAME: Jay A. Young

AREA OF RESP: Chemical Laboratory Safety

ASSOCIATION: Independent Consultant, Chemical Health and Safety

EXPERIENCE: $\quad 50$ Years

- Chemical consultant specializing in the safe manufacture, use, precautionary labeling, proper handling, and appropriate disposal fo chemicals used in industry, the household, and the laboratory (1980-).

- Chemical consultant in international trade and in trade secret litigations; deposes and/or testifies as an expert witness (for plaintiff or defense) in litigations involving chemical reactions and product liability (1980-).

- Manager of Technical (Safety) Publications for the Chemical Manufacturer's Association (1977-1980)/

- $\quad$ Professor at King's College, Pennsylvania for many years and was a Visiting Professor at Carleton University in Ottawa. Taught for 7 years in the Southeastern United States and was associated with the ISIS project at Florida State University (1949-1977)

- Safety consultant for various industrial concerns, academic institutions and technical publishers (1980-).

EDUCATION: $\quad$ B.A., Chemistry, Indiana University (1939)

M.S., Physical Chemistry, Oberlin (1940)

Ph.D., Physical Chemistry, Notre Dame (1950)

OTHER: $\quad$ Editor of "Improving Safety in the Chemistry Laboratory,"

Wiley-Interscience (1991)

Author of "Chemical Reactions," in the Encyclopedia

Britannica (1974-1991)

Chairman of the American Society Division of Chemical Health and Safety (1985).

Founding Member of the American Conference on Chemical Labeling (1980). 


\section{APPENDIX G - Chemical Safety Oversight Review (CSOR) TRIP Report of Lawrence Livermore National Laboratory (LLNL)}




\subsection{SUMMARY}

A Chemical Safety Oversight Review (CSOR) of the Lawrence Livermore National Laboratory (LLNL) was conducted by a Department of Energy (DOE) Team from the Office of Environment, Safety and Health (EH) during the period July 27, 1992, through July 31, 1992. The purpose of the LLNL CSOR was to review chemical processes and chemical use and storage on a limited sampling basis, with the focus on high-hazard/high-risk processes and activities and their potential risk to workers within a facility and co-located workers. The principal objective of the review was to identify significant management, programmatic, or technical deficiencies in chemical safety that may be indicative of DOE-wide safety deficiencies that may require prompt action by $\mathrm{EH}$ and the line organizations. The eight-member Team also compiled observations and descriptions of LLNL chemical safety programs and activities as part of a long-term EH chemical safety oversight program to gather data that could be used to determine the need for technical assistance or additional guidance in this area.

No significant safety deficiencies in chemical safety indicating DOE-wide problems posing imminent danger to workers, the general public, or the environment were identified by the Team. A number of observations were recorded for integration into the longer-term $\mathrm{EH}$ review of workplace chemical safety.

The review found that chemical safety at LLNL is addressed through a variety of activities, both formal and unstructured. Chemical safety is managed through both dedicated and integrated requirements manifested in programs, plans, processes, procedures, training, and management.

The Team noted several significant efforts that had been made at LLNL to improve safety and health in response to findings from the last Tiger Team visit. These included appointing Assurance Managers, updating the Chemical Hygiene Plan and Chapter 2 of the LLNL Health and Safety Manual, conducting self-assessments, and tracking noted deficiencies to completion. There has been notable development in general hazard and safety analysis processes, including those for chemical safety, and further development is ongoing or planned. A chemical inventory database is under development. The Team observed severall effective chemical safety practices; however, inadequate progress is being achieved in assuring that these practices are transferred and implemented throughout the laboratory.

Accountability and ownership of chemical safety issues have been addressed and responsibilities have been assigned through functional managers, building managers, and activity managers; however, implementation varies with the managers. While hazards are considered in site development planning, ownership seemed to "end at the fence," in some cases. Impacts on or from adjacent facility operations were not recognized in some instances. Many managers receive training in safety and health; however, the training is somewhat inconsistent in quality and omits some important areas of the safety and health manual. Skill and experience levels of key managers also vary widely. As a 
result, there is not consistent understanding and implementation of safety and health requirements by these managers.

The implementation of the assurance function and environment, safety and health (ES\&H) teams is a significant development in achieving independent and objective reviews of safety at LLNL. Compared to systems at other laboratories, the assurance function and the ES\&H teams perform in more of a facilitation or expert-support role. Chemical safety program quality varied from organization to organization, and was strongly correlated with the manager's interest and abilities. Technical support is available within each organization or can be matrixed from other organizations. Several organizations had especially competent staff assigned to key positions for implementing safety and health programs. The experience and background of these key employees are especially important at LLNL, compared to other sites where the processes for safety reviews are more structured and centrally controlled than LLNL's matrix system. Significant discretion is given to Associate Directors (ADs) and division heads in the application of rules, guidelines, and best management practices beyond mandatory compliance with prescribed standards and local, State, Federal, and University of California regulations.

Generally, LLNL has placed a significant emphasis on its conduct of operations since the Tiger Team visits. The CSOR Team observed that ongoing experimental projects are conducted under carefully reviewed facility and operational safety procedures. It was noted, however, that some operations with inherently high hazards/risks were being performed without detailed step-by-step procedures that defined the system safety parameters or the limiting conditions of safe operations. The formal lockout/tagout program at LLNL is not fully consistent with DOE best practices. In many cases, supervisors and managers did not "walk the spaces" in their own work areas or buildings or in the areas that surround them.

The Emergency Preparedness Program was well-planned, although real-time chemical inventories in consistent formats are needed to support emergency responders. Chemical laboratory safety and industrial hygiene are generally well-founded; however, in some cases, facility-specific plans may be necessary to effectively address all hazards. Chemical hazards (e.g., toxicity, flammability, corrosiveness) were generally addressed for systems, processes, and laboratories. Operators, however, were seldom aware of what specific external events (e.g., load drop, wrong chemicals, vehicular impact) could impact safety. Chemical systems generally incorporated worker safety considerations into their design. Seismic detailing was especially noteworthy throughout LLNL.

LLNL has achieved notable development in addressing all risks, but chemical safety, is not as yet developed, managed, analyzed, or supported to the same degree as radiological safety. This is true even when, in some cases, the actual risks are greater. In the face of projected budget constraints, LLNL is looking for means to improve safety in general without requiring additional expenditure of resources. Discussions with several LLNL managers and review of their prioritization processes indicate that this would be done by eliminating or deferring low-priority tasks, rather than by devising more cost-effective strategies for improvement. 


\subsection{INTRODUCTION}

LLNL is operated by the University of California under contract with DOE and is managed by the San Francisco Field Office (DOE/SF). Founded as a nuclear weapons design laboratory in 1952, LLNL is now a multiprogram, mission-oriented institution engaged in basic and applied research programs that require a multidiscipline approach. The main facility covers 821 acres and is located in Livermore, California. A larger, isolated site is used for high explosive testing, research, and development.

The LLNL CSOR is one of five accelerated reviews being conducted as part of the EH Workplace Chemical Accident Risk (WCARR) program, as outlined in the Paul L. Ziemer to the Secretary Action Memorandum of April 3, 1992, "Establishment of an Office of Environment, Safety and Health Chemical Safety Oversight Task Group to Review Department of Energy Workplace Chemical Safety Programs." These reviews are being conducted to identify any significant deficiencies in chemical safety that have DOE-wide implications and that may require prompt actions by $\mathrm{EH}$ and the line organizations.

The CSOR Team's principal efforts were focused on investigating chemical systems and chemical use and storage to (1) identify significant chernical safety deficiencies; (2) assess their risk significance, particularly to workers within facilities and co-located workers; and (3) determine their relevance and importance to chemical safety DOE-wide. General public and environmental impacts were also considered.

In pursuing the primary investigations critical to short-term chemical safety concerns, the Team investigated the overall aspects of chemical safety at LLNL, including special strengths and vulnerabilities, and compiled additional information germane to EH's long term WCARR program. The thrust of the CSOR was on information gathering and analysis, not on compliance.

The details of the Team's review efforts, including observations and descriptions, derived concerns and findings, recommendations, and notes on compliance items, are documented in Section 3. Some compliance items related to Occupational Safety and Health Administration (OSHA) regulations, DOE Orders, and LLNL procedures were identified and have been conveyed to appropriate contractor personnel. These items are discussed in the body of this report.

The LLNL CSOR was conducted in accordance with the EH Office of Safety and Quality Assurance (EH-30) Protocol for Chemical Safety Reviews (Draft, April 15, 1992), using the companion Lines of Inquiry (Draft, April 1992) and the recently drafted Lines of Inquiry Suitable for Application to Chemical Laboratories (Draft, July 6, 1992).

The CSOR Team, under the direction of a DOE Team Leader, was composed of eight DOE staff and consultants with expertise in various aspects of chemical safety, including: process safety 
management; industrial hygiene; hazards, safety and risk analysis; management and operations; and chemical laboratory safety. Biographical sketches of the Team members are provided in Appendix A.

The Team looked at defense-in-depth for chemical systems and processes, as well as for chemical use and storage, including design and analysis, control and primary containment, mitigation of chemical accidents, and chemical accident recovery. The Team reviews included walkdowns and examinations if process systems and laboratories, observation of ongoing activities, document and procedure reviews, interviews, and general program reviews. Appendix B provides a list of facilities visited by the Team and identifies LLNL personnel from each major area participating in or providing general input into the review process.

The majority of the Team's effort was devoted to process, system, and facility walkdowns; verifying system and equipment functions; and ascertaining the application of industrial hygiene, process safety review, safety procedures, and safety analysis to the systems and processes for protecting workers within facilities and co-located workers, the general public, and the environment.

The Team met with management and technical representatives from the major areas reviewed onsite in an initial, general meeting and in meetings and discussions held before each area walkdown. Individual and small group meetings and discussions were also held, and interviews of key personnel were conducted by Team members.

At an exit meeting on Friday, July 31, 1992, the Team reviewed the results of the CSOR, and a copy of a draft trip report was provided to DOE/SF and the University of California.

\subsection{DISCUSSION}

The CSOR Team review of the LLNL chemical safety program and practices was intended primarily to investigate any chemical safety deficiencies and identify any significant deficiencies with DOE-wide implications. In the course of the review, routine findings and understandings of chemical safety at LLNL evolved and were documented. Discussions and descriptions of the Team's review efforts are summarized below. The Team's observations reflect experience related to DOE and other Federal requirements, industrial standards and good practices, and lessons learned from other DOE programs and activities.

\subsection{Chemical Hazard and Risk Analyses}

The CSOR Team examined the hazard and risk analysis systems related to chemical safety and their use at LLNL facilities. The chemical source terms that could be released from containment, methods used to identify chemical hazards, and methods used to determine potential consequences to the receptors were evaluated. The Team also reviewed methods used to analyze hazards controls and the 
consequences from catastrophic accidents/releases to the employees within a facility and co-located employees. Impacts on the general public and environment were also considered.

\subsubsection{Hazard Classification}

Chapter 2 of the Health and Safety Manual contains guidelines for facility classification based on DOE Order 5481.1B. The guidelines were updated in March 1992 by the issuance of a new, draft guidance document from Headquarters. In the past, facilities were classed as high hazard (reactor and nonreactor), moderate hazard, low hazard, or excluded. These classes are now being modified to correspond to Category 1, 2, 3, and 4 ( 4 being the lowest hazard), but the process will not be completed until the new guidance document has been formally approved by Headquarters. Currently, LLNL has 3 high-hazard facilities, 90 moderate-hazard facilities, 84 low-hazard facilities, and 465 excluded facilities. In the past, the Safety Analysis Document (SAD) and Environmental Safety Assessments methods have been used to classify facilities.

Recently, a new hazard classification method was developed using an adjusted PLG Hazard Classification method. This method was used to determine hazard class and candidates for Operational Safety Requirements (OSRs) or inventory limits (e.g. 251 Building, March 27, 1992), and a conservative approach was used to calculate releases. LLNL developed their own evaluation criteria, based on permissible exposure limits (PELs), while waiting for guidance from DOE. LLNL is now implementing a method recommended by the Office of Defense Programs (DP) ("Hazard Classification of DP Facilities" memorandum, June 2, 1992), which is based strictly on inventory levels. Under this system, chemical facilities with chemical quantities above the threshold quantities in Appendix A of the Process Safety Management Standard (Title 29 of the Code of Federal Regulations [CFR] 1910.119) would be classified as Category 2 facilities. Facilities with chemical levels above the release quantities in 40 CFR 302, and with less than Category 2 levels, would be classified as Category 3 facilities. LLNL is in the process of reclassifying their facilities based on this new approach.

\subsubsection{Hazard Identification}

Discussions with LLNL personnel indicate that various procedures are used to handle or analyze hazards, ranging from referencing the facility safety procedures (FSPs), which generally contain a section listing potential hazards, to referencing operational safety procedures (OSPs). The OSPs describe controls in more detail and list procedures directly related to controlling the hazards of a specific operation. LLNL personnel understood that the OSPs are to be completed prior to startup of a new operation that goes beyond the approvals and limits in the FSP.

A new safety review process, including a "Hazardous and Radioactive Materials Table," has been developed at LLNL that includes reviews of hazardous conditions, potential consequences, required controls, and safety procedures (Health and Safety Manual, Chapter 2, Appendix 2-A). Use of this process will be mandatory in March 1993, but it is currently being used on a limited, voluntary basis. 
The Team noted that the process had been used appropriately for Building 241, Oil Shale Facility, as a part of the FSP. The CSOR Team did not observe the process in use when visiting other LLNL facilities.

ES\&H teams are assigned to each program. A health and safety technician, who is assigned by each facility or group of facilities, is a member of the Hazard Control Team (HCT). These teams are often called upon to analyze operations and hazards. Gas Yard management recently requested an ES\&H team to perform a hazard assessment that is currently in the review stage. The CSOR Team did not review this assessment.

Chemistry (827) at the 300 Site uses a "Chemistry Job Summary For Explosives" approval process for every operation, even if it is a repeat procedure. These reviews include approvals by the ES\&H Team Leader and by explosive safety experts. This process includes multiple management and technical reviews and approvals. Areas reviewed include material composition, compatibility, toxicity, thermal stability, spark sensitivity, and impact sensitivity.

Material Safety Data Sheets (MSDSs) are available throughout the site. Lists of chemicals are often posted or available at the entry to the areas (rooms, storage buildings, or racks) that contain them. At one outside storage rack (Building 141), each chemical was listed with its hazard designation (corrosive, flammable, oxidizer, etc.) This practice should make it easy for workers to assess inventories and follow up on inconsistencies in storage (Building 141). A standard hazard-warning poster marked with the hazard classification of the material in the room or area was displayed in rooms where chemicals are stored. At the entrance to the chemical use area in Building 222, the FSP, applicable OSP, emergency instructions, and the chemical inventory list (which includes the quantity on hand) were available.

\subsubsection{Analysis/Documentation}

Current programs and documentation at LLNL include OSPs, FSPs, Engineering Safety Notes (ME Department), SADs, and safety analysis reports (SARs). The FSP and OSP are designed to evaluate the risk at the job site, while the SAD deals with the bounding safety envelope. If the safety controls are covered in the FSP, an OSP is not needed. FSPs are to be updated every 3 years, and operational changes result in either a supplement to the FSP or an OSP. The level of approval for the OSP is based on the level of hazard (Appendix 2-D, Health and Safety Manual).

As a part of the LLNL Tiger Team Corrective Action Plan commitment to develop and update SARs, LLNL is currently finalizing the schedule for the SAR upgrade. In effect, this upgrade will phase out the present program, which uses the SAR for moderate- and high-hazard facilities and the SAD for low-hazard facilities. Current internal guidance is found in the "Safety Analysis Guide," Supplement 6.06 of the Health and Safety Manual, which was issued in September 1988 (stemming from DOE Order 5481.1B and SAN MD 5481.1A), and in those portions of Chapter 2 in the Health and Safety Manual related to the SAD. 
Engineering Safety Notes are developed as a result of the OSP review process and deal primarily with high-pressure hazards. The engineering department calculates pressures and establishes inspection and testing schedules. They also perform the seismic calculations to assure that any new equipment or operation will be installed according to seismic requirements. High-pressure setups (over $300 \mathrm{psi}$ ) are designed and installed by certified engineers.

Safety analyses were available onsite for two of the facilities visited by the Team. Personnel at other facilities indicated that a safety analysis had been completed but was not available at the site or could not be found at the time, which demonstrates that the safety analysis is not in frequent use at these facilities. A 1981 SAD (300 Area Building 834) reviewed by the Team identified bounding accidents, considered external issues, and quantified the release consequences of the bounding accidents. A 1988 SAR (300 Area Building 825, 826, 827-UCID-21416) included explosion, fire, industrial, and industrial hygiene issues, but contained only a minimal review of external hazards and no quantitative release analysis.

The Team reviewed both final and draft SADs. The final SAD (Building 693, February 1992) included a variety of scenarios and considered external events, such as cold temperatures, earthquakes, and extreme winds. The SAD also described the bounding safety envelope of credible consequences, determined facility hazard class, and demonstrated that accident consequences and associated probabilities provided an acceptably low level of risk (used to calculate maximum acceptable inventory levels). The Emergency Prediction Information (EPI) code (Gaussian dispersion) was used to calculate release levels, and Emergency Response Planning Guide (ERPG) levels were used as criteria to evaluate the postulated releases. A draft SAD (Laser Demonstration Facilities Complex, March 1992) contained an evaluation of the consequences of maximum releases, fires, or explosions of ethanol and $\mathrm{CFC}-113$ to determine the facility classification, the operating basis accidents (OBAs), and the risks associated with OBAs. The maximum releases were calculated and compared with the classification criteria. Another SAD was developed by a contractor for the Materials Management Area. The EPI code was used to develop release concentrations with inventory limits established. The accident scenarios were based on maximum quantities of material and resulted in no OSRs. These 1992 safety analysis processes, which are designed to ensure that quantitative safety analyses are consistently performed, are much improved over the earlier process.

The program areas are responsible for developing the SARs (or SADs in the past). The Criticality and Safety Analysis Group exercises oversight by reviewing the safety analysis; however, they do not develop the SAR.

Interim analysis of hazards will be performed by the ES\&H team (formerly the Hazard Control Team) assigned to the facility. Documentation of these analysis efforts may be found in a memorandum to file, a log book, or the Deftrack system (a tracking system for recommendations or deficiencies). These records were not reviewed by the CSOR Team. The health and safety technicians, who are assigned to and resident in the facilities and have daily contact with facilities personnel and operations, monitor operational changes and problems. 
Facilities personnel understand that the FSP forms the basic safety envelope. If there is a deviation from the safety envelope, an OSP will be developed prior to startup.

In the site Environmental Impact Statement, the bounding accident was a 100-pound chlorine release. In interviews, the Team learned that several of the facility managers were aware of this bounding scenario and considered it as the bounding accident for their facility.

It appeared that some significant hazards have not been evaluated. This is illustrated by the full "hydrogen skid" (approximately 30,000 cubic feet) in the 600 Tanker Yard. This skid was adjacent to the entrance of the Wood Scrap Yard and the inner fence for the site boundary. There was an accumulation of combustible materials underneath and adjacent to the hydrogen skid. Trees in the boundary buffer area are also adjacent to the hydrogen skid. A fire in this buffer area (adjacent to Greenville Rd.) would involve the hydrogen skid. Also, if the Wood Yard is involved in a fire, the temperature of the hydrogen tanks could be raised through radiant heat, which could burst the tank valves supplying hydrogen to the existing fire and result in a vapor cloud explosion. Apparently, the ES\&H team for the area had evaluated this hazard or a similar issue related to propane, but the CSOR Team did not receive or review any documentation related to their analysis or implementation plans.

\subsubsection{Compressed Gases}

Where compressed or cryogenic cylinders are subject to vehicle damage, poor maintenance, or damage from falling, there is the possibility of a chemical release or cylinder projectiles that could injure employees onsite or the public offsite.

A number of deficiencies were noted with regard to compressed and cryogenic cylinders:

- Storage racks with unsecured restraining bars-sliding/swinging bar

- Smaller cylinders, some toxic or corrosive, with no provision for securing in outside storage areas

- Some incompatibility in outside storage sheds

- Storage of cylinders on pallets unsecured on their side

- Storage of compressed gas and cryogenic cylinders adjacent to vehicular traffic areas without sufficient physical protection

- Rusty cryogenic cylinders.

\subsection{Chemical Laboratory Safety}

Generally, operating activities at LLNL are expected to meet proven and accepted practices and requirements to assure chemical safety. These include, but are not limited to, the National Research Council's "Prudent Practices for Handling Hazardous Chemicals in Laboratories." As a best practice, all workers should be trained to recognize and report occupational safety hazards, and facility managers should be held accountable for the tracking and correction of the noted hazards. In 
laboratories, researchers should take ownership of the workspace, the various chemicals used, and the waste produced. They should also take responsibility for the safety of their activities, including the safety of others who share the building space. The laboratory managers should be held accountable for assuring that such ownership and responsibility are taken.

The HCT at LLNL assists supervisors and employees in maintaining safe work areas by providing information on the hazardous properties of materials and relevant regulations, recommending methods of control, and monitoring the work environment.

LLNL supervisors are responsible for ensuring that the laboratory employees wear appropriate personnel protective equipment (PPE) while performing their jobs. Most employees observed were wearing appropriate or authorized PPE during performance of their duties.

Housekeeping in most laboratories and storage room visited by the CSOR Team was orderly and clean. Flammable liquids were stored in flammable liquid cabinets.

\subsubsection{Chemical Hygiene Plan}

Title 29 CFR 1910.1450, "Occupational Exposure to Hazardous Chemicals in Laboratories," became effective May 1, 1990. This regulation requires laboratories engaged in the use of small quantities of hazardous chemicals to have a written Chemical Hygiene Plan (CHP) and a Chemical Hygiene Officer (CHO) to provide technical guidance in the development and implementation of the plan. A CHP plan should cover safe laboratory work practices and procedures, control measures to reduce employee exposure to hazardous chemicals, performance of fume hoods and other protective equipment, and employee training and information.

LLNL has designated an industrial hygienist to serve as the CHO for the site. A sitewide CHP has been developed by a Health and Safety Committee and is partially implemented. Because the plan lacks facility-specific information, FSPs are currently being updated to include this information. However, LLNL is providing job-specific training to laboratory workers and supervisors.

\subsubsection{Hazardous Materials Inventory}

The current inventory system at LLNL appears to exist in a variety of formats, ranging from handwritten hardcopies to computer database files; therefore, a separate chemical inventory is maintained for each laboratory. Carcinogens have been identified, and in most cases, quantities are known. LLNL facilities are attempting to minimize their inventories. Efforts to control quantities of chemicals include an "excess chemicals" program to allow the transfer of excess chemicals to facilities that have a need for such chemicals and an active hazardous and toxic chemical substitution program.

A sitewide automated system using bar codes is planned for the future. This system is expected to provide chemical identity, quantity, and location. 


\subsection{Chemical Process Safety}

The primary elements of process safety management include technology, personnel, and facilities. The CSOR Team's observations in these areas are outlined and discussed below.

\subsubsection{Technology}

An ongoing chemical process safety program should assure current, complete documentation of process design and operating parameters and procedures; current, complete documentation of information relating to the hazards of materials and process technology; periodic assessment and documentation of process hazards and implementation of actions to minimize risks associated with chemical operations; and management of changes to chemical operations to maintain or enhance the safety of the facility.

\subsubsection{Process Technology/Process Safety Information}

All processes should be reviewed continuously and upgraded for safety and efficiency. For hazardous processes, new systems or techniques should be sought to increase inherent safety. Also, processes requiring or producing fewer numbers or smaller quantities of hazardous process materials, intermediates, byproducts, and wastes should be sought.

Discussions with facility personnel revealed the numbers and quantities of hazardous and toxic chemicals onsite are being reduced. For example, the size of LLNL gas inventories are being reduced, and empty containers are returned to the Building 518 Compressed Gas Supply and Distribution area. In addition, chlorine is no longer stocked in the area.

A sitewide surplus chemicals exchange program allows chemicals that are no longer needed at one facility to be obtained and used by another facility instead of purchased new. The extent of implementation of this program was not verified by the CSOR Team.

A study is underway at Site 300 to find a less hazardous solvent to substitute for the trichloroethylene (TCE) used in Building 834. In addition, a new laboratory program has been funded in the Nuclear Chemistry Division to examine the substitution of less hazardous chemicals in processes currently using highly toxic materials.

The most common risk-reduction methods implemented at LLNL are administrative controls, such as limits on quantities of hazardous materials permitted within a facility. These controls rely on the knowledge and compliance of all personnel interacting with the chemical processes.

In general, the CSOR Team found that individual facilities at LLNL vary significantly in the attention given to chemical safety. Staff at some facilities were exceptionally cognizant of the hazards posed by the chemicals in use, while staff at other facilities were not aware of all the relevant chemical 
hazards. For example, staff at the Gallium Arsenide Laboratory, Building 166, and at the new Microfabrication Laboratory, Building 153, were able to describe and explain their toxic and flammable gas handling systems and procedures in intricate detail. On the other hand, at the LASER Dye Operations, Buildings 490 and 492, some staff seemed to have only superficial understanding of the indications and hazards associated with an alcohol fire, which could lead to confusion in their choice of appropriate emergency responses.

While there are good practices at some facilities, LLNL lacks consistent, effective, sitewide chemical safety practices. At some facilities, specific practices were poor. For example, the CSOR Team found that all poison gases in active use at LLNL were safely maintained within environmental cabinets. However, many containers that were not hooked up were often unrestrained and/or stored with other incompatible hazardous gases, such as flammables, corrosives, and pyrophorics.

While most facilities have some kind of inventory, no real-time, sitewide chemical inventory exists for LLNL, and some facilities do not maintain current chemical inventories. For example, Building 151 , the main facility for the Nuclear Chemistry Division, does not maintain a current database inventory that defines the quantities of chemicals on hand, and no real-time inventories exist for the individual laboratories within the building. LLNL is developing a computer-based chemical tracking system, CHEMTRACK, but the schedule for full implementation of the system appears uncertain because of the need to develop additional operating software. Although the CSOR Team noted that a plethora of commercial software is available for maintaining chemical inventories and that such inventory systems are already in place at other DOE laboratories, LLNL was unable to find a program that meets their bar-coding requirements.

Examples of valves and piping with inadequate labelling were observed in several facilities. For example, at the Building 492 LASER Dye Operations Pump Facility, high pressure valves were not tagged for identification. In addition, the ethanol-fill and load-out connections for the Pump Facility, which are nearly identical in appearance, are not labeled, and there are no arrows or other indications as to which way these valves are opened or closed.

The ES\&H Suggestion Program is an example of a program initiated by Plant Engineering to increase awareness of ES\&H issues within LLNL. The program solicits suggestions from staff for protecting the environment, improving job or workplace safety, and eliminating needless health risks. The CSOR Team did not verify the effectiveness of this program.

\subsubsection{Process Hazards Analysis/Process Hazards Reviews}

Hazards analyses should be conducted as early as possible, preferably in the design stage of any process, to identify, eliminate, protect against, or mitigate potential process hazards. In addition, periodic hazards reviews should be conducted for existing facilities, especially if process changes or upgrades are under consideration. 
Hazard analyses must reflect actual operating practices, as opposed to ideal behavior. The individuals operating a facility should participate in assessing its hazards of operation. The advantages of using their knowledge is twofold. First, the staff, themselves, become more aware of the hazards associated with equipment and operations; second, the resulting hazards assessment incorporates the interfaces between the equipment and operations and operations personnel. Insight may be gained for both normal operations and accidents or process upsets.

The system of facility hazard classification at LLNL is discussed in detail in Section 3.1, Hazard and Risk Analyses. Hazards analysis as it relates to chemical process safety is discussed below.

Discussions with facility management revealed that new sections have recently been added to Chapter 2 of the LLNL Health and Safety Manual to aid in hazards identification and risk reduction and to assure a more unified approach to dealing with process and systems hazards. This chapter, which deals with work planning, safety procedures, and management oversight, now includes a matrix and a process for identifying the hazards, potential consequences, surveillance, controls, and training associated with any system or process. The matrix can be completed for new or existing facilities or processes. Its use will become mandatory in March 1993; however, at present, use of the matrix is voluntary. The Hazards Control Department was unable to provide a completed matrix to the CSOR Team.

The Site 300 High Explosives Facility, Building 827, was the only LLNL facility visited by the CSOR Team that has a full SAR describing its safety envelope. However, the accident analysis includes only minimal review of external hazards, and the release analysis is qualitative in nature.

Some LLNL facilities have completed SADs. The SADs are generally qualitative in nature, and, by present day DOE standards, most are somewhat deficient in hazards and safety documentation. However, the SAD for the Site 300, Building 834 area, prepared in 1981, does contain a quantitative accident analysis that considers external hazards and quantifies the release consequences of the bounding accident.

For the most part, SADs at LLNL do not function as working safety documents. Not all facilities that have SADs have them immediately available for reference. For example, SADs are not available at the Liquid Waste Treatment Facility, Building 514, or the LASER Dye Operations, Buildings 490 and 492. Facility personnel were often unable to describe the accidents postulated in their SADs.

LLNL is currently reviewing the need to prepare SARs and other safety documents for its facilities. The criteria used for determining the level of safety documentation needed for any given facility are discussed in Section 3.1, Hazard and Risk Analyses.

FSPs and/or OSPs are available for most facilities. The FSPs define the safety envelope for their respective facilities. Work outside of this envelope is permitted within a facility contingent upon the 
implementation of one or more OSPs. The role of FSPs and OSPs in evaluating facility hazards and risk is discussed in Section 3.1, Hazard and Risk Analyses.

\subsubsection{Operating Procedures and Safety Practices}

Safety manuals and operations manuals and/or standard operating procedures (SOPs) in written form should exist for all processes. In addition, management should promote safety consciousness and good practices, and safety awareness and good housekeeping should be evident at all levels.

Chemical safety is based more on area management than on a sitewide program with responsibilities common to every manager. Most programs and managers at LLNL do not exhibit a proactive attitude toward safety or emphasis on best practices. Ownership of hazards or poor practices recognized during walkarounds was often relegated to another "responsible" organization or function. Followup by Team members indicated little communication between organizations. For example, in the main laboratory facility for the Nuclear Chemistry Division, Building 151, several cylinders of methane are manifolded together (two manifolds that feed a common supply header). At each installation, several cylinders are valved open and only one pressure regulator is in place, so that all open tanks are equalized in pressure. Although this practice may facilitate system operability by alleviating the need to valve-open full cylinders periodically, the consequences of failure of one cylinder or connector would be compounded by the release of a larger amount of gas from all open cylinders. The CSOR Team questioned the building manager about the need to manifold so many cylinders together, especially with stiff tubing rather than flexible tubing, and to valve-open more than one or two at a time. The building manager responded that the methane was a laboratory utility for which Plant Engineering was responsible. While the system setup met acceptable practice, and had been reviewed for OSHA compliance, it did not reflect best practices, and the building manager did not feel responsible for a potential hazard located in his facility because the system was assigned to another group.

Outside Building 166, the Gallium Arsenide Laboratory, the CSOR Team found a full bottle of flammable gas strapped to a pallet lying prone on the edge of a transportation corridor. Facility personnel explained that the gas is delivered from the Compressed Gas Supply and Distribution Area by the site Transportation Division. Although it is the responsibility of the requesting facility to properly store materials upon arrival at the drop points, the building staff indicated that facility personnel are not notified of deliveries and must check the delivery area periodically.

In the same area are several three-sided compressed gas storage sheds. Instead of chains, these sheds have metal restraining bars for tanks. Most of these bars are loose and inadequate to restrain large tanks; one is mounted upside down. Four small bottles are entirely unrestrained. Facility personnel explained that the sheds are laboratory issue and better facilities are unavailable. A similar explanation was offered by facility staff for the external tank storage area at Building 131 in the Mechanical/Electrical Engineering area. Here, poor restraints were observed for large gas containers, 
and small containers were unrestrained. This hazard is exacerbated by the storage of flammables, toxics, corrosives, poisons, oxidizers, and pyrophorics within the same shed.

The 600 Area Tanker Yard, which stores large quantities of flammable materials, is located next to a wood scrap yard and about 100 yards from a public access road. Scrap wood with nails, metal pipes and bars, and other litter pervades the yard, increasing the risk of a transportation accident. A large, full hydrogen trailer is stored within a short distance of a large pile of scrap wood, creating the potential for escalating a simple fire into an explosion.

Discussions with personnel revealed that SOPs are available for most processes. LLNL sitewide Health and Safety Manuals were also available at all facilities when the CSOR Team requested them. The extent and adequacy of the SOPs, the LLNL Health and Safety Manual, and other working safety documents was not verified by the CSOR Team. The limited number of SOPs that were reviewed were general in nature. The sitewide Health and Safety Manual is adequate from a chemical perspective.

\subsubsection{Management of Change}

A formal, integrated process should exist for initiating and accommodating changes in facility and equipment design and process operations. All changes should be documented; facility diagrams and/or process piping and instrumentation diagrams (P\&IDs) should be updated; operations and safety manuals, maintenance schedules, and SOPs should be updated; and personnel should be trained or retrained in a coordinated and timely manner.

In general, management of change at LLNL addresses facilities and operations rather than processes. A site planning committee meets periodically to consider facility use and to review operations in new facilities to assure that they are compatible with the proposed facility classification. A more detailed description of this procedure and an evaluation of its status is presented in Section 3.5, Management and Operations. Changes in processes to reduce risks are discussed below.

Hazards analysis for modified operations are managed by the Hazards Control Department. The ES\&H Team Leader initiates a review and identifies those safety groups that should participate. New or modified operations are reviewed to determine if they fit within the safety envelope defined by the FSP. If so, the operations are approved, and no further analysis is required. If not, a formal OSP is written, to which Engineering Safety Notes may be added. No separate chemical hazards analysis process appears to exist at LLNL, and discussions with facility personnel did not reveal a plan to develop a formal process to document chemical process changes.

Changes to existing facilities to reduce risk should be based on engineering analyses and should incorporate best engineering practices. For example, the location of detection, monitoring, and warning devices depends on where releases are likely to occur, where personnel are likely to work, 
and the amount and direction of ventilation. Also, the need for redundancy within any given system depends on the reliability of the equipment and instruments within it.

The installation of detection and alarm or warning systems can reduce risk. For example, at Site $\mathbf{3 0 0}$, Building 834D, vapor sensors have been installed to detect TCE. However, facility personnel do not know at what concentration the sensors are set to alarm, nor does the safety documentation cover this area. The sensors are tested by holding a rag soaked in TCE under them. Also, the sensors alarm in the facility control room in Building 834. There is no alarm or warning light on the outside of Building 834D near the door. A sign on the outside of the door reads "Hazardous Area. Do not enter if you smell TCE." A warning light on the outside of Building 834D would reduce the risk of accidental personnel exposure to TCE.

LLNL has a sitewide incident reporting system. There is no sitewide policy requiring individual facilities to maintain records of incidents, and the CSOR Team found that most facilities do not do so. Facility-specific incident databases, as well as the sitewide chemical incident database, are not widely used to enhance chemical safety onsite. DOE's Occurrence Reporting Process System (ORPS) did not appear to be used to help identify accident causes.

\subsubsection{Personnel}

An ongoing chemical process safety program should assure identification of the skills and knowledge necessary for each employee to perform his or her job; establishment of procedures and work practices for safe operating and maintenance activities; training for all employees to reach and maintain proficiency in safe work practices and the skills and knowledge necessary to perform their jobs; demonstration and documentation of skill proficiency prior to employee assignment to independent work, and periodically thereafter; establishment of programs to assure that employees are fit for duty; and provisions that contractors either have programs for their own employees or are included in the company's programs.

\subsubsection{Emergency Planning and Response/Incident Reporting and Investigations}

A formal, written emergency response plan should exist, and both onsite and appropriate offsite personnel should be trained to respond to accidents, including releases, fires, explosions, and natural disasters.

From a worker-safety perspective, if an individual is overcome in a chemical release, he or she must be rescued quickly. First responders must be able to don appropriate $P Y E$ and enter the affected area with instruments appropriate to assess the release situation in minutes. In addition, facility managers must be able to tell the first responders quickiy what potential hazards they might encounter. Complete and current chemical inventories for individual laboratories, as well as for entire facilitie or buildings, are needed to provide this function. 
Emergency evacuation procedures for LLNL facilities are documented. However, as site visitors, generally under escort in hazardous areas, CSOR Team members were not briefed onsite emergency signals and response, including how to exit the site either during emergency evacuation or after hours. Again, as escorted visitors, the Team received neither emergency evacuation briefings nor other appropriate operation- or facility-specific safety briefings upon entering the site or process facilities, except at Building 222/241, Chemical and Materials Sciences, where they were briefed on chemical safety prior to laboratory walkthroughs.

Discussions with facility personnel revealed that there is a fully equipped fire department within the LLNL site. Personnel within the fire department are all trained as "first responders." In addition, a trained hazardous materials (HAZMAT) Team and a full complement of HAZMAT supplies and equipment are available to respond to any releases of hazardous materials. Emergency response providers are fully trained to respond to all types of emergencies, including medical emergencies.

All site emergencies are directed through the Fire Department. As necessary, an on-call Laboratory Emergency Duty Officer can activate a larger central Emergency Management Center (EMC). A more detailed discussion of emergency response operations at LLNL is presented in Section 3.5, Management and Operations. This section addresses, in greater detail, emergency response needs from a chemical hazards perspective.

Planning and execution of emergency response drills enhance personnel awareness of potential process hazards and the severity of possible consequences. Chemical initiators for an emergency response drill are seldom used to help increase the awareness of chemical hazards at LLNL. No local drills for chemical emergencies were noted by the CSOR Team.

\subsubsection{Training and Performance}

All personnel should be appropriately and fully trained in both job and process safety and emergency procedures. This area is addressed in detail in Section 3.5, Management and Operations. Training and performance, as they relate to chemical process safety, are discussed below.

Training requirements for LLNL personnel have their bases in Federal and State regulations; DOE Orders; and facility, process, and specific job needs. Performance-based training appears to be in the beginning stages of implementation at the site. Discussions with facility managers revealed that job task analyses have been performed for only one facility visited by the CSOR Team (i.e., the Liquid Waste Treatment Facility, Building 514).

The CSOR Team found that complete records of formal, classroom training and job qualification records are available for staff at several of the facilities visited, including the Liquid Waste Treatment Facility and the Explosives Facility, Building 827 at Site 300 . At other facilities, however, documentation of job qualification and on-the-job training was lacking. 
The indications that personnel at LLNL are concerned with chemical process safety concepts varied widely at LLNL. For example, at the LASER Dye Operation Pump Facility, staff seemed unconcerned that high pressure valves are not tagged for identification. In contrast, tagging of valves within the Building 241 Refractory Materials Oil Shale Facility was thorough and complete.

With respect to bottled gases; at the Site 300 , Building 834 area, helium tanks were found unchained, prone, on a pallet on a slope, and within a few inches of a roadbed. CSOR Team members observed a garbage truck pass within 2 to 3 feet of the bottles. Even within the Building 518 Compressed Gas Supply and Distribution area, dewars extended beyond the storage area protected by vehicle guards. Indeed, throughout the site, large gas storage tanks, including large cryogenic tanks, are adjacent to transportation corridors and are unprotected from vehicle accidents.

Also, within the Building 518 Compressed Gas Supply and Distribution area, waste gas sheds that contain toxic and flammable gases do not have internal door handles. Because they impeded the closing of the shed doors, the handles were removed when shelving was installed in the sheds. It is possible that facility personnel might be trapped inside the sheds.

There is a flammables storage shed at Site 300 , behind Building $827 \mathrm{C}$. Inside placement of chemicals is problematic. Although most chemicals were packaged in Department of Transportation (DOT) approved containments or were provided with limited-volume secondary containment, the containers are stacked, and incompatible chemicals are stored above one another (e.g., oxidizers above nitromethane and next to kerosene).

Two gas cylinder storage sheds behind Building 131, the Mechanical and Electrical Engineering area, contain unrestrained gas cylinders. Flammables, toxics, poisons, corrosives, oxidizers, and pyrophorics are stored together precariously.

In the LASER area behind Building 166, a flammables cabinet with a "Mutagenic and Toxic" label contains not only propanol and other flammable (nonwaste) chemicals, but also hazardous waste and rhodamine dyes that are toxic and mutagenic. The cabinet was not locked.

\subsubsection{Facilities}

An ongoing chemical process safety program should assure consideration and mitigation of the potential safety effects of expansions, modifications, and new facilities on personnel and the offsite public; facility design, construction, and maintenance using sound engineering practices consistent with recognized codes and standards; safety reviews for all new and modified facilities during design and prior to start up; documented maintenance and inspection programs; sufficient layers of protection through technology, facilities, and personnel to prevent escalation from a single failure to a catastrophic event; and provision for control of processes and equipment during emergencies resulting from natural events, utility disruptions, and other external conditions. 


\subsubsection{Mechanical Integrity}

The mechanical integrity of all process equipment, piping, vessels, and tankage should be maintained through a formal, written plan and schedules for inspections, testing, and maintenance. Written procedures should exist, and maintenance personnel should be trained. Logs should be maintained for all surveillances, inspections, calibrations, tests, and maintenance work. In addition, new equipment should be verified as meeting design criteria and standards.

CSOR Team observations revealed that the integrity of most process systems was adequately addressed and maintained. However, the adequacy of testing and maintenance programs was not verified by the Team.

Discussions with facility personnel that focused on mechanical integrity were limited (e.g., Oil Shale Facility, Site 300 facilities). Where discussions focused on materials of construction, appropriate materials were normally in use.

\subsubsection{Prestartup Safety Reviews}

There is a formal process, including Operational Readiness Reviews and Management Prestart Reviews, for reviewing the safety of new processes and facilities or existing processes and facilities that have undergone significant modification. Representatives at one relatively new facility did not reveal an awareness or understanding of this process. Instead, they described a different process in which Plant Engineering is responsible for the development and review of proposed new facilities and modifications to existing facilities and design safety standards guide the design process. Sign-off reviews by the Hazards Control Department are the mechanism to assure that chemical safety needs are adequately considered. The alternate process described is not necessarily inadequate to assure readiness, but its use, in lieu of the formal program, illustrates a programmatic deficiency at the site.

Discussions with facility personnel revealed that ES\&H evaluations address facilities and operations rather than processes. If the hazards identified in the ES\&H evaluation fall outside of the safety envelope defined in the FSP, they may trigger engineering reviews from the perspective of both safety and operations, the development of Engineering Safety Notes, and/or the development and implementation of OSPs. A more detailed discussion and evaluation of the development of Engineering Safety Notes is presented in Section 3.5, Conduct of Operations.

\subsection{Industrial Hygiene}

\subsubsection{Industrial Hygiene Program}

The Hazard Control Department consists of the Health and Safety Division and the Operational Safety Division. The IH Group is located within the Safety and Health Division. The Operational Safety Division consists of seven multidiscipline HCTs. The IH Group supports the HCTs by providing the 
necessary industrial hygienists to serve as team members. When an industrial hygienist is assigned to a team, approximately 90 percent of his/her time is spent supporting team activities. The IH Group also develops policy and procedures for the Health and Safety Manual, FSPs, and OSPs.

Inadequate staffing of the IH Group and among the health and safety technologists has resulted in the inability to perform all of the necessary periodic sampling required by industrial hygiene programs. Additionally, not all IH staff had the security clearance necessary to access all areas of facilities under their responsibility. Therefore, periodic sampling is not always performed at the proper intervals.

\subsubsection{Hazard Recognition and Control}

A critical element to the reduction of risk in industrial hygiene programs is the ability to recognize and detect hazardous chemicals in the workplace. To assure hazards are identified, regular walkthrough surveys are conducted by industrial hygiene technicians at LLNL. The HCT industrial hygienists evaluate the operation to determine the hazards and exposure levels; identify the existing engineering controls and determine the need for additional controls; determine the necessary personal protective equipment; and determine sampling requirements.

Several facilities were evaluated to determine if programs are developed sufficiently to properly protect workers from chemical hazards. The CSOR Team inspected facilities that presented a potential risk of chemical exposure to the working population. Controls measures were developed by the HCT to reduce the chemical exposure risk to the employees. In most cases, dedicated, directreading monitors were provided in facilities where highly toxic materials were found.

An aggressive attempt is being made to minimize the number of chemicals in the workplace, and where possible, efforts are being made to substitute hazardous materials with less hazardous ones.

Facilities are equipped with an appropriate number of safety showers and eye wash stations that are required to be checked monthly by the technicians. Almost all toxic chemical handling takes place in laboratory hoods or glove boxes, which minimizes the potential for employees exposure. All laboratory hoods receive a quarterly smoke test and an annual full-performance test.

LLNL has made a concentrated effort to provide employees with proper protective equipment for laboratory use. Where no data exist for a chemical, the IH Group has the ability to test various types of equipment and provide the laboratory with the most protective type. Respiratory protection training is required for those employees who are required to wear respirators. Employees must be fittested to ensure proper fit.

A well-developed confined space entry program is in place at LLNL. All potentially hazardous enclosed spaces are being investigated to determine if they meet the requirements for confined space, and a sign is posted on those which meet the criteria. The majority of the facility confined spaces have been identified and posted. 


\subsubsection{Hazard Communication Program}

A hazard communication program provides for the transmittal of information to the worker regarding the chemicals used in the workplace. A comprehensive hazard communication program includes requirements for MSDSs, labeling and other forms of warning for chemical containers, and worker training regarding chemical hazards and protective measures. An encompassing hazard communication program has been developed and implemented by the IH Group.

An aggressive effort is being made to obtain MSDSs for all chemicals used at the LLNL. When a chemical is received in Central Supply, it is not transferred to the user until the accompanying MSDS is received. The IH Group has a full-time MSDS clerk that has access to thousands of MSDSs electronically and, when requested, provides facility users with the most up-to-date MSDSs. In cases of an emergencies, MSDSs can be telefaxed to the user. This computerized system is not sitewide and is not provided on a 24-hour basis. Therefore, most chemical users keep several hardcopies of pertinent MSDSs on hand. A sitewide computerized MSDS system is planned for the near future.

Storage cabinets and areas were inspected in various facilities visited during the tour for proper labeling and warning information and for inventory posting with quantities. In most cases, the information was found.

Hazard communication training consists of generic as well as job-specific training. As part of the training program, a number of training aids have been developed, including specific courses for specific hazardous substances (e.g., lead, beryllium, and hydrogen fluoride); commercial pamphlets on right-to-know; posters describing how to read an MSDS; a hazard material identification guide; and information on the safe storage of chemicals. After training, line supervisors reinforce the requirements outlined in the hazard communication program.

\subsection{Conduct of Operations}

Assessment of chemical safety in operations with potential risk to workers from chemical hazards involves an examination at all levels of practices and procedures that govern operations. This is particularly true of many of the chemical operations at LLNL, which are batch operations or which include several sequential, manually performed steps. Information was gathered in the assessment areas of Procedural Controls, Control and Primary Containment, Mitigation of Chemical Accidents, and Chemical Accident Recovery. These assessment areas were selected to represent the successive "levels of defense" commonly used to ensure the safety of workers and of the general public.

The operating facilities evaluated range from multifunction laboratories, including both nuclear and nonnuclear laboratories that support research in defense, waste management, and other fields, to nuclear and nonnuclear facilities that support general site functions, such as waste treatment and receiving and distribution of chemicals. Facilities selected as candidates for this assessment were 
judged by the CSOR Team to have the highest potential for serious worker injury or for offsite health effects, based on the chemicals and quantities used therein.

The following sections focus on identifying deficiencies in LLNL chemical safety programs, compared to ideal programs.

\subsubsection{Procedural Controls}

The CSOR Team noted that each of the process areas and research laboratories has at least two levels of procedural control to govern operations, including chemical activities. These procedural controls include an FSP and an OSP. The former describes the general safety features, such as installed safety systems (i.e., ventilation, etc.) of the facility or building. The latter defines: appropriate reference documents to be reviewed before performing chemical research activities; personal requirements and qualifications of chemical researchers; ranges or types of work and the types of hazardous materials covered by the OSP; PPE requirements for procedures involving each of the specific hazardous materials listed; and the personal responsibilities and controls that must be assumed by the researchers in their work. Further, OSPs list the general actions to be taken in the event of chemical emergencies.

The Team found that much of the routine chemical-related process work, particularly those processes that are complex or hazardous, was governed by a third procedural level, which consisted of step-bystep operating procedures. It was clear to the Team that those facilities in which the supervisors and workers perceived a greater danger in their work (e.g., the High Explosives areas) had more complete operating procedures. Most of the procedures for routine operations that were reviewed by the Team included the appropriate "Cautions" and "Warnings" for routine operations, but neither of these were emphasized or highlighted (i.e., set apart from the remainder of the text) to be readily visible. Further, no specific limiting conditions of safe operation, or other quantitative parameters that would define the system safety envelope and that workers could use to prevent or mitigate chemical accidents were found in the third-level procedures that were reviewed by the Team.

The Team also noted other routine and less complex, but equally hazardous, processes that had no written procedures. An example was found at Building 514, the Liquid Treatment Facility, in which four hazardous chemicals are manually measured, dispensed, and transported in the routine batch treatment of radioactive mixed waste water. The dispensing system, including the flow controls, hoses, and spill containments for incompatible and highly reactive chemicals, were all located within a few inches of each other. Safety of the process operators in these relatively simple activities appeared to rely heavily on the operator's attentiveness and manual dexterity and on the use of PPE. Although the Team was assured that this operation has been safe in the past, and continues to be safe, there is an automated system that has been installed and is currently undergoing prestart testing.

For the less routine work found within the chemical laboratories in the larger-scale experimental processes at LLNL, the operations are performed with less emphasis on detailed step-by-step 
procedures and with a greater dependence on training and expertise. Although chemical researchers and workers assigned to this experimental work were found to have received on-the-job training in the general procedures for their areas, their expertise and qualifications are based on education and on past performance in related research work (i.e., much of the experimental work being performed has never before been attempted). Generally, these experimental processes are governed by the FSPs and OSPs, but the third detailed level of procedural control, the step-by-step instructions (noted above) for routine operations, is lacking.

LLNL management repeatedly emphasized a preference for engineered safeguards (i.e., equipment, hardware, interlocks, etc.), rather than for administrative or procedural controls, to ensure chemical safety. However, in designing equipment and hardware for experimental projects, it may not be possible to identify all potential problems so that the appropriate engineered safeguards can be included. Thus, the need for third-level procedural controls, including well-defined system safety limits or some equivalent system safety envelope, is of paramount importance in experimental work. The lack of this procedural level for laboratory and experimental processes is apparent at LLNL.

There is also an apparent inconsistency and lack of understanding among site supervisors in the application of a formal lockout and tagout program as it applies to chemical isolation. The lockout and tagout program (Supplement 26.13 of the Health and Safety manual) mentions, but does not specifically address, methods for the isolation of high pressure fluids, high temperature fluids, and otherwise hazardous chemicals. In application, the Team found supervisors in one facility that thought one closed and tagged line or block valve would be sufficient isolation for entry of maintenance workers into a waste treatment tank (best practice of the industry requires double block valve isolation) and supervisors in another facility that did not understand the need for a formal lockout/tagout log.

\subsubsection{Design and Analysis}

The continued safety of chemical system operations depends heavily on the degree of rigor and thoroughness employed in the initial engineering design and in the selection process used for materials of construction, equipment, and other components. To be fully effective, the minimum standards used in the initial design of a system must be utilized, assuming that they have been found to be appropriate, in all subsequent repair or improvement work performed on that system (i.e., configuration management).

It is apparent that LLNL has implemented a program for the control of site design processes that considers the risks posed by chemicals in processes and laboratories. Although the program is not formally presented in detail in the Health and Safety manual, there is evidence that it is working reasonably well. The critical elements of the program are the OSPs prepared by the facility owners and the Engineering Safety Notes prepared by the engineering groups. 
The OSPs address the hazards associated with the facility and are updated by means of the ES\&H evaluation process when hazards or hazard levels change.

The Engineering Safety Notes provide formal engineering analyses that address the hazards identified in the OSPs. Engineering Safety Notes are reviewed and approved documents, with review and approval levels defined by the risk designation of the facility as determined in the FSPs and OSPs. Configuration management is achieved by virtue of the fact that OSPs and Engineering Safety Notes are "living" documents. It was also noted that the engineering groups have attempted to maintain "asbuilt" drawings for all LLNL facilities and systems. Several examples of the program effectiveness were noted in the toxic gas systems. LLNL was the only contractor evaluated by the CSOR process to consistently use toxic gas cylinder cabinets and all-welded runs of small bore stainless steel tubing systems for this service. The mechanical and structural design of these installations was excellent.

In the brief facility tours, the Team noted that many hazards of relatively minor consequence were present in several of the LLNL facilities but were unidentified by the management and supervision in these facilities. Similar hazards had already been identified and corrected in adjacent facilities. The majority of these existing hazards could have been readily recognized (and corrected) by engineers or building managers and supervisors, who are aware of hazards and are routinely "walking the building spaces," or by the sharing of "lessons learned" between facilities.

The site-specific design manual prepared by the Mechanical Engineering Department is noteworthy. LLNL is the first DOE laboratory evaluated by the CSOR process that has developed such a manual. It is a controlled document, but it has been distributed to a relatively large number of individuals at the site. The only potential drawback to this distribution is that the manual contains a significant number of "cookbook" formulae and methods of calculation that could be used by unqualified personnel to perform "quick fixes" to mechanical problems - without having the benefit of an educated understanding of the limitations involved. This is only a potential weakness and by no means implies that the manual should be collected or redistributed.

\subsubsection{Control and Primary Containment}

LLNL facilities acquire chemicals through a near-just-in-time procurement process or by directdelivery of bulk quantities. The LLNL site stores no longer maintain an inventory of chemicals; thus, the onsite inventory of hazardous and toxic chemicals in stores and in individual facilities has been reduced. Additional efforts to control quantities of these chemicals include an "excess chemicals" program to allow the transfer of excess chemicals from one facility to others that have a need for such chemicals and an active hazardous and toxic chemicals substitution program.

LLNL performs the onsite delivery of all less-than-bulk-quantity chemicals. Although the Team noted some deficiencies, an indepth evaluation of the onsite chemical transportation program was not performed. 
There appears to be an effective program at LLNL for the selection and maintenance of pressure vessels and containments. Every pressure vessel in current service at the site appeared to be in good repair, and none of the portable gas cylinders, dewars, or high pressure "tube trailers" were found to be overdue for pressure testing. An annual preventive maintenance program for pressure relief valves has been implemented at the site. The only deficiency in this program noted by the Team was observed at several nitrogen and liquid oxygen dewar locations. Many of these vessels lacked the appropriate vehicle barriers, and one nitrogen dewar was not labeled properly.

Process and service piping in all laboratory and process areas was found to be appropriately labeled and generally well supported. However, several hazardous chemical and high pressure systems were identified that were not provided with appropriate identification of critical throttling and isolation valves. Although valve identification is not requirement, it is a best practice of the chemical industry, because it facilitates the use of detailed operating and isolation instructions.

\subsubsection{Mitigation of Chemical Accidents}

LLNL has developed and implemented programs to deal with the mitigation of chemical spills and other types of chemical accidents. Most toxic and hazardous chemicals have been adequately identified and been provided with secondary containment. With the exception of compressed gases, all original containers have been labeled adequately. Labeling methods for secondary containers or packages meet the minimums of the laboratory safety requirements, but are inconsistently applied across the site. In most cases, access to hazardous and toxic chemicals is well controlled, and flammables are properly packaged and stored. However, in one facility, toxic mutagens were found to be stored in an unlocked storage flammable materials cabinet with flammables present.

Secondary containment for all large hazardous or toxic chemical storage tanks has been provided. In almost every instance in which 55-gallon drums of hazardous chemicals and wastes were stored, spillcontaining pallets were provided, and the majority of cabinets and open storage shelves for smaller quantities of hazardous chemicals were equipped with spill trays. Cleanup kits and bags of absorbents were found in most laboratory and chemical processing areas, but it was not determined that any specific training for individuals in these areas had been provided. Adequate supplies of PPE were identified, but the adequacy of training in its use was not evaluated.

Generally, the fire suppression systems provided for the facilities evaluated by the Team were found to be appropriately sized and selected for their intended service and were well maintained. No instances of fire water/chemical incompatibility were noted and, in most cases, fire water volumes had been considered in the design of containments, drains, etc. Many different types (i.e., pressurized water, dry chemical, Halon, etc.) of portable fire extinguishers are provided throughout the LLNL facilities. However, when questioned, some of the operating personnel admitted that they were not completely familiar with their use. It was subsequently determined that not all LLNL personnel are required to be trained in the use of portable extinguishers. Because of the potential for small fires in 
almost all of the LLNL facilities and, due to the fact that plentiful numbers of extinguishers are provided, the lack of training among workers is a potential programmatic weakness.

\subsubsection{Chemical Accident Recovery}

Because of the hazardous nature of many of the operations at LLNL, workers receive special training in emergency preparedness. Drills in which both operations and emergency responders are actively involved, are performed on a regular basis. Although the emergency responders have routine drills involving mock chemical spills and releases, it could not be verified by the Team that the operations groups had chemical-related practice.

The LLNL Fire Department is responsible for responding to all plant emergencies, including fire and ambulance calls and HAZMAT accidents. All "911" calls are routed through the Firehouse, and Fire Department personnel are qualified "first responders," with training and qualification in radiation and chemical work, including the use of specialized PPE. When "911" calls are received, the decision for immediate response is made by the Fire Captain or Chief and the on-call Laboratory Emergency Duty Officer (LEDO) is notified. When immediate response is indicated, the Fire Department responds to the scene of the incident, and the Captain or Chief becomes the incident commander. The LEDO is kept apprised of the situation and has the authority to activate the EMC. If the emergency has the potential to impact the environment, the Environmental Duty Officer (EDO) may also be called. Although the response time for LEDOs and EDOs may approach 20 minutes during the off-shift or on weekends, the Fire Department incident commander can reach the scene of the incident within minutes and has the authority to assume full control.

The effectiveness of building pre-fire plans and other emergency response plans depends on having a good definition of current building hazards, including inventories of hazardous and toxic chemicals. Although there appears to be several positive opinions among site managers regarding the existence of real-time chemical inventories, the CSOR Team could not verify that such inventories exist for many of the facilities visited. The present method of conveying laboratory inventory information to responders in some LLNL facilities is to file hard copies of room inventories in the collection boxes that are attached to laboratory room doors or to the wall adjacent to the doors. The Team questioned the availability of such inventories after the box was consumed by fire or damaged by explosion. Although LLNL is attempting to develop a workable program to bar-code all chemicals, thus maintaining an up-to-date electronic database for chemical inventories, it is apparent that this system will not be realized for several months, at best.

There have been appropriate Memorandum of Understandings developed with local and State agencies that may provide mutual emergency aid. Likewise, an agreement with a local hospital for the emergency treatment of chemically exposed or injured workers is in effect. 


\subsection{Management and Operations}

\subsubsection{Management Organization}

A review of LLNL management's implementation and oversight of chemical safety was performed. Discussions were held with all levels of management, from the Laboratory Director of LLNL to firstline supervisors.

As noted by the Tiger Team, LLNL uses a matrix structure to carry out the missions of the Laboratory. Both LLNL line and support organizations perform activities requiring a knowledge of chemical safety in day-to-day operations. The actual matrix approach used at LLNL involves a number of innovations that impact chemical safety, as discussed below.

Research and development programs are organized under the direction of Associate Laboratory Directors (ADs), each of whom is responsible for a broad topical area (Physics, Chemistry and Material Science, Lasers, etc.). The general view presented during the course of interviews and facility inspections was that responsibility and authority for implementation of requirements was placed at the AD level. An ES\&H Council, consisting of representatives from the ADs, as well as top management meet frequently to discuss a range of issues, but actual implementation is effectively at the discretion of each $\mathrm{AD}$.

As a matter of Laboratory-wide policy, each $A D$ was required to create a position for a Deputy Associate Director (DAD) for Assurance, whose function is to arrange for and provide technical support for ES\&H and quality, including support for self-assessments. Assurance Managers from each Directorate were assigned to an ES\&H Council Working Group, which provides input and support to the ES\&H Council.

Facilities are assigned to each $\mathrm{AD}$, and each $\mathrm{AD}$ is responsible for conducting operations in facilities assigned to him according to all the rules and requirements set forth in the Health and Safety Manual. Facility Managers have been assigned and are responsible for assisting the ADs in carrying out ES\&H and operational activities needed to support the research or infrastructure activities carried out in the designated facilities.

Matrixed support is also provided by assigning specialists at each facility, and through the actions of multidiscipline teams from the Hazards Control Department. Each of these teams is assigned to a general area of specialty (e.g., lasers).

The Laboratory Director has established an organization that performs reviews of operations. These were described as topical reviews against the related parts of the LLNL Health and Safety Manual (e.g., hazard communications, high pressure safety). This organization reports to the Laboratory Director level. 


\subsubsection{Management Processes}

Work involving handling, use, or storage of chemicals at LLNL is required to be performed in accordance with the Laboratory's Health and Safety Manual. The manual has been undergoing major revision during the last few years. The chapter dealing specifically with chemicals was reissued in December 1991; a closely related chapter, "Work Planning, Safety Procedures and Management Oversight," was reissued on March 13, 1992. Translation of this guidance into FSPs and OSPs is to be completed no later than March 13,1993. These new chapters were said to have been carefully reviewed by the ES\&H Council, and unanimous agreement was required before they were issued. Implementation of these new requirements, and the other improvement programs underway at the Laboratory appear to be accomplished through the established matrix arrangements, and at the pace and depth deemed appropriate by each $\mathrm{AD}$.

Since one of the Health and Safety Manual sections most important to chemical safety (i.e., Supplement 21.01 covering the OSHA Laboratory Standard) is new, and not yet fully implemented, many of the management processes to assure chemical safety are somewhat immature.

Fundamentally, key employees must be provided with the training or assistance needed to fully understand the hazards posed by operations in their areas and the kinds of measures needed to adequately control those hazards. Only then can improved performance be expected to be fully effective and uniformly applied. The Health and Safety Manual provides clear statements of requirements; however, the understanding of these requirements was generally weak. In some respects, this may be attributed to qualitative differences in the training, qualifications, and experience of key staff.

There is heavy reliance in the management systems at LLNL upon the decisions made by supervisors. Supervisors are responsible for ensuring that workplace hazards are identified, workers are trained, PPE is available to the workers, and the workers perform the required tasks safely. To accomplish their assignments, the supervisors need to be able to identify chemical safety hazards in the workplace, to know when and how to obtain matrix support from industrial hygiene and safety professionals in other organizations, and to be able to apply basic supervision skills that are necessary to direct and ensure the safety of their direct staff. If supervisors are ignorant of specific chemical safety issues, they are likely to fail to identify hazards or the need to use industrial hygiene support.

The training program does not provide the supervisors with the information needed to perform this task. A training course, "Chemical Hygiene Plan: Implementation Requirements for Supervisors," was given on July 30, 1992 (to be repeated on August 5, 1992). The course materials were not as complete as at other sites and seemed to omit important guidance contained in the Health and Safety Manual. In general, because this training deficiency constitutes a common-mode failure in the system, there is no assurance that chemical safety hazards will be consistently identified by the supervisors at LLNL. In any event, considerable variation was observed in the understanding of chemical safety requirements, and this course would not be expected to change that situation. 
Effective training is critical to the performance of the implementation of chemical safety in the Operations organizations, since the supervisor must make the determination to request industrial hygiene or safety reviews.

It was unclear whether the content of other training courses provide the indepth, practical knowledge needed by supervisors to effectively manage the handling, storage, and disposal tasks required. (RCRA-related training was reviewed, and is comprehensive.) LLNL does have a process to identify training courses needed for individuals. The effectiveness of training received is apparently not measured.

Even when supervisors may not have needed skills, chemical safety support is provided by safety specialists and industrial hygienists who are available to the supervisors on a matrixed basis. These individuals have training and qualifications to provide professional consulting support to the line supervisors and managers related to chemical safety. However, based upon interviews, it appears that the DAD for Assurance in each organization has more direct and greater influence on management of operations from a chemical safety standpoint. The qualities and attitudes of these individuals appeared to vary widely.

LLNL has created general review teams under the Hazard Control Department, each of which has one or two individuals with special training or expertise in areas relevant to safe management of chemical hazards. These multidiscipline teams provide an additional and potentially powerful supplement to other chemical safety capabilities.

Facility Managers have line responsibility for facility safety as representatives of the AD. These managers perform self-assessment and support functions to assist operators and the AD in ensuring that safety policies are being implemented in the workplace. The chemical safety training requirements for these individuals are similar to those of the supervisors, and, consequently, the same deficiencies that applied to the supervisors apply here. However, discounting the training process issues, the amount of understanding of chemical safety requirements varies from facility to facility. The facility managers generally have not achieved a uniform, high level of chemical safety awareness. Some potential reasons for this are the diversity of the facility managers' other line responsibilities, deficiencies in individual training, or facility managers who have not identified chemical safety as a significant issue. At LLNL, chemical safety varies widely from location to location as described in other sections of this report. However, it was noted during the walk-through tours of LLNL facilities that implementation of chemical safety principles tends to be more effective where RCRA requirements apply in the workplace.

There does not seem to be consistency in the ranking of priorities for budgeting safety and health activities. Two different risk-based prioritization systems were identified by the CSOR Team. Both drop out lower ranked items when budgets are reduced. Thus, needed improvements can go unfunded for years. There is no coordinated or systematic management structure on funding safety 
and health activities or on developing lower-cost alternative corrective action strategies. The Team could not determine how projects related to safety are funded in relation to other priorities.

\subsubsection{Management Involvement In Chemical Safety Processes}

Managers at all levels should have effective means in place to determine whether the requirements for chemical safety are being met. This includes management by walkdown (as part of the conduct of operations activities), periodic inquiries as to the status of established performance objectives and criteria, use of tracking and trending data, and the continuing input from audit programs. Important results are communicated vertically and laterally in the organization.

Chemical safety at the LLNL plant is not a separately administered program. The mechanisms for assuring safe management of hazardous chemicals are embedded in existing management systems, industrial hygiene and other topical area programs, and FSPs. LLNL has developed a supplement to the Health and Safety Manual dealing with CHP requirements. The generic plan was reviewed and judged to comply fully with the OSHA requirements. The process for chemical safety review, as defined in Supplement 21.01, requires that all FSPs and OSPs be reviewed and approved by the ES\&H team, which includes a qualified industrial hygienist. FSPs for facilities that house any experiment or operation meeting the minimum criteria defined in this Supplement must incorporate the requirements of the generic CHP. However, a formal requirement that FSPs comply with 29 CFR 1910.1450 could not be identified in the Health and Safety Manual. In all events, effective implementation depends on vigilant oversight by line management, with the active support of a qualified CHO.

The requirements of the OSHA Laboratory Standard and the additional requirements under the process safety regulation were, with a few exceptions, unrecognized by the managers interviewed. One reason for this lack of recognition at L.LNL is that very few, if any, experiments or operations use or store amounts of toxic or hazardous chemicals that approach the threshold quantities defined in the standard. This does not imply that these managers are unaware of the regulations covering the chemicals they are working with.

The ability to show compliance with OSHA requirements (whether for laboratories, for the process systems in large waste treatment systems, or in the other facilities) is largely lacking; a cross-check between actual programs and procedures against applicable OSHA criteria is not specifically required by LLNL managers. Management control over day-to-day operations to assure good chemical safety practices is attained by following the requirements contained in the Health and Safety Manual, which has been developed to reflect applicable standards and regulations, and reliance is placed upon individual scientists and engineers to implement general ES\&H programs and procedures. In this context, considerable variation was found in capabilities and effectiveness. There were examples of outstanding and progressive management, with resultant controls over chemical hazards. In other cases, the safety and health organizations and senior management did not appear to provide needed support to assure that performance met expectations. 
However, the use of FSPs and OSPs, based upon the new safety analysis requirements of Section 2 of the Health and Safety Manual, will lead to improved handling of hazardous materials, including chemicals. Presumably, conduct-of-operations-related improvements will provide immediate and substantial improvements in management of all risks, including hazardous chemical risks.

In general, LLNL delegates responsibility for compliance with chemical safety requirements to the ADs. Although adherence to chemical safety requirements in each division is periodically assessed by the Assurance Review Office (ARO), the division-level feedback mechanisms to ensure that each Directorate did in fact comply with these requirements was found (based on interviews) to be dependent upon the individual characteristics of the respective ADs; other mechanisms (e.g., walking of spaces, performance appraisals, feedback from biweekly staff meetings, tracking and reviewing commitments) to self-assure effective performance did not appear to be working.

With some notable exceptions, the ADs do not routinely monitor performance in this area. There appears to be wide variation in performance. Some facilities reflected substantial management interest and attention. The housekeeping and operational setup at other facilities evidenced a lack of involvement by management.

Again, some managers have taken steps to avoid these situations, and their operations show care and attention to actions that promote workplace safety. Although LLNL is to be commended for undertaking many new initiatives that will benefit ES\&H performance, the management of change at the $\mathrm{AD}$ level is not consistently effective.

The ARO conducted an appraisal in September 1991 of LLNL's Health Hazard Communication Program. This document identified many of the deficiencies noted above and indicates that the ARO is a fully capable organization in terms of issue identification. Requirements identified by support organizations and deficiencies identified in audits are captured in a deficiency tracking system. This system includes controls for closeout and appears to capture all major items requiring action. The CSOR Team was not able, during this visit, to assess whether the institutional recommendations of the 1991 ARO Hazard Communication Appraisal had been effectively acted upon. 
Appendix A--Biographies 

NAME:

AREA OF RESP: Team Leader

ASSOCIATION: DOE/Office of Risk Analysis and Technology

EXPERIENCE:

- U.S. Department of Energy, Germantown, MD

- $\quad$ Director, Risk Analysis and Technology Division, EH-33.1

- $\quad$ Acting Director, Safety Inspections Division, EH-331

- $\quad$ Acting Director, Safety Technology Division, EH-332

- $\quad$ Team Leader for Technical Safety Appraisals

- Tennessee Valley Authority, Chattanooga, TN

- $\quad$ Corporate Health Physicist, TVA's Office of Nuclear Power

- $\quad$ TVA Central Emergency Response Team

- U.S. Nuclear Regulatory Cornmission, Rockville, MD

- Health Physicist, technical reviewer for radiation protection and emergency preparedness for licensing and design changes for reactors, prepared safety evaluation reports, performed inspections and Team evaluations, evaluated reactor emergency preparedness exercises.

- Task Manager for NRC/INPO Coordination Plan for Radiological Protection Activities.

- $\quad$ Contracts Project Manager for work with DOE Labs

- $\quad$ NRC Incident Response Team

- $\quad$ General Electric, Schenectady, NY

- $\quad$ Knolls Atomic Power Lab, Kesselring Site

- $\quad$ Manager, Radiological Monitoring

- $\quad$ Lead Engineer, Dosimetry and Health Physics

- $\quad$ Lead Engineer, Radiological Training

- $\quad$ Radiological Controls Shift Supervisor

- Instructor, Chemistry and Radiological Controls, qualified as nuclear navy Engineering Laboratory Technician

- $\quad$ Kesselring Site Emergency Response Team

- U.S. Air Force

- Officer, Pilot/Aircraft Commander

- $\quad \mathrm{KC}-135, \mathrm{EC}-135, \mathrm{C} / \mathrm{E}$

- $\quad$ Standardization/Evaluation aircrew member

EDUCATION: $\quad$ B.A. Chemistry, State University College at Potsdam, NY

OTHER: $\quad$ Member, Health Physics Society 
NAME:

AREA OF RESP: Management and Organization

ASSOCIATION: $\quad$ Management Strategies, Inc.

EXPERIENCE: $\quad 30$ years, with Westinghouse, North American Aviation, USDA, USDOE, USNRC, and private consulting

- Chemical pesticides research, investigating impact of pesticides, and their control.

- $\quad$ Environmental R\&D investigating consequences of accidental releases of hazardous materials.

- Safety and risk analysis of nuclear and non-nuclear facilities.

- Safety engineer for plutonium facility.

- $\quad$ Program manager, responsible for safety and siting of major DOE projects.

- Senior manager at USNRC, including development of safety and siting criteria and development of resource management strategy for licensing reviews.

- Senior manager at DOE, including positions as DAS for Safety, Health and Quality Assurance, and as Principal Deputy Assistant Secretary for Nuclear Energy.

- Management consultant, providing expertise in risk-based resource management, performance improvements management, and program strategy development.

EDUCATION: $\quad$ B.A., Chemistry, Whitman College

J.D., University of Florida

L.L.M., University of Florida 
NAME:

AREA OF RESP: Chemical Engineering, Process Engineering, Systems Engineering, Hazards and Risks

ASSOCIATION: Battelle Columbus

EXPERIENCE: 22 years in chemical and energy processes

- Battelle, Energy Systems Group

- Manager, Systems Engineering: performs and coordinates functional requirements analysis, facility reviews and hazards identification.

- Deputy Manager, HLW Transportation Systems; directed technoeconomic tradeoff studies, and policy/regulatory analyses.

- $\quad$ Manager, HLW Disposal, Systems Integration and Configuration Control: Coordinated scoping of engineering trade-off studies, risk analyses and requirements development.

- Hoescht-Celanese, Petrochemicals Technical Center

- Superintendent, Chemical Engineering: managed bench-scale research, process modeling and design consulting groups.

- U. S. Department of Energy, Office of Energy Systems Research

Chief of Planning and Evaluation: coordinated strategic and technoeconomic assessments for energy conversion technologies.

- $\quad$ Chief of Chemical and Physical Energy Storage: managed technology development for closed-cycle hydrogen systems, chemical heat pipes, phase change systems, and flywheels.

- Institute of Gas Technology, Engineering Research Division

- Manager, Alternative Fuels: experimental research and analytical modeling for fuels production and combustion.

- $\quad$ E.I. Du Pont de Nemours

Research Engineer: polymers and fibers.

EDUCATION: $\quad$ B.S., Chemical Engineering, Purdue University

M.S., Chemcial Engineering, University of California, Berkeley

Graduate study, Engineering Dynamics, University of California

Graduate study, Law, George Washington University

OTHER: American Institute of Chemical Engineers, American Chemical Society, Society for Advancement of Material and Process Engineering, Tau Beta Pi, Sigma Xi, Phi Lambda Upsilon. 
AREA OF RESP: Report Coordinator, Safety and Health

ASSOCIATION: $\quad$ M. H. Chew and Associates

EXPERIENCE: 14 years

- $\quad$ M. H. Chew and Associates

- $\quad$ Administrative Assistant to Tiger Team Leader to the Tiger Team Assessment at the Los Alamos National Laboratory (LANL). Responsible for assisting Tiger Team Leader with communications, weekly and monthly reports, schedules, and administrative support.

- $\quad$ Report Coordinator responsible for the overall coordination and production of the draft report at the Princeton Plasma Physics Laboratory.

- $\quad$ Report Coordinator for the Management Team Report of the Tiger Team Assessment at the Idaho National Engineering Laboratory (INEL) and LANL.

- $\quad$ Report Coordinator for the Safety and Health SubTeam Reports of the Tiger Team Assessments at the Naval Petroleum and Oil Shale Reserves Colorado, Utah, and Wyoming, Idaho Chemical Processing Plant, Lawrence Berkeley Laboratory, Pittsburgh Energy Technology Center, Princeton Plasma Physics Laboratory, Los Alamos National Laboratory, Oak Ridge K-25 Site, and the AMES Laboratory.

- Westinghouse Idaho Nuclear Company, Inc.

Report Coordinator for Safety and Health SubTeam Reports of the Tiger Team Assessments at Savannah River Site, Pinellas Plant, and Brookhaven National Laboratory. Report Coordinator for Technical Safety Appraisal Reports at Oak Ridge National Laboratory, Strategic Petroleum Reserve Site, Y-12 Plant TSA Followup, and the Idaho Chemical Processing Plant at INEL.

EDUCATION: $\quad$ B.S., Education: Corporate Training, Idaho State University

OTHER:

Certified Instructional Trainer for Corporate Training

Word-Processing Instructor, Eastern Idaho Technical College 
NAME:

AREA OF RESP: $\quad$ OSHA, Hazard and Risk Analysis

ASSOCIATION: Battelle-Pacific Northwest Laboratory

EXPERIENCE: $\quad 20$ Years

- $\quad$ Experience in occupational safety, industrial hygiene, human factors, fire safety, and safety management.

- $\quad$ Consulted with numerous organizations on safety issues and processes. Has assisted in program review/development and accident analysis. Has performed safety process review and audits to determine general and chemical process hazards.

- $\quad$ Managed groups of consultants and put together a service program that significantly reduced accident frequency for those firms serviced. He managed training, industrial hygiene and general safety programs for these consulting programs. Other responsibilities included training, safety literature development, budgeting, policy and procedures development, and performance management.

Worked on state governmental committees developing administrative rules related to safety issues. Developed with the Oregon Insurer Group the legislative response to rules related to safety and insurance. Worked on the American Society of Safety Engineer's Accreditation Committee and Career Promotion Committee in Oregon.

Developed a Preliminary Hazard Analyses for a new and existing DOE research facilities. The chemical hazards, consequences and control measures were evaluated.

EDUCATION: $\quad$ B.S. Physics, Oregon State University

M.S. Industrial Engineering, Oregon State University

OTHER:

Certified Safety Professional 
AREA OF RESP: Coordinator

ASSOCIATION: $\quad$ U.S. Department of Energy, Headquarters

EXPERIENCE: $\quad 32$ Years

- U.S. Department of Energy

- Supervisory Appraisal Specialist: Responsible for the overall planning and conduct of Tiger Team Assessments, Technical Safety Appraisals, Management Appraisals, Nuclear Safety Program Appraisals, Design Reviews, and Comprehensive Appraisals. Responsible for the overall production for draft reports in the field and final publication of reports at DOE Headquarters; also for providing coordination and editorial support on DOE/EH appraisals.

- Staff Assistant, Office of Environmental Compliance and Overview. Recommended specific changes in administrative procedures for the purpose of increasing efficiency, eliminating unnecessary details, and providing needed management control.

- Staff Assistant, Office of Bio-Medical and Environmental Research. Obtained and communicated information to organizations and individuals inside/outside the Agency on a wide range of Agency organization, personnel, and procedures.

- $\quad$ Staff Assistant, Office of the Commissioner, USAEC.

Administrative Assistant, Office of the Assistant General Manager for Research and Development, USAEC.

- $\quad$ Other Related Experience

Administrative and conference planning responsibilities within the USAEC, ERDA, and DOE.

EDUCATION: $\quad$ Numerous work-related courses and workshops at various colleges, training centers, SSDC, and the American Management Association.

OTHER: Member, U.S. Delegation to Disarmament Conference, Geneva, Switzerland Recipient of Federal Government Awards for superior performance. 
AREA OF RESP: $\quad$ Management and Operations

ASSOCIATION: $\quad$ U.S. Department of Energy, Safety and Quality Assurance

EXPERIENCE: 21 Years

- U.S. Department of Energy

- $\quad$ Executive Assistant to the Deputy Assistant Secretary, Safety and Quality Assurance. Technical, policy, and management review and analysis of occupational safety issues.

- $\quad$ Senior Program Analyst, Office of Civilian Radioactive Waste Management

- DOE Hearing Official for the first and second geologic repository site public hearings. Intergovernmental liaison with Governor's offices, and other State and Local and Indian Tribal Representatives, and Monitor Retrievable Storage Review Commission.

- U.S. Nuclear Regulatory Commission

- $\quad$ Special Assistant to the Chairman, for safety policies related to high level and low level radioactive waste, including below regulatory concern, international nuclear safety, State and Intergovernmental programs.

- Developed regulatory guides, regulations, and guidance documents (NUREGS) on nuclear-related safety subjects, such as: reactor safety, nuclear medicine, industrial radiography, environmental impact, and transportation.

- $\quad$ Developed Environmental Standard Review Plans used in reviewing Environmental Impact Statements for nuclear power plants.

- $\quad$ Co-author of training manual, "Working Safely in Gamma Radiography."

- Contractor to USDOE, Transportation Management Division, Office of Environmental Restoration and Waste Management

- $\quad$ Senior Waste Management Analyst for transportation of hazardous and radioactive materials.

- $\quad$ NUS Corporation

- Wrote and edited Environmental Impact Statements (EIS) for nuclear power plants.

- $\quad$ Batelle, Pacific Northwest Laboratories

- Team member of group developing Environmental Impact Statements for the U.S. Atomic Energy Commission

EDUCATION: $\quad$ B.A. Communications, University of Washington, Seattle, Washington USNRC, Technology Transfer Program for Probabilistic Risk Analysis

OTHER: Member, American Nuclear Society 
NAME:

AREA OF RESP: $\quad$ Conduct of Operations

ASSOCIATION: $\quad$ Kaiser Engineers Hanford (KEH) detailed to USDOE EH-30

EXPERIENCE: 23 Years, professional engineering in design, construction and operations management, consulting, and program management.

Program Manager, KEH, temporarily assigned to DOE-Germantown to help develop safety assessment programs, evaluate contractor safety performance and proposed corrective action plans; resolve compliance issues, and conduct site safety assessments.

- $\quad$ Principal Design Engineer, KEH, managed multi-discipline, nuclear-related design projects and performed detailed mechanical design analyses.

- $\quad$ Engineering Design Consultant, nuclear, petroleum, petroleum chemical, pulp and paper, and inorganic chemical operations.

Plant Production Supervisor, inorganic chemicals operations.

Plant Engineer, project and maintenance management and engineering responsibilities for inorganic chemical operations.

EDUCATION:

B.S., Mechanical Engineering, Washington State University, Pullman, WA

OTHER:

Member American Society of Mechanical Engineers.

Registered Professional Engineer, Montana and Washington. 
NAME: $\quad$ Jacqueline D. Rogers

AREA OF RESP: Industrial Hygiene

ASSOCIATION: Office of Health Physics and Industrial Hygiene, Industrial Hygiene Programs Division, Headquarters, Department of Energy

EXPERIENCE: 16 years

- U.S. Department of Energy, Germantown, MD

- Industrial Hygienist: Responsible for developing DOE health and safety policy

- $\quad$ OSHA type safety and health inspections for Technical Safety Appraisals (TSAs).

- Occupational Safety and health Administration (OSHA), U. S. Department of Labor, Washington, D.C.

- $\quad$ Directorate of compliance Programs, Office of Health Compliance Assistance. Senior Level Industrial hygienist. Responsible for developing compliance guidance documents for OSHA field staff for a wide range of health enforcement issues.

- Directorate of Field Operations. Industrial Hygienist. Project Coordinator for the OSHA Industrial Hygiene Technical Manual.

Directorate of Technical support. Industrial Hygienist responsible for assisting in the development of chapters for the OSHA Field Operation Manual. Accompany senior level industrial hygienist on official OSHA compliance inspections.

EDUCATION: $\quad$ M.S., Physiology, University of Connecticut B.S., Biology, Federal City College 
NAME:

AREA OF RESP:

ASSOCIATION:

EXPERIENCE:

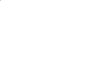

Senior Scientist, Environment, Safety and Health. Member of a chemical and radiological safety Team to evaluate the safety of operating nuclear facilities within the weapons complex. Estimated potential interactions and evaluated potential for severe chemical accidents - fire, explosions, spills and incompatible mixings.

- $\quad$ Conducted Hazard and Operability Studies (HAZOPs) to assess the potential for onsite fatalities and/or serious injuries, offsite environmental or safety impacts, significant plant downtime and/or capital losses of equipment, and significant process upset and/or loss of product containment.

- $\quad$ Responsible for technical administration of contracts for development of guidance documents in preparation of a safety analysis report (SAR) for a geologic repository for high-level radioactive waste.

- Managed a risk assessment contract to estimate worst-case environmental and human health consequences of demolishing a laboratory building contaminated with chemical warfare material.

Directed development of occupational radiation protection and emergency planning guidance documents.

Managed design, coordination, and development of technical workshop materials for two national and four international training seminars and workshops in chemical and nuclear safety.

EDUCATION: $\quad$ M.S., Biological Sciences, University of Illinois

M.A., Linguistics, Columbia University

B.S., (cum laude) Mathematics, University of Illinois

OTHER:

American Association for the Advancement of Science, American Institute of Biological Sciences, New York Academy of Sciences, Alpha Lambda Delta, Phi Beta Kappa, Sigma Xi, Phi Kappa Phi 
Appendix B--List of Facilities Visited and Personnel Contacted 



\section{Facilities Visited at LLNL}

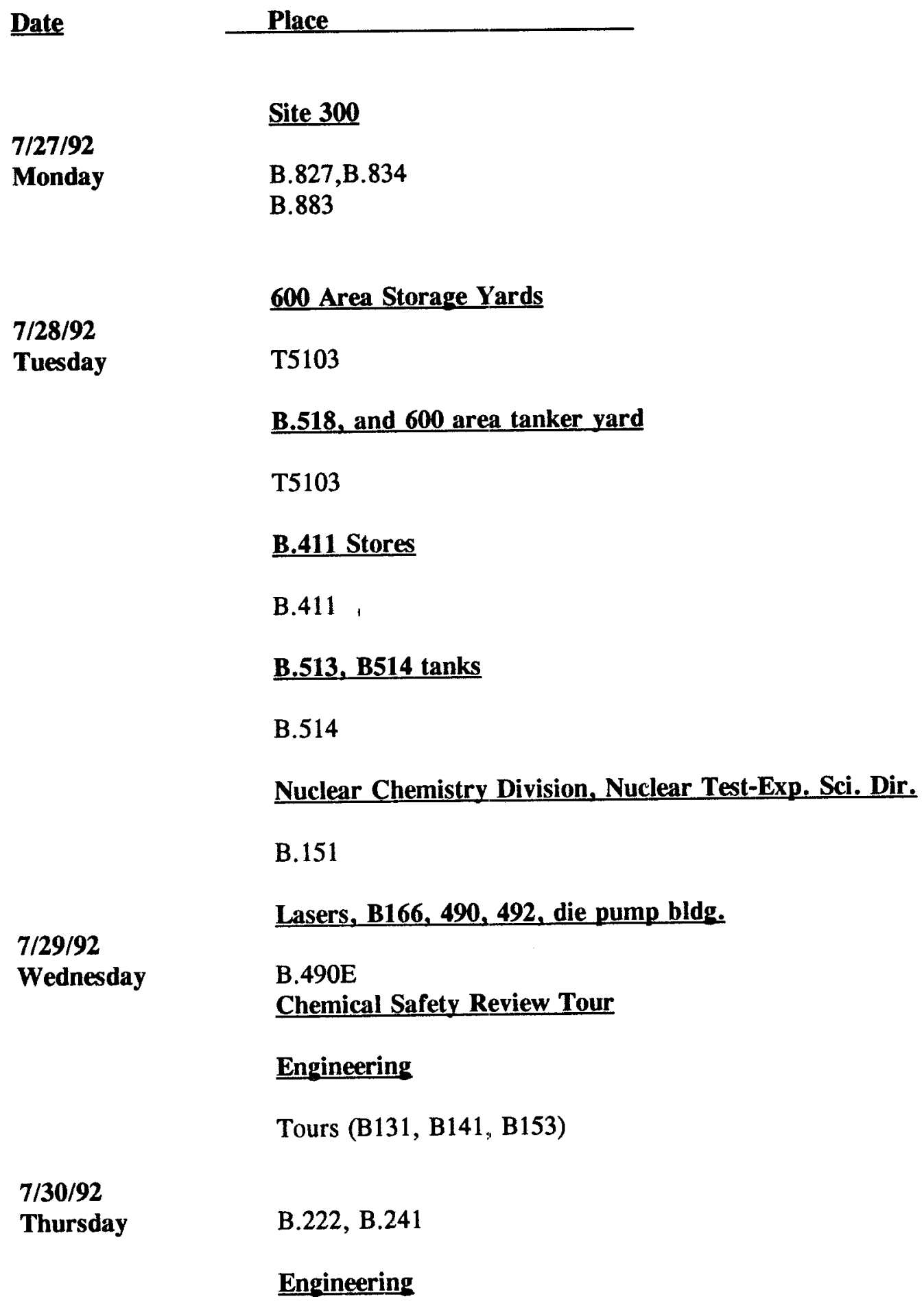

B.131, B.141, B.153, B.231, B.322, T1482 


\section{Personnel Contacted}

July 27, 1992

300 Area

Don Bitz

Ward Black

Bruce Clegg

Jim Lane

Ron Samoian

John Shingleton

Dave Wetherel

\section{July 28, 1992}

600 Area Storage Yards/B.518 and 600 area tanker yard

Fred Pocoroba

\section{B.4ll Stores}

Don Kelly

B.513, B.514 tanks

Scott Kidd

B. 151

J. Landrum

R. Wikkerink

July 29, 1992

Lasers, B. 166, 490, 492 \& die pump bldg.

\section{Alan Casamajor}

B.131 and HiBay

Les Jones

Jim McAlhany

Gus Olson

Chuck Woods

\section{B.141}

Ray Gonfiotti

Gus Olson 
B.153

Jim Folta

Les Jones

Gus Olson

Holly Peterson

Ron Cochran, Lab. Exec. Officer

Richard Fortner, AD Nuclear Test-Experimental Science

Chris Gatrousis, AD for C \& MS

Richard O'Neil, DAD/Operations (Assurance Manager), Nuclear Test-Experimental Science

July 30, 1991

B.222 \& B.241

Jim Fischer

Mark Costantino

B.231

Bob Lucido

Gus Olson

Dan Schurmann

B-322

Jack Dini

Jack Lima

Ernie Lopez

Gus Olson

Ray Goluba, Project Manager for Tiger Tearn Action Plan

Dennis Fisher, AD Plant Operations

Stan Toste, DAD Electronics Engineering

Jerry Schweickert, Chemical Hygiene Officer

George Campbell, HC Dept. Head

George Morris, SAR

Duane Sewell, Deputy Director, LLNL

\section{July 31, 1992}

W. E. Keheley, DOE-LLNL

Tom Gilmartin, Asst to the Princapal Laboratory Assoc Director 

APPENDIX H - Short List of Hazardous Chemicals Used In Department of Energy Operations (DOE) and Their Characteristics 



\section{APPENDIX H}

Several thousand different chemicals are used in chemical laboratories and process operations throughout the DOE complex. Some are extremely hazardous, while others are benign. Some are present in large quantities; most are present only in laboratory quantities. This appendix identifies and provides the hazardous characteristics of eight of the more hazardous chemicals found on Department of Energy (DOE) sites: arsine $\left(\mathrm{AsH}_{3}\right)$, chlorine $\left(\mathrm{Cl}_{2}\right)$, germane $\left(\mathrm{GeH}_{4}\right)$, hydrogen fluoride $(\mathrm{HF})$, nitric acid $\left(\mathrm{HNO}_{3}\right)$, phosgene $\left(\mathrm{COCl}_{2}\right)$, sulfuric acid $\left(\mathrm{H}_{2} \mathrm{SO}_{4}\right)$, and uranium hexafluoride $\left(\mathrm{UF}_{6}\right)$.

\section{DEFINITIONS}

Exposure Limits

- The Occupational Safety and Health Administration'(OSHA) permissible exposure limit (PEL) is used first. Unless noted otherwise, exposure limits are 8-hour, time-weighted average (TWA) concentrations. OSHA ceiling concentrations shall not be exceeded at any time, unless noted otherwise.

- Chemicals for which National Institute for Occupational Safety and Health (NIOSH) has published recommendations; the NIOSH-recommended exposure limits (REL, i.e., 8- or 10hour TWA and/or ceiling) are also noted.

- The American Conference of Governmental Industrial Hygienists (ACGIH) TWA and ceiling Threshold Limit Values (TLVs) are also noted.

\section{IDLH Level}

- The Immediately Dangerous to Life or health (IDLH) level defined by the SCP only for the purpose of respirator selection represents a maximum concentration from which, in the event of respirator failure, one could escape within $\mathbf{3 0}$ minutes without experiencing any escapeimpairing or irreversible health effects.

- Where the notation "Ca" appears. NIOSH has recommended that the substance be treated as a potential human carcinogen; IDLHs are not listed for those substances. "N.A." indicates that an IDLH has not been assigned.

ERPG-2 The Emergency Response Planning Guidelines (ERPGs) published by the American Institute of Industrial Hygiene Association defines EPRG-2 as follows. The maximum airborne concentration below which it is believed that nearly all individuals could be exposed for up to 1 hour without experiencing or developing irreversible or other serious health effects or symptoms which could impair an individual's ability to take protective action.

ERPG-3 The Emergency Response Planning Guidelines (ERPGs) published by the American Institute of Industrial Hygiene Association defines EPRG-3 as follows. The maximum airborne concentration below which it is believed that nearly all individuals could be exposed for up to 1 hour without experiencing or developing life-threatening health effects.

Threshold Quantities (TQs) are listed in the Federal Register, Vol. 57, No. 36, Monday, Feb. 24, 1992, page 6407. 
NAME

SYNONYM

FORMULA

DOT CLASS

DESCRIPTION

STATEMENT OF HAZARDS

EMERGENCY RESPONSE

PERSONAL PROTECTIVE EQUIPMENT

SPILL OR LEAK PROCEDURES

HEALTH HAZARDS

EXPOSURE LIMIT (OSHA)

IDLH

ERPG-2

ERPG-3

OSHA TQ

FIRE AND EXPLOSION

HAZARDS

FLAMMABILITY LIMITS
Arsine

Arsenic hydride, arsenic trihydride, hydrogen arsenide, arseniuretted hydrogen, arsenious hydride

$\mathrm{AsH}_{3}$

Poison A, Label: Poison Gas and Flammáble Gas

Colorless gas with a garlic-like odor.

Highly toxic and flammable gas. Low ignition energy. May be fatal if inhaled in very low doses.

Wear special protective clothing and positive pressure self-contained breathing apparatus.

Releases may require isolation or evacuation. Approach release from upwind. Eliminate all ignition sources. Stop or control the leak, if this can be done without undue risk. Use water spray to cool and disperse vapors and protect personnel. Report any release in excess of 1 pound.

Highly toxic. Human Carcinogen. May be fatal if absorbed through skin or inhaled in very low doses. Inhalation causes headache, vomiting, anoxia, nervousness, abdominal pains, chills, death. Symptoms may appear up to a few hours after exposure. Rapid release of compressed gas may cause frostbite.

$0.05 \mathrm{ppm}, 0.2 \mathrm{mg} / \mathrm{m}^{3}$

$6 \mathrm{ppm}, 19 \mathrm{mg} / \mathrm{m}^{3}$

None

$0.5 \mathrm{ppm}, 1.6 \mathrm{mg} / \mathrm{m}^{3 *}$

$45 \mathrm{~kg}, 100 \mathrm{lbs}$.

Flammable gas. Decomposes at $572^{\circ} \mathrm{F}\left(300^{\circ} \mathrm{C}\right)$ with deposition of arsenic, which vaporizes at $752^{\circ} \mathrm{F}\left(400^{\circ} \mathrm{C}\right)$. Gas is heavier than air and may travel to a source of ignition and flashback. Closed containers may rupture violently when heated.

Lower $5.1 \%$

Upper $78 \%$

\footnotetext{
* Estimated value (10 x TWA [time-weighted average])
} 
INSTABILITY AND

REACTIVITY HAZARDS

STORAGE

RECOMMENDATIONS
Reacts violently with oxidizing materials, acids, halogens. Reacts with light to deposit arsenic.

Separate from oxidizing materials, acids, halogens. Store in a cool, dry, well-ventilated location. Outside or detached storage is preferred.

USUAL SHIPPING CONTAINERS Steel cylinders

MELTING POINT

$-179^{\circ} \mathrm{F}\left(-117^{\circ} \mathrm{C}\right)$

BOILING POINT

$-81^{\circ} \mathrm{F}\left(-62^{\circ} \mathrm{C}\right)$

VAPOR PRESSURE

$>760 \mathrm{~mm} \mathrm{Hg}$ at $20^{\circ} \mathrm{C}$ 
NAME

SYNONYM

FORMULA

DOT CLASS

DESCRIPTION

STATEMENT OF HAZARDS

EMERGENCY RESPONSE

PERSONAL PROTECTIVE

EQUIPMENT

SPILL OR LEAK PROCEDURES

HEALTH HAZARDS

EXPOSURE LIMIT

IDLH

ERPG-2

ERPG-3

OSHA TQ

FIRE AND EXPLOSION

HAZARDS

INSTABILITY AND

REACTIVITY HAZARDS

STORAGE

RECOMMENDATIONS

USUAL SHIPPING CONTAINERS

MELTING POINT

BOILING POINT

VAPOR PRESSURE

\section{Chlorine}

Bertholite

$\mathrm{Cl}_{2}$

Nonflammable gas

Greenish-yellow gas with bleach-like choking odor.

Corrosive. Highly toxic. May be fatal if inhaled. Strong oxidizer. Most combustibles will burn in chlorine as they do in oxygen.

Wear special protective clothing and positive pressure self-contained breathing apparatus.

Approach release from upwind. Stop or control the leak, if this can be done without undue risk. Use water spray to cool and disperse vapors and protect personnel. Control runoff and isolate discharged material for proper disposal. Report any release in excess of 10 pounds.

Irritating and corrosive to all living tissue. Causes severe or permanent eye damage. Causes skin burns. Causes collapse of respiratory system.

$1.0 \mathrm{ppm}, 3.0 \mathrm{mg} / \mathrm{m}^{3}$ (OSHA)

$0.5 \mathrm{ppm}, 1.5 \mathrm{mg} / \mathrm{m}^{3}$ (NIOSH)

$30 \mathrm{ppm}, 87 \mathrm{mg} / \mathrm{m}^{3}$

$3.0 \mathrm{ppm}, 8.7 \mathrm{mg} / \mathrm{m}^{3}$

$20 \mathrm{ppm}, 57.8 \mathrm{mg} / \mathrm{m}^{3}$

$682 \mathrm{~kg}, 1500 \mathrm{lbs}$.

Strong oxidizer. Most combustibles will burn in chlorine, forming irritating and toxic gases. Cylinders may vent rapidly or explode when heated.

Strong oxidizer. Reacts with organic materials, active metals, reducing agents, and ammonia. Reacts with water to form corrosive, acidic solutions.

Store in a cool, dry, well-ventilated location. Separate from combustible, organic, or easily oxidizable materials. Isolate from acetylene, ammonia, hydrogen, hydrocarbons, ether, turpentine, and finely divided metals. Outside or detached storage is preferred.

Shipped in steel cylinders as a liquid under its own vapor pressure. Tank cars and tank barges.

$-150^{\circ} \mathrm{F}\left(-101^{\circ} \mathrm{C}\right)$

$-29^{\circ} \mathrm{F}\left(-34^{\circ} \mathrm{C}\right)$

Gas 
NAME

SYNONYM

FORMULA

DOT CLASS

DESCRIPTION

STATEMENT OF HAZARDS

EMERGENCY RESPONSE PERSONAL PROTECTIVE EQUIPMENT
SPILL OR LEAK PROCEDURES

HEALTH HAZARDS

EXPOSURE LIMIT (ACGIH)

IDLH

ERPG-2

ERPG-3

OSHA TQ

FIRE AND EXPLOSION

HAZARDS

FLAMMABILITY LIMITS

INSTABILITY AND

REACTIVITY HAZARDS

STORAGE

RECOMMENDATIONS

\section{Germane}

Monogermane, Germanium hydride, Germanium Tetrahydride

Germanium Tetrahydride: $\mathrm{GeH}_{4}$

Poison A, Label: Poison Gas and Flammable Gas

Colorless, odorless gas, shipped as a liquefied gas under its own vapor pressure.

Slightly soluble in hot $\mathrm{HCl}$, decomposes in nitric acid.

Poison by inhalation. A hemolytic gas. Ignites spontaneously in air. Incompatible with $\mathrm{Br}_{2}$.

Should symptoms of intoxication appear after inhalation, remove the victim to an uncontaminated area, sparing him any muscular effort. Use artificial respiration if needed. Summon physician immediately. Stop flow of gas.

Cylinders involved in a fire should be kept cool with water to prevent rupturing and the escape of a flammable or spontaneously flammable gas.

Positive pressure, self-contained, breathing apparatus for emergency use; protective gloves (leather), safety goggles, safety shoes, shower, eye bath.

Stop the flow of gas by closing the cylinder valve. Evacuate the area.

Germane is assumed to be toxic due to its resemblance to other hydrides.

$0.2 \mathrm{ppm}, 0.6 \mathrm{mg} / \mathrm{m}^{3}$

None

None

None

None

It is liable to spontaneous combustion in air; however, auto-ignition is not frequently encountered.

Unknown

Decomposes into its elements at $350^{\circ} \mathrm{C}$.

Storage area should be specifically designed for flammable gas cylinders with "NO SMOKING" and "NO OPEN FLAME" signs. Consult local Fire Department Regulations. Installations containing germane must be absolutely gas-tight.

USUAL SHIPPING CONTAINERS Steel Cylinders

MELTING POINT

$-265^{\circ} \mathrm{F},\left(-165^{\circ} \mathrm{C}\right)$ 
CHEMICAL HAZARD PROFILES, Germane, cont.

BOILING POINT

FREEZING POINT

VAPOR PRESSURE $-127^{\circ} \mathrm{C},\left(-89^{\circ} \mathrm{C}\right)$

$-165^{\circ} \mathrm{C}$

$351 \mathrm{kPa}$ at $15^{\circ} \mathrm{C}$ (MSDS)

$76 \mathrm{~mm} \mathrm{Hg}$ at $20^{\circ} \mathrm{C}$ (NFPA) 
NAME

SYNONYM

FORMULA

DOT CLASS

DESCRIPTION

STATEMENT OF HAZARDS

EMERGENCY RESPONSE

PERSONAL PROTECTIVE

EQUIPMENT

SPILL OR LEAK PROCEDURES

HEALTH HAZARDS

EXPOSURE LIMIT (NIOSH)

IDLH

ERPG-2

ERPG-3

OSHA TQ

FIRE AND EXPLOSION

HAZARDS

INSTABILITY AND

REACTIVITY HAZARDS

STORAGE

RECOMMENDATIONS

USUAL SHIPPING

CONTAINERS

MELTING POINT

BOILING POINT

VAPOR PRESSURE

\section{Hydrogen Fluoride}

Hydrofluoric acid gas, fluohydric acid gas, anhydrous hydrofluoric acid, HFA

HF

Corrosive Material

Colorless gas, fumes in air. Irritating odor.

Corrosive. Causes severe eye and skin burns. Highly toxic. May be fatal if inhaled. Rapid release of compressed gas may cause frostbite.

Wear special protective clothing and positive pressure self-contained breathing apparatus.

Releases may require isolation or evacuation. Stop or control the leak, if this can be done without undue risk. Use water spray to cool and disperse vapors, protect personnel, and dilute spills to form less hazardous mixtures. Absorb in noncombustible materials for proper disposal. Report any release in excess of 100 pounds.

Highly toxic. Corrosive. May be fatal if inhaled. Causes severe eye and skin burns. May cause pulmonary edema. Contact with dilute solutions ( $<20 \%$ in water) may not produce immediate pain or visible damage; pain and arrythmia can be delayed for as long as 24 hours after the exposure.

$3.0 \mathrm{ppm}, 2.5 \mathrm{mg} / \mathrm{m}^{3}$

$30 \mathrm{ppm}, 24 \mathrm{mg} / \mathrm{m}^{3}$

$20 \mathrm{ppm}, 16 \mathrm{mg} / \mathrm{m}^{3}$

$50 \mathrm{ppm}, 41 \mathrm{mg} / \mathrm{m}^{3}$

$455 \mathrm{~kg}, 1000 \mathrm{lbs}$

Not combustible, but if involved in a fire is an extreme irritant.

Evolves heat when combined with water.

Reacts with a broad range of materials. Etches glass.

Store in a cool, dry, well-ventilated location. Separate from silica, incompatible metals, concrete, glass, ceramics, and oxidizing materials. Do not put even dilute solutions in glass containers.

Anhydrous gas is shipped in steel cylinders; pressurized tanks on trucks, rail cars, barges. Solutions are shipped in polyethylene, fluorocarbon or wax-lined bottles.

$-117^{\circ} \mathrm{F}\left(-83^{\circ} \mathrm{C}\right)$

$67^{\circ} \mathrm{F}\left(20^{\circ} \mathrm{C}\right)$

$760 \mathrm{~mm} \mathrm{Hg}$ at $20^{\circ} \mathrm{C}$ 
NAME

SYNONYM

FORMULA

DOT CLASS

DESCRIPTION

STATEMENT OF HAZARDS

EMERGENCY RESPONSE PERSONAL PROTECTIVE EQUIPMENT

SPILL OR LEAK PROCEDURES

HEALTH HAZARDS

EXPOSURE LIMIT (NIOSH)

IDLH

ERPG-2

ERPG-3

OSHA TQ

FIRE AND EXPLOSION HAZARDS

FLAMMABILITY LIMITS

INSTABILITY AND

REACTIVITY HAZARDS

STORAGE RECOMMENDATIONS
Nitric Acid

Aquafortis, azotic acid, fuming nitric acid

$\mathrm{HNO}_{3}$

Oxidizer (Over $40 \%$ ), Corrosive Material (40\% or less), oxidizer (fuming)

Colorless to light brown fuming liquid. Fuming nitric acid is reddish fuming liquid.

Oxidizer. Corrosive. Causes severe eye and skin burns. Toxic. May be harmful if inhaled. Fuming nitric acid is more corrosive and reactive.

Wear special protective clothing and positive pressure self-contained breathing apparatus.

Releases may require isolation or evacuation. Approach release from upwind. Stop or control the leak, if this can be done without undue risk. Use water spray to cool and disperse vapors and protect personnel. Prompt cleanup and removal are necessary. Control runoff and isolate discharged material for proper disposal. Report any release in excess of 1000 pounds.

Corrosive. Causes severe eye and skin burns. Toxic. May be harmful if inhaled. Combustion may produce irritants and toxic gases including nitric acid and oxides of nitrogen.

$2.0 \mathrm{ppm}, 5.2 \mathrm{mg} / \mathrm{m}^{3}$

$100 \mathrm{ppm}, 260 \mathrm{mg} / \mathrm{m}^{3}$

None

$20 \mathrm{ppm}, 52 \mathrm{mg} / \mathrm{m}^{3}$ *

$227 \mathrm{~kg}, 500 \mathrm{lbs}$ ( $94.5 \%$ by weight or greater)

Strong oxidizer. Contact of concentrated nitric acid with combustible materials may increase the hazard from fire and may lead to an explosion. Decomposes at fire temperature with release of oxides of nitrogen. Releases hydrogen gas on contact with many metals.

Not applicable.

Strong oxidizer. Reacts vigorously with combustibles or readily oxidizable materials, organic solvents, metal powders, carbides, cyanides, sulfides, and alkalies. See National Fire Protection Association (NFPA) 491M. Reacts with alkalies. Fuming nitric acid dissolves in water, releasing heat. Adding small quantities of water to concentrated nitric acid may cause vigorous reaction.

Store in a cool, dry, well-ventilated location. Separate from alkalies, metals, organics, and other oxidizing materials. See also NFPA Standard 43A, Code for the Storage of Solid and Liquid Oxidizers.

* Estimated value (10 x TWA [time-weighted average]) 
CHEMICAL HAZARD PROFILES, Nitric Acid, cont.

USUAL SHIPPING

CONTAINERS

MELTING POINT

BOILING POINT

VAPOR PRESSURE
Glass bottles and carboys, special metal drums; tanks on trucks, rail cars, barges.

$-44^{\circ} \mathrm{F}\left(-42^{\circ} \mathrm{C}\right)$

$181^{\circ} \mathrm{F}\left(83^{\circ} \mathrm{C}\right)$

Fuming: $6.8 \mathrm{~mm} \mathrm{Hg}$ at $20^{\circ} \mathrm{C}$

95-98\%: $113 \mathrm{~mm} \mathrm{Hg}$ at $38^{\circ} \mathrm{C}$

67\%: $6.8 \mathrm{~mm} \mathrm{Hg}$ at $20^{\circ} \mathrm{C}$

over $40 \%: 8-11 \mathrm{~mm} \mathrm{Hg}$ at $25^{\circ} \mathrm{C} ; 17-25 \mathrm{~mm} \mathrm{Hg}$ at $38^{\circ} \mathrm{C}$ 
NAME

SYNONYM

FORMULA

DOT CLASS

DESCRIPTION

STATEMENT OF HAZARDS

EMERGENCY RESPONSE

PERSONAL PROTECTIVE EQUIPMENT

SPILL OR LEAK PROCEDURES

HEALTH HAZARDS

EXPOSURE LIMIT (NIOSH)

IDLH

ERPG-2

ERPG-3

OSHA TQ

FIRE AND EXPLOSION

HAZARDS

FLAMMABILITY LIMITS

INSTABILITY AND

REACTIVITY HAZARDS

STORAGE

RECOMMENDATIONS

USUAL SHIPPING CONTAINERS

MELTING POINT

BOILING POINT

VAPOR PRESSURE
Phosgene

Carbon oxychloride, carbonyl chloride, chloroformyl chloride

$\mathrm{COCl}_{2}$

Poison A

Low-boiling liquid with smell ranging from musty hay at low concentrations to sharp and pungent odor at high concentrations.

Highly toxic. Low-boiling liquid. May be fatal if inhaled. Corrosive. Causes severe burns of eyes and skin.

Wear special protective clothing and positive pressure self-contained breathing apparatus.

Approach release from upwind. Releases may require isolation or evacuation. Stop or control the leak, if this can be done without undue risk. Water will increase evaporation of spilled material. Control runoff and isolate discharged material for proper disposal. Report any release in excess of 10 pound.

Highly toxic. May be fatal if inhaled. Pulmonary edema may be delayed up to 24 hours. Severely irritating to eyes and respiratory tract. Corrosive. Liquid causes severe burns of eyes and skin. Toxic hydrogen chloride is formed when water reacts with phosgene.

$0.1 \mathrm{ppm}, 0.4 \mathrm{mg} / \mathrm{m}^{3}$

$2 \mathrm{ppm}, 8 \mathrm{mg} / \mathrm{m}^{3}$

None

$1 \mathrm{ppm}, 4 \mathrm{mg} / \mathrm{m}^{3}$

$45 \mathrm{~kg}, 100 \mathrm{lbs}$

Low-boiling liquid.

Not applicable.

Reacts with alkalies, ammonia, alcohols, active metals, and many other materials.

Store in a cool, dry, well-ventilated location. Outside or detached storage is preferred. Must be stored in a dry location. 
NAME

SYNONYM

FORMULA

DOT CLASS

DESCRIPTION

STATEMENT OF HAZARDS

EMERGENCY RESPONSE PERSONAL PROTECTIVE EQUIPMENT

SPILL OR LEAK PROCEDURES

HEALTH HAZARDS

EXPOSURE LIMTT

IDLH

ERPG-2

ERPG-3

OSHA TQ

FIRE AND EXPLOSION

HAZARDS

FLAMMABILITY LIMITS

INSTABILITY AND

REACTIVITY HAZARDS

STORAGE

RECOMMENDATIONS

USUAL SHIPPING CONTAINERS

MELTING POINT

BOILING POINT

VAPOR PRESSURE
Uranium Hexaflouride

None Found.

$\mathrm{UF}_{6}$

Not Available.

Colorless, volatile crystal, sublimes. Soluble in liquid bromine, chlorine, carbon tetrachloride, sym-tetrachloroethane, and fluorocarbons.

Highly corrosive. Very reactive. Reacts vigorously with water (to form $\mathrm{HF}$ and $\mathrm{UO}_{2} \mathrm{~F}_{2}$, which will clog respirator filters), alcohol, ether, and most metals.

Self-contained breathing apparatus.

Cloud may be knocked down with water, but aqueous HF will be formed (see Hydrogen Fluoride). Stay clear of cloud.

On contact with water forms HF (see Hydrogen Fluoride) and $\mathrm{UO}_{2} \mathrm{~F}_{2}$, which will clog respirator filters.

None

$105 \mathrm{mg} / \mathrm{m}^{3}$ *

None

$180 \mathrm{mg} / \mathrm{mn}^{3 *}$

$2000 \mathrm{~kg}, 4400 \mathrm{lbs} *$

Not Available.

Not applicable.

Reactive with water. Attacks glass in the presence of only a small amount of water (water becomes a reaction intermediate which is regenerated by the second stage of the reaction). Also reacts vigorously with hydrocarbon oils, alcohol, ether, and most metals.

Store in clean, dry containers. Can be stored indefinitely in glass containers that have been vacuum baked.

Usually metal. Glass may be used if precautions are taken to remove all water from the container.

$64.5^{\circ} \mathrm{C}$ at $2 \mathrm{~atm}$

Sublimation, $56^{\circ} \mathrm{C}\left(133^{\circ} \mathrm{F}\right)$. Triple point, $1140 \mathrm{~mm} \mathrm{Hg}, 64.1^{\circ} \mathrm{C}$ $\left(147.3^{\circ} \mathrm{F}\right)$

$80.8 \mathrm{~mm} \mathrm{Hg}$ at $20.4^{\circ} \mathrm{C}$

\footnotetext{
* Based on the hydrogen fluoride value and the reaction UF6 $+2 \mathrm{H} 2 \mathrm{O}->\mathrm{UOF} 2+4 \mathrm{HF}$

* Estimated TQ (threshold quantity)
} 
NAME

SYNONYM

FORMULA

DOT CLASS

DESCRIPTION

STATEMENT OF HAZARDS

EMERGENCY RESPONSE PERSONAL PROTECTIVE EQUIPMENT

SPILL OR LEAK PROCEDURES

HEALTH HAZARDS

EXPOSURE LIMIT

IDLH

ERPG-2

ERPG-3

OSHA TQ

FIRE AND EXPLOSION

HAZARDS

FLAMMABILITY LIMITS

INSTABILITY AND

REACTIVITY HAZARDS

STORAGE

RECOMMENDATIONS

USUAL SHIPPING CONTAINERS Glass bottles and carboys, special drums, tank trucks, tank cars, and

MELTING POINT

BOILING POINT

VAPOR PRESSURE tank barges.

Sulfuric Acid

Oleum, oil of vitriol, battery acid, chamber acid, fertilizer acid

$\mathrm{H}_{2} \mathrm{SO}_{4}$

Corrosive material

Colorless to brown, odorless, oily liquid.

Corrosive. Causes severe eye and skin burns. Water reactive. Oleum is extremely reactive with water. Reaction with metals may produce hydrogen gas.

Wear special protective clothing and positive pressure self-contained breathing apparatus.

Keep water away from release. Stop or control the leak, if this can be done without undue risk. Control runoff and isolate discharged material for proper disposal. Report any release in excess of 1000 pound.

Corrosive. Causes severe eye and skin burns.

$25 \mathrm{ppm}, 1.0 \mathrm{mg} / \mathrm{m}^{3}$ (OSHA)

$25 \mathrm{ppm}, 1.0 \mathrm{mg} / \mathrm{m}^{3} / 10-\mathrm{hr}$ TWA (NIOSH)

$80 \mathrm{mg} / \mathrm{m}^{3}$

$10 \mathrm{mg} / \mathrm{m}^{3}$

$30 \mathrm{mg} / \mathrm{m}^{3}$

$455 \mathrm{~kg}, 1000 \mathrm{lbs}$ (Oleum-- $65 \%$ to $80 \%$ by weight; also called Fuming Sulfuric Acid)

Not combustible. Strong dehydrating agent, which may cause ignition of finely divided materials on contact. Reaction with metals may produce hydrogen gas. Oxides of sulfur may be produced in fire.

Not applicable.

Water reactive. Reacts with alkalies, releasing heat. Reacts with metals, releasing hydrogen gas. Reacts with picrates, chlorates, nitrates, and many other materials.

Store in cool, dry, well-ventilated location. Separate from combustibles and other reactive materials. Separate from carbides, chlorates, fulminates, nitrates, picrates, and powdered metals.

$50^{\circ} \mathrm{F}\left(10^{\circ} \mathrm{C}\right)(100 \%)$; varies with acid strength.

$518^{\circ} \mathrm{F}\left(270^{\circ} \mathrm{C}\right)(100 \%)$; varies with acid strength.

Less than $0.001 \mathrm{~mm} \mathrm{Hg}$ at $20^{\circ} \mathrm{C}(96-100 \%)$ 


\section{APPENDIX I - Summary of Department of Energy (DOE) Chemical Incidents}





\section{APPENDIX I}

\section{REVIEW OF ACCIDENT/INCIDENT DATA FROM SAFETY PERFORMANCE MEASUREMENT SYSTEM (SPMS)}

\section{Background}

Accident data in the SPMS database is contained in a module called the Computerized Accident/Incident Reporting System (CAIRS). The CAIRS database contains injury/illness and motor vehicle accident records for all Department of Energy (DOE) and contractor organizations from calendar year 1981 to the present and property loss records from 1975 to the present. The database contains over 50,000 records. The actual number of accident events is somewhat less than the number of records or reports, because a single event might result in multiple reports with one for each injury and one for any resulting property damage. Multiple reports occur in only a small fraction of the accident events with high consequence events being more likely to have multiple reports.

\section{Analysis of High-Consequence DOE Chemical Accidents (Type A or B Investigations Required)}

To determine whether chemical accidents represent catastrophic loss potential within DOE, accidents requiring Type A and B accident investigations were examined. Type A investigations are required for accidents that result in the following: (1) a fatality; (2) five or more lost workday cases; (3) an accidental release of pollutants with potentially significant effects on the public or offsite environment; (4) a release designated as "hazardous" by the Environmental Protection Agency (EPA); (5) property loss over $\$ 250,000$, or (6) nuclear criticality or an internal uptake or whole-body radiation exposure over five times the annual standard. Type $B$ investigations are required for accidents that result in the following: (1) an occupational illness that requires hospitalization; (2) five or more occupational illnesses from the same cause, of which at least one is a lost workday case; (3) an occupational illness that results in more than 5 days away from work, property loss over $\$ 50,000$ and not more than $\$ 250,000$, or an internal uptake or quarterly radiation exposure over the annual limits.

When the SPMS system was accessed in February 1992, the CAIRS database contained 137 reports from Type A accident investigations and 153 reports from Type B accident investigations for a total of 290 reports.

Of the 137 Type A accident reports, 9 were considered to be chemically related reports. Two accidents resulted in multiple reports; thus, only six accident events required Type A investigations. Five of the six were fires or explosions; one accident involved a spill and the resulting contamination from a dissolution process involving nitric acid and plutonium. Total property losses from these five events reached $\$ 1.6$ million. Chemical accidents (explosions) resulted in 2 of DOE's 50 fatalities over this 11-year period. These two events occurred in natural gas explosions. 
Type B investigations were conducted for 13 chemically related accident events, which resulted in 24 reports due to 3 events in which multiple workers were affected. Of the 13 accidents, 9 involved fires or explosions, and 2 of those resulted in radioactive contamination. The remaining four accidents included one acid leak and three chemical exposure accident events. Table I.1 summarizes the Type A and Type B chemical accident events.

Chemical accident reports represented 11 percent of the accident reports from Type A and B investigations. Chemical accidents other than those involving high explosives were responsible for 4 percent of total property losses recorded in Type A and B investigations (excluding losses from motor vehicle accidents). Chemical injury and illnesses reports comprised 34 percent of the injury and illness reports from all sources and 20 percent of the total lost work days. However, since there may be multiple reports for one event, chemical injury and illness events represented only 14 percent of the total illness and injury events. One event resulted in nine reports of chemical exposure, with no resulting lost time from the exposures.

Chemicals resulting in explosions or fires were methane, hydrofluoric acid, hydrogen, nitric acid, plutonium, and acetylene. Chemicals responsible for occupational injuries and illnesses were NaF, a sulfur additive for water treatment, and halon thermal decomposition products.

\section{Analysis of All DOE Chemical Injuries and Illnesses (Type A, B, or C Investigations)}

For the period covering calendar year 1981-1991 (Note: Data taken from SPMS December 13, 1991), chemical injuries and illnesses comprised 2 percent of the total injury and illness records from Type A, B, and C investigations. Based on 80 recent chemical accidents, these events were about evenly distributed among four categories:

- $\quad$ Eye Injuries (including chemical irritations and burns)

- $\quad$ Skin Burns (corrosive, cryogenic, and hot chemicals)

- Dermatitis (including immediate and chronic use cases)

- Inhalation Injuries (including acute and chronic toxic effects and anoxia).

The categories of chemicals frequently associated with DOE's chemical injuries and illnesses were:

- Solvents (including alcohols and chlorinated hydrocarbons)

- Corrosive chemicals (including acids and caustics)

- $\quad$ Oil and petroleum products

- Halon and its thermal degradation products

The ratio of serious chemical injury and illness events requiring Type $A$ or $B$ investigations to the total number of recordable chemical injury or illness events (any occupational illness or injuries requiring more than simple first-aid) is less than 1 accident in 100. The ratio of chemical injuries and illnesses to all classes of injuries and illnesses is 1 chemical injury or illness for every $\mathbf{5 0}$ injuries or 
illnesses. The expected number of chemical-related events requiring a Type A or B investigation is less than two per year across the complex.

\section{Summary and Perspective}

The review of all accidents recorded in the CAIRS database over calendar year 1981-1991 did not reveal any cases of chemical release that resulted in injury or exposure of the public. Chemical accidents represent a small percentage (2 percent) of the total DOE accident experience (excluding motor vehicle accidents). However, 11 percent of the accidents that required Type A or B investigations involved chemical use. The frequency of high consequence chemical accidents that require a Type A or B investigation is less than two per year throughout DOE.

\section{REVIEW OF OCCURRENCE DATA FROM THE OCCURRENCE REPORTING AND PROCESSING SYSTEM (ORPS)}

\section{Background}

The ORPS database contains information about occurrences at DOE facilities, causes of these occurrences, and corrective actions taken. Occurrences are classified as either emergency, unusual, or off-normal in accordance with guidance contained in DOE Order 5000.3A. The database includes occurrences from 1990 to the present. As of March 26, 1992, there were over 10,000 records or cases in the database.

\section{Analysis of Emergency Occurrences}

There were only nine emergency occurrences in the ORPS database as of June 1992. The only emergency occurrence that could be considered chemical in nature was a fire in a coal bunker of a boiler plant.

\section{Analysis of Remaining Occurrences}

In searching for occurrences of a chemical nature, three categories were evaluated:

(1) Hazardous Substances/Regulated Pollutants -- 217 unusual occurrences; 987 offnormal occurrences

(2) Fire/Explosions -- 2 emergency occurrences; 27 unusual occurrences; 77 off-normal occurrences

(3) Occupational Illness/Injuries -- 35 unusual occurrences; 148 off-normal occurrences 
The vast majority of the occurrences in the hazardous substance/regulated pollutant category were minor spills of fuels, antifreeze, hydraulic fluid, paint, or other products. There were also a large number of cases where discharges exceeded NPDES permit limits. About 10 percent of the occurrences in this category were considered to be chemical releases with limited potential worker exposure to toxics or fire/explosions. These occurrences included:

- $\quad$ small quantities of mercury from instrumentation

- $\quad$ asbestos from deteriorating insulating/construction materials

- $\quad$ acid and caustic spills in laboratory, process operations, and reactors

- fuel leaks, including crude oil and propane at petroleum reserve locations

- gas leaks including chlorine, boron trifluoride, hydrogen fluoride, fluorine

- small quantities of organic solvents

- $\quad$ other process chemicals including EDTA, HEDTA, hydroxyacetic acid.

Only 8 of the 106 fire/explosion occurrences appeared to be chemical related. These are as follows:

- $\quad$ Fire in a boiler plant coal bunker (noted previously)

- Coal dust explosion and fire in a coal-fired steam generating facility

- Rupture of a dissolver in a hot chemistry laboratory

- Uranium chip fires (three)

- Isopropyl alcohol fire

- Unidentified chemical fires (two)

Of the 148 occurrence reports in the illness/injury category, there were 19 reports of actual or potential chemical exposure, injury, or illness. The chemicals involved were:
Acids (3) Lead (1)
Asbestos (1) Mercury (1)
Beryllium (2) Welding fumes (1)
Chlorine (1) Asphyxia in nitrogen-purged system (1)
Concrete (1) Unidentified chemical (7)

Review and Root Causes of Recent Chemical Occurrence Reports (January 1991-June 1992)

Recent chemical occurrence reports were identified, and a representative set of the more significant occurrence reports was summarized. Refer to the attachment to the Secretarial Information Memorandum, Appendix A, for the summaries of occurrences between January 1991 and March 1992 and to Table I.2 for the summaries between April 1992 and July 1992.

The occurrence reports listed include three events that required Type B accident investigations and were, thus, the most significant in terms of consequences. The first of these events was a coal dust explosion and fire in a steam plant that resulted in approximately $\$ 60,000$ damage. The second event 
was a sulfuric acid splash that occurred while attempting to flush an acid supply line prior to a decommissioning and removal project. About a gallon of concentrated (93 percent) acid was sprayed on three workers from an unrestrained polyvinylchloride (PVC) pipe when a pneumatically operated valve was opened on the pressurized acid line. The last event involved the accidental release of hydrogen fluoride through an open valve downstream from a rupture disk.

Root causes of the significant chemical occurrences were categorized as follows (47 occurrences with cause information):

- 26 percent management problems

- 26 percent equipment or material problems

- 21 percent personnel errors

- 15 percent lack of or inadequate procedures

- 13 percent design deficiencies

This breakdown is fairly evenly divided. It indicates that chemical safety may be improved with increased management attention, preventive maintenance, and inspection to ensure the mechanical integrity of chemical containers and process equipment and with improved procedures and training.

\section{$\underline{\text { Near Misses }}$}

An additional factor that should be considered in any chemical accident database review is the potential for an event to result in significantly higher consequences with only minor changes in the accident circumstance; that is, consideration of near misses. It is difficult to surmise whether an event could be classified as a near miss based upon the limited information provided in the occurrence reports in the ORPS database. However, the recent hydrogen fluoride (HF) release at $\mathrm{Y}-12$ is an obvious example. The Type $B$ accident investigation for this release was reviewed, and several conditions were identified that, only by happenstance, served to reduce the accident consequences. These conditions included the occurrence of the accident off-shift and the location of employees, the cold temperature, stable atmosphere, and wind direction, all of which served to moderate the consequences of the release of HF. Other potential examples of near misses identified in the ORPS database search included the propane releases, sulfuric acid spill, and isopropyl alcohol fire described in Table I.2.

\section{Summary and Perspective}

Spot checks of the complete ORPS database indicate that most of the chemical-related occurrences were found by searching the three categories noted above. Based on the analysis of these categories, chemical occurrences comprise less than 2 percent of the total occurrence reports. Chemicals do not appear to be a cause of high- consequence accidents, as noted by the lack of chemical incidents classified as emergency occurrences. 


\section{CONCLUSIONS}

A wide variety of chemical accidents/incidents have occurred and are occurring at DOE facilities. Although their frequencies and consequences do not appear to be large when compared with all accidents at DOE facilities, deficiencies in a number of chemical safety areas have been noted in current practices. These deficiencies, in addition to a number of recent potential near misses, indicate the need for an enhanced chemical safety program at DOE. 
Table I.1

\section{Accidents Requiring Type $A$ and B Investigations (as of 12/31/91)}

Date Case \# Description

06-03-81 81134 Tube trailer detonated during transfer of hydrogen gas, injuring two workers.

09-06-81 81029 Compressor valve left open; leaking gas ignited on restart; two injured.

03-31-82 82015 Fire damaged exhaust hood, fan, and duct; unattended propane burner.

04-02-82 82284 Several hundred gallons of dilute nitric acid with Plutonium contaminated equipment.

12-08-82 82394 Reaction to sodium fluoride during repackaging; procedure violation.

82395 Reaction to sodium fluoride during repackaging; procedure violation.

04-19-83 $83054 \mathrm{CCl}_{4}$-soaked plutonium chips exploded in burn vessel causing contamination.

05-22-83 83032 Leaking propane gas resulted in explosion of microwave relay station.

12-18-83 83041 Fire destroyed wellhead and tubing unit when fluid/gas was ignited by sparks.

07-13-84 84033 Killed in gas explosion in compressor building; procedure not followed. 84034 Multiple injuries from gas explosion; procedure not followed.

84036 Gas explosion in compressor building; lockout procedure not followed.

04-11-85 85164 Leaking hose connection on acetylene cylinder ignited; burned lagging.

06-26-85 85018 Sixteen-inch gas pipe ruptured and burned due to internal corrosion, inspection LTA.

08-25-85 85020 Sump tank exploded causing fire; resulted in death.

85021 Sump tank exploded and destroyed tanks and vehicle.

05-08-86 86370 Respiratory illness from decomposed sulphurous additive to water chiller.

12-09-86 86106 Fumes from halon reaction in incinerator irritated lungs and eyes.

86107 Fumes from halon reaction in incinerator irritated eyes; conjunctivitis.

86108 Fumes from halon reaction in incinerator irritated eye; conjunctivitis.

\section{Table I.1}


Accidents Requiring Type A and B Investigations (as of 12/31/91)

Date $\quad$ Case \# Description

86109 Fumes from halon reaction in incinerator irritated eyes; conjunctival burns.

86121 Fumes from halon reaction in incinerator irritated eyes; conjunctivitis.

86122 Fumes from halon reaction in incinerator irritated eyes and lungs.

86123 Fumes from halon reaction in incinerator irritated and burned eyes.

86124 Fumes from halon reaction in incinerator irritated eyes; conjunctivitis.

86125 Fumes from halon reaction in incinerator irritated eye; conjunctivitis.

12-19-87 87005 Nitric acid spilled from feed tank through acid-incompatible pipe nipple.

02-10-88 88001 Received head and facial burns when welding arc ignited gas surge in vessel.

88002 Received head and facial burns when welding arc ignited gas surge in vessel.

88003 Fire/heat damage occurred in vessel when welding arc ignited surge of gas.

06-15-89 89096 Combustible lacquer residues in spray booth ignited during lightning storm.

01-23-91 91016 Coal dust accumulated in fire box and exploded, resulting in boiler fire.

02-09-91 91012 Pyrex dissolver exploded during dissolution of uranium metal. 


\section{Summary of Selected Chemical Safety Deficiencies \\ From April 1992 Through Mid-June 1992 \\ (Supplemental to List attached to Secretarial Memorandum in Appendix A)}

4/29/92 - Hydrochloric Acid Spill - A leak occurred in a pipe that runs between an external 6,500-gallon hydrochloric acid (HCL) tank and a deionized water facility. Several hundred gallons of diluted (37 percent) HCL solution spilled onto the ground and ran down a small concrete-lined waterway to a concrete-paved driveway; 3 gallons also leaked into the facility itself. There were no injuries or personnel contaminations from this spill. The spill was contained and stabilized for cleanup beginning on April 30, 1992.

6/3/92 - Overfilled Sulfuric Acid Tank - At about 1100 hours, a 3,500-gallon sulfuric acid tank located outside of Building 108 along the north exterior wall overflowed about 3 to 5 gallons of product into a barrel at the end of the tank overflow pipe. The barrel was located within a diked area along with the tank.

6/25/92 - Sulfuric Acid Spill - Concentrated sulfuric acid was being drained from a bulk tank through a double-valve drain to a tygon hose to a 55-gallon drum. The hose slipped from the bung on the drum and drained approximately 1 quart of acid onto the pallets supporting the drums. The hose was immediately reinserted into the drum, effectively stopping the source of the spill. No acid was observed to have reached the ground. 
APPENDIX $\mathbf{J}$ - Summary of Comparative Analysis of Department of Energy (DOE) Orders

to the

Occupational Safety and Health (OSHA) Administration

Part 29, Code of Federall Regulations (CFR), Section 1910.119

Requirements 



\section{OVERVIEW OF APPENDIX J}

This matrix outlines the current DOE standing with respect to the new Process Safety Management (PSM) rule by analyzing 32 DOE Orders, 2 DOE Safety Guides, and 1 DOE Notice that contain information pertinent to chemical process safety. The matrix also compares the specific requirements of the orders and guides with the requirements of the new PSM rule and categorizes the 14 requirements of the PSM rule having been complied with partially (Partial), complied with fully (Full), or not complied with at all (None). Listed beside the sections and subsections of the PSM rule in the matrix is a column containing the DOE Orders that relate to specific PSM rule sections or subsections. The comments and order-development requirements addressed in the last column contain observations on the scope of the orders and suggestions for strengthening the DOE Chemical Process Safety Program with respect to the applicable PSM requirements.

The matrix is intended to help illustrate a top-down evaluation of the DOE chemical safety requirements and the line organizations' chemical safety programs. The matrix points out (1) overt chemical safety program weaknesses, (2) DOE's status of conformance with the new Occupational Safety and Health Administration (OSHA) rule, 29 CFR Part 1910.119, "Process Safety Management of Highly Hazardous Chemicals," and (3) the need for improved chemical safety policy and guidance for application at DOE facilities over the next year. Specifically, the study for which this matrix was developed addresses item (2), above, in the review of DOE Orders pertinent to Chemical Process Safety and the comparative analysis with the PSM rule that was performed to determine specific areas of compliance strengths and weaknesses. 
Appendix $\mathrm{J}$

Matrix -- Cross-cut of DOE Orders to the OSHA Process Safety Management Rule

\begin{tabular}{|c|c|c|c|c|c|}
\hline Point & Section & Subsection & $\begin{array}{c}\text { Compliance } \\
\text { (Partial, Full, None) }\end{array}$ & Related Orders & $\begin{array}{l}\text { Comments and Order } \\
\text { Development Requirements }\end{array}$ \\
\hline \multirow[t]{4}{*}{ C. Employee Participation } & & & Partial & & \multirow{4}{*}{$\begin{array}{l}\text { 5483.XX } \\
\text { PSM Onder } \\
\text { PSM Guidance }\end{array}$} \\
\hline & $\begin{array}{l}\text { 1. Employers shall develop a written } \\
\text { plan of action regarding } \\
\text { implementation of employee } \\
\text { participation required by this } \\
\text { paragraph. }\end{array}$ & & Partial & 5483.XX & \\
\hline & $\begin{array}{l}\text { 2. Employers shall consult } \\
\text { employees on the conduct and } \\
\text { development of process hazards } \\
\text { analysis and on the development } \\
\text { of other elements of process } \\
\text { safety management in this } \\
\text { standard. }\end{array}$ & & Partial & $\begin{array}{l}5480.10 \\
5483.1 \mathrm{~A} \\
5483 . \mathrm{XX}\end{array}$ & \\
\hline & $\begin{array}{l}\text { 3. Employers shall provide to } \\
\text { employees access to process } \\
\text { hazards analyses and to all other } \\
\text { information required to be } \\
\text { developed under this standard. }\end{array}$ & & Partial & $\begin{array}{l}\text { 3790.1A, } \\
5480.10 \\
5483.1 \mathrm{~A}, \\
5483 . \mathrm{XX}\end{array}$ & \\
\hline \multirow[t]{4}{*}{ D. Process Safety Information } & $\begin{array}{l}\text { The employer shall complete a } \\
\text { compilation of written process safety } \\
\text { information before conducting any } \\
\text { process hazard analysis. The } \\
\text { information should include: }\end{array}$ & & Full & & \multirow{4}{*}{$\begin{array}{l}\text { SG/830.110 provides } \\
\text { compliance only when the } \\
\text { chemical process is covered } \\
\text { as part of a nuclear Safety } \\
\text { Analysis Report (SAR). } \\
\text { PSM Order }\end{array}$} \\
\hline & $\begin{array}{l}\text { 1. Information pertaining to the } \\
\text { hazards of the highly hazardous } \\
\text { chemicals in the process. }\end{array}$ & & Full & $\begin{array}{l}3790.1 \mathrm{~A} \\
5400.1,5480.10 \\
5500.1 \mathrm{~B} \\
5500.3 \mathrm{~A} \\
\text { SG/830.110 }\end{array}$ & \\
\hline & $\begin{array}{l}\text { 2. Information pertaining to the } \\
\text { technology of the process. }\end{array}$ & & Full & $\begin{array}{l}5480.1 \mathrm{~B} \\
\mathrm{SG} / 830.110\end{array}$ & \\
\hline & $\begin{array}{l}\text { 3. Information pertaining to the } \\
\text { equipment in the process. }\end{array}$ & & Full & $\begin{array}{l}\text { 5480.1B, } \\
\text { SG/830.110 }\end{array}$ & \\
\hline
\end{tabular}


Appendix J

Matrix -- Cross-cut of DOE Orders to the OSHA Process Safety Management Rule

\begin{tabular}{|c|c|c|c|c|c|}
\hline Point & Section & Subsection & $\begin{array}{c}\text { Compliance } \\
\text { (Partlal, Full, None) }\end{array}$ & Related Orders & $\begin{array}{l}\text { Comments and Order } \\
\text { Development Requirements }\end{array}$ \\
\hline \multirow[t]{10}{*}{ E. Process Hazard Analysis } & & & Full & & \multirow{10}{*}{$\begin{array}{l}\text { SG/830.110 provides } \\
\text { compliance only when the } \\
\text { chemical process is covered } \\
\text { as part of a nuclear SAR. } \\
\text { PSM Order } \\
\text { Scenario Screening and } \\
\text { Acceptance Criteria }\end{array}$} \\
\hline & $\begin{array}{l}\text { 1. The employer shall perform an } \\
\text { initial process hazard analysis on } \\
\text { processes covered by this } \\
\text { standard. }\end{array}$ & & Full & $\begin{array}{l}\text { 5480., 5483.XX, } \\
5500.3 \mathrm{~A} \\
\text { SG/830.110 }\end{array}$ & \\
\hline & $\begin{array}{l}\text { 2. The employer should use } \\
\text { appropriate methodologies in } \\
\text { evaluating hazards of process } \\
\text { being analyzed. }\end{array}$ & & Full & $\begin{array}{l}5481.1 \mathrm{~B}, \\
5483 . \mathrm{XX} \\
5500.3 \mathrm{~A} \\
\text { SG/830.110 } \\
\end{array}$ & \\
\hline & \multirow{7}{*}{$\begin{array}{l}\text { 3. The Process Hazard Analysis } \\
\text { should address: }\end{array}$} & & Full & & \\
\hline & & i. The hazards of the process. & Full & $\begin{array}{l}5480 ., 5480.10 \text {, } \\
5481.1 \mathrm{~B}, \\
5483 . \mathrm{XX}, \\
5500.1 \mathrm{~B}, \\
5500.3 \mathrm{~A}, \\
\text { SG/830.110 }\end{array}$ & \\
\hline & & $\begin{array}{l}\text { ii. The identification of any previous } \\
\text { incident which had a likely } \\
\text { potential for catastrophic } \\
\text { consequences. }\end{array}$ & Full & $\mathrm{SG} / \mathbf{8 3 0 . 1 1 0}$ & \\
\hline & & $\begin{array}{l}\text { iii. Engineering and administrative } \\
\text { controls applicable to the hazards. }\end{array}$ & Full & $\begin{array}{l}\text { 5480., 5481.1B, } \\
5500.3 \mathrm{~A} \\
\text { SG/830.110 }\end{array}$ & \\
\hline & & $\begin{array}{l}\text { iv. Consequences of failure of } \\
\text { engineering and administrative } \\
\text { controls. }\end{array}$ & Full & $\begin{array}{l}5480 ., 5481.1 \mathrm{~B}, \\
5483 . \mathrm{XX} \\
5500.3 \mathrm{~A} \\
\mathrm{SG} / 830.110 \\
\end{array}$ & \\
\hline & & v. Facility siting. & Full & $\mathrm{SG} / \mathbf{8 3 0 . 1 1 0}$ & \\
\hline & & vi. Human factors. & Full & $\mathrm{SG} / \mathbf{8 3 0 . 1 1 0}$ & \\
\hline
\end{tabular}


Appendix $\mathrm{J}$

Matrix -- Cross-cut of DOE Orders to the OSHA Process Safety Management Rule

\begin{tabular}{|c|c|c|c|c|c|}
\hline Point & Section & Subsection & $\begin{array}{c}\text { Compliance } \\
\text { (Partial, Full, None) }\end{array}$ & Related Orders & $\begin{array}{l}\text { Comments and Order } \\
\text { Development Requirements }\end{array}$ \\
\hline \multirow[t]{5}{*}{ E. Process Hazard Analysis (cont.) } & & $\begin{array}{l}\text { vii. A qualitative evaluation of a range } \\
\text { of the possible safety and health } \\
\text { effects of failure of controls on } \\
\text { employees. }\end{array}$ & Full & $\begin{array}{l}\text { 5483.XX, } \\
5500.3 \mathrm{~A} \\
\text { SG/830.110 }\end{array}$ & \\
\hline & $\begin{array}{l}\text { 4. The process hazard analysis shall } \\
\text { be performed by a team with } \\
\text { expertise in engineering and } \\
\text { process operations, and the team } \\
\text { should include at least one } \\
\text { employee with specific knowledge } \\
\text { of the process being examined and } \\
\text { one employee knowledgeable in } \\
\text { the hazard analysis methodology } \\
\text { being used. }\end{array}$ & & Full & $\mathrm{SG} / \mathbf{8 3 0 . 1 1 0}$ & \\
\hline & $\begin{array}{l}\text { 5. The employer shall establish a } \\
\text { system to promptly address the } \\
\text { teams findings and } \\
\text { recommendations, assure that the } \\
\text { recommendations are resolved in } \\
\text { a timely manner and that } \\
\text { resolution is documented, } \\
\text { document what actions are to be } \\
\text { taken, complete the actions as } \\
\text { soon as possible, develop a } \\
\text { schedule for action completion, } \\
\text { and communicate the actions to } \\
\text { the affected employees. }\end{array}$ & & Full & $\begin{array}{l}5480.10 \\
5481.1 B \\
\text { SG/830.110 }\end{array}$ & \\
\hline & $\begin{array}{l}\text { 6. Update the process hazards } \\
\text { analysis every five years (at } \\
\text { least). }\end{array}$ & & Full & $\mathrm{SG} / 830.110$ & \\
\hline & $\begin{array}{l}\text { 7. Employers shall retain process } \\
\text { hazard analyses and updates or } \\
\text { revalidations for each process } \\
\text { covered by this section, as well as } \\
\text { the documented resolution of } \\
\text { recommendations for the life of } \\
\text { the process. }\end{array}$ & & Full & $\begin{array}{l}\text { 5481.1B, } \\
\text { SG/830.110 }\end{array}$ & \\
\hline
\end{tabular}


Appendix J

Matrix -- Cross-cut of DOE Orders to the OSHA Process Safety Management Rule

\begin{tabular}{|c|c|c|c|c|c|}
\hline Point & Section & Subsection & $\begin{array}{c}\text { Compliance } \\
\text { (Partial, Full, None) }\end{array}$ & Related Orders & $\begin{array}{l}\text { Comments and Order } \\
\text { Development Requirements }\end{array}$ \\
\hline \multirow[t]{9}{*}{ F. Operating Procedures } & & & Full & & \multirow{9}{*}{$\begin{array}{l}\text { SG/830.110 provides } \\
\text { compliance only when the } \\
\text { chemical process is covered } \\
\text { as part of a nuclear SAR. } \\
\text { PSM Order }\end{array}$} \\
\hline & \multirow{5}{*}{$\begin{array}{l}\text { The employer shall develop and } \\
\text { implement written operating } \\
\text { procedures that provide clear } \\
\text { instructions for safely conducting } \\
\text { activities addressing each of the } \\
\text { following: }\end{array}$} & & Full & & \\
\hline & & i. Steps for each operating phase. & Full & $\begin{array}{l}5480.19,5480.5, \\
5500.1 \mathrm{~B}, \\
\text { SG/830.110 }\end{array}$ & \\
\hline & & ii. Operating limits. & Full & $\begin{array}{l}\text { 5480.19, 5480.5, } \\
5481.1 \mathrm{~B}, \\
\text { SG/830.110 }\end{array}$ & \\
\hline & & iii. Safety and health considerations. & Full & $\begin{array}{l}5480.19 \\
5500.1 B, \\
\text { SG/830.110 }\end{array}$ & \\
\hline & & $\begin{array}{l}\text { iv. Safety systems and their } \\
\text { functions. }\end{array}$ & Full & $\begin{array}{l}5480.5 \\
\text { SG/830.110 }\end{array}$ & \\
\hline & $\begin{array}{l}\text { 2. Operating procedures shall be } \\
\text { readily accessible to employees. }\end{array}$ & & Full & $\begin{array}{l}5480.19 \\
\text { SG/830.110 }\end{array}$ & \\
\hline & $\begin{array}{l}\text { 3. Operating procedures shall be } \\
\text { reviewed as often as necessary to } \\
\text { assure that they reflect current } \\
\text { operating practice. Employer } \\
\text { shall certify annually. }\end{array}$ & & Full & $\begin{array}{l}5480.19 \\
\text { SG/830.110 }\end{array}$ & \\
\hline & $\begin{array}{l}\text { 4. The employer shall develop and } \\
\text { implement safe work practices to } \\
\text { provide for the control of hazards } \\
\text { during specified operations. }\end{array}$ & & Full & $\begin{array}{l}5480.10 \\
\text { SG/830.110 }\end{array}$ & \\
\hline
\end{tabular}


Appendix J

Matrix -- Cross-cut of DOE Orders to the OSHA Process Safety Management Rule

\begin{tabular}{|c|c|c|c|c|c|}
\hline Point & Section & Subsection & $\begin{array}{c}\text { Compliance } \\
\text { (Partial, Full, None) }\end{array}$ & Relaced Orders & $\begin{array}{l}\text { Comments and Order } \\
\text { Development Requirements }\end{array}$ \\
\hline \multirow[t]{6}{*}{ G. Training } & & & Full & & \multirow{6}{*}{$\begin{array}{l}5480.5 \text { calls for complete } \\
\text { compliance by nuclear } \\
\text { facilities with this point. } \\
\text { PSM Order } \\
\text { PSM Training } \\
\text { Lab Safery Management }\end{array}$} \\
\hline & \multirow[t]{3}{*}{ 1. Initial Training. } & & Full & & \\
\hline & & $\begin{array}{l}\text { i. Employees shall be trained in an } \\
\text { overview of the process and in } \\
\text { operating procedures as specified } \\
\text { in [IV. Operating Procedures } \\
\text { (F)]. }\end{array}$ & Full & $5480.5,5500.3 \mathrm{~A}$ & \\
\hline & & $\begin{array}{l}\text { ii. In lieu of initial training for } \\
\text { employees already involved in } \\
\text { operating a process, the employer } \\
\text { may certify in writing that the } \\
\text { employee has the required } \\
\text { knowledge, skills, and abilities to } \\
\text { safely carry out the duties as } \\
\text { specified. }\end{array}$ & Full & $5480.2,5480.5$ & \\
\hline & $\begin{array}{l}\text { 2. Refresher Training shall be } \\
\text { provided at least once every three } \\
\text { years, and more often if } \\
\text { necessary. }\end{array}$ & & Full & $5480.2,5480.5$ & \\
\hline & $\begin{array}{l}\text { 3raining Documentation. The } \\
\text { employer shall ascertain and } \\
\text { record that each employee } \\
\text { involved in operating a process } \\
\text { has received and understood the } \\
\text { required training. }\end{array}$ & & Full & $5480.2,5480.5$ & \\
\hline \multirow[t]{2}{*}{ H. Contractors } & & & Partial & & \multirow{2}{*}{ PSM Order } \\
\hline & $\begin{array}{l}\text { 1. Application. Point VI applies to } \\
\text { contractors performing } \\
\text { maintenance and repair, } \\
\text { turnaround, major renovation, or } \\
\text { specialty work on or adjacent to a } \\
\text { covered process. }\end{array}$ & & None & None & \\
\hline
\end{tabular}


Appendix $\mathrm{J}$

Matrix -- Cross-cut of DOE Orders to the OSHA Process Safety Management Rule

\begin{tabular}{|c|c|c|c|c|c|}
\hline Point & Section & Subsection & $\begin{array}{c}\text { Compliance } \\
\text { (Partial, Full, None) }\end{array}$ & Related Orders & $\begin{array}{l}\text { Comments and Order } \\
\text { Development Requirements }\end{array}$ \\
\hline \multirow[t]{9}{*}{ H. Contractors (cont.) } & \multirow[t]{7}{*}{ 2. Employer Responsibilities: } & & Partial & & \\
\hline & & $\begin{array}{l}\text { i. Obtain and evaluate information } \\
\text { concerning the contract } \\
\text { employer's safety performance } \\
\text { and programs. }\end{array}$ & Full & $\begin{array}{l}5480.1 B, 5480.2 \\
5480.9\end{array}$ & \\
\hline & & $\begin{array}{l}\text { ii. The employer shall inform } \\
\text { contract employers of the known } \\
\text { potential work related hazards. }\end{array}$ & Full & $\begin{array}{l}5480.10,5480.9 \\
5483 . X X\end{array}$ & \\
\hline & & $\begin{array}{l}\text { iii. The employer shall explain the } \\
\text { emergency action plan. }\end{array}$ & None & None & \\
\hline & & $\begin{array}{l}\text { iv. The employer shall develop and } \\
\text { implement safe work practices } \\
\text { consistent with [IV. Operating } \\
\text { Procedures }(F)] \text { of these points. }\end{array}$ & Full & $\begin{array}{l}5480.1 \mathrm{~B} \\
5480.10\end{array}$ & \\
\hline & & $\begin{array}{l}\text { v. The employer shall periodically } \\
\text { evaluate the performance of } \\
\text { contract employers in fulfilling } \\
\text { their obligations listed below in } \\
\text { VI.3. }\end{array}$ & Full & $\begin{array}{l}\text { 5480.1B, } \\
5480.10,5480.5\end{array}$ & \\
\hline & & $\begin{array}{l}\text { vi. The employer shall maintain a } \\
\text { contract employee injury and } \\
\text { illness log related to work in the } \\
\text { process areas. }\end{array}$ & None & None & \\
\hline & \multirow{2}{*}{$\begin{array}{l}\text { 3. Contract employer } \\
\text { responsibilities: }\end{array}$} & & Partial & & \\
\hline & & $\begin{array}{l}\text { i. Ensure that each contract } \\
\text { employee is trained in the proper } \\
\text { work practices for safe } \\
\text { performance of their job. }\end{array}$ & Full & $5480.9,5483 . \mathrm{XX}$ & \\
\hline
\end{tabular}


Appendix J

Matrix -- Cross-cut of DOE Orders to the OSHA Process Safety Management Rule

\begin{tabular}{|c|c|c|c|c|c|}
\hline Point & Section & Subsection & $\begin{array}{c}\text { Compliance } \\
\text { (Partial, Full, None) }\end{array}$ & Related Orders & $\begin{array}{l}\text { Comments and Order } \\
\text { Development Requirements }\end{array}$ \\
\hline \multirow[t]{4}{*}{ H. Contractors (cont.) } & & $\begin{array}{l}\text { ii. The contract employer shall } \\
\text { assure that each contract } \\
\text { employee is instructed concerning } \\
\text { the known potential job-related } \\
\text { hazards and the applicable } \\
\text { provisions of the emergency } \\
\text { action plan. }\end{array}$ & Full & $\begin{array}{l}\text { 5483.1A, } \\
5483 . \mathrm{XX}\end{array}$ & \\
\hline & & $\begin{array}{l}\text { iii. The contract employer shall } \\
\text { document that each contract } \\
\text { employee has received and } \\
\text { understood the training required } \\
\text { by this paragraph. }\end{array}$ & None & None & \\
\hline & & $\begin{array}{l}\text { iv. The contract employer shall } \\
\text { assure that each contract } \\
\text { employee follows the safety rules } \\
\text { of the facility. }\end{array}$ & Full & $\begin{array}{l}\text { 5483.1A, } \\
\text { 5483.XXX }\end{array}$ & \\
\hline & & $\begin{array}{l}\text { The contract employer shall } \\
\text { advise the employer of any unique } \\
\text { hazards presented or discovered } \\
\text { by the contract employer's work. }\end{array}$ & Full & $\begin{array}{l}5480.5,5480.9 \\
5483 . \mathrm{XX}\end{array}$ & \\
\hline \multirow[t]{5}{*}{ I. Prestartup Safety Review } & & & Full & & \multirow{5}{*}{$\begin{array}{l}\text { SG/830.110 provides } \\
\text { compliance only when the } \\
\text { chemical process is covered } \\
\text { as part of a nuclear SAR. } \\
\text { PSM Order }\end{array}$} \\
\hline & $\begin{array}{l}\text { The employer shall perform a } \\
\text { prestartup safety review for new } \\
\text { facilities and for significantly } \\
\text { modified facilities. }\end{array}$ & & Full & $\mathrm{SG} / 830.110$ & \\
\hline & \multirow{3}{*}{$\begin{array}{l}\text { 2. The prestartup safety review shall } \\
\text { confirm that prior to introduction } \\
\text { of highly hazardous chemicals to } \\
\text { a process: }\end{array}$} & & Full & & \\
\hline & & $\begin{array}{l}\text { i. Construction and equipment is in } \\
\text { accordance with design specs. }\end{array}$ & Full & $\mathrm{SG} / \mathbf{8 3 0 . 1 1 0}$ & \\
\hline & & $\begin{array}{l}\text { ii. Safety, operating, maintenance, } \\
\text { and emergency procedures are in } \\
\text { place and adequate. }\end{array}$ & Full & SG/830.110 & \\
\hline
\end{tabular}


Appendix J

Matrix -- Cross-cut of DOE Orders to the OSHA Process Safety Management Rule

\begin{tabular}{|c|c|c|c|c|c|}
\hline Point & Section & Subsection & $\begin{array}{c}\text { Compliance } \\
\text { (Partial, Full, None) }\end{array}$ & Related Orders & $\begin{array}{l}\text { Comments and Order } \\
\text { Development Requirements }\end{array}$ \\
\hline \multirow[t]{2}{*}{ I. Prestartup Safety Review (cont.) } & & $\begin{array}{l}\text { iii. For new facilities, a process } \\
\text { hazard analysis has been } \\
\text { performed and recommendations } \\
\text { have been resolved or } \\
\text { implemented before startup. } \\
\end{array}$ & Full & $\mathrm{SG} / \mathbf{8 3 0 . 1 1 0}$ & \\
\hline & & $\begin{array}{l}\text { iv. Employee training for all process- } \\
\text { involved employees has been } \\
\text { completed. }\end{array}$ & Full & SG/830.110 & \\
\hline \multirow[t]{4}{*}{ J. Mechanical Integrity } & & & Full & & \multirow{4}{*}{$\begin{array}{l}\text { SG/830.110 provides } \\
\text { compliance only when the } \\
\text { chemical process is covered } \\
\text { as part of a nuclear SAR. } \\
\text { PSM Order } \\
\text { Chemical Standards }\end{array}$} \\
\hline & $\begin{array}{ll}\text { 1. Application. This section applies } \\
\text { to: } \\
\text { i. Pressure vessels and storage } \\
\text { tanks. } \\
\text { ii. Piping systems. } \\
\text { iii. Relief and vent systems. } \\
\text { iv. Emergency shutdown systems. } \\
\text { v. Controls. } \\
\text { vi. Pumps. }\end{array}$ & & N/A & $\mathbf{N} / \mathbf{A}$ & \\
\hline & $\begin{array}{l}\text { 2. The employer shall establish and } \\
\text { implement written procedures to } \\
\text { maintain equipment integrity. }\end{array}$ & & Full & SG/830.110 & \\
\hline & $\begin{array}{l}\text { 3. The employer shall train each } \\
\text { employee involved in maintaining } \\
\text { equipment integrity in an } \\
\text { overview of that process and its } \\
\text { hazards and in procedures } \\
\text { applicable to the employee's job } \\
\text { tasks. }\end{array}$ & & Full & $\mathrm{SG} / 830.110$ & \\
\hline
\end{tabular}


Appendix $\mathbf{J}$

Matrix -- Cross-cut of DOE Orders to the OSHA Process Safety Management Rule

\begin{tabular}{|c|c|c|c|c|c|}
\hline Point & Section & Subsection & $\begin{array}{c}\text { Compliance } \\
\text { (Partial, Full, None) }\end{array}$ & Related Onders & $\begin{array}{l}\text { Comments and Onder } \\
\text { Development Requirements }\end{array}$ \\
\hline \multirow[t]{5}{*}{ J. Mechanical Integrity (cont.) } & \multirow[t]{5}{*}{ 4. Inspections and testing. } & & Full & & \\
\hline & & $\begin{array}{l}\text { i. Inspections and tests shall be } \\
\text { performed on process equipment. }\end{array}$ & Full & $\begin{array}{l}\text { 5480.1B, } \\
\text { SG/830.110 }\end{array}$ & \\
\hline & & $\begin{array}{l}\text { ii. Inspections and testing shall } \\
\text { follow recognized and generally } \\
\text { accepted good engineering } \\
\text { practices. }\end{array}$ & Full & SG/830.110 & \\
\hline & & $\begin{array}{l}\text { iii. The frequency of inspections and } \\
\text { tests shall be consistent with } \\
\text { manufacturers' recommendations } \\
\text { and good engineering practices, } \\
\text { and more frequently if determined } \\
\text { to be necessary by prior operating } \\
\text { experience. }\end{array}$ & Full & SG/830.110 & \\
\hline & & $\begin{array}{l}\text { iv. The employer shall document } \\
\text { each inspection and test that has } \\
\text { been performed on process } \\
\text { equipment. The documentation } \\
\text { should include date performed, } \\
\text { name of inspector or tester, serial } \\
\text { number or other I.D. of } \\
\text { equipment, a description of the } \\
\text { inspection or test, and the results. }\end{array}$ & Full & $\mathrm{SG} / 830.110$ & \\
\hline
\end{tabular}


Appendix $\mathrm{J}$

Matrix -- Cross-cut of DOE Orders to the OSHA Process Safety Management Rule

\begin{tabular}{|c|c|c|c|c|c|}
\hline Point & Section & Subsection & $\begin{array}{c}\text { Compliance } \\
\text { (Partial, Full, None) }\end{array}$ & Related Orders & $\begin{array}{l}\text { Comments and Order } \\
\text { Development Requirements }\end{array}$ \\
\hline \multirow[t]{5}{*}{ J. Mechanical Integrity (cont.) } & $\begin{array}{l}\text { 5. The employer shall correct } \\
\text { deficiencies in equipment that are } \\
\text { outside acceptable limits before } \\
\text { further use or in a safe and timely } \\
\text { manner when necessary means are } \\
\text { taken to assure safe operation. }\end{array}$ & & Full & $\begin{array}{l}\text { S480.1B, } \\
\text { SG/830.110 }\end{array}$ & \\
\hline & \multirow[t]{4}{*}{ 6. Quality assurance. } & & Full & & \\
\hline & & $\begin{array}{l}\text { i. In new plant construction, the } \\
\text { employer shall assure that } \\
\text { equipment is suitable as fabricated } \\
\text { for the process in which it is to be } \\
\text { used. }\end{array}$ & Full & SG/830.110 & \\
\hline & & $\begin{array}{l}\text { ii. Appropriate checks and } \\
\text { inspections shall be performed to } \\
\text { assure that equipment is installed } \\
\text { properly and consistently with } \\
\text { design specifications. }\end{array}$ & Full & $\begin{array}{l}\text { S480.1B, } \\
\text { SG/830.110 }\end{array}$ & \\
\hline & & $\begin{array}{l}\text { iii. The employer shall assure that } \\
\text { maintenance materials, spare } \\
\text { parts, and equipment are suitable } \\
\text { for the process application for } \\
\text { which they will be used. }\end{array}$ & Full & $\mathrm{SG} / 830.110$ & \\
\hline \multirow[t]{2}{*}{ K. Hot Work Permit } & & & None & & \multirow{2}{*}{$\begin{array}{l}\text { Possible compliance may } \\
\text { be found in Fire Safety } \\
\text { Orders scheduled to be } \\
\text { examined. }\end{array}$} \\
\hline & $\begin{array}{l}\text { The employer shall issue a hot } \\
\text { work permit for hot work } \\
\text { operations conducted on or near a } \\
\text { covered process. }\end{array}$ & & None & None & \\
\hline
\end{tabular}


Appendix J

Matrix -- Cross-cut of DOE Orders to the OSHA Process Safety Management Rule

\begin{tabular}{|c|c|c|c|c|c|}
\hline Point & Section & Subsection & $\begin{array}{c}\text { Compliance } \\
\text { (Partial, Full, None) }\end{array}$ & Related Orders & $\begin{array}{l}\text { Comments and Order } \\
\text { Development Requirements }\end{array}$ \\
\hline K. Hot Work Permit (cont.) & $\begin{array}{l}\text { 2. The permit shall document that } \\
\text { the fire prevention and protection } \\
\text { requirements in } 29 \mathrm{CFR} \\
1910.252 \text { (a) have been } \\
\text { implemented prior to beginning } \\
\text { hot work, will indicate date(s) for } \\
\text { authorized hot work, and will } \\
\text { identify the object on which hot } \\
\text { work is to be performed. }\end{array}$ & & None & None & \\
\hline \multirow[t]{8}{*}{ I.. Management of Change } & & & Full & & \multirow{8}{*}{$\begin{array}{l}\text { SG/830.110 provides } \\
\text { compliance only when the } \\
\text { chemical process is covered } \\
\text { as part of a nuclear SAR. } \\
\text { PSM Order }\end{array}$} \\
\hline & $\begin{array}{l}\text { 1. The employer shall establish and } \\
\text { implement written procedures to } \\
\text { manage changes to process } \\
\text { chemicals, technology, } \\
\text { equipment, and procedures. }\end{array}$ & & Full & $\begin{array}{l}\text { 5480.10, } \\
5483 . X X \\
\text { SG/830.110 }\end{array}$ & \\
\hline & \multirow{6}{*}{$\begin{array}{l}\text { 2. The procedures shall, prior to } \\
\text { changes, address the following: }\end{array}$} & & Full & & \\
\hline & & $\begin{array}{l}\text { i. The technical basis for the } \\
\text { proposed change. }\end{array}$ & Full & $\begin{array}{l}5480.5 \\
5483 . X X \\
\text { SG/830.110 } \\
\end{array}$ & \\
\hline & & $\begin{array}{l}\text { ii. The impact of change on safety } \\
\text { and health. }\end{array}$ & Full & $\begin{array}{l}5480.10,5480.5 \\
5483 . X X \\
\text { SG/830.110 }\end{array}$ & \\
\hline & & $\begin{array}{l}\text { iii. Modifications to operating } \\
\text { procedures. }\end{array}$ & Full & $\begin{array}{l}\text { 5483.XX, } \\
\text { SG/830.110 }\end{array}$ & \\
\hline & & iv. Necessary time period for change. & Full & $\mathrm{SG} / 830.110$ & \\
\hline & & $\begin{array}{l}\text { v. Authorization requirements for } \\
\text { proposed change. }\end{array}$ & Full & $\mathrm{SG} / 830.110$ & \\
\hline
\end{tabular}


Appendix $J$

Matrix -- Cross-cut of DOE Orders to the OSHA Process Safety Management Rule

\begin{tabular}{|c|c|c|c|c|c|}
\hline Point & Section & Subsection & $\begin{array}{c}\text { Compliance } \\
\text { (Partial, Full, None) }\end{array}$ & Related Orders & $\begin{array}{l}\text { Comments and Order } \\
\text { Development Requirements }\end{array}$ \\
\hline \multirow[t]{3}{*}{ L. Management of Change (cont.) } & $\begin{array}{l}\text { 3. All employees with job tasks } \\
\text { affected by the change shall be } \\
\text { informed of, and trained in, the } \\
\text { change prior to the startup of } \\
\text { process. }\end{array}$ & & Full & $\begin{array}{l}5480.2 \\
5483 . X X \\
\text { SG/830.110 }\end{array}$ & \\
\hline & $\begin{array}{l}\text { 4. If a change covered by this } \\
\text { paragraph results in a change in } \\
\text { the process safety information, } \\
\text { such information shall be updated. }\end{array}$ & & Full & $\begin{array}{l}5483 . X X \\
\text { SG/830.110 }\end{array}$ & \\
\hline & $\begin{array}{l}\text { 5. If a change covered by this } \\
\text { paragraph results in a change in } \\
\text { the operating procedures, such } \\
\text { procedures or practices shall be } \\
\text { updated accordingly. }\end{array}$ & & Full & $\begin{array}{l}\text { 5483.XX, } \\
\text { SG/830.110 }\end{array}$ & \\
\hline \multirow[t]{3}{*}{ M. Incident Investigation } & & & Partial & & \multirow{3}{*}{ PSM Onder } \\
\hline & $\begin{array}{l}\text { The employer shall investigate } \\
\text { each incident which resulted in, } \\
\text { or could reasonably have resulted } \\
\text { in, a catastrophic release of a } \\
\text { highly hazardous chemical in the } \\
\text { workplace. }\end{array}$ & & Full & $\begin{array}{l}5000.3 \mathrm{~A}, \\
5480.19,5480.5 \text {, } \\
5484.1\end{array}$ & \\
\hline & $\begin{array}{l}\text { 2. An incident investigation shall be } \\
\text { initiated as promplly as possible, } \\
\text { but not later than } 48 \text { hours } \\
\text { following the incident. }\end{array}$ & & Full & $5000.3 \mathrm{~A}$ & \\
\hline
\end{tabular}


Appendix $J$

Matrix -- Cross-cut of DOE Orders to the OSHA Process Safety Management Rule

\begin{tabular}{|c|c|c|c|c|c|}
\hline Point & Section & Subsection & $\begin{array}{c}\text { Compliance } \\
\text { (Partial, Full, None) }\end{array}$ & Related Orders & $\begin{array}{l}\text { Comments and Order } \\
\text { Development Requirements }\end{array}$ \\
\hline \multirow[t]{10}{*}{ M. Incident Investigation (cont.) } & $\begin{array}{l}\text { 3. An incident investigation team } \\
\text { shall be established and consist of } \\
\text { at least one person knowledgeable } \\
\text { in the process involved and other } \\
\text { persons with appropriate } \\
\text { knowledge and experience to } \\
\text { thoroughly investigate and analyze } \\
\text { the incident. }\end{array}$ & & Full & $5480.19,5484.1$ & \\
\hline & \multirow{2}{*}{$\begin{array}{l}\text { 4. A report shall be prepared at the } \\
\text { conclusion of the investigation } \\
\text { which includes (at least): }\end{array}$} & & Full & & \\
\hline & & i. Date of incident. & Full & $5000.3 \mathrm{~A}, 5484.1$ & \\
\hline & & ii. Date investigation begun. & Full & $5000.3 \mathrm{~A}, 5484.1$ & \\
\hline & & iii. Description of incident. & Full & $\begin{array}{l}5000.3 \mathrm{~A} \\
5480.19,5484.1\end{array}$ & \\
\hline & & $\begin{array}{l}\text { iv. The factors that contributed to the } \\
\text { incident. }\end{array}$ & Full & $\begin{array}{l}5000.3 \mathrm{~A} \\
5480.19,5484.1\end{array}$ & \\
\hline & & $\begin{array}{l}\text { v. Any recommendations resulting } \\
\text { from the investigation. }\end{array}$ & Full & $\begin{array}{l}\text { 5000.3A, } \\
5480.19,5484.1\end{array}$ & \\
\hline & $\begin{array}{l}\text { 5. Employer shall establish a system } \\
\text { to promptly address and resolve } \\
\text { the incident report findings and } \\
\text { recommendations. Resolutions } \\
\text { and corrective actions shall be } \\
\text { documented. }\end{array}$ & & Full & $\begin{array}{l}5000.3 \mathrm{~A} \\
5480.5,5484.1\end{array}$ & \\
\hline & $\begin{array}{l}\text { 6. The report shall be reviewed by } \\
\text { all affected personnel whose job } \\
\text { tasks are relevant to the incident } \\
\text { findings. }\end{array}$ & & Partial & $5000.3 \mathrm{~A}$ & \\
\hline & $\begin{array}{l}\text { 7. Incident investigation reports shall } \\
\text { be retained for five years. }\end{array}$ & & None & & \\
\hline
\end{tabular}


Appendix $\mathrm{J}$

Matrix -- Cross-cut of DOE Orders to the OSHA Process Safety Management Rule

\begin{tabular}{|c|c|c|c|c|c|}
\hline Polnt & Section & Subsection & $\begin{array}{c}\text { Compliance } \\
\text { (Partial, Full, None) }\end{array}$ & Related Orders & $\begin{array}{l}\text { Comments and Order } \\
\text { Development Requirements }\end{array}$ \\
\hline $\begin{array}{l}\text { N. Emergency Planning and } \\
\text { Response }\end{array}$ & $\begin{array}{l}\text { The employer shall establish and } \\
\text { implement an emergency action plan } \\
\text { for the entire plant in accordance with } \\
\text { the provisions of } 29 \text { CFR } 1910.38(a) \text {. } \\
\text { The emergency action plan should also } \\
\text { include procedures for handling small } \\
\text { releases. }\end{array}$ & & Full & $\begin{array}{l}5480.10,5480.5 \\
5500.1 \mathrm{~B} \\
5500.2 \mathrm{~A} \\
5500.3 \mathrm{~A} \\
\text { SG/830.110 }\end{array}$ & $\begin{array}{l}\text { Three separate orders } \\
\text { require full compliance } \\
\text { with this point. } \\
\text { PSM Training }\end{array}$ \\
\hline \multirow[t]{6}{*}{ o. Compliance Audits } & & & Full & & \multirow{6}{*}{$\begin{array}{l}\text { Order } 5483.1 \mathrm{~A} \text { calls for } \\
\text { complete compliance with } \\
29 \mathrm{CFK} 1910 \text {. } \\
\text { PSM Order }\end{array}$} \\
\hline & $\begin{array}{l}\text { 1. Employers shall certify that they } \\
\text { have evaluated compliance with } \\
\text { the provisions of this section at } \\
\text { least every } 3 \text { years. }\end{array}$ & & Full & $5483.1 \mathrm{~A}$ & \\
\hline & $\begin{array}{l}\text { 2. The compliance audit shall be } \\
\text { conducted by at least one person } \\
\text { knowledgeable in the process. }\end{array}$ & & Full & $5483.1 \mathrm{~A}$ & \\
\hline & $\begin{array}{l}\text { 3. A report of the findings of the } \\
\text { audit shall be developed. }\end{array}$ & & Full & $5483.1 \mathrm{~A}$ & \\
\hline & $\begin{array}{l}\text { 4. The employer shall promptly } \\
\text { determine and document an } \\
\text { appropriate response to each of } \\
\text { the findings of the compliance } \\
\text { audit, and document that } \\
\text { deficiencies have been corrected. }\end{array}$ & & Full & $5483.1 \mathrm{~A}$ & \\
\hline & $\begin{array}{l}\text { 5. Employers shall retain the two } \\
\text { most recent compliance audit } \\
\text { reports. }\end{array}$ & & Full & $5483.1 \mathrm{~A}$ & \\
\hline
\end{tabular}


Appendix $J$

Matrix -- Cross-cut of DOE Orders to the OSHA Process Safety Management Rule

\begin{tabular}{|c|c|c|c|c|c|}
\hline Point & Section & Subsection & $\begin{array}{c}\text { Compliance } \\
\text { (Partial, Full, None) }\end{array}$ & Related Orders & $\begin{array}{l}\text { Comments and Onder } \\
\text { Development Requirements }\end{array}$ \\
\hline \multirow[t]{4}{*}{ P. Trade Secrets } & & & None & None & \multirow{4}{*}{$\begin{array}{l}\text { Possible compliance may } \\
\text { be found in Security and } \\
\text { Safeguard Orders } \\
\text { scheduled to be examined. }\end{array}$} \\
\hline & $\begin{array}{l}\text { 1. Employers shall make all } \\
\text { information necessary to comply } \\
\text { with the section available to: } \\
\text { a. persons responsible for compiling } \\
\text { the process safety information } \\
\text { b. those assisting in the deveiopment } \\
\text { of the process hazard analysis } \\
\text { c. those responsible for developing } \\
\text { the operating procedures } \\
\text { d. those involved in incident } \\
\text { investigations, emergency } \\
\text { planning and response, and } \\
\text { compliance audits } \\
\text { without regard to possible trade } \\
\text { secret status of such information. }\end{array}$ & & None & None & \\
\hline & $\begin{array}{l}\text { 2. Nothing in this paragraph shall } \\
\text { preclude the employer from } \\
\text { requiring the persons to whom the } \\
\text { information is made available to } \\
\text { enter into confidentiality } \\
\text { agreements not to disclose the } \\
\text { information as set forth in } 29 \\
\text { CFR } 1910.1200 \text {. }\end{array}$ & & None & None & \\
\hline & $\begin{array}{l}\text { 3. Subject to the rules and } \\
\text { procedures set forth in } 29 \text { CFR } \\
1910.1200 \text {, employees shall have } \\
\text { access to trade secret information } \\
\text { contained within the process } \\
\text { hazard analysis and other } \\
\text { documents required to be } \\
\text { developed by this standard. }\end{array}$ & & None & None & \\
\hline
\end{tabular}




\section{KEY:}

PSM Order - This point will be (or needs to be) covered in a future Process Safety Management of Highly Hazardous Chemicals Order.

PSM Guidance - Process Safety Management guidance needs to be developed in implementing this point.

PSM Training - Training needs to be performed for the correct implementation of this point.

Lab Safety Management - Training needs to be performed in areas dealing with Laboratory Safety as well as Process Safety.

5483.XX - Simple modification of this draft Order could result in full compliance with this point. 

UNITED STATES

DEPARTMENT OF ENERGY

WASHINGTON, D.C. 20585

FIRST CLASS MAIL

POSTAGE \& FEES PAID

US. DEPT OF ENERGY

PERMIT G2O

OFFICIAL BUSINESS

PENALTY FOR PRIVATE USE, $\$ 300$

EH-30 